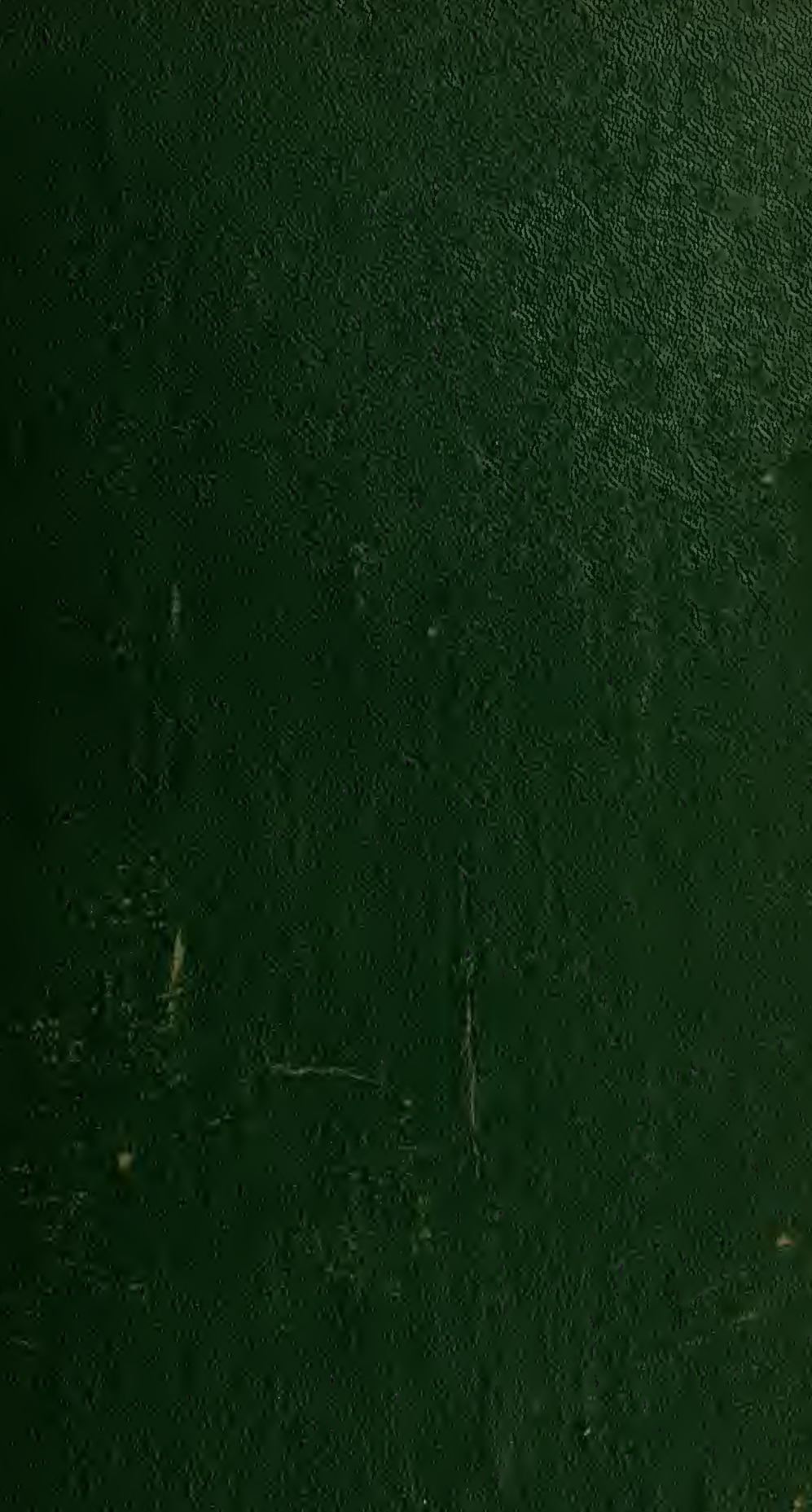









Dans les nomenclatures générales qui embrassent tous les produits du travail, la mếme section comprend la Verrerie, les Vitraux peints, les Émaux et la Mosãique ${ }^{1}$, parce que les matières premières ont une origine commune; mais au point de vue des arts, cette classification ne peut plus être suivie, pour le motif que les qualités expressives des matières sont mises en œuvre dans une intention distincte et par des artistes d'un talent différent.

C'est la Verrerie proprement dite que nous avons mission de traiter. La tâche n'est point facile; pour suivre l'histoire de la Verrerie à travers les siècles et les contrées, nous manquons d'un fil conducteur sans solution de continuité; certains peuples n'ont pas eu le goût de la Verrerie d'art, et dans les pays

1. La Mosaïque, par M. Gerspach, a fait l'objet d'un volume qui a déjà paru. La BibliothèQue DE L'ENSEIGNEMENT DEs BEAuXARTS publiera successivement les Vitraux peints et les Émaux. 
où elle a été appréciée, les éléments d'investigation font parfois défaut, à cause de la nature de la matière, la plus fragile de toutes celles que les arts ont employées.

L'essai que nous tentons présente par suite des lacunes que des recherches plus heureuses parviendront sans doute à combler. D'autre part, nous n'avons pu, à cause des dimensions du volume, utiliser tous les renseignements que nous avons recueillis, ni même consacrer un chapitre à la technique; on trouvera du reste dans les ouvrages spéciaux tout ce qui se rapporte à la fabrication.

Notre désir était de suivre l'ordre chronologique; nous avons dû y renoncer et adopter un classement par pays, et ensuite par régions dans chaque pays, lorsqu'il y avait lieu.

Mais, nous le répétons, l'étude que nous présentons est forcément incomplète, et la Verrerie de plusieurs peuples et de certaines localités attend encore son histoire spéciale. 


\section{L'ART DE LA VERRERIE}

\section{L'ANTIQUITÉ}

C'est bien du verre qu'on peut dire avec raison que son origine se perd dans la nuit des temps.

Les investigations de l'archéologie ne sont point d'accord avec les affirmations des historiens anciens pour fixer, même approximativement, l'époque où l'homme fit sur la nature la conquête du verre, mais il est hors de doute que l'usage en était con nu dès la plus haute antiquité.

La tradition veut que Sésostris, grâce à la science des prêtres de Thèbes et de Memphis, ait eu en sa possession un sceptre en

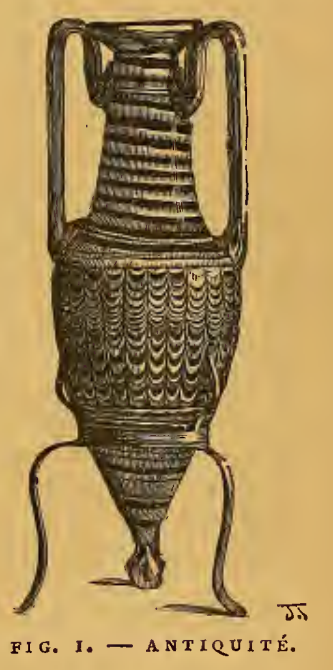

(Musée du Louvre.) verre imitant l'émeraude ${ }^{1}$. On assure que le prénom

I. Boudet. Sur l'Art de la verrerie née en Égypte. 
de la reine Hatasou, Râ-Ma-Kâ, qui régna dans la XVIII e dynastie, c'est-à-dire au $x v^{e}$ siècle avant l'ère chrétienne, se trouve inscrit sur le grain en pâte vitrifiée d'un collier trouvé à Thèbes ${ }^{1}$; d'autre part, l'archéologie a relevé sur les parois des hypogées de Beni-Hassan-el-Gadim qui renferment la tombe de Roteï des figures d'ouvriers soufflant le verre, et on pense que ces figures ont été exécutées sous la même XVIIIe dynastie (fig. 2).

Salomon blâme ceux qui admirent la couleur du vin au travers de leurs verres ${ }^{2}$.

Hérodote (484-406 av. J.-C.) écrit avoir vu dans le temple d'Hercule, à Tyr, une colonne lumineuse pendant la nuit; d'après lui, cette colonne était en émeraude, mais il est plus probable qu'elle était en verre de couleur, si même elle a jamais existé; le même auteur assure que les Éthiopiens faisaient avec le verre des espèces de châsses dans lesquelles ils embaumaient leurs morts. Selon Elien, écrivain grec du III* siècle, Xerxès, fils de Darius, découvrit le corps de Bélus, chef assyrien, dans un cercueil de verre.

Aristophane parle de coupes à boire en verre. "Partout, on nous forçait à boire un vin pur et généreux dans des coupes d'or et de verre ", dit un ambassadeur athénien envoyé à la cour du roi de Perse au vie siècle avant notre ère ${ }^{3}$; dans le livre de Job, il est écrit :

I. Gardner Wilkinson. The mamers and Customs of the ancient Égyptians, t. III, édition 1847 .

2. Proverbes, chapitre XXIII, verset 3 I.

3. Acharniens, vers 74 . 


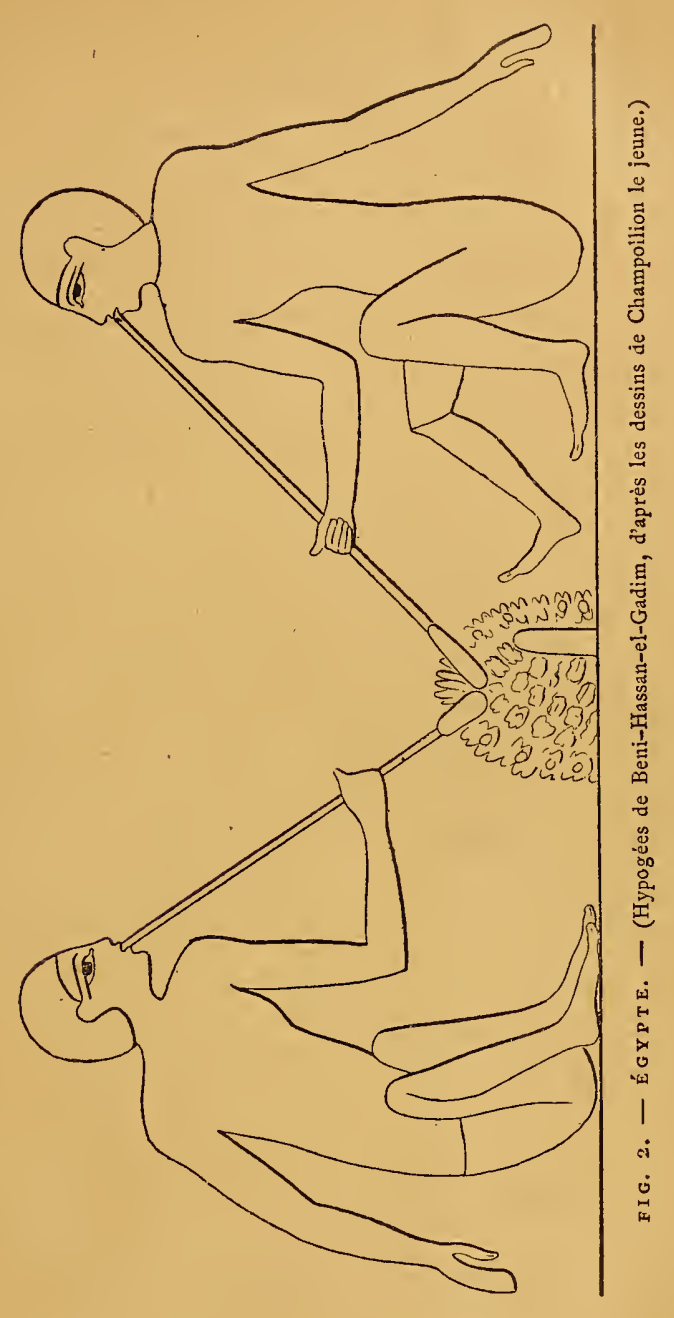


"L'homme ignore le prix de la sagesse; il ne l'égalerait pas à l'or et au verre. ”

Strabon, dans sa géographie, enseigne qu'entre Ptolémaïs et Tyr le rivage est

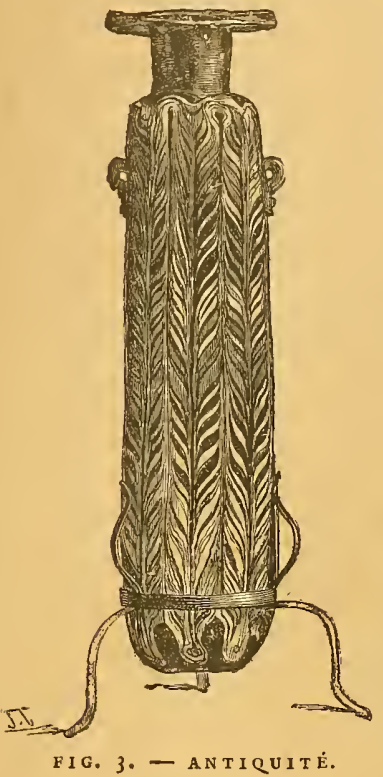

(Musée du Louvre.) couvert de monticules dont on extrait le sable propre à faire le verre, et que ce sable est transporté à Sidon où on le soumet au feu; l'auteur écrit aussi qu'Auguste se fit montrer le corps d'Alexandre conservé dans un cercueil de verre où il avait été placé par Séleucus Eubiosactes.

Mais c'est Pline surtout que l'on aime à consulter. Nous reproduisons, malgré sa longueur, le texte complet du célèbre écrivain d'après la traduction de Littré, qui fait remarquer que Pline est un littérateur traitant, sans préparation aucune, des sujets scientifiques; Cuvier avait déjà émis la même opinion.

Il est dans la Syrie une contrée nommée Phénicie 1, confinant à la Judée et renfermant, entre les racines du mont Carmel, un marais qui porte le nom de Cenderia. On croit qu'il donne naissance au fleuve Bélus, qui, après un trajet de cinq mille pas, se jette dans la mer auprès de Ptolé-

1. Pline. Lib, XXXVI. 
maïs; le cours en est lent, l'eau malsaine à boire, mais consacrée aux cérémónies religieuses. Ce fleuve, limoneux et profond, ne montre qu'au reflux de la mer le sable qu'il charrie. Alors, en effet, ce sable, agité par les flots, se sépare des impuretés et se nettoie. On perise que, dans ce contact, les eaux de la mer agissent sur lui et que sans cela il ne vaudrait rien. Le littoral sur lequel on le recueille n'a pas plus de cinq cents pas et, pendant plusieurs siècles, ce fut la seule localité qui produisit le verre. On raconte que des marchands de nitre y ayant relâché, préparaient, dispersés sur le rivage, leur repas; ne trouvant pas de pierres pour exhausser leurs marmites, ils employèrent à cet effet des pains de nitre de leur cargaison : ce nitre soumis à l'action du feu, avec le sable répandu sur le sol, ils virent couler des ruisseaux transparents d'une liqueur inconnue, et telle est l'origine du verre.

Depuis, comme l'industrie est ingénieuse et avisée, on ne se contenta pas de mêler du nitre au sable et on imagina d'y incorporer la pierre aimant, dans la pensée qu'elle attire à elle le verre fondu comme le fer. De la même façon, on se mit à introduire dans la fonte divers cailloux luisants, puis des coquillages et des sables fossiles. Des auteurs disent que le verre de l'Inde se fait avec du cristal brisé et que, pour cela, aucun ne peut lui être comparé. Pour la fonte, on emploie du bois léger et sec, et on ajoute du cuivre de Chypre et du nitre, surtout du nitre d'Ophir. On le fond, comme le cuivre, dans des fourneaux contigus, et on obtient des masses noirâtres, d'un aspect gras. Le verre fondu est tellement pénétrant qu'avant même qu'on l'ait senti, il coupe jusqu'aux os toutes les parties du corps qu'il touche. Ces masses se fondent de nouveau dans les fourneaux, où on leur donne la couleur; puis, tantôt on le souffle, tantôt on le façonne au tour, tantôt on le cisèle comme l'argent. Jadis Sidon était célèbre pour ses verreries; on y avait même inventé des miroirs de verre. Telle fut anciennement la fabrication de ce produit. Aujourd'hui, à l'embouchure du fleuve Vulturne, en Italie, sur la côte, dans un espace de six mille pas, entre 
Cumes et Liternum, on recueille un sable blanc très tendre; on le broie au mortier et à la meule; ensuite on y mêle trois parties de nitre, soit au poids, soit à la mesure; le mélange étant en fusion, on le fait passer dans d'autres fourneaux : là il se prend en une masse à laquelle on donne le nom d'ammonitre. Cette masse est mise en fusion et elle donne du verre pur et des pains de verre blanc. Cet art a passé même en Gaule et en Espagne, où l'on traite le sable de la même façon. On raconte que, sous le règne de Tibère, on imagina une mixture qui donnait un verre malléable, et que toute la fabrique de l'artiste fut détruite pour empêcher l'avilissement du cuivre, de l'argent et de l'or. Ce bruit a été longtemps plus répandu que le fait n'est certain; mais qu'importe? Du temps de Néron, on a trouvé un procédé de vitrification qui fit vendre 6,000 sesterces ${ }^{1}$ deux coupes assez petites qu'on nommait ptérotes.

Il n'est pas difficile de distinguer dans ce récit l'erreur de la vérité. On ne peut admettre la découverte du

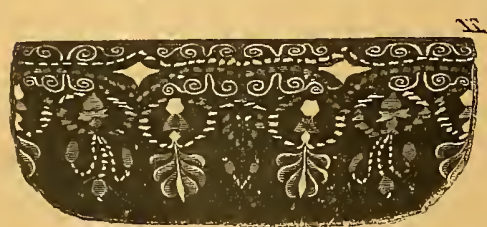

FIG. 4. - ANTIQUITÉ

verre telle que Pline la rapporte, par la raison bien simple qu'une température de $\mathrm{I}, 000$ à $\mathrm{I}, 200 \mathrm{dc}$ grés centigrades est absolument nécessaire pour fondre et vitrifier une masse composée de sable et de nitre, et que ce n'est pas avec un feu en plein air destiné à cuire des aliments qu'on peut arriver à une pareille chaleur. Le verre malléable à froid, sur lequel Pline émet du reste un doute, est une fable; quant aux détails sur la fabrication, ils sont exacts et

I. Le sesterce valait environ vingt centimes. 
montrent que les mêmes procédés ont, à peu de chose près, été suivis dans tous les temps et dans tous les pays. Le prix de 6,00o sesterces n'est pas exagéré pour deux coupes, surtout si elles étaient décorées. Pline aurait pu ajouter qu'on vendait aussi pour 3 sesterces des verres à boire ordinaires. Enfin, il paraît certain que ce sont bien les abords du fleuve Bélus qui pendant longtemps ont fourni le sable aux verriers.

L'obsidienne a souvent été confondue avec le verre; il n'est pas inutile de rappeler ce qu'en dit Pline, d'autant plus que l'auteur entre, à ce propos, dans de nouveaux détails sur la verrerie.

Au verre ${ }^{1}$ appartiennent les vases obsidiens, assez semblables à la pierre qui a été découverte en Égypte par Obsidius. Cette pierre est très noire, quelquefois transparente, mais d'une transparence mate, de sorte que, attachée comme un miroir à la muraille, elle rend plutôt l'ombre que l'image des objets. Beaucoup en font des bijoux. J'ai vu, en obsidienne, des statues massives du dieu Auguste, qui prisait fort cette substance demi-transparente. Lui-même a consacré comme des merveilles, dans le temple de la Concorde, quatre éléphants de pierre obsidienne. L'empereur Tibère rendit aux Héliopolitains, pour leurs cérémonies, une statue de Ménélas en pierre obsidienne, trouvée dans la succession d'un préfet d'Égypte. Cela montre qu'il faut reporter plus haut qu'on ne le fait l'usage de cette substance, confondue aujourd'hui avec le verre, à cause de la ressemblance. D'après Xénocrate, l'obsidienne se trouve dans l'Inde, dans le Samnium, en Italie et en Espagne sur les côtes de l'Océan. On fabrique, par le moyen d'unè teinture, de l'obsidienne pour divers ustensiles de table et un verre entièrement rouge, opaque, qu'on nomme hémation. On fait aussi du verre

I. Pline. Lib. XXXVI. 
blanc, du verre imitant le murrhin, l'hyacinte, le saphir, de toutes les couleurs, en un mot. Nulle substance n'est plus maniable, nulle ne se prête mieux aux couleurs; mais le plus estimé est le verre incolore et transparent, parce qu'il ressemble le plus au cristal. Pour boire, il a même chassé les coupes d'argent et d'or; mais, à moins qu'on n'y verse d'abord du liquide froid, il ne résiste pas à la chaleur, et cependant des boules de verre remplies d'eau, exposées aux rayons du soleil, s'échauffent tellement qu'elles brûlent les étoffes. Le verre en fragments ne fait que se souder au feu; pour le fondre entièrement, il faudrait le broyer. La verrerie fait divers objets de verre coloré, par exemple des pièces d'échiquier qu'on nomme abaculi; ces objets offrent même quelquefois plusieurs nuances. Le verre fondu avec le soufre se durcit en pierre.

L'obsidienne est une sorte de verre volcanique qui a de l'analogie avec le verre de bouteille; la matière est verte foncée ou noire, très dure. Elle est peu employée de nos jours.

\section{I}

Il est donc à présumer que c'est en Égypte que les premières verreries furent établies, car aucun témoignage certain ne peut

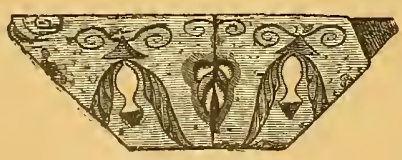

FIG. $S$ - NTIQUITÉ.
Is. être opposé, jusqu'à présent, aux souffleurs de verre des hypogées de Beni-Hassan. Mais, sur les produits eux-. mêmes, la plus grande prudence doit être observée; les classements ne sont pas toujours irréprochables et fréquemment on a pris pour du verre des objets en terre 
blanche que la cuisson faisait légèrement tourner au bleu et qui étaient trempés dans un vernis tirant sur le vert. Peut-être le grain du collier de la reine Râ-Mâ-Kâ, est-il en cette matière? Les plus anciens verres égyptiens conservés dans les musées présentent rarement un caractère absolument particulier, et nous ne pouvons citer comme type égyptien très pur que le flacon du musée du Louvre qui s'épanouit à l'évasement en fleur de lotus (fig. 6); en général, les formes et les matières égyptiennes ont été reproduites ultérieurement en d'autres pays. Les verres de. l'ancienne Égypte sont ou transparents avec une légère teinte verdâtre ou opaques, soit unis, soit veinés et chevronnés de filets et de rubans d'une couleur tranchant sur le fond; ces mélanges prouvent que les Égyptiens avaient remarqué

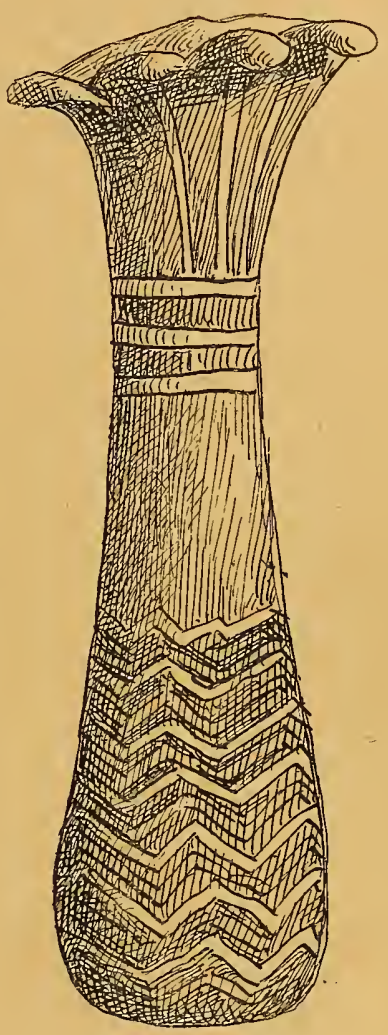

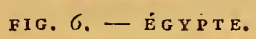

(Musée du Louvre.) que les verres de couleur pouvaient être fondus et soudés ensemble sans mélange de couleurs. Ils sont incontestablement les inventeurs de ce genre encore prati- 
qué de nos jours. Les formes sont celles des alabastrons, des canthares, des pyxis, des flacons à verser que l'on retrouve partout dans l'antiquité, en Assyrie, en Asie Mineure, en Grèce, en Étrurie. Les Égyptiens portaient des amulettes et des colliers en verre; ils se servaient du verre dans les usages funèbres; mais c'est avec réserve qu'il faut interpréter Hérodote, Strabon et Diodore de Sicile, lorsqu'ils assurent qu'à Alexandrie et en Éthiopie les morts étaient placés dans des cercueils en verre. Strabon dit également qu'il existe en Égypte une matière spéciale, indispensable à certaines couleurs pour la verrerie de luxe; mais' ce n'est là qu'un texte, car aucun monument de ce genre n'est arrivé jusqu'à nou's.

On assure que les Égyptiens savaient dorer le verre; qu'ils fabriquaient des verres avec des figures peintes dont les couleurs changeaient selon le point où l'on se plaçait pour les regarder; que certains de leurs hiéroglyphes étaient recouverts d'une couche de verre et qu'à Diospolis, capitale de la Thébaïde, il y avait des verreries où l'on produisait les vases murrhins si célèbres dans l'antiquité. Avant de se prononcer sur ces questions, il convient d'attendre que les fouilles aient mis au jour quelques pièces authentiques ${ }^{1}$.

I. On ne saurait prendre trop de précautions lorsqu'il s'agit de déterminer la date d'un objet de haute antiquité; en voici un exemple : l'archéologue italien Rosellini rapporta d'Égypte un petit vase de porcelaine chinoise, trouvé par lui dans un tombeau égyptien qui n'avait jamais été ouvert, et dont la date remontait, selon lui, à une époque peu postérieure au xvi11 ${ }^{\mathrm{e}}$ siècle avant notre ère; l'opinion de Rosellini fut confirmée par Wilkinson; or ce vase, ainsi que d'autres pièces absolument semblables, portait une inscription qui plus tard fuı déchiffrée par Stanislas 
La Grèce eut ses verrer̉ies, et c'est à elle qu'on doit les premières fontes de verre opaque pour la mosaïque; la Grèce, cependant, ne paraît pas avoir atteint dans l'art de la verrerie la perfection des Égyptiens et surtout des Romains; elle appelait le verre "pierre fusible ». Les auteurs anciens ne signalent aucun objet d'art en verre de fabrication grecque. Sidon conserva longtemps le monopole, pour ainsi dire, de la fabrication, et l'activité commerciale des Phéniciens répandit l'usage du verre dans tout le bassin de la Méditerranée. Il est probable que les verres trouvés dans les tombes étrusques ont été importés, soit par les Phéniciens de Tyr, soit par les Phéniciens de Carthage, qui étaient en relation avec les habitants de l'Italie dès le $\mathrm{rr}^{\mathrm{e}}$ et le $\mathrm{v}^{\mathrm{e}}$ siècle avant notre ère. Syracuse paraît avoir eu une verrerie, puisque c'est là qu'Archimède avait fait fabriquer une sphère céleste en verre.

Mais insensiblement la fabrication s'étendit en Italie, en Espagne et dans les Gaules. Rome, au commencement de l'empire, avait des verreries près du cirque Flaminius et du mont Colius; elles se multiplièrent dans la suite, car Alexandre Sévère mit leurs produits au

Julien; il fut alors démontré que les caractères de l'inscription appartenaient à une écriture inventée en Chine entre les années 48 et 33 avant Jésus-Christ, et que le texte était tiré de l'œuvre d'un poète qui vivait sous la dynastie Thang, de $7 \mathrm{r} 3$ à $74 \mathrm{I}$ de l'ère chrétienne.

Étant à Pompéi au moment d'une fouille, nous avons vu mettre au jour une bouteille à vin, cassée, en verre déjà irisé, qui se trouvait à côté d'objets antiques; la bouteille ne pouvait guère dater que du siècle dernier, d'après sa forme et sa matière; elle avait sans doute été abandonnée après un repas et recouverte à la suite de fouilles postérieures. 
rang des arts somptuaires; les verreries de Cumes acquirent une certaine célébrité ainsi que celles de Sorrente, dont les coupes gravées étaient recommandées pour boire le vin du pays; c'est de Sorrente sans doute que provenaient en partie les verres de Pompéi, car les recherches spéciales auxquelles nous nous sommes livré ne nous ont fait découvrir dans les ruines, jusqu'à présent mises au jour, aucune trace de fours de verrerie.

Sous la domination romaine, l'Égypte continua à fabriquer et comme précédemment à exporter la verrerie sur le littoral de la mer Rouge; ses navigateurs pous. sèrent même jusqu'à l'embouchure du Gange et peutêtre jusqu'en Chine. Hadrien, qui aimait l'Égypte au point d'avoir fait adopter le style égyptien par les décorateurs romains, reçut en présent, pendant un de ses voyages, des verres de couleur provenant d'un temple; il les envoya à Rome, à son beau-frère, le consul Servianus, et lui recommanda de les servir aux convives les jours de fête. Sous Aurélien, un impôt fut établi sur la verrerie égyptienne, ce qui indique qu'elle faisait concurrence aux verreries de l'Italie.

Dans les Gaules, il existait certainement des verreries : Pline l'affirme et les témoignages matériels aussi; on ne saurait conclure à coup sûr à la présence de fabriques par une accumulation plus ou moins considérable de pièces de verres anciennes, mais il y a présomption que des fabriques se trouvaient en Normandie et certitude qu'il y en avait en Poitou; dans ce pays, certaines localités ont été longtemps désignées sous les noms de verra. ria, vitreria, portus vitraria, et, à côté de débris de verre, on a trouvé des scories. A Lyon, on a décou- 
vert à Saint-Irénée, en 1757 , une stèle funéraire qui fit partie de la collection des Génovéfains pour être ensuite déposée au palais des Arts. Nous donnons le texte de la première partie de l'inscription :

ET MEMORIA IETERNE IVL

I ALEXSADRI NATIONE AFRI CIVI

CARTHAGINESI OMINI OPTIMO OPIF

ICI ARTIS VITRIAE QVI VIX ANNO LXXV

MENSEM V DIES XIII SINE VLLA

LESIONE ANIMICVM COIVGE

SVA VIRGINIA CVM QVA VIX

SIT ANNIS XXXXVIII EXQVA

CREAVIT FILIO III ET FILIAM

EX QVIBVS HIS OMNIBVS NE

POTE VIDITE DEOS SVPEST

ITES SIBI RELIQVIT...

Et à la mémoire éternelle de Julius Alexander, né en Afrique, citoyen de Carthage, homme excellent, faiseur d'ouvrages de l'art de la verrerie. Il vécut soixante-quinze ans, cinq mois, treize jours, sans aucun affaiblissement d'esprit. Avec son épouse Virginia il vécut quarante-huit ans et en eut trois fils et une fille. De tous ses enfants il vit naître des petits-enfants et les laissa tous lui survivant.

Il est assez fréquent que dans la verrerie les enfants continuent le métier de leur père; il est possible que Julius Alexander ait fondé à Lyon une dynastie de verriers. 


\section{I}

Nous allons maintenant étudier la verrerie antique au point de vue de la fabrication, de l'usage et de l'art décoratif. Nous nous appuierons surtout sur les pièces que nous avons eues sous les yeux au musée de Naples, cet établissement ayant sur les autres l'avantage de posséder une collection ne provenant pas seulement des tombeaux, mais bien de maisons habitées ou la vie a pu ètre surprise en pleine activité ${ }^{1}$.

Un coup d'œil d'ensemble sur une collection de verres antiques fait remarquer aussitôt l'aspect général de la matière; les objets ont une teinte laiteuse et semblent plongés dans une buée. En examinant de plus près, on voit des verres restés clairs; d'autres ont perdu à des degrés différents leur qualité essentielle, la transparence; il en est enfin que le toucher fait tomber en poussière. Ces états sont l'effet direct d'une décomposition dont les agents les plus actifs sont l'air ambiant et l'humidité; d'autres éléments, tels que le temps et la composition de la pâte, contribuent aussi dans une certaine mesure à la transformation, mais ce sont l'air et l'humidité qui jouent le rôle principal.

La décomposition se manifeste d'abord par une

1. Le musée de Naples renferme plus de pièces de verrerie antique que tous les autres musées réunis; il y a quelques années, le nombre des objets dépassait six mille, et il augmente toujours. 
légère irisation, puis par des reflets métalliques, verts, jaunes, blancs, azurés dont les couleurs nacrées se confondent; enfin la matière s'effleurit en lamelles et finalement tombe en poussière au moindre contact. Les objets trouvés dans les tombeaux hermétiquement clos ont gardé une certaine transparence et de la solidité. Les verres de Pompéi sont, en général, bien conservés; ceux qui ont échappé à l'action des matières lancées par le Vésuve ont été enfouis dans la cendre; la couche, haute de plusieurs mètres, s'est tassée et a formé une enveloppe impénétrable à l'air et à l'humidité on a dit que la cendre avait activé la décomposition du verre, c'est une erreur. Il suffit d'assister à une fouille pour constater que les parois

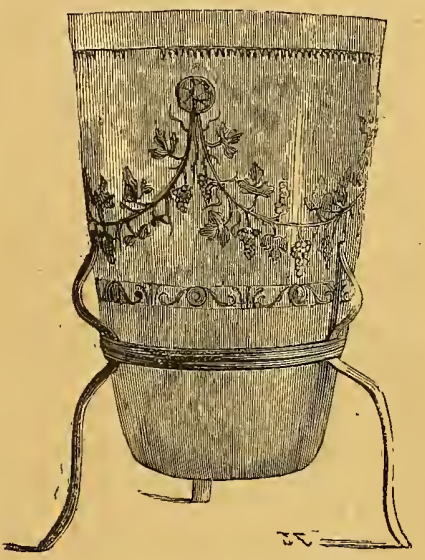

FI G. 7. - A N TIQUITÉ.

(Musée du Louvre.) des murrs revêtus de couleurs sont restées vives et brillantes; si la cendre n'a pas eu d'action détériorante sur la peinture, elle n'a pu agir sur le verre beaucoup plus résistant. Nous avons recueilli quelques morceaux de verre dans les thermes romains de l'Esquilin que Titus fit élever sur une partie du palais d'Or de Néron; après leur abandon, les salles et les cours furent comblées par des gravois, des poteries brisées et des matériaux de toutes sortes; l'air et l'eau: 
ont pénétré dans ces décombres mal tassés à cause de la forme des débris et qui font murailles sur les parties vides des ruines. En comparant ces morceaux de verre avec ceux de Pompéi, on constate une différence dans la décomposition; c'est à peine si, dans les verres les plus détériorés de Pompéi, quelques minces lamelles nacrées se détachent, tandis qu'il est difficile de toucher le verre des thermes de Titus sans l'anéantir. Nous avons pris dans la main le morceau inférieur d'un vase à pied; sous une légère pression des doigts, ce qui restait de la paroi s'est détaché par feuilles; le pied a résisté davantage à cause de son épaisseur, mais un faible grattage l'a réduit symétriquement à la moitié de son volume. Nous avons recommencé en d'autres endroits cette facile expérience, et nous avons toujours constaté, en observant des qualités et des épaisseurs semblables, que le verre le mieux conservé était celui qui avait le moins subi le contact de l'air et de l'humidité. L'action du temps est beaucoup moins importante que celle de la composition chimique; le verré à teinte verdâtre dans la tranche, le verre bleu, se conservent beaucoup mieux que le verre blanc, toutes choses égales d'ailleurs en ce qui concerne le milieu ambiant. Il est inutile de réfuter l'assertion qui veut que l'irisation des verres antiques ait été voulue. Lorsque les anciens faisaient du verre blanc ordinaire, ils avaient évidemment, comme nous, l'intention de fabriquer un objet transparent, et non pas de détruire la qualité essentielle du verre, qui est précisément la transparence. Ce serait une erreur que d'attribuer à l'antiquité tous les verres irisés; chacun a pu remarquer des traces de décompo- 
sition très apparentes sur les verres à vitres à couronne de nos anciennes màisons.

L'analyse chimique du verre antique démontre que les substances employées étaient les mêmes que de notre temps ${ }^{1}$; il ne faut attacher aucune attention à quelques différences dans les dosages, car de semblables écarts existent dans les produits modernes, ni s'étonner de ne pas retrouver par l'analyse toutes les matières de la composition primitive, l'action du feu en faisant disparaître une partie pendant la fonte. Les anciens se servaient du cobalt pour le bleu, de l'oxyde de cuivre pour le bleu et le vert, du plomb pour le cristal,

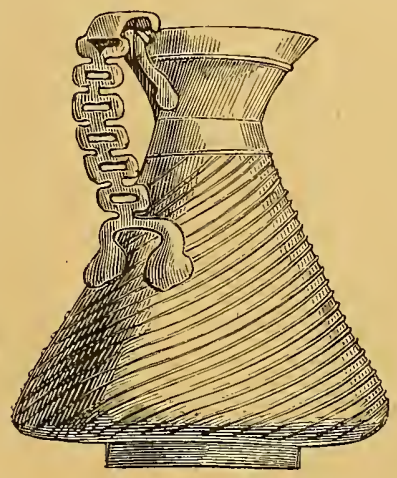

F1G. 8. -- ANTIQUITÉ.

(Collection Charvet.) qu'ils fabriquaient à l'effet d'imiter le cristal de roche 2 . Comme de nos jours, ils ajoutaient au sable et aux produits chimiques une certaine quantité de verre cassé; les juifs amenés en captivité par Titus et d'autres petits

r. Voici, entre beaucoup d'exemples, deux analyses comparatives.

VERRE DE POMPÉI

Silice.... 69

Chaux .... 7

Soude..... I 7

Alumine .... 3
VERRE MODERNE

68

9

I 7

4

2. Analyses de M. Girandin à_Rouen. 
trafiquants échangeaient à Rome des allumettes et d'autres menus objets contre du verre cassé ${ }^{1}$.

Le verre était blanc ou coloré dans la masse; les couleurs les plus fréquentes sont le bleu, le vert, le violet, le jaune; la plus rare est le rouge. Souvent plusieurs couleurs sont mélangées dans la fonte : le verre alors prend l'aspect des agates; ailleurs, elles sont disposées avec symétrie et forment d'ingénieuses combinaisons dans la pâte; des fils, des rubans de couleur se déroulent en spirales dans une masse transparente ou opaque, c'est le filigrane; des vermiculés, de tons différents, sont aplatis dans les fonds, c'est une sorte de mille fiori (fig. 9). Pour marquer l'opulence, le verrier introduisait dans la matière en fusion quelques feuilles d'or; l'objet augmentait alors de prix vénal, mais non de qualité; il n'en était plus ainsi lorsque l'or était posé en doublé, c'est-à-dire sous une mince couverte de verre blanc.

Quelle qu'ait été l'habileté des fondeurs de verre dans l'antiquité, elle n'a pas été poussée aussi loin que le prétendent certains auteurs, Pétrone notamment. “ $\mathrm{Si}$, écrit-il ${ }^{2}$, le verre n'était pas fragile, je le préférerais à l'or; maintenant, je le sais, c'est chose vile... Cependant il s'est trouvé un ouvrier qui fit une fiole de verre

I. Martial. Livre ler, épig. 42.

.... Quid ergo? verna es.

Hoc quod Transtiberinus ambulator,

Qui pallentia sulfurata fractis

Permutat vitreis...

Qu'es-tu donc? un pauvre bouffon; ce qu'est un industriel ambulant d'au delà du Tibre, qui troque des allumettes contre des verres cassćs. (Trad. Nisard.)

2. Pétrone. Satyricon, c. 4I. 
qui ne se brisait pas. Il fut admis auprès de l'empereur (Tibère), auquel il la présenta; l'ayant reprise des mains de César, il la lança sur le pavé. L'empereur fut saisi d'effroi; mais lui ramassa de terre la fiole qui était simplement bossuée comme l'eût été un vase d'airain; puis il tira de son sein un petit marteau avec lequel il la redressa parfaitement. Cela fait, il crut les cieux ouverts pour lui. Tibère lui demanda si un autre que lui connaissait cette composition du verre; sur sa réponse négative, l'empereur donna l'ordre de lui trancher la tête, disant que, si ce secret était connu, l'or ne serait plus que de la boue. „Pline cependant, en général fort crédule, ajoute en répétant l'anecdote avec quelques variantes, que l'histoire a été plus souvent racontée qu'elle n'est vraie. Il est certain que le verre malléable à froid n'a jamais existé.

L'antiquité connaissait le verre soufflé, moulé et coulé. Le verre était soufflé au moyen de la canne, comme il n'a cessé de l'être depuis les verriers thébains représentés sur les grottes de Beni-Hassan-el-Gadim. Le moulage souffle se faisait dans des moules en bois ou en métal; des premiers sortent les pièces unies ou avec des cordons circulaires; des seconds, les verres à figures en relief non rapportées; le moule (forma) était très employé et servait aux ouvrages en terre cuite, en métal, aux fromages, à la pâtisserie. Le moulage en plein avec simple pression produisait des grains de collier, des masques tragiques et d'autres effigies en relief ou en creux; c'est par ce moyen que les verriers estampillaient à chaud leurs produits d'une marque de fabrique et indiquaient leurs noms ou le contenu du 
vase; nous connaissons ainsi Artas de Sidon, Amaranus, Imius, Frontinus, Firmus, Daccius et environ soixante autres fabricants. Les marques de fabrique étaient des initiales, des petites figures humaines, des animaux, des objets mobiliers, des palmes, etc. Le coulage, plus rarement usité, servait pour les plaques de verre unies, employées dans l'architecture; les pièces coulées ne sont comparables ni par leur transparence, ni surtout par leurs dimensions, aux ouvrages du même genre de la fabrication moderne.

\section{V}

C'est pour le service de la table que les anciens faisaient du verre l'usage le plus fréquent.

Les manipulations auxquelles le vin donnait lieu dans l'antiquité étaient plus compliquées que de notre temps. Certains vins étaient réduits par la cuisson à une consistance sirupeuse et même solide; d'autres étaient mélangés avec du miel, des aromates et même de l'eau de mer; rarement le vin de table ordinaire était servi pur, parce que les vins anciens étaient très capiteux, notamment les crus de Chio, de Lesbos, de Naxos, de Thasos, de Crète, de Rhodes, de Libye et d'Égypte. De là certaines complications dans le service. Le vin était d'abord conservé en cave dans des tonneaux de bois cerclés de fer, dans des outres et des amphores à panses ovoïdes, en pointe ou à pied; puis, lorsqu'il était de bonne qualité, on le soutirait en le transvasant 
dans des récipients plus petits, qu'on logeait dans un

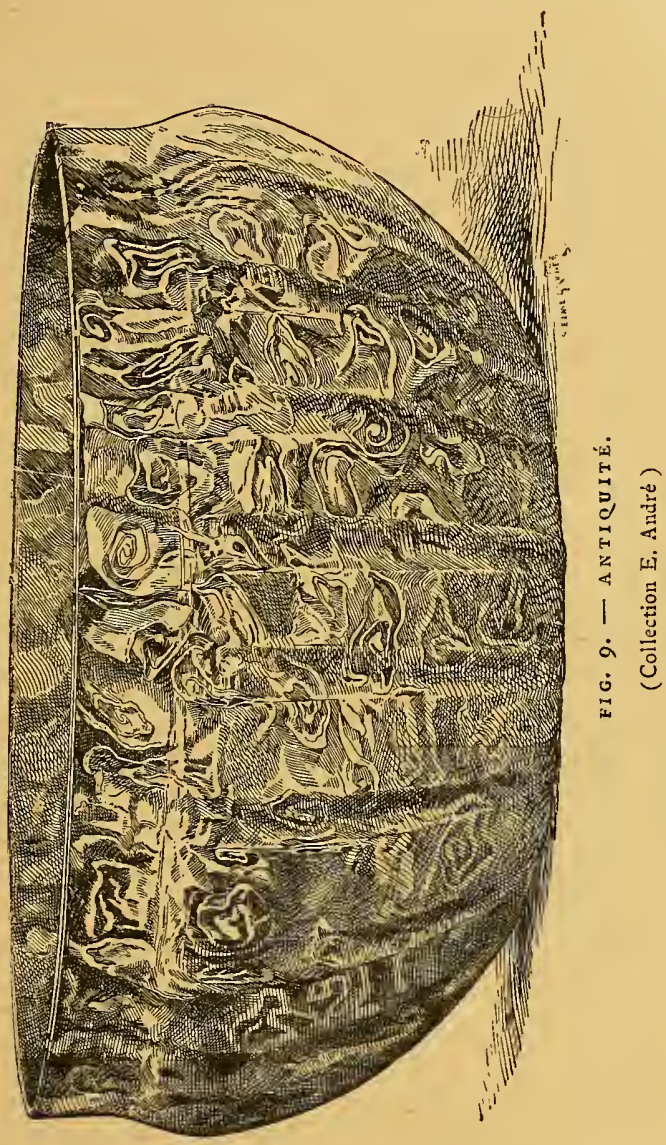

local, apotheca vinaria, situé aux étages supérieurs des maisons. Déjà une partie de ces seconds récipients 
étaient en verre ${ }^{1}$, " on apporte, dit Pétrone, des amphores de verre soigneusement bouchées avec du gypse et portant des étiquettes avec ces mots : Falerne d'Opimius de cent ans ». Pour mélanger, filtrer et répandre sur la passoire chargée de neige, l'esclave, pincerna, commis aux vins, versait le liquide dans des vases, acratophorum, armillim, crater, à larges ouvertures et à anses solides, posés soit à terre, soit sur un buffet, trapezophorum, soit sur la table même; dans ce dernier cas, les vases étaient de plus petite contenance et quelquefois en verre. L'esclave puisait dans ces vaisseaux au moyen de tasses sans pied, scyphus, ou de brocs à bec et à anses uniques, cenochœ, urceus, capis, et remplissait les verres à boire qu'il présentait aux convives sur un plateau, scutella, dont plusieurs échantillons en verre ont été conservés. Il arrivait aussi que le vin était versé dans des bouteilles. lagena, guttus, epichysis, cotyla, placées sur la table à portée des convives; ces bouteilles pouvaient être remplies à l'aide d'un entonnoir en verre, infundibulum, et garnies d'un bouchon, obturaculum, en liège ou en verre. Les précautions étaient naturellement en raison de la qualité; du temps de Pline, certains vins coûtaient I, ooo sesterces - 225 à 250 francs - les I 2 amphores - 233 litres. - Sous l'empereur Commode, les vins ordinaires de Falerne, de Sorrente et de Tibur valaient

I. Malgré d'importants travaux, et notamment ceux de Panofka et de Gerhard, on n'est pas encore d'accord sur tous les noms des vases antiques. Les anciens avaient des dénominations génériques et ensuite des appellations spéciales, qui ont changé selon les pays et les époques. 
I franc 50 le litre, et le vin de cabaret 40 centimes et moins; pour ce vin-là, on prenait peu de soins et on le versait directement de l'outre dans le gobelet du buveur.

Athénée, dans son Banquet des savants, donnant la nomenclature des verres à boire, dresse une liste de cent noms, et il semble que cette liste n'est pas complète. L'érudition n'est pas arrivée encore à mettre une forme en regard de chaque dénomination antique et à déterminer la nature de la matière qui, pour un certain nombre de modèles, peut être indifféremment de la terre, du métal ou du verre; voici cependant quelques noms de vases à boire dont nous avons reconnu des échantillons en verre.

Cantharus. Coupe à pied et à anses élevées. "Çà, valet, verse; verse, par Jupiter ! dans ce canthare ${ }^{1}$. »

Scyphus. Tasse apode conique à anses. "Mais moi, tenant le skyphos tout plein, j'en bois un peu en portant la santé à Erxion qui avait une aigrette blanche ${ }^{2}$."

Ptérotus. Coupe très évasée, à pied et à deux anses ${ }^{3}$.

Patina, en grec lékané. Bol sans anses et souvent sans pied; il était alors posé sur un trépied en terre, en métal et même en verre. " Du Chio pris avec plaisir dans des calices lékané ${ }^{4}$. ”

Calix. Coupe peu profonde, à anses, à pied bas. "Maintenant, rince ce calice pour donner à boire en y

I. Xénarque.

2. Anacréon.

3. Pline.

4. Aristophane. 
ajoutant ce qui a coulé par la passoire 1." "Mais un calice de Chio est suspendu en haut à des chevilles ${ }^{2}$." Ce passage nous fournit une explication sur l'utilité des petites anses des verres à boire, qui ne pouvaient servir à la préhension, mais à la suspension des coupes vides.

Diatreta. Vase cylindrique arrondi par le bas et entouré d'un réseau de verre à jour. En principe, les vases de ce genre étaient faits pour les boissons chaudes, le réseau n'étant dans la pratique qu'une suite d'anses faisant le tour de la panse; mais bientôt, en raison de la difficulté du travail, la diatreta devint un vase de grand luxe.

Crmbium. Coupe à boire à deux anses dont la forme avait quelque analogie avec les barques appelées $c y m b a$.

Calathus. Verre à boire conique, évasé aux deux extrémités.

Rythum. Vase primitivement en forme de corne. "Il faudra boire aujourd'hui pendant un temps prescrit trois rythes des plus grands qu'il y ait... mais il me semble qu'en peu de temps j'en viderais bien deux ${ }^{3}$. "

Les quelques noms que nous venons de citer sont loin de représenter toutes les formes des verres à boire en verre, compris dans la dénomination générique de pocula, car, à peu de modèles près, les anciens avaient presque tous les types dont nous nous servons maintenant. Mais le service de table comportait encore d'autres vases en verre : l'acetabulum, coupe à vinaigre

I. Phérécrate.

2. Hermippus.

3. Epinicus. 
placée sur la table pour y tremper le pain; le gut-
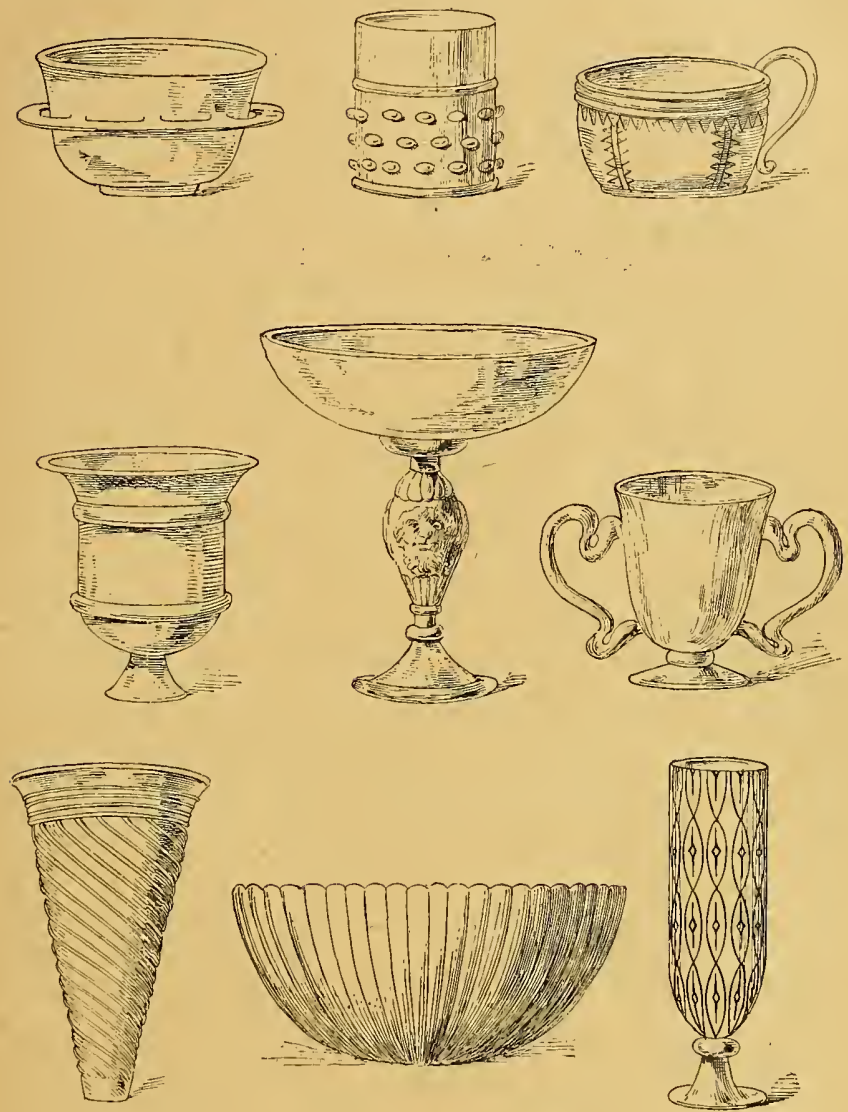

FIG. 10. - ANTIQUITÉ.

(Service de table.)

turium, broc à eau; les huiliers retenus dans l'incitega, porte-bouteilles en métal; les coupes à fruits, et enfin 
la verrerie de luxe dont le but était la décoration du festin.

Les coupes de table servaient également dans les fêtes religieuses; on choisissait naturellement les plus élégantes de forme et les mieux décorées. La patera cependant était à peu près exclúsivement réservée aux libations, sa forme, qui est celle d'une soucoupe avec ou sans manche, était gênante pour boire, mais commode pour répandre le vin sur la tête des victimes. La futile était un vase arrondi en pointe par le bas, afin qu'il ne fût pas possible de le déposer sur la terre, les rites interdisant de souiller par le contact certains vases consacrés. Le catinus était une sorte de plat creux destiné à recevoir l'encens qu'on jetait sur le feu pendant les sacrifices;-c'est à cet ordre qu'appartient le vase hexagone de la cathédrale de Gênes appelé: Sacro catino. Il fit partie du butin attribué aux Génois en I IOI par Godefroy de Bouillon, après la prise de Césarée; l'objet fut considéré comme une relique; on crut qu'il avait servi au Christ dans la Cène, mais sa dimension exiguë peut exclure cette hypothèse. Jusque vers la fin du siècle dernier, la vue même de la coupe était interdite; pendant l'occupation française, elle fut brisée par accident et on put s'assurer alors qu'elle est en verre et non en agate.

La pharmacie, la droguerie et l'épicerie employaient aussi des récipients en verre nommés généralement ampulla. Les flacons à collyres avec inscription du nom de l'oculiste ou du médicament sont fort nombreux; on connaissait, entre beaucoup d'autres, les collyres à la rose, au safran, au lierre, à la myrrhe. Les onguents, 

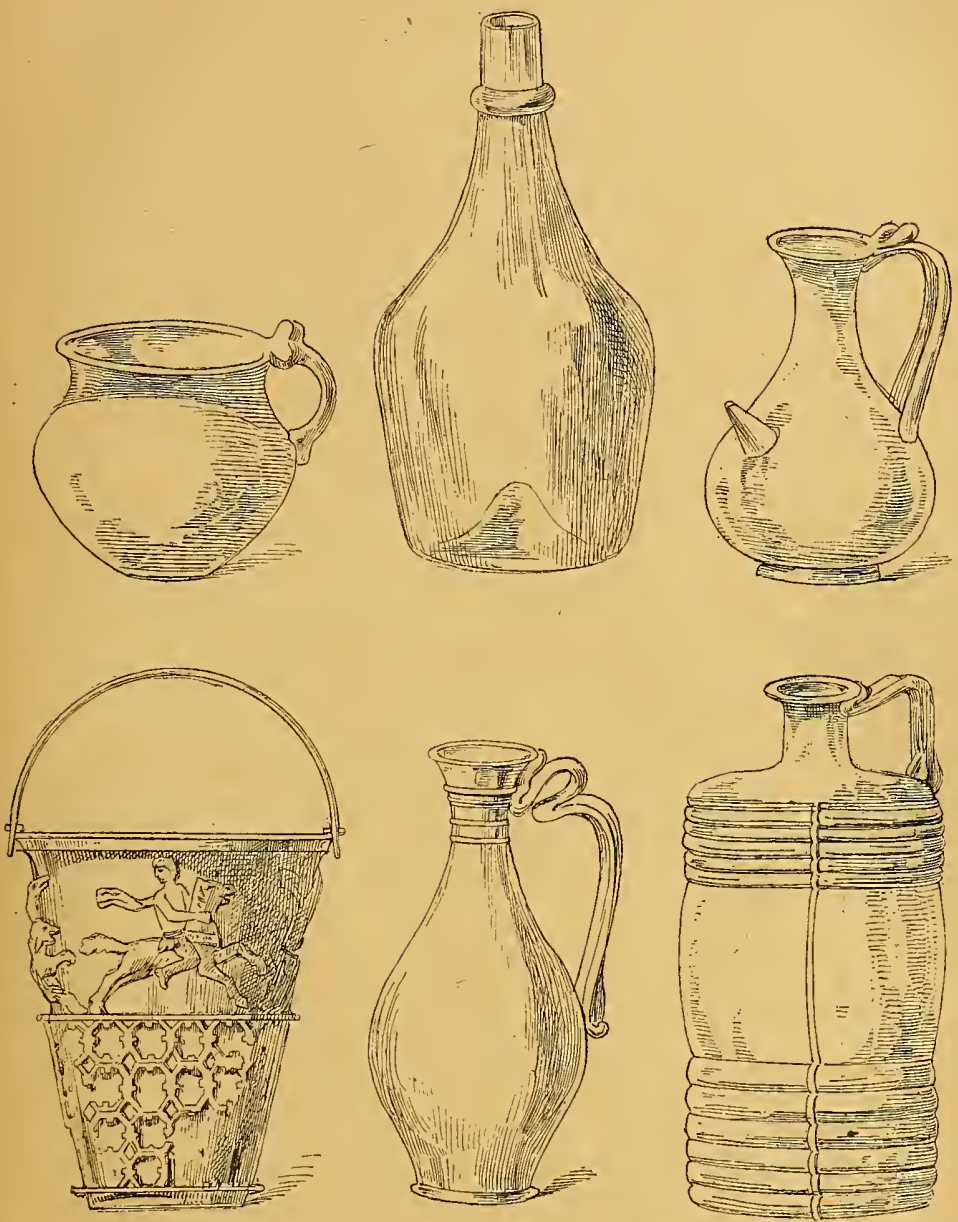

FIG. II. - ANTIQUITÉ. - (Récipients.)

les remèdes à l'état sirupeux, les fruits secs, les légumes 
frais, étaient conservés dans le magasin dans des bocaux en verre commun, à large ouverture ourlée d'un fort cordon de verre rapporté pour fortifier le col et faciliter le bouchage.

La parfumerie jouait, comme en tout temps et en tout pays, un rôle important dans la toilette des femmes. Les odeurs, les pommades, les poudres, les
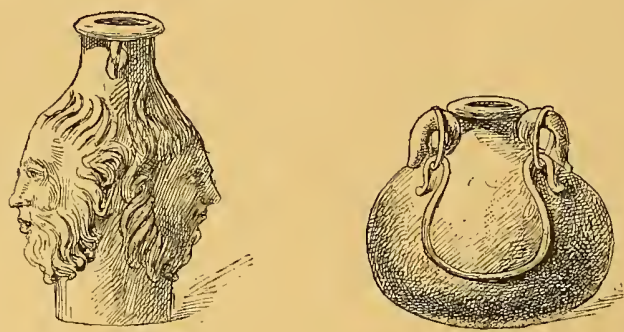

FIG. I2, - ANTIQUITÉ.

(Vases à parfums)

fards, les noirs, étaient contenus dans des flacons de verre, unguentaria, d'autant plus petits que le produit était plus précieux; pour donner plus de prix à la marchandise, on l'enfermait dans des fioles de fantaisie en forme de grappe de raisin et de tête humaine à longs cheveux ondés. On a trouvé une boîte qui nous paraît bien donner le type d'un nécessaire de toilette; elle renfermait deux petits flacons de verre, une tablette et une spatule; les flacons étaient certainement destinés à quelques fards en poudre ou de consistance épaisse; la tablette servait à délayer et la spatule à appliquer; les petites cuillers et les baguettes de verre filigrané remplissaient les mêmes offices. Les femmes élégantes 
aimaient à jouer avec des boules de verre pour entretenir la fraîcheur de leurs mains. Nous croyons aussi que

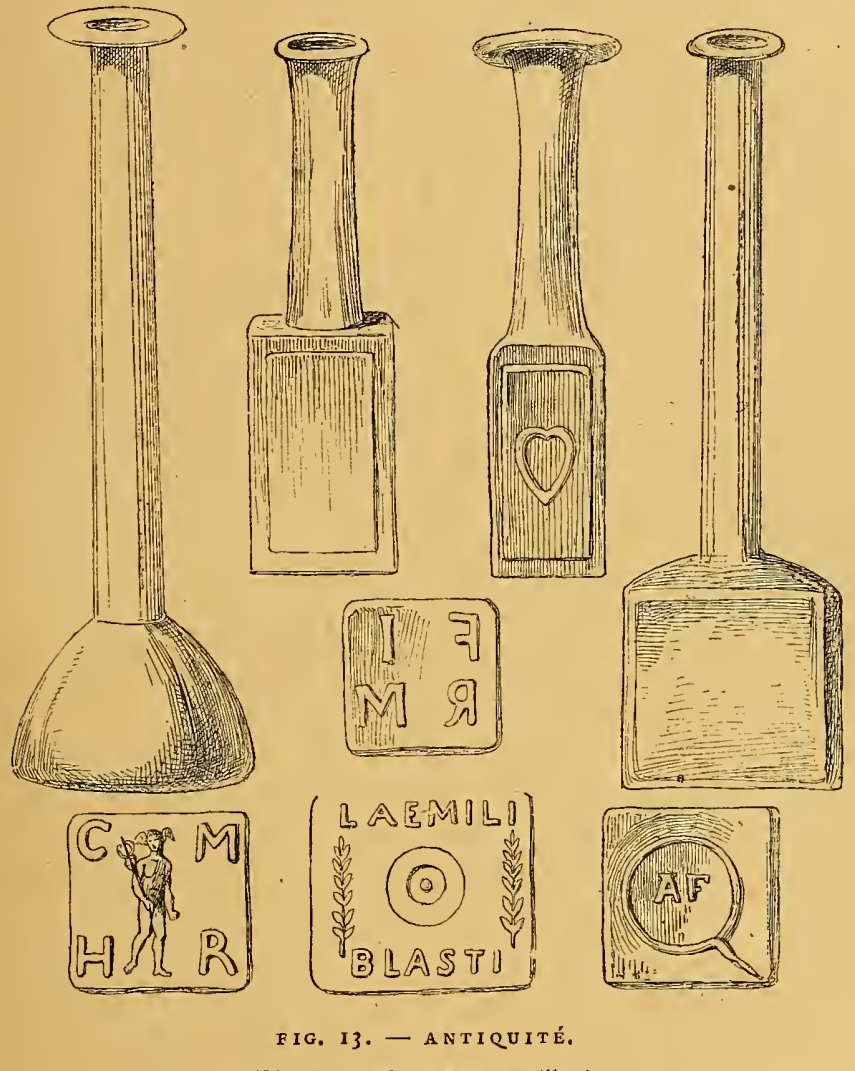

(Verres à parfums et estampilles.)

le plus grand nombre des alabastrons, des pyxis ou boîtes, des petites fioles rondes qu'on prend souvent 
à tort pour des lacrymatoires, étaient des vases de parfumerie.

Le miroir, speculım, est le complément indispensable d'un cabinet de toilette; en présence des textes formels de Pline et d'Aristote, il est certain que les anciens avaient des miroirs en verre. "Sidon, dit Pline, célèbre par ses verreries, s'était aussi occupée de miroirs. "On a découvert des miroirs à main en verre, mais "ils refiètent plutôt l'ombre de l'image que l'image ellemême ", pour employer l'exacte définition que Pline applique à l'obsidienne et qu'on peut appliquer avec autant de raison à un miroir de verre noir fixé à une muraille de Pompéi qui reflète dès qu'il est rendu humide. "Si les métaux doivent être polis pour servir de miroirs, le verre et le cristal ont besoin d'une feuille de métal pour rendre l'image de l'objet qu'on leur présente. " De cette phrase d'Aristote on ne saurait cependant conclure que l'antiquité connaissait l'étamage au mercure.

Le verre servait aussi à la parure; les femmes mettaient dans leurs cheveux des oiseaux en verre très légers qui semblaient posés sur une branche. L'imitation avouée des pierres précieuses et du cristal de roche était une fabrication suivie et avancée. Afin de donner satisfaction aux goûts de luxe des gens peu fortunés, on faisait en verre des boutons, des colliers, des bracelets, les chatons de bague, des cachets, des camées, des intailles. Les meubles, les cuirasses, les gardes d'épée étaient ornés de petits morceaux de verres de couleur rehaussés quelquefois par une feuille d'or posée en dessous. Mais à côté des marchands 

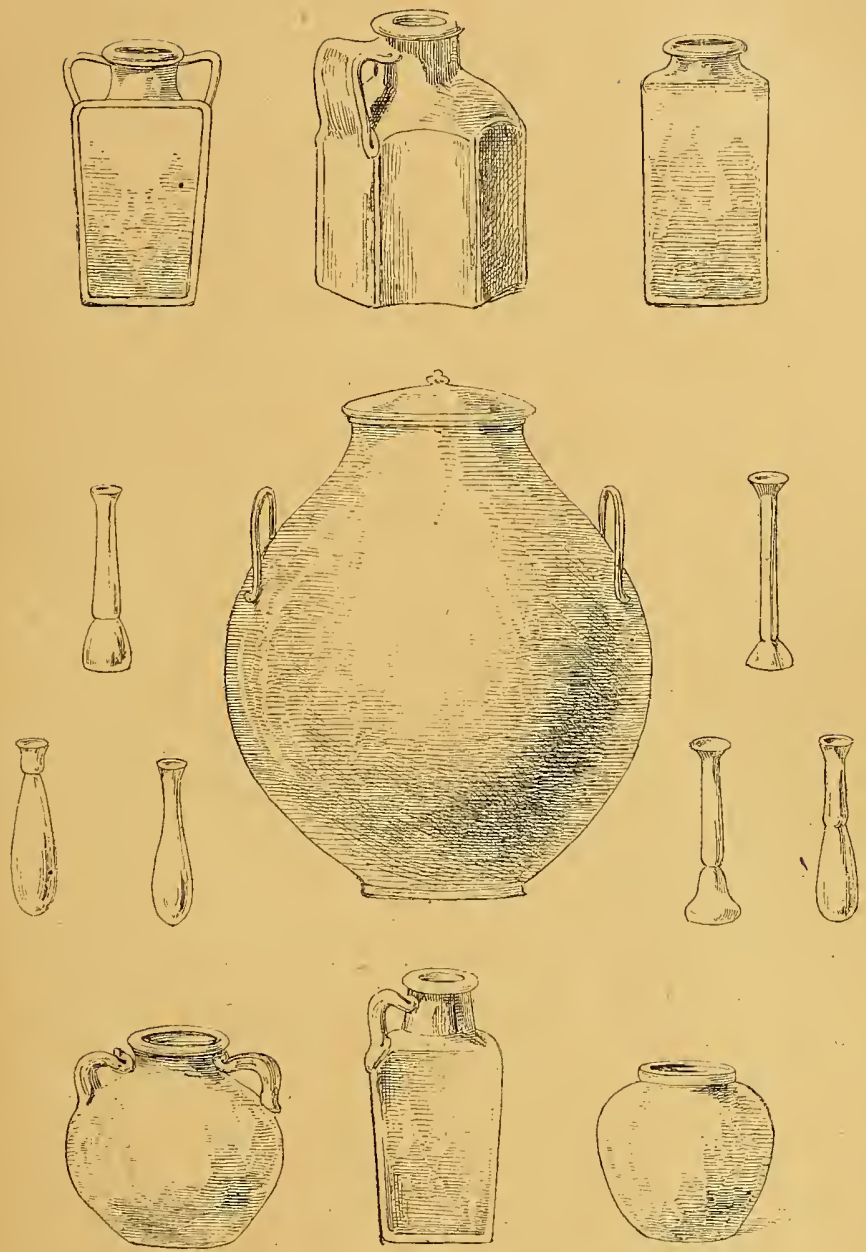

FIG. 14. - ANTIQUItÉ, - (Vases funéraires.)

honnêtes, il en était de peu délicats qui vendaient du 
faux pour du vrai. Pline constate ces falsifications et dit qu'il n'y a pas de fraude qui procure de plus grands bénéfices; on avait trouvé le moyen de transformer des pierres vraies en pierres fausses d'une autre espèce; il existait même des livres dans lesquels est expliquée la manière de donner au cristal la couleur de l'émeraude et de faire une sardoine avec une sarde. L'écrivain indique différents moyens de reconnaître les pierres fausses transparentes : il faut d'abord les éprouver le matin avant la quatrième heure ${ }^{1}$; les peser : les vraies sont plus lourdes; les mettre dans la bouche pour sentir le froid : les vraies sont plus froides; les regarder avec soin : les fausses ont des vésicules, des filaments et un reflet inégal; en détacher un fragment et le broyer sur une lame de fer: les fausses ne supportent pas certaines gravures. Tous ces moyens étaient très inefficaces, comme le prouve l'anecdote racontée par Trébellius Pollion ${ }^{2}$. L'impératrice avait acheté des perles de verre qu'on lui avait vendues pour de vraies perles; lorsqu'elle s'aperçut de la supercherie, elle demanda justice. Gallien fit saisir le marchand comme pour le livrer à la fureur d'un lion, mais ce fut un chapon que, d'après ses ordres, on fit sortir de la cage, et, comme toute l'assistance s'étonnait d'un spectacle si ridicule, Gallien fit faire cette annonce par le curion: "Ce trompeur a été trompé », et il renvoya le marchand.

Les urnce ou olla, urnes funéraires, sont devenues classiques; elles caractérisent l'incinération. Les urnes

I. Dix heures du matin.

2. Trebellius Pollio. Vie de Gallien. 
L'A N T I Q U I T É.

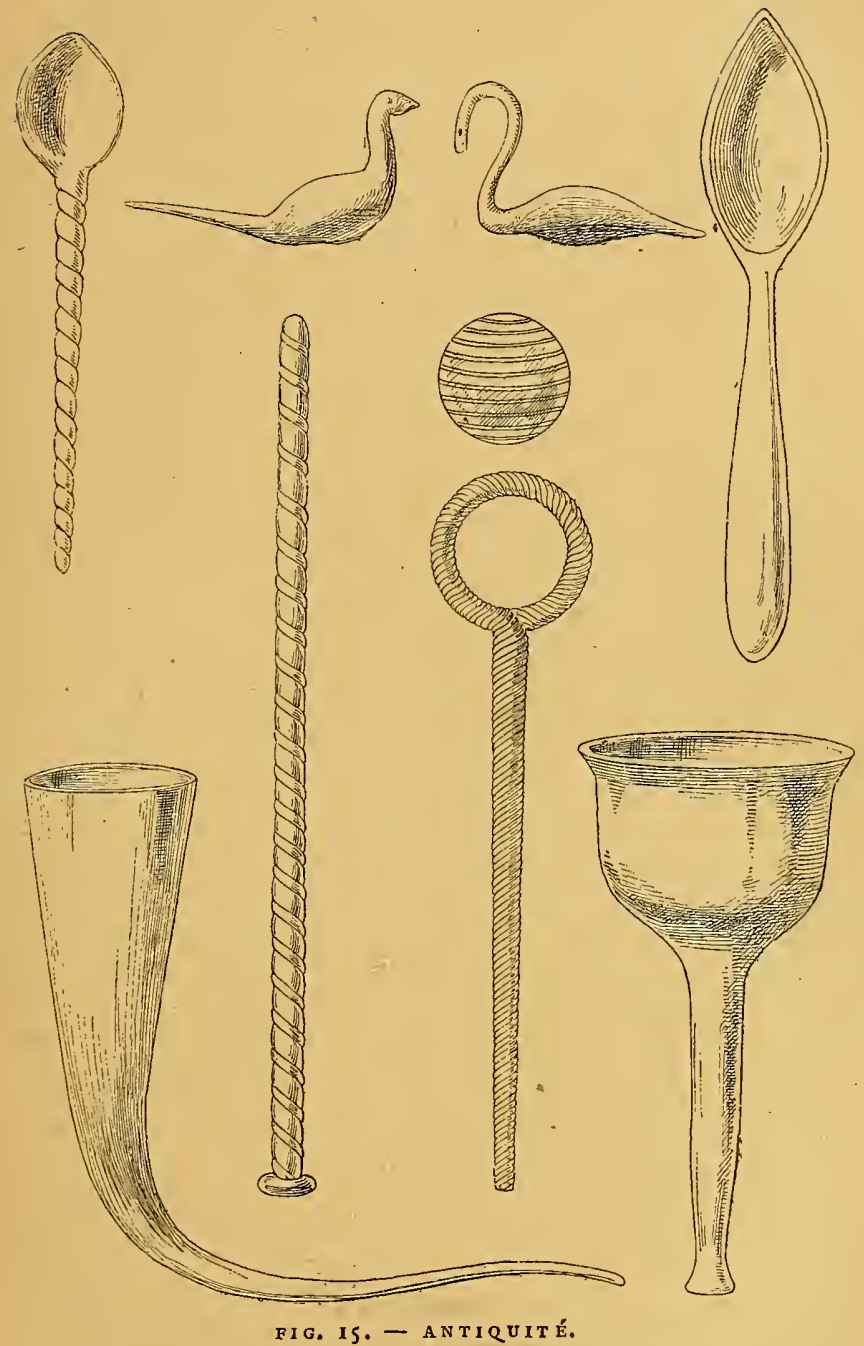

(Oiseaux pour la parure, cuillers, entonnoirs, bagnettes à fard.) 
en verre affectent diverses formes : la plus fréquente est sphéroïdale; on a remarquéqu'elles sont sans ornement; le vase de Portland ferait à ce principe une rare et superbe exception, s'il était réellement prouvé qu'il renfermait des cendres. Les urnes étaient placées dans les sarcophages, dans les cinerarii, niches du columbarium, ou sur une cimaise (podium), qui faisait le tour du monument. Elles n'étaient pas aussi nombreuses qu'on pourrait le croire d'après les pièces qui figurent dans les musées; leur conservation tient à leur fragilité même, car on les garantissait par des enveloppes de terre cuite ou de plomb. Les gens pauvres ne pouvant se les procurer achetaient, pour leurs parents, des vases de terre; la classe moyenne n'en usait que modérément, et nous n'en avons compté qu'une dizaine dans le columbarium intact du personnel de la maison d'Auguste et de Livie, qui renferme les restes de près de trois mille personnes; cependant les inscriptions qui surmontent les urnes scellées deux à deux dans le mur indiquent que les morts occupaient d'importants emplois, tels que médecin, nourrice de l'empereur, argentier, officiers du palais. Les urnes ne sont pas toujours munies d'anses et de couvercles; souvent elles sont bouchées avec un morceau de terre pétrie. Les lacrymatoires, qu'on trouve en si grande quantité, sont de petites fioles allongées; on leur a donné ce nom parce qu'on a supposé qu'elles étaient destinées à recueillir des larmes; en fait, elles renfermaient des parfums; leurs dimensions, qui parfois sont très minimes, permettent de supposer qu'elles n'étaient généralement qu'un symbole. 
Certaines applications du verre à la physique ne sont pas absolument prouvées. Alexandre fit construire le célèbre phare au sommet de la tour Hamgerahs sur la digue d'Alexandrie; la lentille avait, paraît-il, une puissance extraordinaire; elle mesurait cinq palmes de diamètre, soit environ un mètre vingt-cinq centimètres, mais était-elle en verre? Nous en doutons fort, car rien ne prouve que les anciens savaient fabriquer des pièces de verre de cette dimension et les doubler d'une surface réfléchissante. Le miroir pouvait être en acier ou en un mélange de métaux; il était réellement redoutable, car un Grec, Sodoras, le fit briser après avoir enivré le gardien. On ne peut davantage se prononcer sur la matière du miroir d'Archimède qui brûla la flotte romaine, ni sur ces sortes de lentilles dont parle Aristophane dans les Nuées et dont se servaient les débiteurs peu délicats pour faire disparaître au moyen des rayons du soleil leur signature, apposée au bas, de la reconnaissance d'une dette inscrite sur une tablette de cire. L'usage que faisait Néron d'une émeraude pour regarder les combats du cirque montre que les anciens savaient apprécier les qualités optiques de certaines matières. Nous pouvons citer, à titre d'exemple personnel, un petit disque de verre que nous avons étudié au musée de Naples; il est plat d'un côté et taillé en plan. convexe de l'autre; son diamètre est de six centimètres et demi et la plus grande hauteur de la convexité est de douze millimètres; la circonférence est usée à la rolıe et disposée pour la sertissure. Le verre ayant été rendu opaque par un commencement de décomposition, nous n'avons pu juger de la qualité optique, mais 
on nous affirme que ses dimensions constituent une loupe; il semble du reste qu'il ait été trouvé à Pompéi à côté de pièces gravées.

Les boules remplies d'eau allumaient le feu par les plus grands froids, au dire de Lactance; on les employait aussi comme moyen de grossissement pour les ouvrages délicats, et, dans les devantures des boutiques, à l'effet de contenir la marchandise et de la rendre ainsi plus désirable aux consommateurs.

L'heure se marquait sur des sabliers et des clepsydres en verre; les parois des lanternes étaient en vessie, en corne ou en verre, et les horticulteurs recommandaient les châssis vitrés pour la culture intensive des légumes.

Depuis qu'on a vu en place à Pompéi des vitres en verre, il est devenu superflu de citer les textes; nous avons mesuré à sa fenêtre une vitre de trente centimètres sur vingt-huit ${ }^{1}$, ce qui est une dimension normale; elle a été obtenue, non par le soufflage, mais comme les glaces, par le coulage. En faut-il conclure que les vitres en verre étaient d'un usage constant? Évidemment non; on en trouve peu dans les ruines; elles étaient rarement employées, à cause dés habitudes de la vie qui n'exigeaient pas, comme de notre temps, de nombreuses fenêtres aux maisons, et aussi à cause de la clémence du climat.

Il est moins aisé de comprendre plusieurs écrivains, Stace ${ }^{2}$ entre autres, qui parlent de plafonds en verre

I. On prétend qu'il existe une glace de $0^{\mathrm{m}}, 70$ sur $0^{\mathrm{m}}, 40$, provenant d'Herculanum; nous avons cherché cette pièce dans les musées sans la trouver.

2. Stace. Sylves, Lib. I, c. v. 
pour éclairer les appartements, et Pline qui nomme ca-

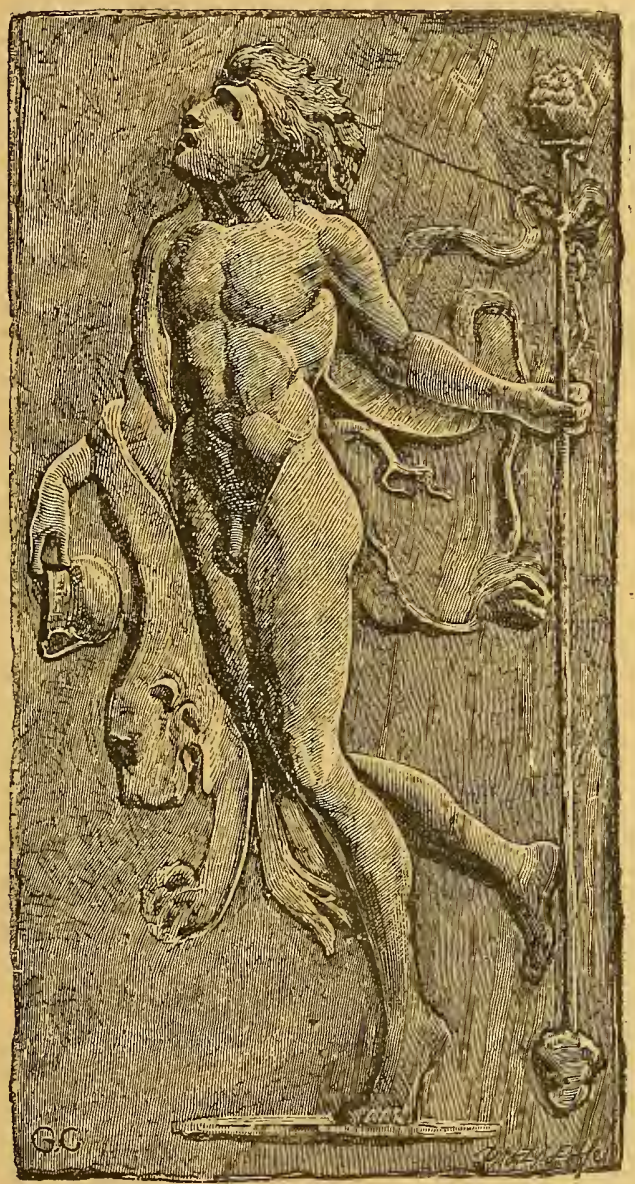

FIG. IG. - ANTIQU1TÉ. - (Piaque moulée.)

mera vitria les plafonds voûtés garnis de verre; en fait, 
on n'a pas découvert encore de dispositions architecturales de nature à justifier ces assertions. Le point cependant est très intéressant; il contribuerait à la solution, vainement cherchée jusqu'ici, du problème de l'éclairage des temples.

Dans la description du célèbre théâtre de Scaurus, beau-fils de Sylla, Pline ${ }^{1}$ s'exprime ainsi :

'La scène était divisée en hauteur en trois parties par trois cent soixante colonnes; la partie supérieure était en marbre, le milieu en verre, genre de luxe qui ne s'est pas vu depuis.

La chose est possible : plusieurs textes, en effet, mentionnent des revêtements en plaques de verre retenues contre le mur par une couche de bitume; on a trouvé quelques plaques avec des figures moulées qui certainement servaient à la décoration des murs; plusieurs archéologues signalent des plaques de verre décorées de peintures; nous n'avons pas été à même d'examiner les pièces et de juger si le décor est peint ou émaillé en léger relief. L'émaillage du verre était connu, mais très rarement employé; en revanche, la mosaïque d'émail était d'un usage courant ${ }^{2}$. La coutume d'appliquer le verre sur les parois des appartements était ancienne; les Phéniciens, les Perses et les Hébreux se servaient de ce genre de décoration.

Le verre servait aussi à divers jeux, sous forme de boules, de dés et de jetons, de pièces pour les échecs et

I. Pline. Naturalis historia, lib. XXIV et LXIV.

2. La Bibliothèque de l'Enseignement des Beaux-Arts a publié un volume spécial sur la Mosaique. 
d'autres formes dont l'usage n'est pas encore déterminé. Des ouvriers spéciaux, oculariani, fabriquaient pour les statues des yeux en verre, en argent et en pierres précieuses. On produisait aussi des objets de pure fantaisie sans aucune utilité pratique. Il est une application cependant dont les anciens ne se sont pas préoccupés, c'est celle du verre à l'éclairage artificiel : ils ne connaissaient ni les lustres, ni les globes, ni les cheminées de lampes en verre; on a trouvé, il est vrai, une lampe en verre du modèle classique, mais, outre que cet objet est à peu près unique, il est certain que c'était une pièce de luxe, peut-être une offrande à quelque dieu, car la mèche allumée aurait fait éclater le bec de verre destiné à la soutenir.

\section{V}

Les verriers de l'antiquité ont donné à leurs produits les formes exigées par la convenance; presque toujours cette forme est gracieuse; bien souvent aussi elle est inspirée par des modèles en terre et en métal. Mais si la forme est la première qualité du verre, elle n'est pas la seule qu'il doive avoir; il lui faut encore une belle matière et une décoration qui séduise le regard. Nous allons examiner les divers modes d'ornementation du verre dans l'antiquité.

L'élément décoratif le plus simple et le plus facile s'obtient par le moulage; la forme générale de l'objet est respectée : mais soit en creux, soit en relief, on mo- 
difie la surface unie par des lignes droites ou brisées, des cercles, des spirales, des côtes, des tores, des olives, des oves, des larmes, des perles, des feuillages, des fruits, des inscriptions, des masques, des figures en pied et toutes sortes d'ornements. Ces motifs pris dạns la pâte à chaud sont en général, en raison même de la fabrication, d'un dessin mou et sans caractère bien marqué; le verre moulé s'obtient sans effort; il suffit à l'ouvrier de souffler ou de presser, et le mérite, s'il y a mérite, revient à celui qui a fait le moule. Nous reproduisons divers moulages, et notamment un vase avec figures trouvé en Normandie; il n'a aucune valeur comme objet d'art, mais il présente cette particularité de rappeler une lutte de gladiateurs sans doute célèbres, car leur noms tetraites, pRVDes sont inscrits sur un vase du musée de Vienne, sur des tasses découvertes en Vendée et en Savoie, et enfin sur les murs de Pompéi ${ }^{1}$.

Lorsque les reliefs définitifs sont rapportés à chaud sur un vase déjà en forme, le verrier doit cueillir un filet de verre et le poser aussitôt sur une surface solide mais incandescente, et il lui faut en ce cas une sûreté de main absolue, les reprises lui étant interdites. L'antiquité a laissé peu de pièces ainsi décorées; elles ont des filets, des serpents, des perles en couleur; mais si l'on veut ranger dans cette catégorie les vases à anses, puisque cet appendice est une pièce rapportée à chaud, le nombre en devient considérable et la qualité se relève.

1. Le nom petrahes du vase de Normandie est évidemment mis à la place de tetraites; c'est une erreur du mouleur. 
Les verriers anciens étaient d'une habileté consommée pour la pose des anses de fantaisie dont les lignes gracieuses et déliées ont servi de modèles aux Véni-

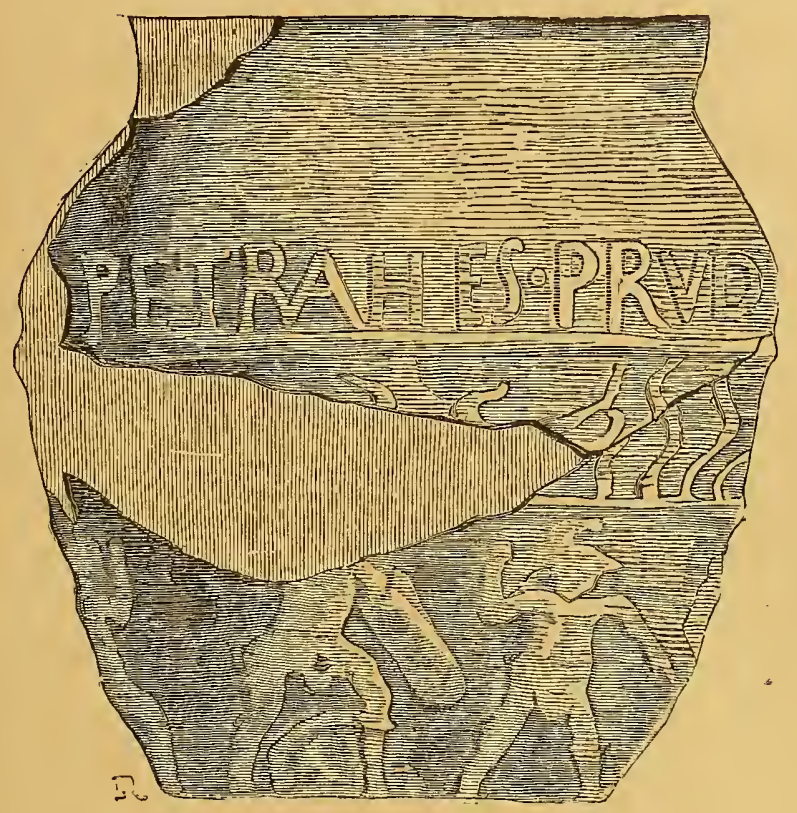

FIG, 17. - ANTIQUITÉ.

tiens de la Renaissance et aux ouvriers de notre temps.

C'est ici qu'au point de vue de la fabrication peuvent se placer les diatreta, vases réticulés, dont la coupe de Strasbourg constitue un type excellent. Cette pièce remarquable a été trouvée en I 835 dans le terrain des fortifications; elle a péri lors du bombardement de la ville 
en 1870 . Le réseau était en verre bleu ainsi que l'inscription:

\section{MAXIMIANV AVGVSTVS.}

La coupe faisait sans doute partie du service de table

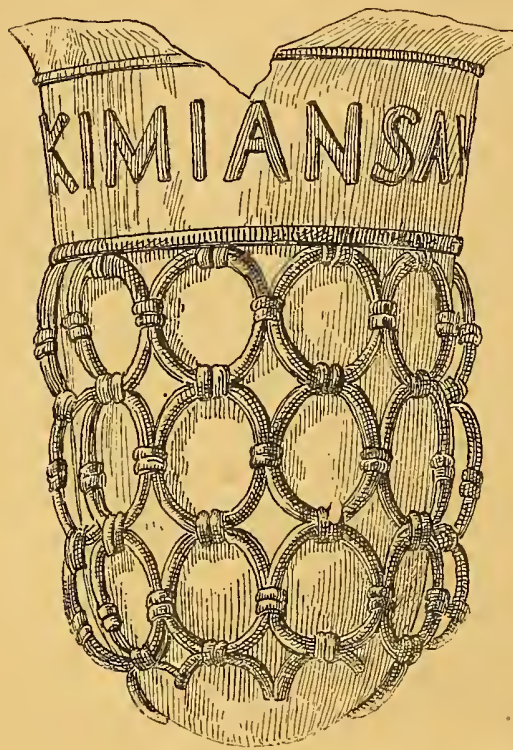

FIG. I 8. - ANTIQUITÉ.

(Vase de Strasbourg.) de l'empereur Maximien, qui passa le Rhin en 297. Un autre vase semblable a été découvert en Italie; il porte les mots :

BIBE VIVAS

MVLTOS ANNOS.

La collection Lionel de Rothschild renferme un vase du même genre, maisen. core plus intéressant: à la place du réseau, l'artiste a mis une composition à personnages qui paraît représenter Lycurgue, roi de Thrace, puni par les Satyres pour avoir persécuté Bacchus; c'est un sujet bien approprié à un vase à boire. Comment ces pièces ont-elles été fabriquées? Il ne paraît pas probable que le corps ait été soufffé à part et ensuite engagé dans le réseau; il faudrait donc admettre que 
les cordons comme les lettres de l'inscription ont été posés à chaud? Quelle que soit l'hypothèse, les diatreta sont d'un travail extraordinaire et constituent un véritable chef-d'œuvre de métier.

La décoration à froid laisse à l'artiste beaucoup plus de temps et de liberté; dans cet ordre, les anciens ont employé trois moyens: la taille, la gravure en creux, la ciselure en relief, sculptura vitri. La taille enlève des parties de la matière; les verres à boire à facettes plates sont taillés à la meule; elle laisse en saillie au niveau normal les ornements et creuse le champ. L'antiquite a été assez sobre de la taille, à moins cependant d'admettre que les diatreta soient taillés, ce qui nous paraît douteux. La gravure en creux a été, au contraire, d'un usage assez fréquent, elle se fait à la pointe de diamant ${ }^{\prime}$ guidée par la main, ou bien à la molette et au foret montés sur un tour; l'instrument est en mouvement; le verrier approche le vase du tranchant de la molette, qui égratigne et mord; il dessine ainsi à sa volonté, inscriptions, ornements, figures, bacchanales, sujets de chasses et de luttes et même plus si l'on en croit Pline ${ }^{1}$, et Clément d'Alexandrie qui dit : " La prétentieuse, inutile et vaine gloire des graveurs sur verre tend à faire trembler ceux qui s'en servent et doit être exterminée par nos bonnes institutions. ' Les verres antiques à décorations gravées ne sont pas rares. On peut voir au musée du Louvre un fragment de coupe provenant de la collection Campana dont le décor représente un satyre dansant devant une ménade; le trésor de l'église

I. "Auxere et artes vitiorum irritamenta. In poculis libidines cælare juvit et per obscenitates bibere $)$.

LA VERRERIE. 
Saint-Marc de Venise possède deux verres avec une chasse à courre et une ronde; le British Museum, une coupe avec Diane surprise au bain par Actéon; le musée de Berlin, une coupe avec la création de l'homme; les collections particulières, de nombreux exemples de décors conçus dans le même esprit. Récemment, le musée du Louvre a reçu en don des fragments de verres trouvés en Dalmatie, à Dukle, l'ancienne Docléa ${ }^{1}$. La coupe mesurait près de quarante centimètres de diamètre; les morceaux conservés semblent indiquer un sujet bachique de satyres et de ménades; l'intérêt de la pièce réside surtout dans sa dimension primitive, car l'exécution est grossière et fort inférieure à d'autres motifs antiques traités en gravure. Les décors en relief et ciselés sont le point culminant de la verrerie antique. Le vase de Portland du British Museum et le vase de la Vendange du musée de Naples sont les pièces les plus fameuses de cette espèce, et méritent d'être spécialement étudiés. Le vase de Portland provient de la collection Barberini dont il a longtemps porté le nom; il avait été trouvé au xvI siècle dans la campagne de Rome, enfermé dans un sarcophage qui paraissait alors être celui de l'empereur Alexandre Sévère. Acquis par la famille ducale de Portland, il fut déposé à titre de prêt au British Museum de Londres où un fou le brisa en morceaux. On se plaît à répéter que la réparation en a été si bien faite qu'il est impossible de s'apercevoir de l'accident; c'est là une exagération : le vase a sans

I. Le don a été fait par M. Saski, officier de dragons, auteur de la découverte. La coupe a été étudiée par M. Mowat, dans la Revue archéologique, novembre 1882 . 
doute été restauré aussi soigneusement que possible,

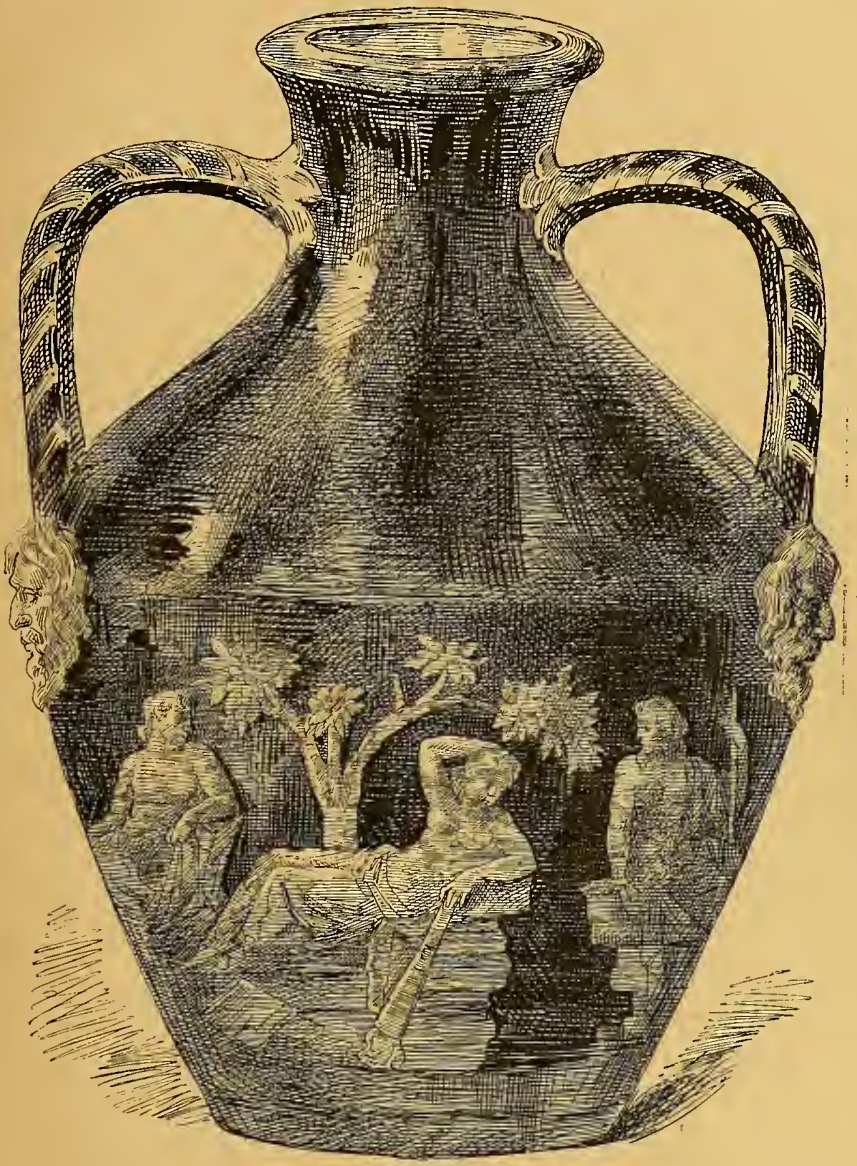

FIG. 19. - ANTIQU1TÉ. - (British Museum.)

mais sa forme a souffert visiblement; en elle-même 
cette forme est, du reste, assez médiocre et peu digne d'une si noble décoration. On a discuté sur le sujet : on a voulu y voir une allégorie de la naissance d'Alexandre le Grand ou une allusion au songe qu'eut Julie, la mère d'Alexandre Sévère. Le Père Montfaucon s'est absolument trompé en faisant une Léda de la femme

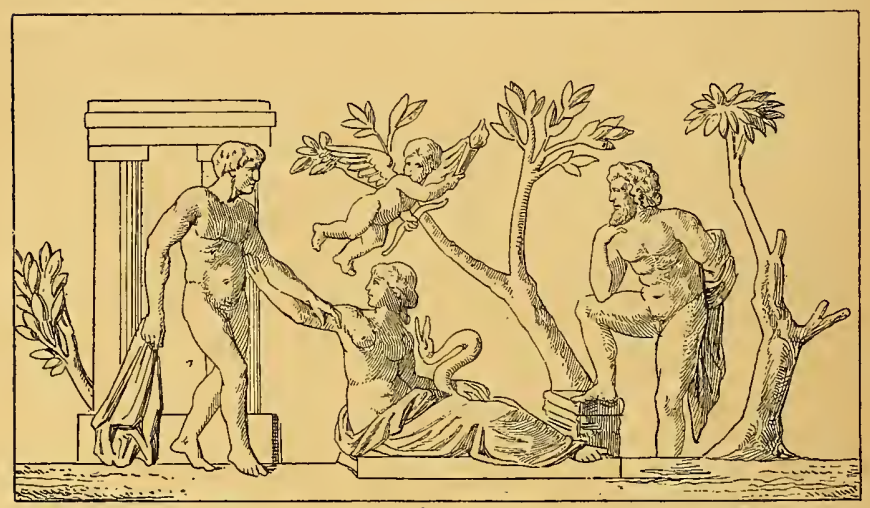

FIG. 20, - ANTIQUITÉ. - (Détail du vase n 19.)

au serpent. Millingen donne l'explication la plus plausible.

Le vase représente le mariage de Thétis et de Pélée. La femme assise, tenant un serpent dans la main gauche, est Thétis; l'homme auquel elle donne la main droite est Pélée. Le serpent rappelle les différentes transformations au moyen desquelles elle comptait échapper au mariage. Le dieu placé devant Thétis est Neptune. Un amour planant dans les airs réunit les deux époux : le portique, derrière Pélée, signifie probablement le palais de ce prince, ou bien le sanctuaire dans lequel Thétis recevait les honneurs divins. Sur le re- 
vers, on voit encore Thétis assise, tenant un flambeau renversé, emblème du'sommeil; l'homme assis à ses pieds est Pélée. L'autre figure, qui porte une lance, est la nymphe du mont Pélion, où la scène se passe ${ }^{1}$.

L'archéologue que nous citons n'a pas vu la figure

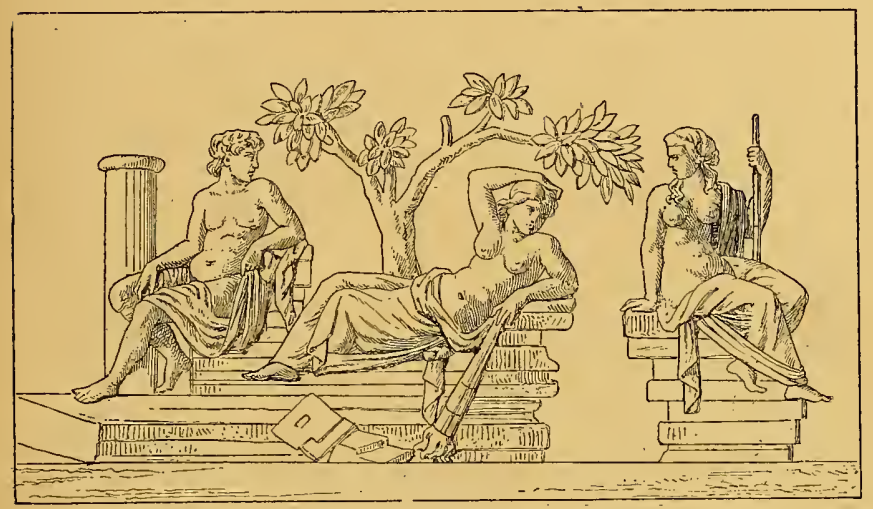

F I G. 2I. - ANTI QUITÉ. - (Détail du vase $n^{\circ}$ I9.)

qui se trouve sous le pied du vase (fig. 22). Elle ne paraît à Montfaucon se rattacher en aucune façon au motif principal; il la décrit ainsi :

L.a figure d'homme porte un bonnet phrygien et tient le doigt sur sa bouche, à la manière des Harpocrates.

La composition du vase de la Vendange ne donne lieu à aucune hypothèse; elle est simple et se lit à première vue. Sur le fond se déroulent des ceps de vigne

I. Millingen. Ancient unedited monuments. 
chargés de fruits mûrs; des enfants cueillent le raisin; un jeune poète récite une ode à Bacchus, un joueur de lyre l'accompagne; plus loin, les grappes sont apportées au pressoir et foulées en cadence au son de

la flûte de Pan et de la

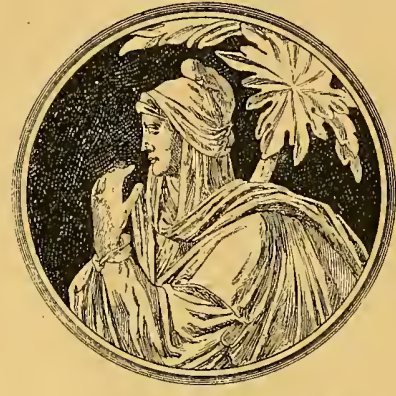

FIG. 22. - ANTIQUITÉ.

(Détail du vase no 19.) double flûte. La décoration est arrètée à la base par une frise d'arbres, de chèvres et de moutons; elle se termine vers les anses par une guirlande de feuilles et de fruits.

Le fond des deux vases est bleu; le décor est en verre opaque blanc, travaillé à la façon des camées.

On admet généralement que le procédé technique est celui du verre doublé, ce qui laisserait supposer que toute la surface bleue aurait été revêtue à chaud d'une couche de verre blanc opaque dans laquelle on a ciselé la composition, après quoi on aurait usé la couverte dans les fonds jusqu'à la rencontre du verre bleu, qu'on aurait enfin poli pour lui rendre son aspect primitif. Le vase de Portland donne l'occasion de montrer l'influence que peut exercer sur l'industrie un seul objet d'art placé dans un musée. Ce n'est pas sur la verrerie ${ }^{1}$, comme il serait logique de le

1. On a vu, à l'Exposition de 1878 , dans la verrerie anglaise, un vase en verre du style et de l'importance du vase de Portland; il avait déjà coûté environ 75,000 francs et exigeait encore près de trois ans de travail. 


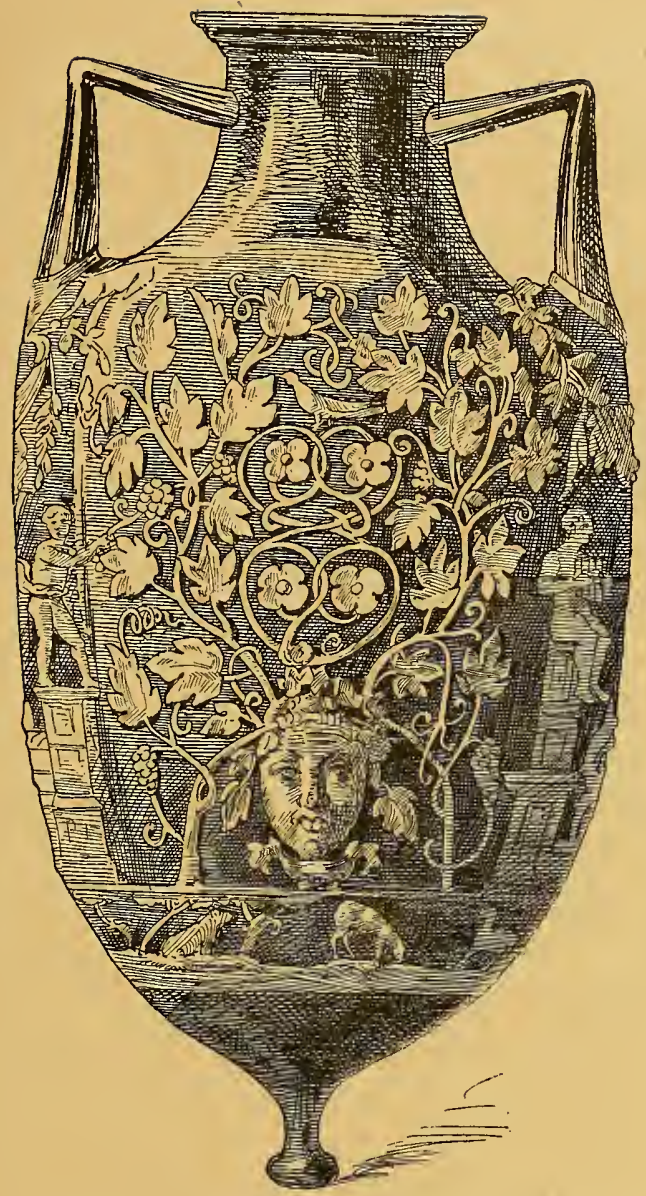

FIG. 23. - Antiquité. - (Musée de Naples.)

croire, que l'action s'est produite, mais sur la céra- 
mique. Le vase de Portland a donné naissance au genre anglais Wedgwood, qui est le nom d'un fabricant de

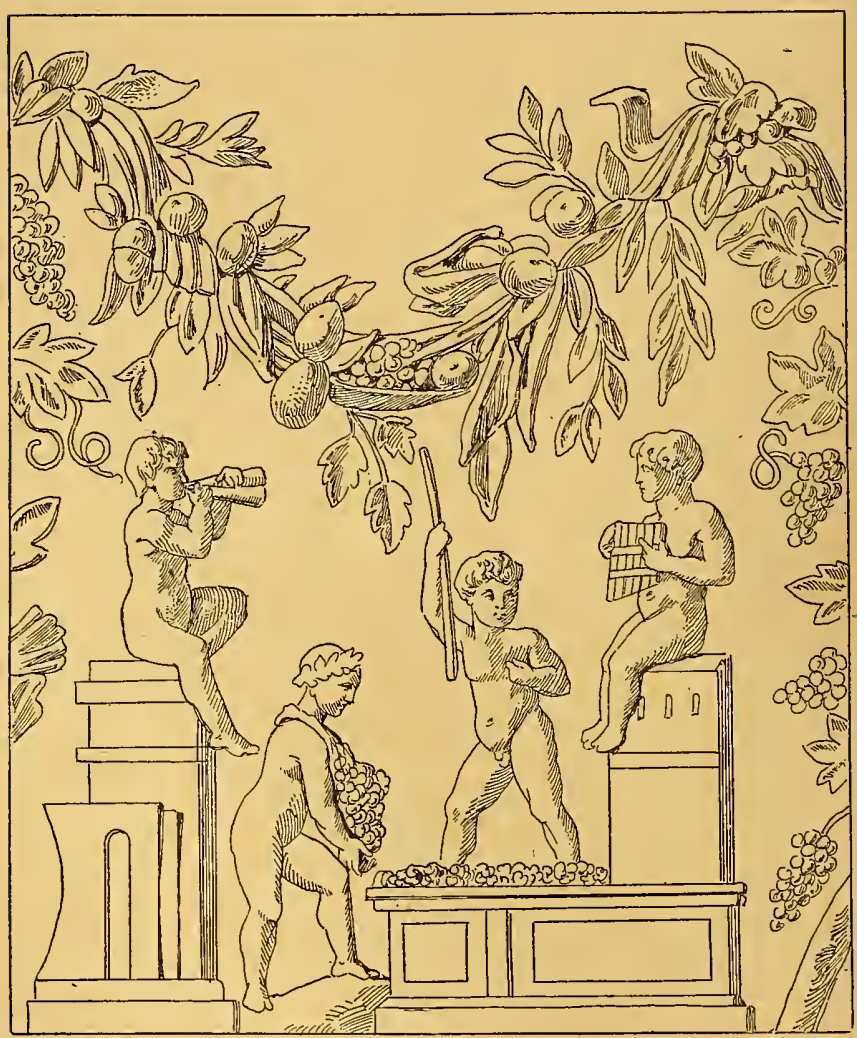

FIG. 24. - ANTICUITÉ. - (Détail du vase $\mathrm{n}^{0}{ }_{23}$.)

porcelaine; le fond des pièces est d'un bleu mat, la décoration est composée de figures et d'ornements en pâte 
blanche. L'aspect général est froid, terne et sans aucune vibration; il ne rappelle le verre en aucune façon et ne

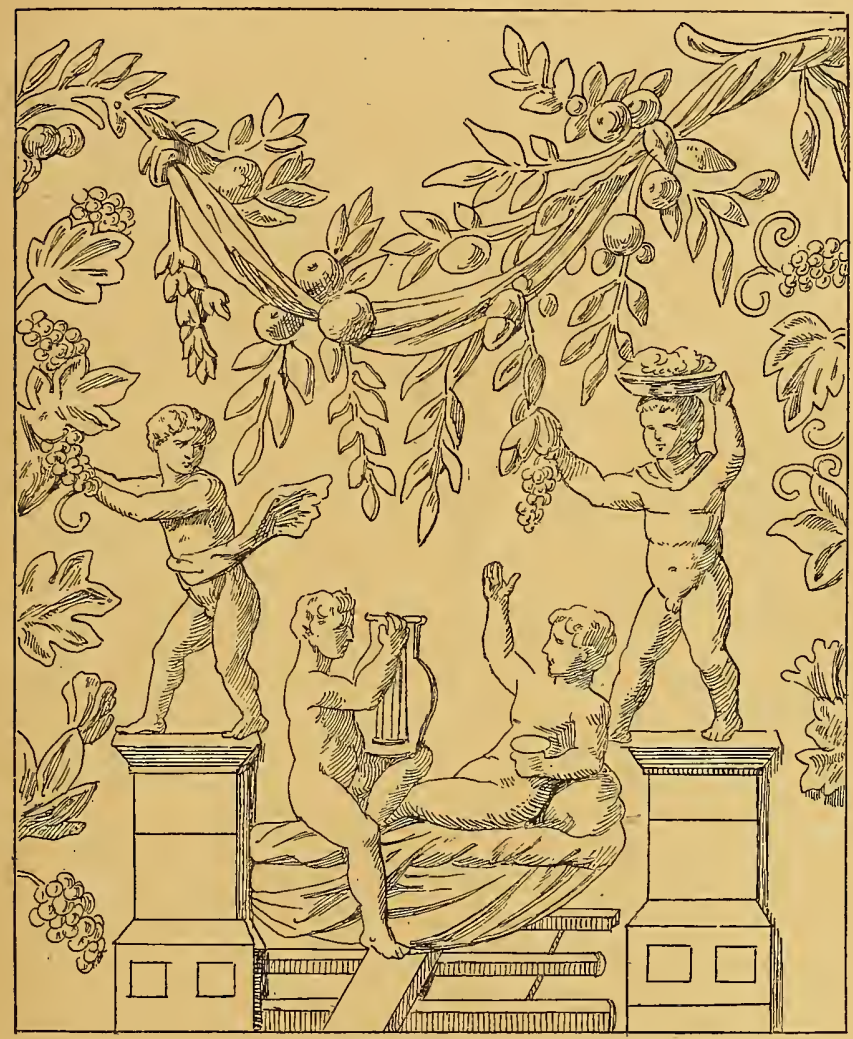

RIG. 25. - ANTIQU1TÉ. - (Détail du vase no 23.)

fait pas valoir les qualités de la porcelaine; c'est un exemple à méditer : il prouve qu'une pièce de verrerie 
ne peut servir de modèle à une fabrication céramique, et que ce n'est pas impunément qu'on substitue une matière à une autre dans la reproduction d'un modèle.

Les vases de Portland et de la Vendange, autant par l'élégance $\in t$ le style de la composition que par le travail de l'artiste, sont des œuvres d'art d'un ordre élevé; ils constituent l'apogée, non seulement de la verrerie antique, mais de la verrerie de toutes les époques et de tous les pays.

Les anciens ont employé les émaux de couleur pour la décoration des vases de verre et des pièces de verre pleines ${ }^{1}$; cette dernière catégorie renferme principalement des objets de parure. On trouve aussi, mais plus rarement, quelques objets entièrement doublés, c'està-dire que la seconde couche de verre enveloppe dans toutes ses parties l'ébauche première.

Il nous reste à parler d'un vase antique que nous croyons unique; il est au musée de Naples. Dans une coupe de verre noir, le graveur a creusé une guirlande à arêtes vives; dans les creux il a coulé du métal et des émaux. Les feuilles sont en émail vert, les fruits en émail rouge, les branches en or; c'est un cloisonné. La coupe a été trouvée à Pompéi, brisée, à côté du Silène ventripotent bien connu; il se pourrait que la garniture tenue par le bras levé du personnage fût précisément celle du vase cloisonné. Nous avons supputé les di-

I. L'émail est un verre coloré dans la masse, par la dissolution d'un oxyde colorant; il ne faut pas confondre les émaux avec les couleurs vitrifiables qui sont simplement tenues en suspension dans la masse. 
mensions; elles ne s'opposent pas à l'hypothèse. La coupe est l'un des objets les plus curieux de la verrerie antique; c'en est le plus rare assurément; l'entente de la décoration est irréprochable comme dessin, couleur et intention générale. Autant le cloisonné eût été peu rationnel sur un verre transparent, puisque par la première paroi le regard se porte sur la seconde et qu'il en résulte une confusion de lignes, autant le procédé a été, judicieusement et par les raisons inverses, appliqué sur un verre noir opaque. Mais rien n'est parfait et nous devons faire quelques réserves sur la technique; l'or et l'émail coulés dans les creux n'avaient pas assez d'adhérence et la chute de la coupe a suffi pour en détacher quelques parties, même dans les morceaux qui n'ont pas été brisés.

\section{I}

Les vases murrhins ne doivent peut-être pas être classés dans la verrerie antique; nous ne saurions toutefois omettre de citer le texte de Pline, ie seul écrivain qui parle avec quelques détails de ces objets si réputés.

VII. Cette même victoire introduisit pour la première fois dans Rome des vases murrhins, et Pompée le premier, à la suite de ce triomphe, consacra à Jupiter Capitolin des coupes et des vases de cette matière, qui bientôt passa aux usages ordinaires de la vie. On fit même des buffets et des plats. Cette sorte de luxe augmenta chaque jour, puisqu'un vase murrhin, dont la capacité n'excédait pas trois setiers, a été 
vendu 70 talents ${ }^{1}$. Un consulaire, qui se servait de cette coupe, il y a quelques années, se passionna tellement pour elle, qu'il en rongea le bord. Ce dommage ne fit qu'en augmenter le prix, et il n'y a point aujourd'hui de vase murrhin qui se cote plus haut. On peut juger combien le même personnage engloutit d'argent en vases de ce genre: ces vases, lorsque l'empereur Néron les enleva à ses enfants, remplirent au delà du Tibre, dans les jardins du prince, un théâtre particulier où ils étaient exposés, et ce théàtre, rempli de spectateurs, suffisait à Néron, même quand il chantait, se préparant à paraître sur le théâtre de Pompée. J'ai vu alors compter les débris d'un seul vase qu'on se plaisait à conserver dans une urne et à montrer, comme si c'eût été le corps d'Alexandre le Grand, pour exciter, je crois, les douleurs du monde et faire honte à la cruauté de la fortune. T. Petronius, consulaire, près de mourir, voulant, par jalousie, déshériter la table de Néron, cassa un bassin murrhin qui avait coûté 300 talents. Mais Néron, en sa qualité de prince, l'emporta sur tous; il acheta une seule coupe 300 talents. Chose bien digne de mémoire qu'un empereur, que le père de la patrie ait bu à si haut prix!

VIII. Les murrhins viennent de l'Orient. On les trouve là en plusieurs localités qui n'ont rien de remarquable, particulièrement dans l'empire des Parthes; mais les plus beaux sont dans la Carmanie. On les croit formés dune humeur qui s'épaissit sous terre par la chaleur. Ils ne surpassent jamais en grandeur de petits guéridons, et rarement ils sont assez épais pour des vases à boire de la grandeur indiquée ci-dessus. L'éclat n'en est point vif, et ils sont plutôt luisants qu'éclatants; mais on estime plus particulièrement la variété des couleurs, et les veines contournées qui s'y dessinent offrent les nuances du pourpre, du blanc et d'une troisième couleur de feu où les deux autres se confondent, comme si, par une sorte de transition, la pourpre devenait

I. Le talent d'argent valait environ 5,500 francs au poids de la matière. 
blanche ou le lait devenait rouge. Quelques amateurs prisent surtout les extrémités et certains reflets comme dans l'arc-en-ciel; d'autres aiment les taches opaques; pour eux, c'est un défaut que la transparence ou la pâleur d'une partie quelconque. On estime encore les grains, les verrues qui ne font pas saillie, mais qui sont sessiles, comme on le voit le plus souvent sur le corps humain. L'odeur que cette pierre exhale est aussi d'un certain mérite.

Que résulte-t-il de ce texte? Rien absolument. Les savants et les archéologues modernes ont disserté; on veut que le murrhin soit l'obsidienne, l'albâtre, la sardoine, l'onyx, le spath-fluor, une gomme, une écaille, une porcelaine. Il faut attendre; jusqu'à ce jour, aucune substance pouvant être du murrhin n'a été découverte; le problème reste entier : le hasard d'une fouille heureuse pourra seul le résoudre. Le moyen âge a employé cette même désignation pour qualifier une substance précieuse; au xiIr et au XIV siècle, l'abbaye de Saint-Alban a reçu des vases murrhins ${ }^{1}$, mais la question est restée dans le même état d'indécision.

La revue que nous venons de passer de la verrerie. antique n'est pas complète; nous avons dû nous borner aux faits essentiels; ils sufiront cependant pour expliquer son rôle et son importance. Les verriers anciens n'ont pas été dépassés comme artistes; comme praticiens, ils ont égalé leurs successeurs, sauf pour

I. Mgr Barbier de Montault a trouvé des textes positifs.

Et in factura unius ciphi murrei unum ciphum murreum.

Voir l'intéressante étude de cet archéologue distingué sur la basilique de Monza, dans le Bulletin monumental. 188I. 
le coulage des grandes glaces, les verres d'optique et la gravure à l'acide. Les anciens faisaient du verre à peu près les mêmes usages que nous; cependant ils n'en connáissaient pas l'application à l'éclairage artificiel. Les objets d'art en verre sont relativement assez rares; les pièces de service chez les gens du peuple étaient en poterie, et dans les maisons opulentes, en or; la verrerie de table paraît avoir été assez goûtée par les classes moyennes, et encore la vaisselle d'argent était-elle, au jugement de Juvénal, un signe approximatif de bien-être; il dit, en effet, que, de son temps, l'aisance d'un petit bourgeois est de 20,000 sesterces de revenu, quelques petits vases d'argent, et deux vigoureux esclaves pour mettre sa vieillesse à l'abri du besoin et des soucis. 


\section{LES CHRÉTIENS ET LES JUIFS}

Les premiers chrétiens ont fait usage du verre dans la célébration du culte, les pratiques funéraires, les agapes, et pour représenter des figures et des emblèmes religieux.

Les calices en verre étaient usités sous le pontificat du pape Zéphirin, de 202 à 2 r $8^{1}$; ils avaient la forme normale d'une coupe à pied, et étaient unis ou décorés de figures et d'inscriptions. Le nombre en était assez considérable, car, indépendamment des calices appartenant à l'autel, il semble que beaucoup de fidèles possédaient des calices particuliers. La patène avait beaucoup d'analogie avec la patère païenne servant aux libations; c'était une coupe très ouverte et aplatie, décorée comme le calice. Le Livre pontifical en attribue l'invention au même pape Zéphirin.

D'Agincourt signale trois calices conservés à Rome et que l'on croit avoir été à l'usage de la primitive

1. Le pape Léon IV, pape de 847 à 855 , interdit les calices en verre. 
église; deux sont des verres à pied cylindrique, le troisième est cônique et de beaucoup le plus intéressant.

La coupe et le pied sont de verre bleu foncé; le bouton qui unit ces deux parties est de métal doré, avec des ornements en dents de scie; les perles qui bordent l'aile du verre
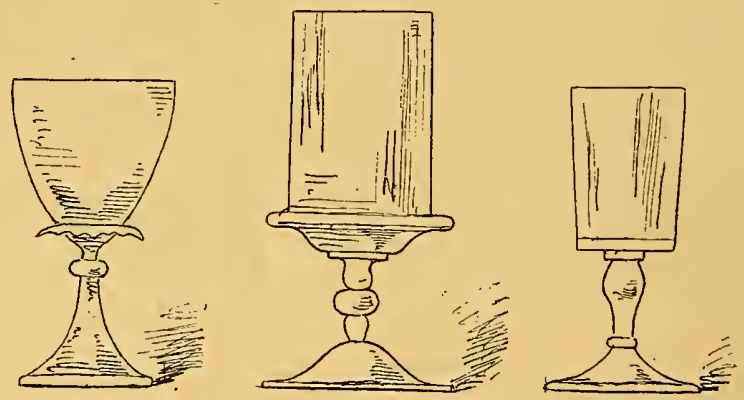

F1G. 26. - CALICES. - (D'après d'Agincourt.)

sont d'émail blanc, ainsi que quatre autres rangs de perles plus petites qui sont placés plus bas; d'autres perles d'émail verdâtre ou rougeâtre ornent les cercles ou ovales du calice; des deux derniers ornements placés à l'extrémité de la coupe, le premier est en or, l'autre en émail rouge; enfin la partie du milieu orné de feuillages est d'or, comme aux verres trouvés dans les catacombes; l'or qui couvrait le pied est aujourd'hui presque entièrement effacé ${ }^{1}$.

Nous regrettons de ne pouvoir partager l'opinion du savant archéologue; la description qu'il donne du

I. Histoire de l'art par les monuments, depuis sa décadence au Iv" siecle jusqu'd son renouvellement aul $\mathrm{xvI}^{\mathrm{e}}$, par J.-B.-L.-C. Seroux d'Agincourt. Paris, I823. 
verre doré et émaillé nous paraît s'appliquer bien plus à la fabrication orientale qu'aux vases des premiers chrétiens; les dessins de d'Agincourt sont insuffisants pour le décor, nous n'en retenons que la forme que nous reproduisons (fig. 26 ).

Le trésor de la basilique royale de Monza ${ }^{1}$ ren-
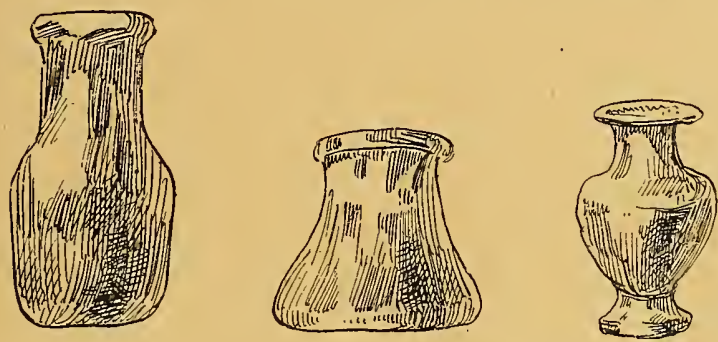

FIG. 27. - AMPOULES DU TRÉSOR DE MONZA.

fermait, du temps de Théodelinde, reine des Lombards de 589 à $6 \mathrm{I}_{4}$ et régente jusqu'en 625 , diverses pièces de verrerie, et notamment une coupe bleue que les inventaires et la tradition tiennent comme étant en saphir alors qu'elle n'est qu'en verre bleu. Nous aurons encore l'occasion de faire remarquer que les erreurs sur la qualité des matières ne sont point rares : on a souvent pris pour des pierres précieuses des verres colorés et pour du cristal de roche du verre simple; il est juste d'ajouter qu'à certaines époques on appelait saphir le verre bleu, à cause de sa couleur et sans aucune intention d'augmenter la valeur de l'objet qu'on savait être en

I. Mgr Barbier de Montault a étudié avec autorité le trésor de Monza dans le Bulletin monumental, de r881 à r 884 . 
verre. Les autres pièces de verre du trésor sont des fioles dans lesquelles furent envoyés de Rome les huiles des martyrs; elles sont de formes correctes, quelques-unes même sont élégantes. Le trésor de SainteCroix de Poitiers possède aussi des fioles en verre
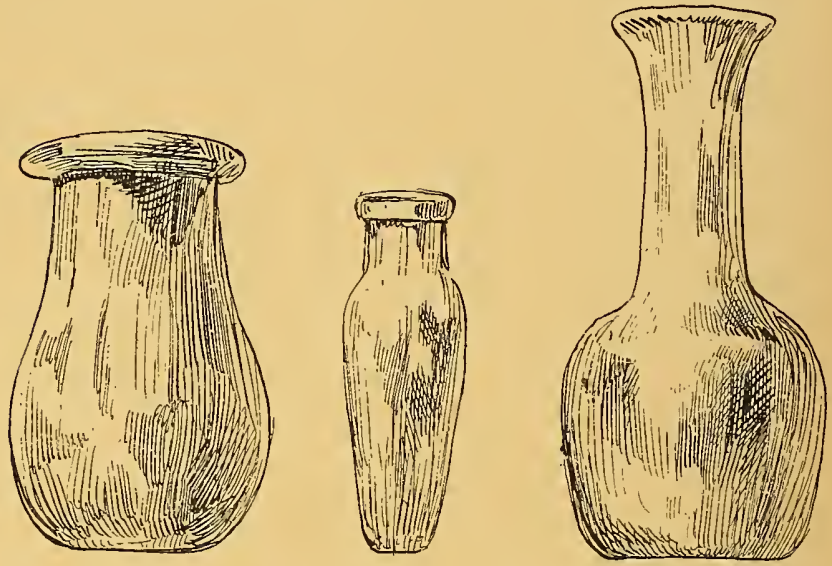

FIG. 28, - AMPOULES DU TRÉSOR DE MONZA.

provenant de sainte Radegonde (5 I9-587), reine de France; ces objets sont d'une fabrication peu soignée et d'un médiocre dessin. Il est probable que ces verres ainsi que ceux de Monza sont d'origine antique; la forme appartient certainement à l'antiquité.

Le poisson était un des symboles les plus populaires de la religion nouvelle; les lettres du mot grec poisson 'I $\gamma^{\theta u ́ s}$ forment les initiales de la phrase Inooús Xprotós

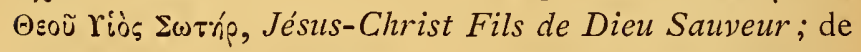
là, sans doute, l'origine du symbole dont l'image se 
rencontre partout, peinte, sculptée, gravée. On a conservé un poisson en verre percé de deux trous pour être porté en amulette. En I7 I8, un bénitier en verre de la forme d'une coquille fut trouvé fixé à une colonne dans les catacombes de Prétextat.

\section{I}

La découverte dans les catacombes d'un grand nombre de rondelles de verre à feuilles d'or historiées a donné lieu à d'intéressantes études. D'ordinaire, ces disques retiennent une feuille d'or entre deux couches de verre; ils formaient ou bien le fond d'une coupe, ou bien une décoration distincte qui s'appliquait sur les parois d'un vase ou enfin une patène.

Les fonds de coupe montrent, dessinés sur l'or et à la pointe, des sujets et des inscriptions nommées « acclamations "; quelquefois l'image est légèrement modelée par des hachures, colorée, rehaussée d'argent; le verre qui sert de base n'est pas toujours blanc, quelques pièces sont sur verre bleu. Les motifs sont tirés de l'Ancien et du Nouveau Testament, comme le sacrifice d'Abraham, Tobie, la résurrection de Lazare, le bon Pasteur, les apôtres Pierre et Paul, le monogramme du Christ, etc.; plus rarement, le motif est l'effigie d'un saint ou la représentation soit d'un symbole, soit d'une scène de famille; les " acclamations " sont l'expression de la douleur, de la joie, d'une espérance, d'un souhait.

Hilaris, vis avec les tiens, sois admis au rafraîchissement dans la paix de Dieu. 
Bois, vis.

La mort nous tirant l'oreille : vivez, dit-elle, car j'arrive - vivons donc pendant qu'il nous est donné d'être bien vivre demain, c'est trop tard, vivons dès aujourd'hui.

Coca, vis pour tes parents.

Cette dernière "acclamation » accompagne une mère qui présente le sein à un enfant.

De l'étude des inscriptions et des motifs on peut conclure que les chrétiens se servaient de coupes en verre dans les agapes funéraires, dans les repas de famille donnés à l'occasion d'un mariage, d'une naissance ou d'un baptême. On explique la présence de ces objets dans les catacombes par ce fait que les fonds, étant plus épais que le corps de la coupe, ont pu résister davantage, et que l'or, matière plus précieuse que le verre, était conservé avec plus de soin. En général, la main qui a tracé ces images a été guidée beaucoup plus par la conviction que par le talent. Cependant quelques dessins sont bien traités et témoignent par leurs dispositions d'un certain goût décoratif. La figure de sainte Agnès que nous reproduisons (fig. 29) est drapée avec ingéniosité et élégance; l'artiste a voulu montrer sans doute la haute naissance de la vierge par l'ampleur des vêtements, le collier et la large fibule qui retient l'ovarium; la sainte est placée dans la pose habituelle des orantes entre deux colombes portant la couronne de la chasteté et celle du martyre. Selon saint Ambroise, Agnès ayant refusé d'abjurer la foi chrétienne pour épouser le fils du préfet de Rome, fut conduite dans un lieu de prostitution, y resta pure et eut la tète tranchée. Les apôtres Pierre et Paul ont 
été souvent représentés sur les fonds de coupes, tantôt en pied, tantôt en buste; le médaillon que nous reproduisons les montre dans une attitude qui ne manque pas

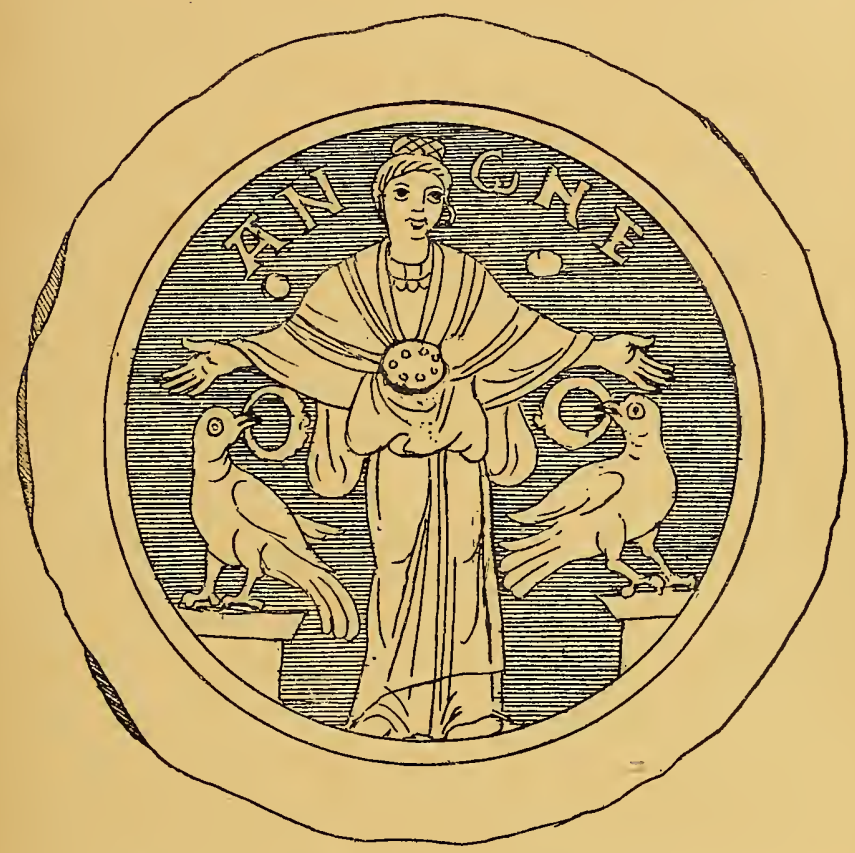

FIG. 29. - VERRE ORBIGULAIRE GHRÉTIEN.

(Sainte Agnès.)

d'esprit; ils tiennent un volumen de la main gauche et, de la droite, donnent la bénédiction ou font un geste d'orateur; entre eux est marqué le monogramme du Christ dans sa forme la plus primitive. Dans l'icono- 
graphie chrétienne, l'âne rappelle quelquefois la Nativité ou l'Entrée à Jérusalem; pourtant nous ne pensons pas que l'on puisse interpréter ainsi l'âne du verre orbicu-

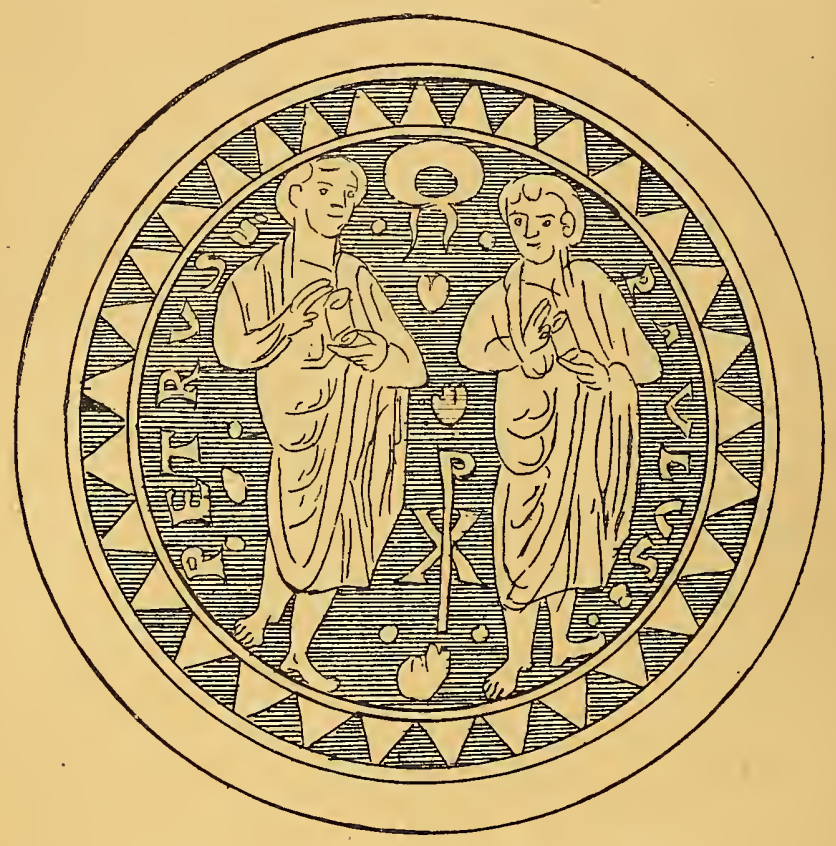

FIG. 30. - VERRE ORBIGULAIRE CHRÉTIEN.

(Les apô:res Pierre et Paul.)

laire que nous représentons et qui nous a paru un des meilleurs à cause de la correction du dessin, du mouvement bien obșervé et de la bordure, heureusement adaptée au motif. L'action de l'animal ne convient, en effet, ni à l'humble monture du Christ ni au com- 
pagnon du bœuf de la crèche; nous voyons tout simplement dans cette figure le nom propre d'un chrétien. Les premiers chrétiens portaient en effet assez tréquemment des noms d'animaux : Aquila, Castorius, Leo,

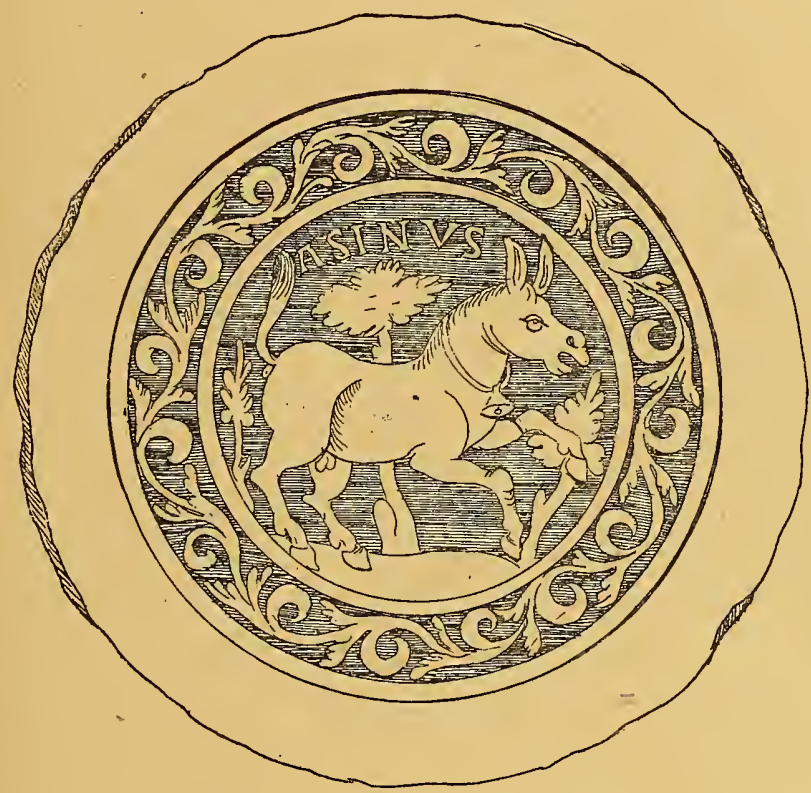

FIG. 3O. - VERRE ORBICULAIRE.

Mus, Panteris, Lupus, etc. etc.; on connaît des Asellus, Asinia, Asellianus; une personne de la famille des Scipions s'appelait Asina; il est donc fort probable qu'il y avait aussi des Asinus et que l'un d'eux avait fait représenter un âne au fond de sa coupe, puisque d'autres chrétiens sont également désignés dans les catacombes 
par l'effigie de l'animal dont ils portaient les noms.

On avait depuis longtemps observé de petits médaillons de verre historiés en forme de tête de clous engagés, comme les fonds de coupes, dans la chaux des loculi, niches creusées dans les parois des catacombes; il est admis maintenant que ces disques servaient beaucoup plus à désigner la sépulture qu'à la décorer, mais il était difficile d'expliquer l'origine des objets évidemment fabriqués dans une autre intention. M. de Rossi a résolu le problème ${ }^{1}$; on a découvert à Cologne un fragment de patène en verre sur lequel avait été appliquée à chaud une série de petits médaillons de verre et d'or figurant des personnages, des lions, des étoiles, des monstres marins. L'illustre archéologue constata que des images étaient semblables à celles des têtes de clous des catacombes; dès lors, plus de doute. Les coupes des chrétiens étant décorées de médaillons orbiculaires, non seulement à la base, mais sur les parois, les unes comme les autres avaient été mises dans les catacombes; ce lion, ce personnage, qu'on ne pouvait expliquer isolément, reçurent un sens par leur disposition sur la coupe primitive et l'on put reconnaître Daniel dans la fosse.

\section{I I}

Depuis deux siècles, à Rome, on donne le nom de ampolla di sangue aux vases trouvés dans les loculi ou murés dans les parois des catacombes à côté des tombeaux

I. De Rossi. Bullettino di archelogia cristiana, décembre I864. 
chrétiens. Ils sont en verre ou en terre cuite; les uns sont vides, d'autres, en très petit nombre, renferment des éponges et des morceaux de linge; d'autres enfin sont imprégnés d'une teinte rougeâtre. Cette teinte provientelle du sang des martyrs ou du vin consacré? Les tissus spongieux ont-ils servi à recueillir le sang? La présence d'un de ces vases est-elle un indice du martyre? Ce sont là des questions fort discutées et non résolues d'une manière absolue. Vers le milieu du xvire siècle, on possédait à Rome quelques vases en verre retenus dans une couche de mortier portant des inscriptions : $s \hat{A}-$ Sang - Sá satvrni - Les archéologues du temps les tenaient pour une preuve certaine, mais depuis, il a été reconnu qu'ils étaient œuuvres de faussaires. 11 est probable que les vases sans traces rougeâtres contenaient de l'eau bénite ou lustrale dont l'usage était déjà consacré dans la religion juive ${ }^{1}$.

Les plaques de verre coloré, en usage dans l'antiquité, ont servi également aux ornements du culte chrétien.

Le grand Constantin éleva sur une colonne la croix dorée, enrichie par-dessus de pierres fines et de verres, qui est dans le Philadelphion, sur le type de celle qu'il vit dans le ciel; la colonne était de porphyre.

Ainsi s'exprime un auteur anonyme qui paraît avoir vécu au $\mathrm{xl}^{\mathrm{e}}$ siècle; il est vraisemblable qu'il ne s'agit pas ici d'émaux, mais de feuilles de verre enchâssées dans le métal.

1. On a trouvé, dans les tombeaux gallo-romains et mérovingiens de la Normandie, des vases en verre avec de semblables taches rougeàtres à l'intérieur. 
Les chrétiens portaient des bijoux décorés de petits morceaux de verre; on a trouvé à Lambæsis un semblable objet composé de verres grenat et vert disposés en forme de croix ; le médaillon central représente JeanBaptiste, gravé en creux. Le Cabinet des médailles possède une petite médaille en verre moulé avec une croix et quatre lettres en relief; nous repro-

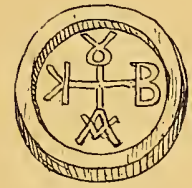

FI G. 32 . JETON EN VERRE. (Cabinet des médailles de la Bibliothèque nationale.) duisons cet objet ${ }^{1}$.

Les chrétiens n'ont pas limité aux feuilles d'or la décoration de leurs verres religieux; ils ont aussi employé la gravure à la molette. Peu de monuments de ce genre ont été épargnés par le temps et on ne peut guère en citer que deux : une coupe trouvée à Rome sur le mont Aventin avec les effigies des douze apôtres placés sous les arcs d'un portique et le fragment d'une coupe baptismale, découverte en 1876 près des Thermes de Dioclétien. Nous reproduisons cette dernière pièce d'après M. de Rossi; c'est le baptême d'une jeune fille nommée Albana. L'eau s'écoule avec abondance d'un vase tenu en suspension dans l'air; la colombe avec le rameau d'olivier, symbole de la régénération et de la paix, s'approche en volant de la tête de la néophyte; un personnage nimbé préside à la cérémonie.

Le monument le plus curieux et le plus complet de la verrerie chrétienne primitive se trouve dans la cóllection Basilewski : c'est une coupe du $\mathrm{v}^{\mathrm{e}}$ siècle

I. M. Ch. Schefer, membre de l'Institut, a trouvé de semblables disques avec inscriptions grecques, dans une fouille près de Beyrouth. 
gravée à la pointe sur la surface extérieure ${ }^{1}$. Elle a été découverte dans une tombe antique à Podgoritza, en Albanie, après un combat entre les Turcs et les Monténégrins, au moment où l'on creusait des fosses pour enterrer les morts. La gravure représente plusieurs motifs

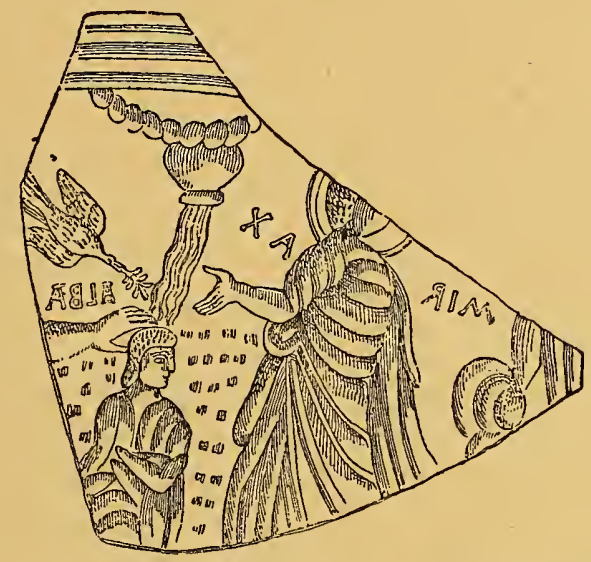

FIG. 33. - COUPE BAPTISMALE GHRÉTIENNE.

accompagnés de légendes incorrectes dont MM. A. Dumont et $\mathrm{E}$. Le Blant ont rétabli le sens précis. On voit, au centre, le sacrifice d'Abraham, et sur le pourtour, l'histoire de Jonas, Adam et Ève et l'Arbre du bien et du mal, la Résurrection de Lazare, Moïse frappant le rocher, Daniel et les lions, les trois Enfants dans la fournaise, la chaste Suzanne. La coupe offre l'occasion de montrer que le symbolisme chrétien s'est manifesté

1. Voir le dessin, page 76 . La coupe a un diamètre de $o^{\mathrm{m}}, \mathbf{2 4}$; elle a été étudiée par MM. de Rossi, A. Dumont, E. Le Blant et R. Mowat. 
dans la verrerie comme dans la peinture et la sculpture. Les jeunes Hébreux dans la fournaise, Daniel exposé aux lions, Jonas, Lazare symbolisent la Résur-

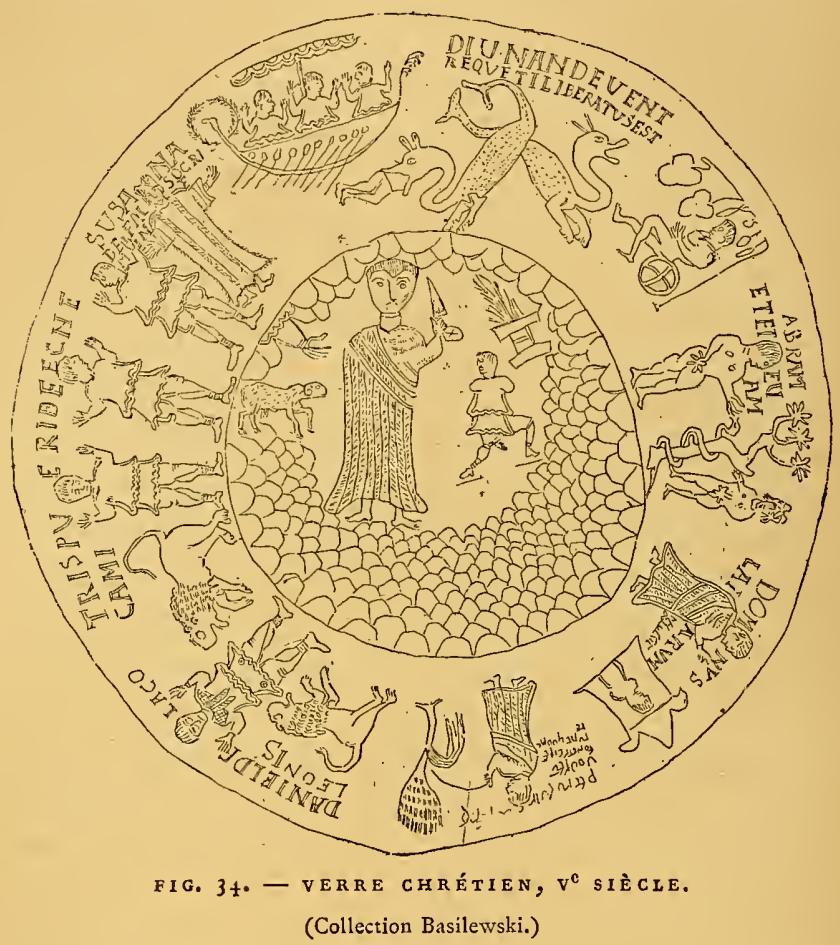

rection, le Martyre, l'Eglise militante; le sacrifice d'Abraham et Suzanne symbolisent l'assistance divine. L'imperfection du dessin et des légendes n'enlève rien du caractère des sentiments qui ont inspiré le graveur ou ceux qui ont fait usage de l'objet. 


\section{V}

Les Juifs ont fait usage des verres à fonds d'or historiés. Buonarotti, dès $\mathrm{I} 7 \mathrm{I} 6$, a signalé et reproduit quelques-uns de ces objets sur lesquels se trouve représenté le candélabre à sept branches; le père Garrucci a confirmé l'observation en la fortifiant par de nouveaux exemples ${ }^{1}$. Il est démontré, d'autre part, que jamais le candélabre à sept branches n'a eu une signification chrétienne, quoi qu'en aient soutenu quelques archéologues distingués. Du reste, quoi de plus naturel que les Juifs, vivant en grand nombre à Rome, aient usé des mêmes moyens de décoration que les chrétiens, qui, aux yeux du peuple, étaient presque leurs coreligionnaires? Le médaillon reproduit (fig. 35) représente l'aron avec la bible sur les étagères gardé par deux lions; la palme de la Judée se dresse en pal entre les candélabres à sept branches, souvenirs du chandelier d'or du Temple; le champ est semé de cédrats etrog et de vases, symboles des félicités du paradis, et de cornes remplies de l'huile destinée à oindre le röi et les pontifes; les mots PIE zezes de l'acclamation, qui signifient " bois, vis ", se retrouvent fréquemment dans les légendes. Le mot zEZEs est une corruption du mot zHCaIC ; pendant longtemps, il fut d'usage à Rome de mêler des mots grecs au latin. La présence de verres juifs dans

1. Garrucci. Vetri ornati di figure in oro trovati nei cimiteri dei cristiani primitivi di Roma. Koma, 1858. 
les cimetières chrétiens s'explique sans difficulté par ce fait qu'on plaçait sur les parois des catacombes les objets les plus divers, afin de reconnaître les sépul-

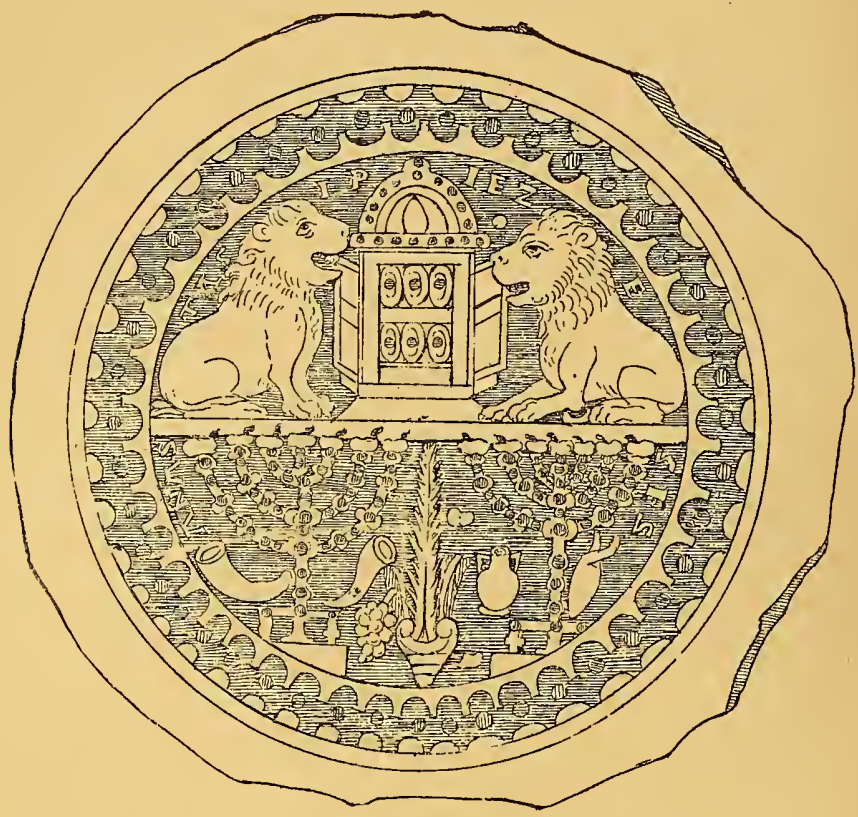

FIG. 35. - VERRE ORBICULAIRE JUIF.

tures, sans se soucier beaucoup de l'origine de ces objets.

M. de Longpérier a donné avec raison une origine juive à un petit flacon en verre blanc opaque trouvé en Asie Mineure ${ }^{1}$. Il est élégant de forme et porte sur ses

I. Bulletin archéologique de l'A thénéum français. Janvier 1856. 
métopes la grappe de raisin, la grenade et le cédrat, emblèmes juifs. Le flacon est moulé, ce qui indique que la fabrication du modèle était courante.

L'objet ainsi que deux autres flacons de verre ont été trouvés par M. Peretié, chancelier du consulat de France, à Beyrouth.

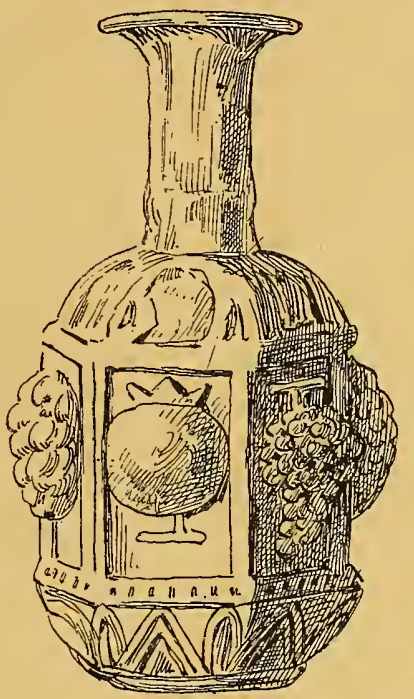

FIG. $36 .-$ VERRE JUIF. 


\section{L'ORIENT}

Lorsque l'empereur Constantin transporta à Byzance le siège du gouvernement, il résolut de donner à la ville un éclat incomparable. Non seulement il fit enlever de l'Italie et de la Grèce les chefs-d'œuvre des arts, mais il appela dans la cité les artistes et les artisans et les protégea d'une façon particulière. Une loi de l'an 337 exempte de toutes charges publiques trente-six professions : les architectes, lambrisseurs, stucateurs, charpentiers, médecins, lapidaires, ouvriers en argent, maçons, vétérinaires, tailleurs de pierres, scieurs de long, constructeurs d'escaliers, peintres, sculpteurs, tourneurs, menuisiers, statuaires, mosaïstes, ouvriers en bronze, forgerons, marbriers, doreurs, fondeurs, teinturiers, ouvriers en marqueterie, orfèvres, miroitiers, constructeurs de chars, fontainiers, verriers, ivoiriers, tabletiers, fouleurs, potiers, plombiers, pelletiers. Les privilèges furent confirmés par les codes de Théodose II et de Justinien; il est possible de voir dans ces actes le germe des maitrises qui, pendant tant de siècles, concentrèrent le travail dans des catégories spéciales, mais 
à l'époque qui nous occupe, le législateur n'avait d'autre but que de faciliter l'exercice de la profession et l'apprentissage, et suos filios erudere. La protection porta ses fruits et les verriers furent nombreux à Constantinople; ils habitaient un quartier de la ville, près de la porte de la Verrerie. Ils se répandirent à Thessalonique, à Alexandrie, en Perse et dans le bassin oriental de la Méditerranée, où déjà les verreries de l'antiquité avaient prospéré.

A de très rares exceptions près, aucun des verres de la fabrication orientale des premiers siècles après la fondation de Constantinople n'est arrivé jusqu'à nous, ou du moins est-il impossible de prouver d'une façon certaine l'origine des verres que l'on attribue à cette époque; nous en sommes donc généralement réduits à des textes. La fabrication comprenait la verrerie commune, les verres à vitre, les pièces de luxe et l'imitation des pierres précieuses. Les architectes de Sainte-Sophie de Constantinople, Athémius de Tralles et Isidore de Milet, garnirent de verres les fenêtres de la basilique de Justinien, dédiée en 537 . Les historiens arabes rapportent qu'à Sanaa, dans la partie de l'Arabie nommée le Yemen, il y avait un palais haut de sept étages; à l'étage supérieur, existait une grande salle dont les fenêtres étaient garnies de vitres de couleur. Le soir. lorsque les lampes étaient allumées, on voyait briller la lumière à une très grande distance. Le palais de Sanaa fut détruit par Osman, qui régna de 644 à 656 .

Le vie siècle nous a laissé un monument très important, conservé par le Cabinet des médailles de la Biblio. thèque nationale de Paris; c'est une coupe dont le fond 
est formé par une feuille d'or (fig. 37 ). Le métal est découpé en compartiments à jour circulaires dans lesquels on a fixé des médaillons de cristal de roche et de verre; ce procédé semble avoir été abandonné par les orfèvres depuis l'invention des émaux cloisonnés à jour. La coupe paraît avoir été donnée au trésor de l'abbaye de Saint-Denis par Charles le Chauve; elle fut, en 1797, envoyée à la Bibliothèque nationale. Le médaillon principal, en cristal de roche taillé, représente un personnage assis sur un trône; les losanges et médaillons sont en verre moulé de couleur blanche, rouge violacé et vert émeraude; la matière est très limpide et les couleurs sont très franches et très brillantes. A l'abbaye, la pièce était désignée sous le nom de coupe de Salomon, et on pensait qu'elle avait été envoyée à Charlemagne par le calife Haroun-alRaschid.

Elle est enrichie de hyacinthes par le bord et au dedans de grenats et d'esmeraudes très fines, au fond d'un très beau saphir blanc sur lequel est entaillée, à demy relief, la figure dudit roy (Salomon) séant en son throsne, tel que l'Écriture saincte le représente au troisième livre des Rois, chap. ${ }^{1}{ }^{1}$.

Une savante dissertation de $M$. de Longpérier ${ }^{2}$ a démontré que l'opinion des religieux de l'abbaye de Saint-Denis était erronée ; ce n'est pas le roi Salomon, mais Chosroès Ier, de la race des Sassanides, roi de Perse de 53 I à 579, qui est représenté dans la coupe.

1. Catalogue du trésor de l'abbaye royale de Saint-Denis. La description, de 1638 , est de Dom Germain Millet.

2. Annales de l'Institut archéologique, tome XV. 
Pour ce qui regarde la verrerie, il est donc certain qu'au va $\mathbf{r}^{\mathbf{e}}$ siècle les Perses en faisaient usage dans les

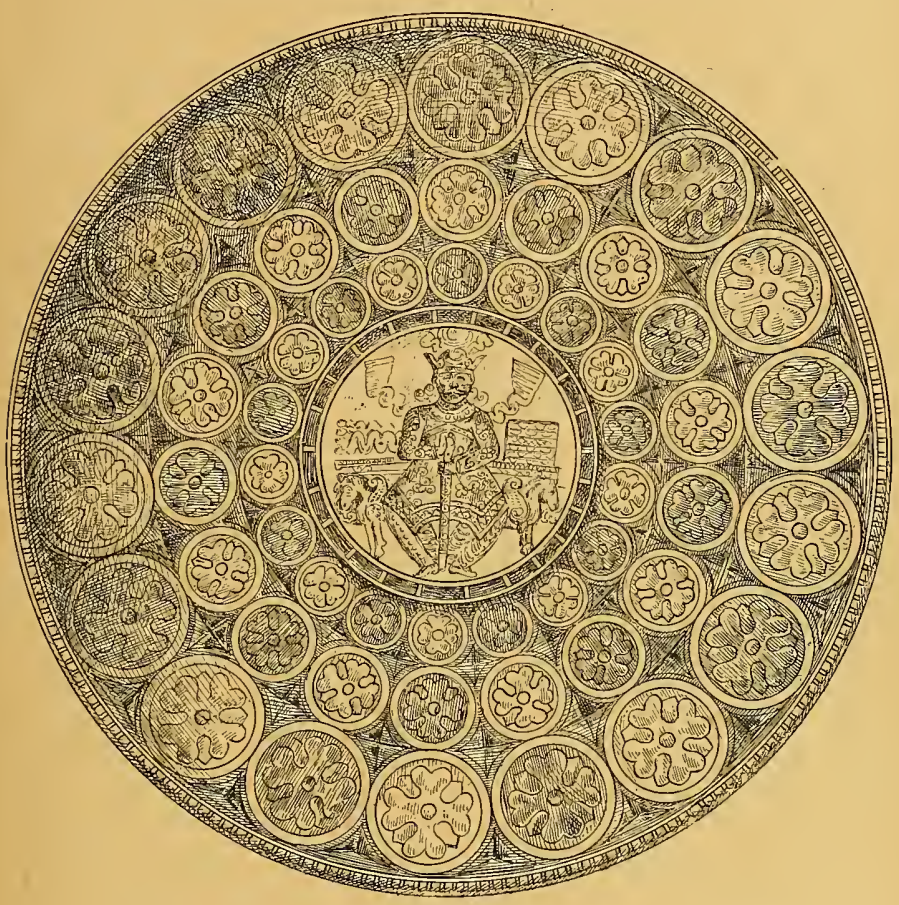

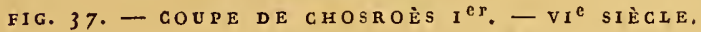

(Bibliothèque nationale.)

objets les plus précieux, puisqu'ils en entouraient le portrait d'un roi surnommé " le Grand ». Selon les chroniqueurs arabes, ils s'en servaient également, vers le même temps, comme de verres à boire. 
Entré dans le palaís, le prince persan s'arrêta dans la grande salle pour prendre sa place au banquet, où l'on servait à boire dans des coupes de cristal de roche, d'or, d'argent et de verre artificiel ${ }^{1}$.

Il est fort probable aussi que les Perses ornaient leurs armes, leurs robes et les équipements des chevaux
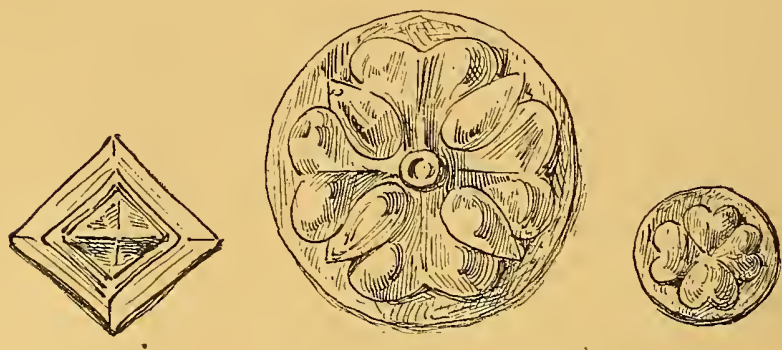

FIG. 38. - DÉTAILS DE LA COUPE DE CHOSROĖS Ier.

de verroteries de couleur. Les pièces de verre devaient ètre d'une très belle qualité, puisqu'à l'abbaye de SaintDenis on a pris celles de la coupe de Chosroès pour des pierres précieuses véritables. Plus d'un siècle après le règne de Chosroès Ier, en 637 , les musulmans étendirent leur domination sur une partie de la Perse; dans le trésor royal de Chosroès ils trouvèrent un tapis dont la bordure représentait un parterre de fleurs figurées, selon les auteurs, par des pierres précieuses vertes, bleues, blanches, jaunes et rouges. Nous émettons un doute sur la qualité de la matière de ces pierres et

I. Extrait du Solwan el motà, cité par M. de Longpérier. Mémoires de l'Académie des inscriptions et belles-lettres, t. XXVI. 
nous pensons que ces turquoises, ces rubis, ces émeraudes, ces topazes pouvaient bien n'être que des verres colorés; en effet, du moment où le verre coloré était employé dans une coupe d'or pour entourer l'effigie du souverain, comme la coupe de Chosroès nous en donne une preuve irrécusable, on peut admettre à plus forte raison que le verre trouvait sa place dans un tapis de pied dont l'usage est certes moins noble que celui d'une coupe royale.

Mais quelle était cette verrerie grecque de luxe si

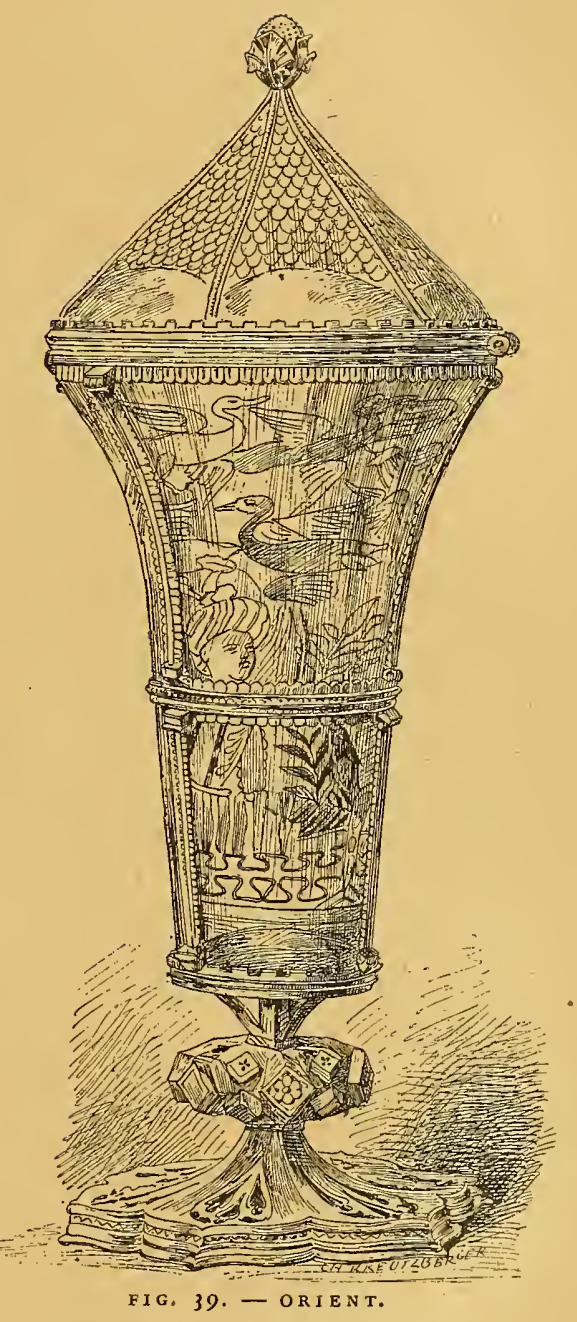

MONTURE DU XV SIÈCLE.

(Grüne Gewölbe à Dresde. 
célèbre et qui servit de point de départ à la verrerie arabe? Nous n'avons sur cette question d'autres renseignements que le récit de Théophile, dont nous détachons ce qui a trait aux Grecs ${ }^{1}$.

Selon cet écrivain, les Grecs fabriquaient des coupes en verre bleu décorées de médaillons dorés représentant des figures humaines, des oiseaux et des feuillages. L'or est appliqué sur la coupe, puis recouvert d'une pellicule de verre incolore pour le préserver; en termes du métier, ce procédé se nomme application sous cou. verte $^{2}$. Si le vase doit être décoré encore avec plus de richesse, ils appliquent, entre les médaillons dorés et sur le col, une pâte vitrifiable " en usage dans les incrustations ", et composent ainsi avec un léger relief des fleurs et des arabesques en couleur blanche, rouge et verte; c'est la décoration émaillée. Enfin, ils ornent les coupes et les fioles à col allongé, rouges et bleues, de filets et d'anses blancs ou d'autres couleurs. L'application des filets constitue ce qu'on a nommé plus tard, à Venise, le filigrane en relief; elle n'est pas spéciale aux Grecs, nous l'avons constatée dans l'antiquité et nous la trouverons également sur les verres mérovin-

I. Nous nous occupons plus longuement de Théophile, dans le chapitre consacré à la verrerie en Occident pendant le moyen âge.

2. M. Labarte, dans son Histoire des arts industriels, indique comme étant de cette fabrication une vasque du musée de Cluny ( $\mathrm{n}^{\circ} 477^{5}$ du catalogue de $188 \mathrm{I}$ ). Le fond est décoré de médaillons, d'entrelacs et de dessins d'or reproduisant des oiseaux et des feuillages. Nous avons examiné cette pièce avec attention et nous avons reconnu que les applications de l'or ne sont nullement sous couverte et que, par conséquent, la vasque ne peut rentrer dans le genre de fabrication décrit par Théophile. 
giens. D'après la description de Théophile, la verrerie grecque d'apparat était d'une grande magnificence; sans avoir le monument sous les yeux, on peut aisément se figurer ces verres dorés recouverts d'émaux de couleurs, ces coupes rouges et bleues garnies d'anses de couleurs différentes, ces compositions où se groupaient la figure humaine, les oiseaux, les fleurs et les ornements, c'està-dire tous les éléments de la décoration. La fabrication grecque dura fort longtemps; au $\mathrm{x}^{\ominus}$ siècle, Constantin VII, empereur d'Orient, fit don de son portrait en verre de couleur au calife de Cordoue Abdurrahman et Romain Ier, dit Lecapène, envoya des verres à Hugues, roi d'Italie.

\section{l:}

Le Coran publié en 634 , deux ans après la mort de Mahomet, fait allusion à la transparence du verre. “Dieu est la lumière des cieux et de la terre; sa lumière ressemble à un mischkah contenant une lampe. " Le mischkah est une niche où l'on place une lampe servant de fanal; les lampes arabes étaient en verre blanc non décoré lorsqu'elles étaient renfermées dans des enveloppes de métal ajourées.

On ne saurait aborder l'histoire des arts pratiqués par les musulmans, sans être arrêté au seuil de cette étude par le problème de la représentation des êtres animés. Sur ce point comme sur tant d'autres, il s'est fait une sorte de légende que les travaux des archéologues ont quelque peine à dissiper; il suffit cependant 
de parcourir les ouvrages ayant trait aux arts orientaux et les manuscrits arabes pour se convaincre par les textes, les dessins et les miniatures que la figure humaine a été très fréquemment représentée. Un écrivain autorisé, M. Lavoix, a élucidé la question qui ne peut plus aujourd'hui prêter à de sérieuses controverses ${ }^{1}$. Le seul verset du Coran qui contienne une allusion à la défense de se servir dans les arts des figures animées, dit : "O croyants! le vin, les jeux de hasard, les statues sont une abomination inventée par Satan; abstenezvous-en et vous serez heureux. " Mais, à côté du texte du Coran, il y a les traditions recueillies par les disciples, les notes explicatives, les commentaires qui donnent la pensée du prophète. Dans ce recueil on trouve ces paroles de Mahomet : "Malheur à celui qui aura peint un être vivant! Au jour du jugement dernier, les personnages qu'il aura représentés sortiront du tableau et viendront se joindre à lui en lui demandant une âme. Alors cet homme, impuissant à donner la vie à son cuvre, brûlera dans les flammes éternelles », et plus loin, "Dieu m'a envoyé contre trois sortes de gens pour les anéantir et les confondre; ce sont les orgueilleux, les polythéistes et les peintres. Gardez-vous donc de représenter soit le Seigneur, soit l'homme, et ne peignez que des arbres, des fleurs et des objets inanimés! » Il est bien certain que toutes les prescriptions écrites dans le Coran même ne sont pas observées; à plus forte raison, s'est-il élevé, aussitôt après la publication des gloses du livre, des dissentiments sur l'application de

I. H. Lavoix, Les arts musulmans (Gazette des Beaux-Arts). 
certains principes. M. Lavoix signale des pièces de monnaie avec l'effigie de l'empereur grec et au revers le nom du calife Omar, compagnon de Mahomet. L'an 60 de l'hégire, on fait des médailles avec la figure d'Abd-el-Malek, chef des croyants. Nous verrons plus loin que, dans le trésor de Moștansser-Billah, il existait par milliers des étoffes brodées et des tapisseries décorées de portraits de califes; sous la dynastie fatimite, les peintres musulmans formaient une école; les statues elles-mêmes étaient en honneur, malgré le Coran qui les déclare ùne abomination. Le sultan Khomorouiah avait dans son palais les statues de ses femmes entourées de musiciennes; elles étaient en bois, revêtues d'un enduit figurant des vêtements de couleur et ornées de couronnes et de pierres précieuses. Est-il besoin, du reste, de rappeler les vases de métal gravé montrant des cavaliers et des animaux, et de dire qu'en Perse l'usage de représenter des êtres animés a toujours existé? Cependant, en certains pays musulmans et en certains temps, les artistes se sont tenus à la lettre des gloses du Coran; mais ailleurs, ils ont exécuté leurs travaux décoratifs en toute liberté, sans aucun souci des textes; il n'y a donc sur ce point nul principe absolu, et la verrerie, comme les autres arts, nous en fournira la preuve.

\section{I I}

Pendant le vir siècle, les Arabes conquirent successivement l'Arabie, la Syrie, l'Égypte, la Perse. 
l'Afrique septentrionale; au commencement du vil1 ils étendirent leur domination sur l'Espagne, et si, dès le milieu de ce siècle, leur empire commença à subir la désagrégation, ils étaient encore très puissants au xie siè-

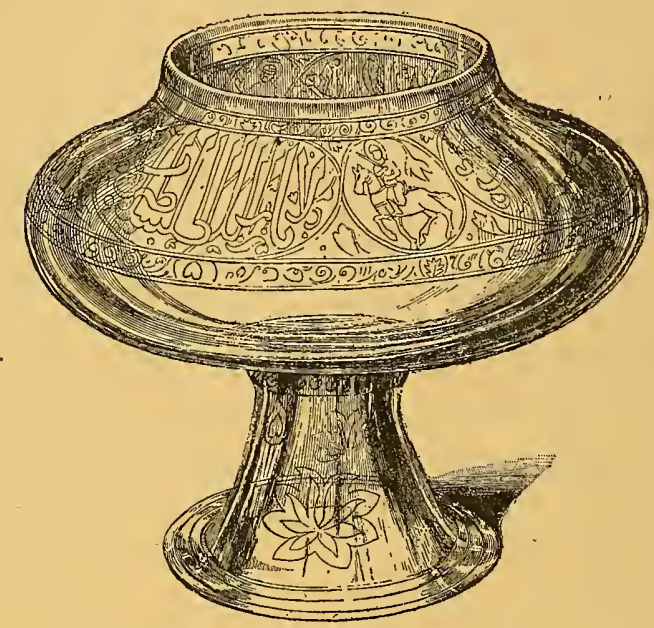

FIG. 40. - ORIENT. XIII SIÈcLE (l).

(Musée germanique de Nuremberg.)

cle, qui est l'époque sur laquelle notre attention a été plus particulièrement attirée. Nous n'avons pas ici à traiter la question de l'art arabe, fort controversée d'ailleurs; s'il est possible de prouver qu'il n'existe pas un art arabe proprement dit, mais seulement un art oriental, on reconnait du moins que les Arabes ont su profiter des arts propres aux peuples dont ils ont triomphé et que les trésors accumulés par leurs princes repré- 
sentent dans leur ensemble les arts des pays conquis, dans leur plus superbe application. Si, jusque vers la fin $d u X x^{e}$ siècle, les monuments authentiques de la verrerie arabe nous font défaut, nous pourrons du moins juger de leur importance par quelques citations et aussi par l'état brillant des arts appliqués à la demeure, à la parure, au vêtement, aux armes, aux objets de luxe dont s'entouraient les califes. Même en dégageant les récits des historiens arabes les plus véridiques de l'exagération habituelle aux pays orientaux, l'esprit reste contondu; le trésor de Mostansser va nous permettre d'apprécier ces magnificences.

Le calife fatimite Mostansser-Billah régna pendant soixante années, de l'an 427 de l'hégire à 487 . C'était un prince faible, indolent; sa fortune était immense. En dehors des impôts, il avait des revenus personnels, notamment celui de vingt mille maisons qui lui appartenaient en propre dans la ville du Caire et aux environs et dont les loyers, au dire des écrivains arabes, étaient exactement payés. Son goût pour le luxe était sans limites; il avait hérité de trésors inestimables et se plaisait à les augmenter; le hasard d'une guerre a permis aux historiens arabes ${ }^{1}$ de nous transmettre une sorte d'inventaire du trésor du calife, et nous trouvons dans ces documents des renseignements suffisants pour nous rendre compte de la situation. Sous l'administration de Mostansser-Billah, le pays fut fréquemment

1. Makrisy, écrivain arabe, né au Caire vers 1360 , mort en $144^{2}$, a, dans ses ouvrages, reproduit en partie les relations écrites du temps de Mostansser. 
agité et en proie à des dissensions civiles. Le calife ayant à réprimer, en $\mathrm{I}_{062}$, une révolte des régiments noirs, appela à son aide les régiments turcs qui battirent les rebelles; après la victoire, généraux, officiers et soldats turcs réclamèrent la récompense des services rendus, et, comme l'argent se faisait attendre, ils proposèrent au calife de lui acheter son trésor. Le faible Mostansser y consentit, et la vente commença d'abord à vil prix, pour dégénérer bientôt en un véritable pillage; de cette vente et de ce pillage il est resté des traces écrites. Les perles, les émeraudes et les autres pierres précieuses se comptaient aux mesures de capacité; les bagues à l'usage personnel du prince étaient au nombre de douze cents; les porcelaines, les faïences à reflets métalliques, les miroirs d'acier enrichis de filigranes d'or et d'argent, les plats et les vases d'or et d'argent émaillés et niellés, les meubles en sardoine et en or massif étaient en quantités dont nous pouvons apprécier l'importance par le nombre des autres objets. Mostansser possédait notamment six mille vases d'or uniquement destinés à contenir des fleurs, trente-six mille pièces en cristal de roche, cinquante mille pièces d'étoffes de Damas brodées d'or et de tapis avec les portraits des hommes célèbres de l'Islam; vingt-deux mille figures d'ambre; deux cent mille épées, cuirasses et armes de tous genres: un nombre équivalent de housses et de caparaçons brodés d'or. Lorsque le prince sortait pour une fête officielle, son escorte était composée de dix mille chevaux tenus en main par autant d'esclaves somptueusement vêtus. Pendant le pillage, un soldat laissa tomber une lampe; le feu prit dans le Dépôt des étendards, où, 
depuis cent ans, les califes avaient accumulé les meubles, les armes et les objets précieux, sans jamais en avoir fait sortir une seule pièce; le crédit annuel d'achat ouvert pour le Dépôt des étendards avait été pendant cent ans de quatrevingt mille dinars, ce qui donne entre onze et douze cent mille francs par an, valeur au poids de la pièce d'or du temps, sans tenir compte de la décroissance du prix de l'argent depuis le $x \bar{I}^{\circ} j u s q u ' a u$ $x{ }^{\circ}$ siècle. Quelle était l'importance de la verrerie dans cette incroyable accumulation? Les historiens arabes négligent de le dire, mais ils signalent du moins la pré-

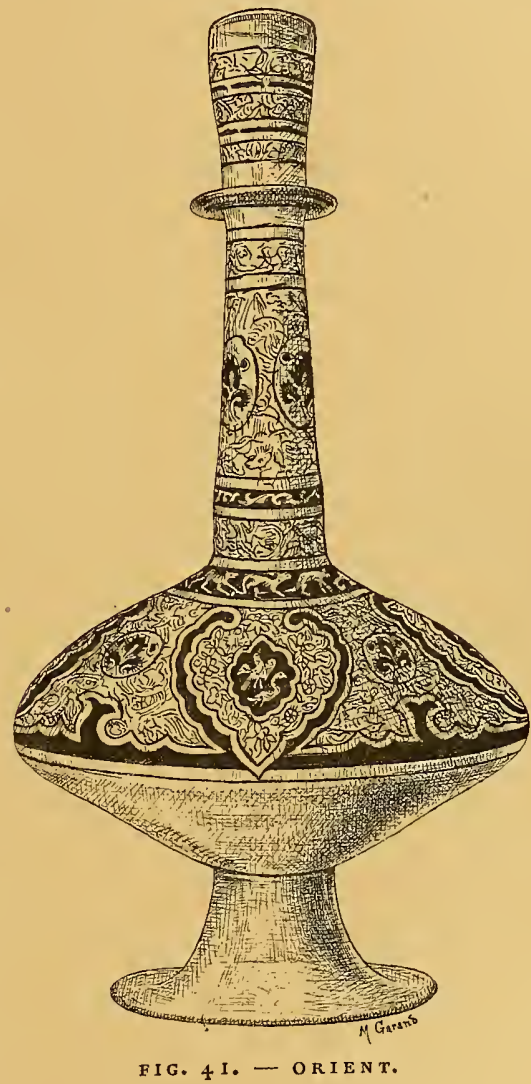

(Collection G. de Rothschild.) sence de grandes quantités de bassins de verre sur lesquels étaient dessinés des figures, des feuillages et des 
ornements, et de miroirs de verre enrichis de filigranes d'or et d'argent. De tous ces trésors on ne connaît peut-être maintenant que deux pièces $^{1}$ : une buire en cristal de roche au musée du Louvre et le vase en même matière qui se trouve à Florence. Nous pensons qu'on pourrait y ajouter le vase en verre envoyé d'Alexandrie, $a u x^{\mathrm{e}}$ siècle, à l'empereur d'Allemagne Henri II, dit le Boitøux, que ce prince trouva digne d'être offert à l'abbé de Cluny, et l'aiguière du trésor de la cathédrale de Saint-Marc à Venise. Le décor taillé de l'aiguière qui, autant que nous avons pu en juger, est bien en cristal de roche et non en verre, représente deux lions accroupis séparés par des rinceaux d'ornement; au-dessus, se développe une inscription avec le nom de l'iman Aziz-Billah, qui fut calife d'Égypte et de Syrie de 975 à 996. Il est certain qu'un nom gravé ne prouve pas absolument que l'objet ait été fabriqué du temps de la personne dénommée; l'inscription peut être un souvenir, une glorification; mais, dans l'espèce, il ne nous paraît pas qu'il puisse y avoir doute. Aziz-Billah possédait d'immenses trésors qui ont été transmis à ses sucsesseurs, notamment à Mostansser, et nous avons relevé. précisément dans l'inventaire déjà cité, l'existence de plusieurs objets, bouteilles et bocaux portant le nom d'Aziz-Billah gravé dans le cristal de roche.

Pendant le règne de Mostansser s'accomplit le voyage de Nassiri-Khosrau dont le manuscrit a été conservé. C'était un Persan du Korassan; il visita la

r. Nous devons ce renseignement à M. Lavoix, conservateur au Cabinet des médailles de la Bibliothèque nationale. 
Syrie, la Palestine, l'Égypte et l'Arabie de l'an ro35 à l'an I $04^{3}$. Nous extrayons de ce document et des notes 1 qui y ont été ajoutées les faits relatifs à l'art de la verrerie que seuls nous pouvons retenir parmi tant de renseignements intéressants contenus dans le livre. Nassiri constate que, dans l'église de la Résurrection, à Jérusalem, les peintures murales sont recouvertes sur toutes leurs surfaces d'une plaque de verre, ce qui leur donne un vif éclat, car les serviteurs de l'église nettoient ces verres tous les jours. Les peintures représentaient l'enfer et le paradis, Jésus monté sur un âne, les portraits d'Abraham, d'Ismaël, d'Isaac et de Jacob avec ses enfants. Dans une mosquée de la ville, vingt Juifs étaient chargés de l'entretien des lampes en verre et en métal. Le voyageur dit qu'à Misr, qui est un faubourg du Caire, on fabrique un verre transparent et d'une grande pureté; il ressemble à l'émeraude et se vend au poids, ce qui indique qu'on le tenait pour très précieux; au bazar, le verre commun était en usage et les droguistes vendaient aux clients les bouteilles pour renfermer les liquides. Nassiri raconte que, du temps du calife Hakim-bi-Amr-Illah, qui régnait de 996 à 1020, un artisan se présenta au palais et offrit de réparer et de remettre dans son état primitif le fameux miroir du phare d'Alexandrie qui brûlait les vaisseaux ennemis; les Grecs avaient fait détruire ce terrible engin en 9i 3 par un eunuque envoyé de Byzance. Le calife

1. Relation du voyage de Nassiri-Khosrau, publié, traduit et annoté par M. Ch. Schefer, membre de I'Institut, premier secrétaire interprète du gouvernement, administrateur de l'École des langues orientales vivantes. Paris, I 88 r. 
refusa l'offre, sous le prétexte que les deux nations étant en paix, le miroir incendiaire n'avait plus de raison d'être. Le récit est intéressant et peut être invoqué en faveur de la puissance de destruction du phare d'Alexandrie qui a été souvent mise en doute. La ka'abah, c'est-à-dire le sanctuaire du temple de la Mecque, était éclairée par quatre fenêtres en verre placées aux quatre angles, "laissant, dit Nassiri, passer le jour et empêchant la pluie de pénétrer dans l'intérieur ». Un autre voyageur constata, en i 83 , que les fenêtres étaient une sorte de marbre transparent appelé balaq qui venait du Yemen; ces plaques étaient couvertes d'arabesques gravées ${ }^{1}$.

Le Persan Aben-Messuy, le célèbre médecin arabe Ibn-Sina, plus connu sous le nom d'Avizenna (980-1037), le rabbin Benjamin de Tolède, mort en I 73 , qui avait visité les synagogues de l'Orient pour étudier les coutumes de ses coreligionnaires, rapportent que de leur

1. Nous avons relu les Mille et une Nuits dans l'espoir d'y trouver quelques notes sur l'usage de la verrerie, car malgré la fantaisie qui règne dans ces contes charmants, ils donnent en bien des points des renseignements exacts sur les habitudes orientales. Le verre n'y est signalé que dans de très rares passages : ce sont des gens du peuple ou des enfants qui prennent des pierres précieuses pour du verre coloré; c'est un bambou, lunette magique, garni de verre à ses extrémités; c'est enfin un marchand pauvre qui vend des verres communs. Jamais dans la description des palais il n'est question de verreries, les coupes sont toujours en matière précieuse, et dans les intérieurs plus modestes elles sont en porcelaine. Quoique le plus grand nombre des faits se passent au $\mathrm{IX}^{\mathrm{e}}$ siècle, du temps du calife Haroun-alRaschid, certains contes paraissent avoir été écrits sous le calife Mostansser-Billah, c'est-à-dire au $\mathrm{xi}^{\mathrm{e}}$ siècle, précisément à l'époque du voyage de Nassiri-Khosrau. 
temps les verreries étaient prospères; nous sálvons par ces écrivains et par d'autres que l'on fabriquait du verre blanc, rouge, jaune, vert et bleu. Ces verreries étaient établies à Alexandrie, au Caire, en Perse, à Sour, situé sur l'emplacement de Tyr, à Alep, à Antioche, à Damás, à Tripoli et ailleurs encore. Ces villes industrieuses étaient des centres de fabrication très importants; dans le port de Tripoli, le commerce avait accumulé des débris de verre cassé en assez grande quantité pour que ces objets fussent devenus des articles d'exportation ${ }^{1}$. La verrerie n'était pas la seule branche d'industrie qu'on y cultivât; on y fabriquait des poteries, du papier et des tissus; au bazar d'Alep, par exemple, le chiffre d'affaires, pour les étoffes seulement, s'élevait par jour à 20,000 dinars ${ }^{2}$. Les lettres de change et de crédit avaient cours; certaines villes avaient des Bourses de commerce qui rapportaient chaque jour près de 6,500 dinars de droits d'entrée.

\section{IV}

Les califes fatimites, qui eurent le pouvoir de l'an 908 à l'an i $7 \mathrm{I}$, ont fait frapper à leur nom de petits disques en verre transparent, ambré, vert, violet rouge vineux et en verre opaque; le Cabinet des médailles de notre Bibliothèque nationale et le British

I. Voir page 140.

2. Au poids de l'or, le dinar pèse de 4 grammes à $4 \mathrm{gr}$. 20 , le gramme d'or vaut $3 \mathrm{fr} .50$ environ, avec une variante de ro pour Ioo. 
Museum de Londres possèdent des échantillons de ce genre de verrerie peu connu (fig. 42). Les uns portent des inscriptions moulées, les autres des ornements, comme le sceau de Salomon ou une fleur ornemanisée. Les disques à inscriptions sont de deux espèces : sur la première, on lit des noms de califes et une indication de valeur : Iman-Moad, Al-Hakim, Dhahir-li-Izoz, AlMostansser-Billah et autres, mais tous califes fatimites;
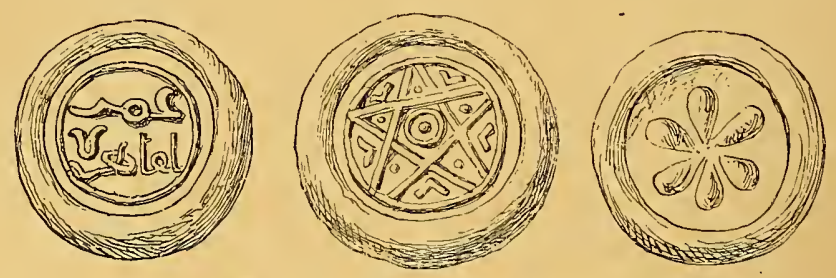

FIG. 42. - JETONS ARABES.

(B.bliothèque nationale.)

les valeurs sont celles du temps: carats, dinar, dichem, felous. La seconde espèce de disques avec inscriptions porte des noms de particuliers: Hamel-Omar, Hachmed au Caire, El-Aoudi, Omar au Caire; ce sont là sans doute des jetons de présence ou des adresses; de même les disques à ornements sont vraisemblablement des amulettes, car quelques-uns ont encore un anneau de suspension. Mais que peuvent être les disques à inscriptions avec indication de valeur? Les numismates anglais veulent que ce soient des monnaies ou des étalons monétaires. Sans prétendre trancher la question, nous ne pouvons nous empêcher de faire remarquer 
que le verre est une matière bien fragile pour une monnaie même fiduciaire, et qu'il n'est pas rationnel de le choisir comme type d'un étalon monétaire dont la condition essentielle est d'ètre un modèle absolument rigoureux; le cueilleur de verre, en effet, ne peut prendre dans la masse en fusion un poids mathématiquement exact, et nous n'avons vu sur aucune pièce une rectification de poids opérée à froid au moyen de la taille. Du reste, l'imitation de ces objets eût été d'une grande facilité et à la portée des verriers les moins habiles.

En Orient, comme dans tous les temps et dans tous les pays où il y avait des verreries, la production comprenait des vases communs à usage domestique; au bazar du Caire, on trouvait des bouteilles et des vases en verre dont la forme était sans doute pareille à celle dont on se sert encore aujourd'hui. Nous pouvons en juger par la miniature d'un manuscrit arabe de la Bibliothèque nationale, tiré de l'ouvrage du xine siècle connu sous le titre de "Séances de Hariri "; l'ouvrage est très populaire dans la littérature arabe et sert de livre classique dans l'enseignement. Hariri raconte la vie d'Abou-Zeyt et entre dans les détails de son existence; le dessin que nous reproduisons montre cinq des personnages tenant à la main des vases en verre, ce qui, à notre point de vue spécial, est un renseignement; mais le dessin est surtout intéressant parce qu'il prouve que, malgré les gloses du Coran, on ne craint pas de mettre entre les mains des enfants des livres à images représentant des êtres animés.

Les Arabes connaissaient et estimaient la verrerie 
antique; nous avons dit qu'un vase en verre de l'antiquité avait fait partie du butin enlevé par les chrétiens

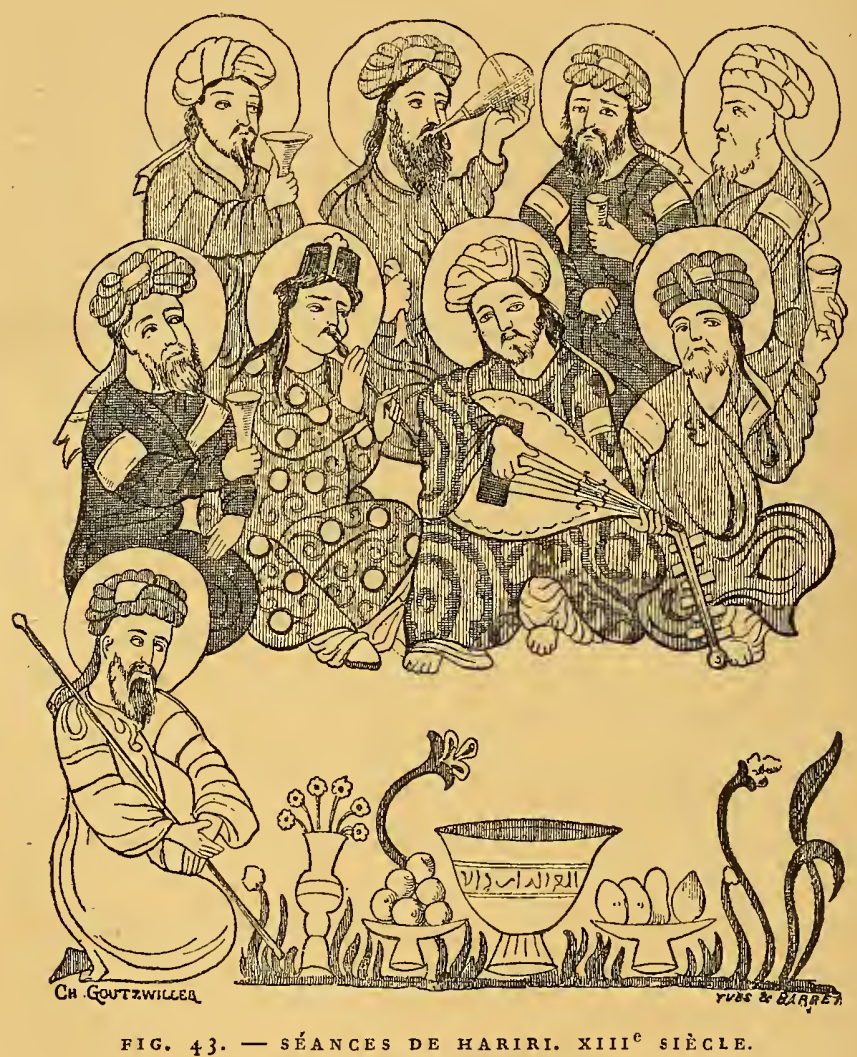

(Manuscrit de la Bibliothèque nationale.)

après la prise de Césarée, où l'objet était précieusement conservé. Le trésor de la cathédrale de Saint-Marc, à 
Venise, possède un vase en verre qui mérite une attention particulière; il est de couleur violet foncé et décoré de pấtes d'application; la décoration consiste en fleurs, ornements et en figures humaines, bustes ou corps entiers renfermés dans des médaillons; l'une deces figures est celle d'un homme tenant une draperie et un thyrse. L'objet, tant par sa décoration que par le travail technique, appartient sans aucun doute à l'antiquité; mais ce qu'il présente de très intéressant, ce sont deux inscriptions arabes en émail; l'úne au bas, à l'extérieur; l'autre au haut, à l'intérieur du col évasé; les caractères de l'inscription sont coufiques. Ce genre de caractères a sans doute été employé plus particulièrcment jusqu'au $\mathrm{IV}^{\mathrm{e}}$ siècle, mais il en a aussi été fait usage aux époques postérieures; on ne saurait donc, jusqu'à plus ample information, fixer de date à cette pièce curieuse.

Le $x_{111^{\mathrm{e}}}$ siècle nous fournit enfin des documents matériels incontestables, qui permettent d'aborder l'étude de la verrerie arabe dans ses plus belles productions. Jusqu'alors nous sommes restés dans l'incertitude, car nous pensons qu'il y a quelque témérité à attribuer aux siècles antérieurs une seule des pièces de verre émaillé gardées avec tant de soin dans les collections publiques ou particulières. Jusqu'à preuve contraire, nous admettons que le plus ancien monument daté et conservé de la verrerie arabe émaillée est 
la coupe de la collection de M. Schefer (fig. 44); elle a le fond d'or, sa décoration est. en émaux bleus et blancs, elle porte un distique arabe, des personnages

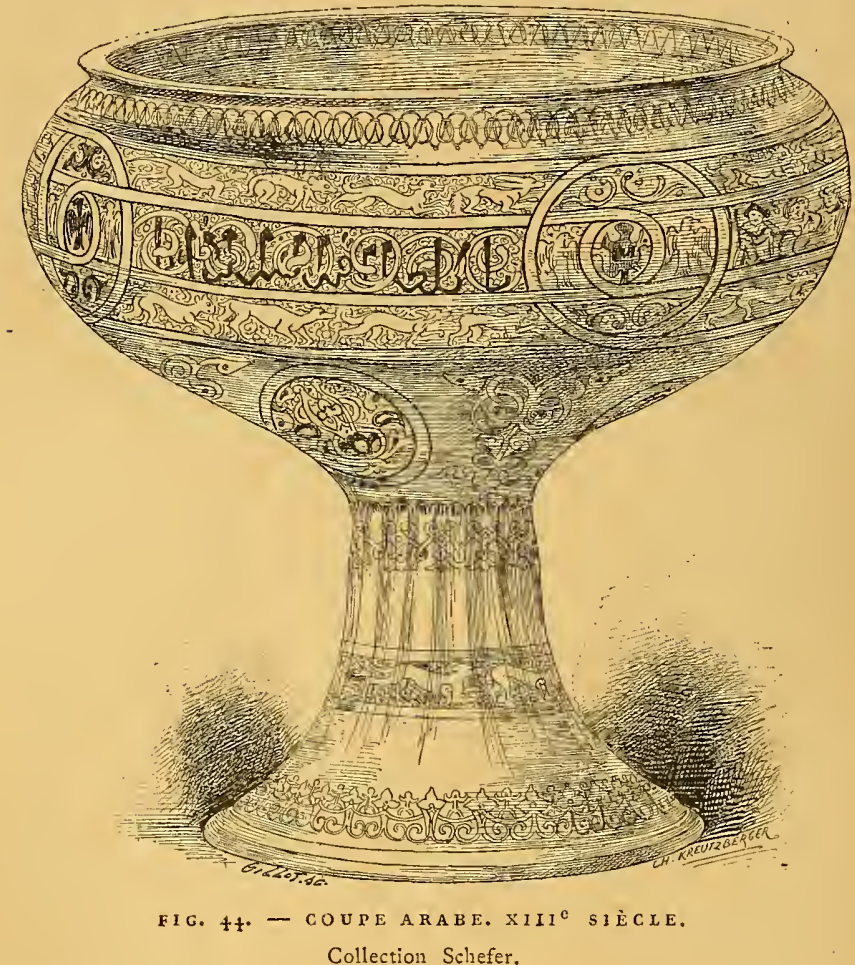

et une course de chiens et d'animaux de chasse; la pièce móntre son certificat d'origine. Ce sont les armes de Berdr-el-Din-ed-Dhahery, commandant des troupes du sultan Bibars, qui mourut en 1277 ; cet objet pré- 
cieux est devenu fort heureusement la propriété d'un savant qui a pu en démontrer la provenance.

On peut attribuer à la même époque un bassin de quarante centimètres de diamètre, décoré de douze médaillons à fond bleu, sujets d'animaux, faucons fondant sur une proie ${ }^{1}$, et une bouteille à long col décoré de fleurs et de rinceaux sur fond bleu; sur la

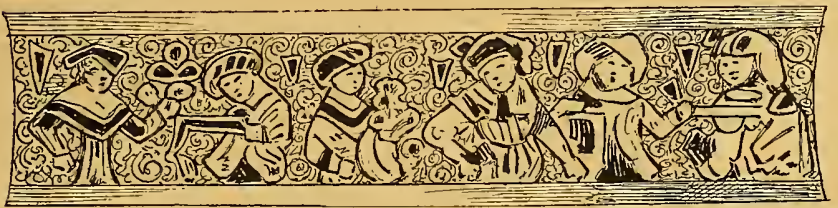

FIG. 45. - DÉTAIL DE L C OUPE ARABE N 44 .

panse on voit des médaillons avec des animaux fantastiques, des arabesques en rouge, vert et blanc, un guépard saisissant une gazelle et l'inscription : A notre seigneur le sultan El-Melek-el-Aschraf, le juste, le sage.

Le musée de Chartres conserve un verre oriental, connu sous le nom de verre de Charlemagne (fig. 46). Avant la Révolution, il appartenait au trésor de l'abbaye de la Madeleine de Châteaudun. En I798, le président $\mathrm{du}$ directoire du département d'Eure-et-Loir voulut l'envoyer à Paris à la Bibliothèque nationale; mais l'ordre qu'il donna ne fut pas exécuté, et le verre fut déposé à la bibliothèque de Chartres, puis au mu-

I. Collection Lionel de Rothschild. 
sée de la ville ${ }^{1}$. La décoration est en émaux blancs et bleus rehaussés de filets dorés; les lettres de l'inscription sont en or pour le fond et pour les bords; le pied est en cuivre et a dû être ar-

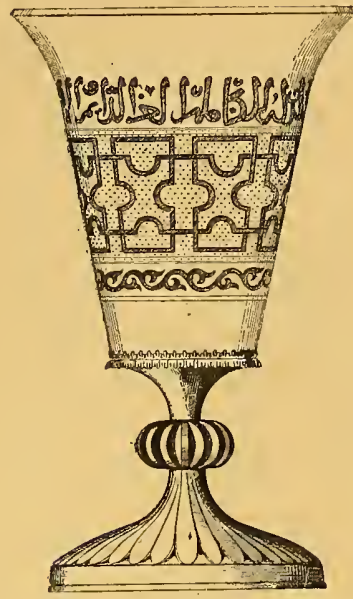

FIG. 46 . VERRE ARABE.

XIII ${ }^{\mathrm{C}}$ SIÈCLE?

(Musée de Chartres.) genté. Les caractères de l'inscription sont de la forme appelée neski, qui a été en usage en Égypte dès le vir ${ }^{\mathrm{e}}$ siècle; d'autre part, ils ont une sensible analogie avec ceux de l'inscription d'un globe céleste fabriqué en I 225 pour le sultan Malek-Kamel. Le texte a été traduit plusieurs fois; on s'accorde à lui donner le sens que voici : Gloire durable, vie longue et exempte de maladie, fortune toujours favorable, prospérité parfaite ${ }^{2}$.

Si le texte de l'inscription

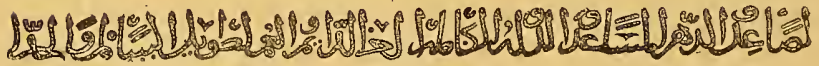

FIG. 47. - INSGRIPTION DU VASE ARABE.

ne fournit aucune information sur l'origine et la date de l'objet, la forme des lettres peut être, selon un juge autorisé, M. Lavoix, attribuée à la fin du xin ${ }^{\mathrm{e}}$ siècle.

I. Doublet de Boisthibault. Revne archéologique, t. XIV.

2. Traduction de Caussin de Perceval. 
Il est donc probable que ce verre a été rapporté d'Orient par les croisés car de la fin du $\mathrm{xI}^{\mathrm{e}}$ siècle à la fin du $\mathrm{XII}^{\mathrm{e}}$, les seigneurs du pays chartrain, du Dunois, du Perche prirent une part active aux croisades et levèrent de nombreuses compagnies dans ces pays. L'opinion que le verre fur donné à Charlemagne par l'ambassade du calife Haroun-al-Raschid ne repose sur aucun fondement.

Le musée de la ville de Douai possède un calice dit " des huit prètres". Nous en donnons le dessin: l'inscription est de fantaisie et n'a pu être traduite. Il est fort possible que le verre ait été apporté d'Orient par Guillaume de Dampierre, en I 25 I, à son retour d'Égypte; ce qu'il y a de certain, c'est qu'il était, au commencement du xive siècle, en la possession d'une demoiselle Marguerite Mallet dit Baudran, qui le légua par testament avec tous ses biens à une fondation destinée à entretenir à perpétuité huit prêtres; le custode en cuir qui renferme le calice est décoré d'ornements au repoussé dans le style du Xirı ${ }^{e}$ siècle.

A côté des verres émaillés, l'Orient du xıII ${ }^{e}$ siècle nous a laissé d'autres pièces dont le type se résume dans les verres dits de Sainte-Hedwige. La sainte est née en I I 74; elle épousa Henri, duc de Silésie et de Pologne; à la mort de son mari, elle entra dans l'ordre de Citeaux et fonda le monastère de Trebnitz, où elle mourut en $\mathrm{i} 243$. Une constante tradition lui attribue la propriété d'un certain nombre de verres que l'on conserve précieusement dans quelques collections de l'Europe ${ }^{1}$;

I. Nous préparons sur les verres de Sainte-Hedwige un 
ce sont des gobelets taillés à la façon du cristal de roche; nous reproduisons celui du musée des antiquités néerlandaises d'Amsterdam. La décoration consiste en un aigle entre deux lions et en deux écussons avec figurès triangulaires; la taille est profonde, largement exécutée; elle donne à l'objet un caractère très marqué et bien dans le style de l'époque. Cette œuvre d'art est-elle d'origine orientale? Nous le pensons, malgré les doutes d'un archéologue distingué ${ }^{1}$; nous fondons notre hypothèse sur l'analogie qui existe entre le décor de ce verre et celui des cristaux de roche orientaux authentiques, l'aiguière d'Aziz-Billah, du trésor de Saint-Marc, par exemple. L'écusson est d'origine orientale et, dès le xir ${ }^{\mathrm{e}}$ et le $x_{11}{ }^{\mathrm{e}}$ siècle, les sultans portaient : Saladin, un aigle; Barbouk, un gerfaut; Bibars, un lion; Kélaoun, un canard; Aly, une fleur de lis. Le triangle du verre d'Amsterdam n'est peut-être qu'un ornement sans signification armoriale, mais il est certainement inspiré par les écussons des sultans. L'inventaire de Charles le Téméraire nous révèle " ung voirre taillé d'un esgle, d'un griffon et d'une double couronne, garny d'argent ${ }^{2}$ ); quoiqu'il ait été inventorié au $\mathrm{xv}^{\mathrm{e}}$ siècle, nous pouvons supposer ce verre d'une époque antérieure et peut-être d'origine orientale, car nous trouvons déjà " l'esgle » dans le verre de Sainte-Hedwige.

travail spécial qui n'a pu trouver sa place dans le présent volume, notre étude étant encore trop incomplète.

1. M. Essenwein, le savant directeur du musée germanique de Nuremberg, attribue à ces verres une origine occidentale, car rien dans sa pensée ne prouve d'une façon absolue qu'ils viennent de l'Orient.

2. M. de Laborde. Les Ducs de Bourgogne. 


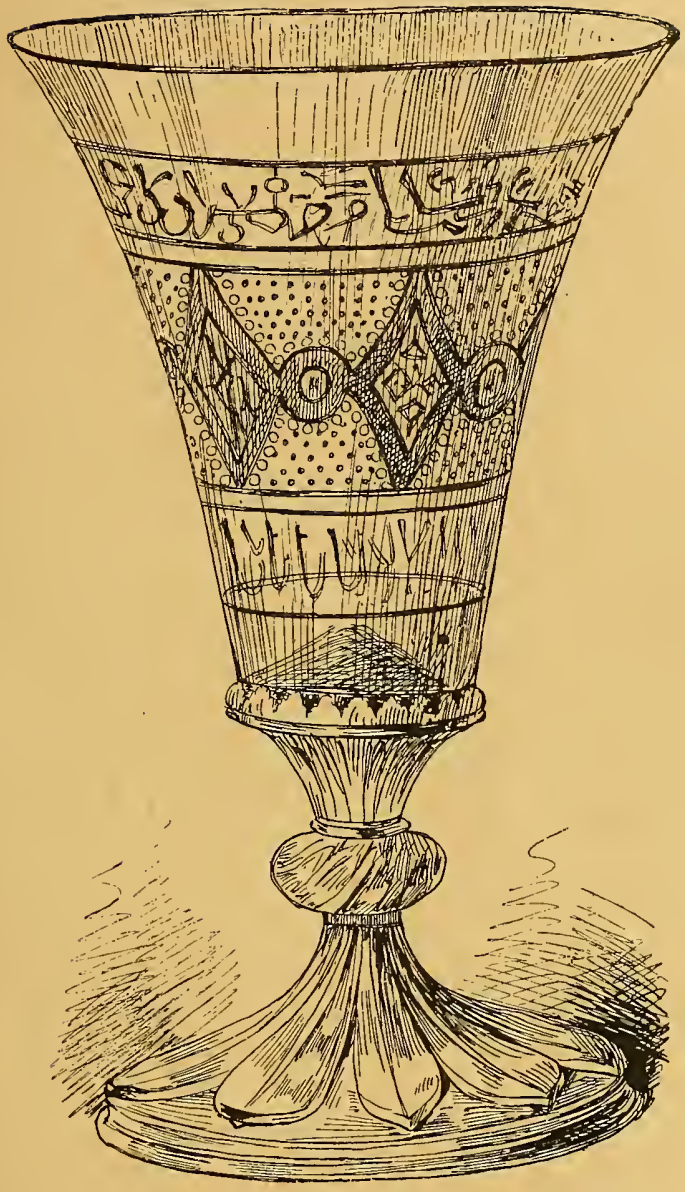

FIG. 48. - VASE ARABE ÉMAILLÉ.

(Musée de Douai.) 


\section{I}

Un écrivain arabe du $\mathrm{xIV}^{\mathrm{e}}$ siècle, Hafiz-Abrou, nous a laissé une indication précise sur la verrerie d'Alep :

Une industrie particulière à Haleb est celle de la verrerie. Nulle part ailleurs, dans le monde entier, on ne voit de plus beaux objets en verre. Quand on entre dans le bazar où on les vend, on ne peut se déterminer à en sortir, tant on est séduit par la beauté des vases, qui sont décorés avec une élégance et un goût merveilleux. Les verreries d'Haleb sont transportées dans tous les pays pour être offertes en présent ${ }^{1}$.

Alep cependant n'était pas la seule ville d'Orient qui, au xive siècle, envoyât ses verreries en Europe; nous trouvons, en effet, fréquemment dans les inventaires du temps des mentions des verres de Damas.

L'inventaire du duc d'Anjou, dressé en 1360 , porte :

"Deus flascons de voirre, ouvrez d'azur à plusieurs diverses choses de l'ouvrage de Damas dont les anses et le col sont de mesme;

"Ungt flascon de voirre ouvré d'azur de l'ouvrage de Damas, dont la garnison est semblable façon ${ }^{2}$."

I)ans l'inventaire de Charles V, fait en 1379 , on lit :

"Troys pots de voirre rouges à la façon de Damas:

I. M. Schefer. Relation du voyage de Nassiri-Khosrau.

2. M. de Laborde. Notice sur les émaux du Louvre. 
"Ung grand voirre ouvré à la façon de Damas par dehors;

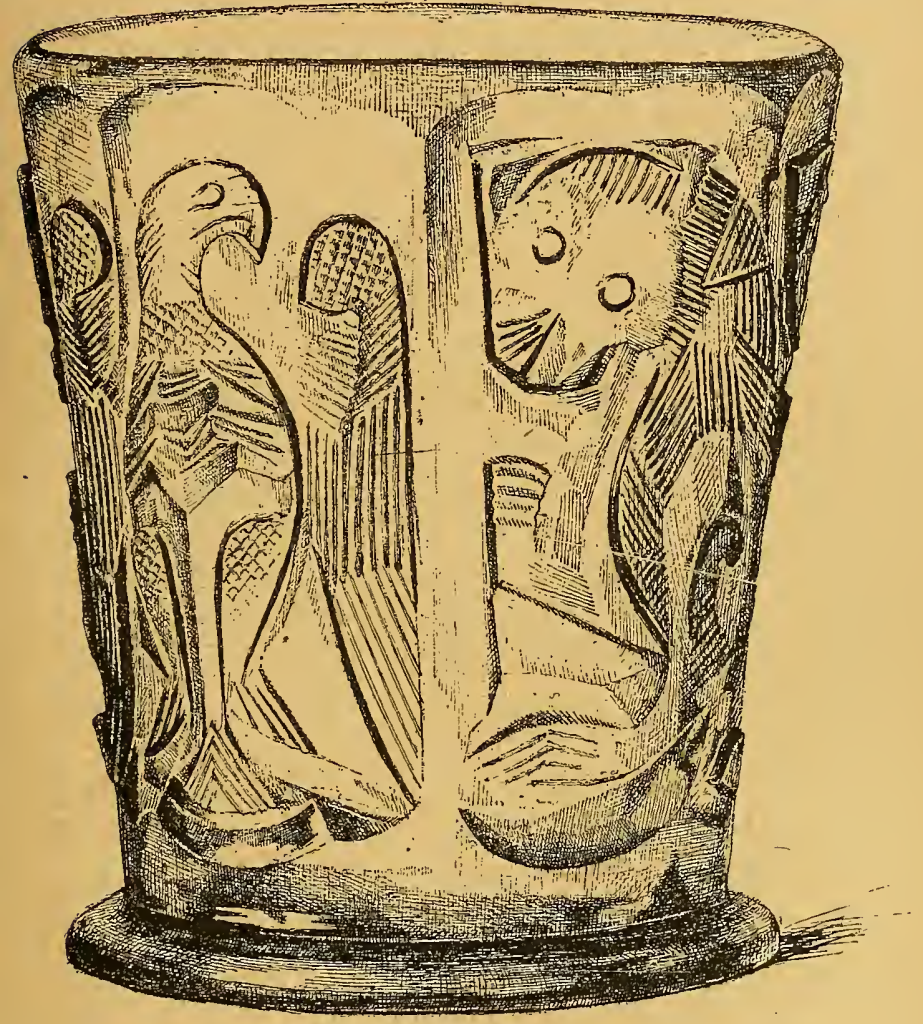

FIG. 49. - VERRE DE SAINTE-HEDWIGE.

(Musée d'Amsterdam.)

“ Ung autre petit voirre ouvré par dehors à ymages à la façon de Damas; 
“Ung très petit hanap de voirre en façon de Damas;

“ Ung baçin plat de voirre paint à la façon de Damas;

"Ung long pot de voirre, ou aiguière de la façon de Damas, le byberon garny d'argent et de fausses pierres;

“Une lampe de voirre ouvrée de façon de Damas, sans aucune garnison d'argent ${ }^{1}$.

Évidemment, les verres dénommés « à la façon de Damas, ouvrage de Damas " ne provenaient pas tous de cette ville; l'expression s'appliquait, en général, aux verreries orientales, mais elle prouve que la capitale de la Syrie avait des fabriques renommées. Il n'y a pas de doute sur la valeur des termes; pour les verres du $\mathrm{x}_{\mathrm{v}} \mathrm{v}^{\mathrm{e}}$ siècle «à la façon de Damas » ne veut pas dire fait en imitation de Damas, mais bien de provenance orientale, car l'Europe ne fabriquait pas alors de produits similaires.

Le roi Chărles VI possédait :

"Une couppe de voirre, painte à la morisque;

"Une bouteille de voirre à deux anses painte comme dessus. "

On appelait peinture à la morisque les verres arabes décorés d'émaux de couleur.

Mais le $x_{1 v^{e}}$ siècle nous a laissé divers monuments de la verreric arabe qui nous permettent, mieux que

I. Manuscrit de la Bibliothèque nationale cité par M. Jules Labarte. 
les inventaires, de juger la perfection du travail. Ce sont d'abord les lampes de mosquée; nous en reprodui-

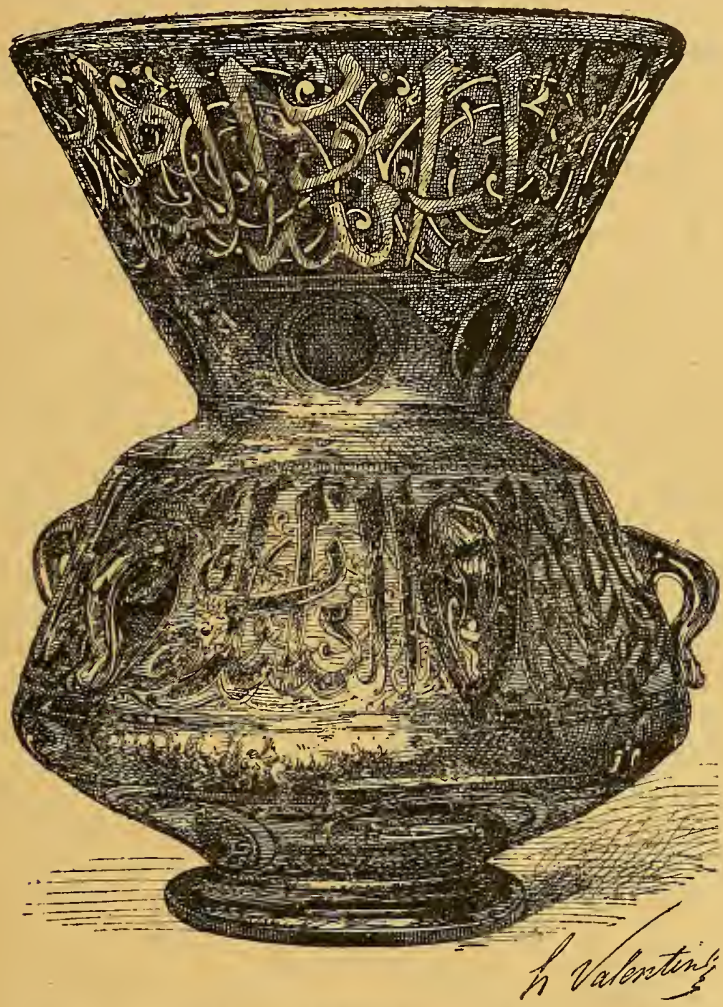

FIG. SO. - LAMPE ARABE ÉMAILLÉE. XIV C SİCLE.

(Collecțion E. André.)

sons quelques types. La lampe à pied de la collection Édouard André (fig. 5o) porte sur le col blanc, en lettres 
bleues, l'inscription classique tirée du Koran (Sourate 24, verset 35) :

Dieu est la lumière des cieux sur la terre. Cette lumière est comme un foyer où se trouve un flambeau, un flambeau placé dans un cristal, cristal sem. blable à une étoile brillante. Sur la panse est émaillée la dédicace : Honneur à notre maître el Solthan el Malek el Nasser Nasser ed douina oua ed-din Mohammed; M. Schefer possède une lampe au même nom; elle est d'un blanc verdâtre émaillé de fleurs bleues et rouges.

M. Lavoix, dont nous avons déjà invoqué l'autorité, fait remarquer que ces deux lampes dédiées au même sultan portaient pour armes : la première une balta, un cimeterre; la seconde, une coupe; d'où il résulte que les armes figurées ne sont pas nécessairement celles du sultan et peuvent appartenir à l'émir qui a ordonné le travail. Le sultan Nasser Mohammed régna en Égypte de I 293 à I $34 \mathrm{I}$, mais pendant une année, en ז 3 Io, il fut remplacé par Bibars II, dont M. A. Goupil possède une lampe qui porte dans un cartouche ces mots en émail rouge : Honneur à notre maître el Solthan el Malek el Modhaffer el âlem cl adel Rokn el douina oua ed-din; la lampe avait ie fond doré; elle est émaillée de fleurs blanches, bleues, rouges, et porte en lettres bleues une légende du Coran. Parmi les lampes de mosquée, on peut citer encore des pièces de 1324 , de 1326 , du sultan Hassan mort en I 36 I, du sultan Barkouk qui régnait en I 382, du sultan Giakmak qui monta sur le trône en $1438^{1}$. Le gobelet et la bou-

I. On comprend que les dates que nous donnons sont prises 
teille de la collection Spitzer que nous reproduisons

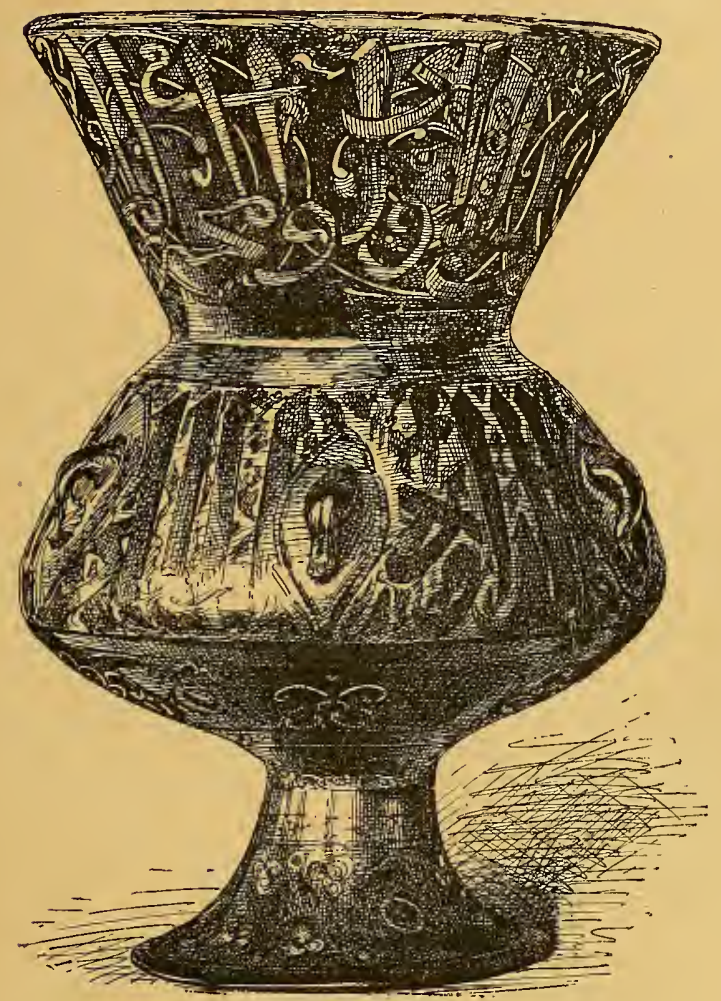

FIG. SI, - IAMPE ARABE ÉMAILLÉE. XIVe SIÈGXE.

(Collection E. André.)

portent un lion; c'est l'écusson du sultan Bibars qui régna

parmi d'autres, et que nous ne pouvons signaler toutes les lampes remarquables existant dans les cabinets des amateurs. 
de I 260 à I 277 , mais il n'en faudrait pas conclure que les précieux objets soient contemporains de Bibars; ils ont pu être commandés postérieurement par un musulman, en témoignage de la reconnaissance de l'Islam envers le vainqueur des croisés et celui qui assura le trône d'Égypte aux Mamelouks pour plus de deux siècles.

Il est possible d'ouvrir une dissertation sur les deux verres arabes de la Grüne gewölbe de Dresde, que nous reproduisons. L'un d'eux (fig. 39), celui qui montre des oiseaux aquatiques émaillés, est certainement plus ancien que le second (fig. 54), dont la décoration consiste en cavaliers jouant à la paume, sujet qui se rencontre souvent sur les vases de métal; les montures sont des $\mathrm{Xv}^{\mathrm{e}}$ et $\mathrm{xv1} \mathrm{1}^{\mathrm{e}}$ siècles, mais les verres sont évidemment antérieurs. Le vase aux cavaliers présente deux inscriptions : l'une paraît tronquée et semble se rapporter à la glorification du mérite, de la suprématie et du sublime; l'autre s'interprète ainsi: Gloire à notre maître le sultan, le roi, le savant, le juste, le combattant, le religieux, le secouru par Dieu, le victorieux, le fort, le grand. D'après la forme de l'écriture, le vase pourrait appartenir au premier quart du xive siècle.

Après une brillante carrière, la verrerie orientale succomba et l'Orient en fut réduit à faire venir de Venise ses lampes de mosquée; le fait sera prouvé par un document authentique provenant du xvi ${ }^{\mathrm{e}}$ siècle $^{1}$. Il y a plus: les verriers de Venise allèrent sur place se substituer aux verriers orientaux, qui semblent perdre

I. Voir page I 70. 
les notions essentielles de la fabrication; vers I 590 , un verrier vénitien arriva à Chiraz, l'une des villes les plusimportantes de la Perse pour le commerce; il enseigna son art pour une somme d'argent assez minime; la fabrication ne réussit pas du moins comme qualité, mais il s'établit des verreries dans tous le pays, notamment à Ispahan et à Chiraz; le verre était de mauvaise composition, à cause des matières employées; il avait une teinte grisâtre, était rempli de bouillons et ne pouvait servir qu'aux usages communs. Les Persans continuèrent à faire venir de Venise les verres pour miroirs et châssis et même leurs bouteilles pour prendre le tabac. Il paraît que les

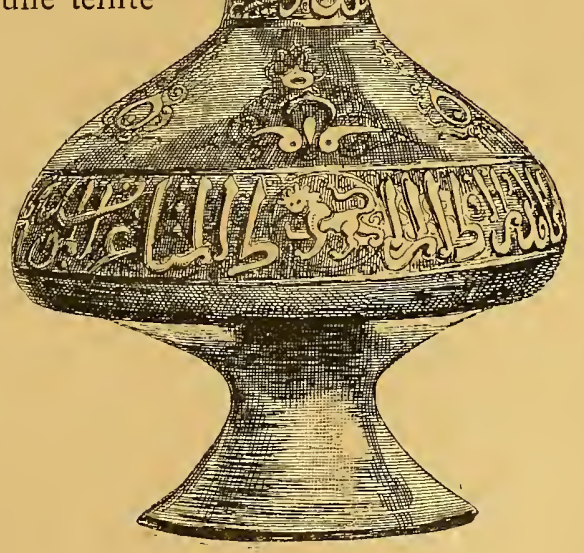
FIG. 52. - ORIENT. - (Collection Spitzer.) Persans avaient une grande habileté pour restaurer les 
objets en verre cassés, à la condition que les fragments ne fussent pas plus petits qu'un ongle; ils les assujettissaient l'un à l'autre avec des fils d'archal et passaient

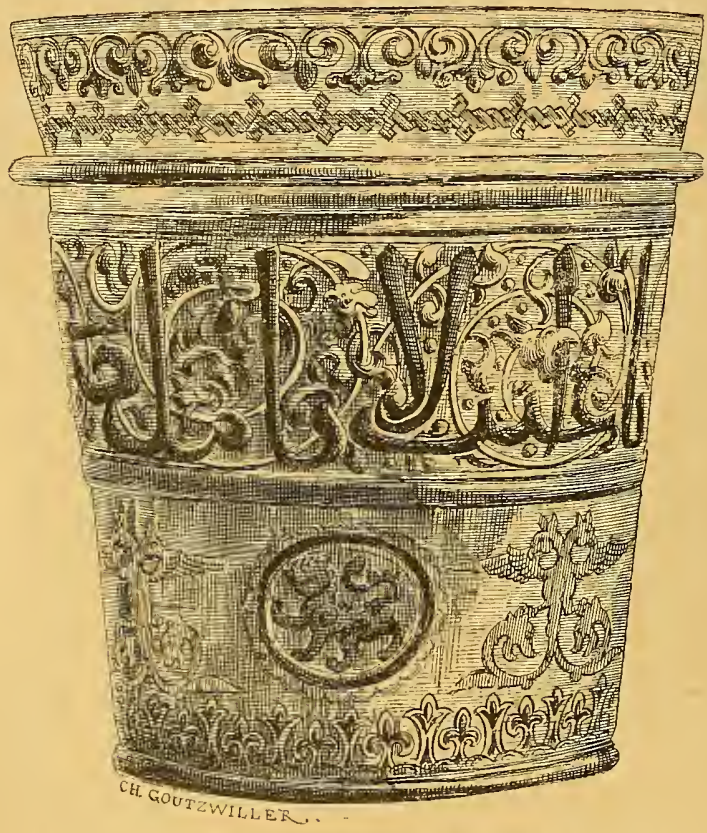

FI 3. 53. - ORIENT. GOBELET ÉMAILLÉ ET DORÉ.

(Collection Spitzer.)

sur la tente un mélange de blanc de plomb ou de chaux calcinée avec du blanc d'œuf. Cette coutume donna lieu à un précepte religieux : "Le verre rompu se remet en son entier; combien plus l'homme peut-il ètre rétabli dans le sien après que la mort l'a mis en 
pièces. » Lorsqu'un usage passe en proverbe, c'est qu'il est très ancien et très populaire; il est probable que celuide raccommoder les verres cassés remontait à l'époque où la verrerie persane produisait des ouvrages d'art.

Si le type de la verrerie arabe peut se caractériser par la lampe évasée, cette forme devenue classique est loin d'être la seule que l'on rencontre; la fabrication comportait des pots, des hanaps, des aiguières, des vases à biberons, des lampes cylindriques, des bassins à pieds, des cornets, des bouteilles à long col, des verres à boire de luxe, des fioles, des bouteilles et des verres communs. Dans cette multiplicité d'objets, il n'en est pas un dont la forme ne soit appropriée à l'usage avec élégance et dont le décor ne soit har-

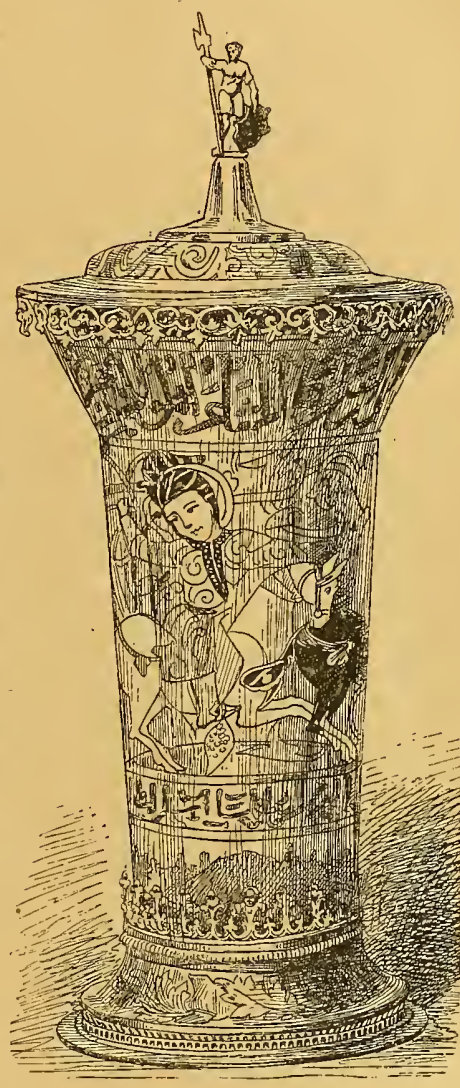

FIG. $S_{t}$. 一 ORIENT.

MONTURE DU XV SIÈCLE COMPLÉTÉE AU XVI ${ }^{\mathrm{e}}$. (Grüne Gewölbe, à Dresde.) monieusement adapté à la forme; le sentiment décoratif 
est toujours juste, aussi bien par le dessin que par la couleur, mais dans aucune pièce nous ne le trouvons mieux exprimé que dans la lampe évasée. La forme se prête en même temps à la suspension et à la position à plat; qu'elle plane ou qu'elle soit posée, la lampe présente à l'œil des lignes correctes et harmonieuses. Le décor a pour mission de remplacer un grillage métallique; aussi est-il en émail et ne laisse-t-il passer qu'une lumière tamisée. Fort souvent, les lampes sont votives; la calligraphie arabe s'y développe alors avec ses lettres élégantes et se mêle aux rosaces, aux médaillons, aux lacis, à tous ces ornements si justement appelés arabesques; les feuillages, les fleurs viennent rompre les lignes, les emblèmes viennent occuper les champs; la pièce ainsi habillée prend un caractère particulier qui ne laisse aucun doute sur son origine, ni sur l'excellence du goût de l'artiste.

La verrerie arabe est, au premier chef, une verrerie d'art; elle a dignement remplacé la verrerie grecque et a tenu le premier rang pendant plusieurs siècles, jusqu'au moment où l'Italie s'est emparée de la suprématie. 


\section{L'OCCIDENT ${ }^{1}$}

\section{I}

La touchante coutume d'ensèvelir avec le mort regretté les objets qu'il a aimés, les emblèmes des fonctions qu'il a remplies, les armes qu'il a portées avec honneur, a persisté longtemps après l'Antiquité; elle n'a même jamais été complètement abandonnée et de nos jours on pourrait sans peine en citer des exemples. Les Mérovingiens, les Alemanni et les Saxons ont ainsi laissé dans leurs tombes des vases et des colliers en verre et des bijoux émaillés ou garnis de verroteries. Les plus singuliers de ces vases ont été trouvés à Douvrend en Normandie, à Reculver et à Fairford en Angleterre et à Selzen en Allemagne; ce sont des verres à boire d'une forme inconnue de l'antiquité; leur originalité consiste en de grosses larmes creuses à l'intérieur, avec crêtes et queues; l'aspect est étrange et quelque peu

I. Nous résumerons d'abord les menus faits épars dans les pays de l'Occident pendant le moyen âge; puis, dans les chapitres suivan's, nous abandonnerons l'ordre chronologique général pour aborder successivement chacun des pays où la verrerie a été cultirée. 
barbare, mais la fabrication dénote une habileté de main incontestable. Les autres vases ont beaucoup d'analogie avec les verres antiques; ils renfermaient sans doute de l'eau bénite, des parfums et du vin, car dans quelques-uns on a constaté des traces d'une matière rougeâtre ${ }^{1}$. Le Poitou comme la Norman-

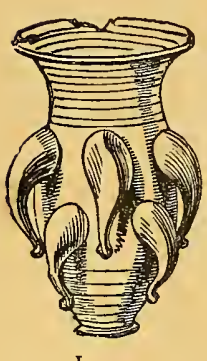

I

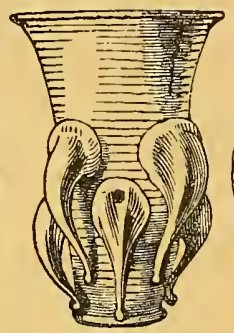

2

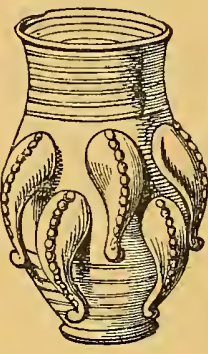

3

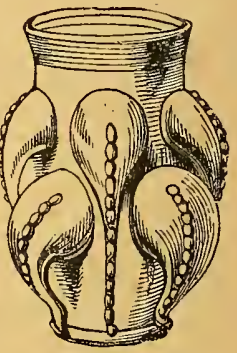

4

FIG. S S. - MOXEN AGE.

.I. Reculver (Kent). - 2. Selzer (près de Mayence). - 3. Fairford (près de Glocester): - 4. Douvrend (Normandie).

die fournit un contingent important à la verrerie de ces époques; on y a découvert des colliers, des épingles, des fibules, quelques verres blancs, jaunes et verts en forme de bouteilles, de plats et de coupes; ces objets ont une analogie parfaite avec les verreries du sol de la Normandie. Une coupe vert foncé trouvée à Grues porte en relief le nom EvTvchia tracé en émail blanc. Eutuchia veut dire Fortunée; on peut supposer que la coupe appartenait à une femme franque d'origine grecque, ou qu'elle avait été faite en son honneur. Limoges a compté parmi ses évêques un prélat nommé

1. L'abbé Cochet. La Normandie souterraine. 
Eutuchius ${ }^{1}$. Une tombe mérovingienne ouverte à notre époque a mis au jour un vase en verre moulé avec une inscription ${ }^{2}$.

OFIKINA LAVRENTIV.
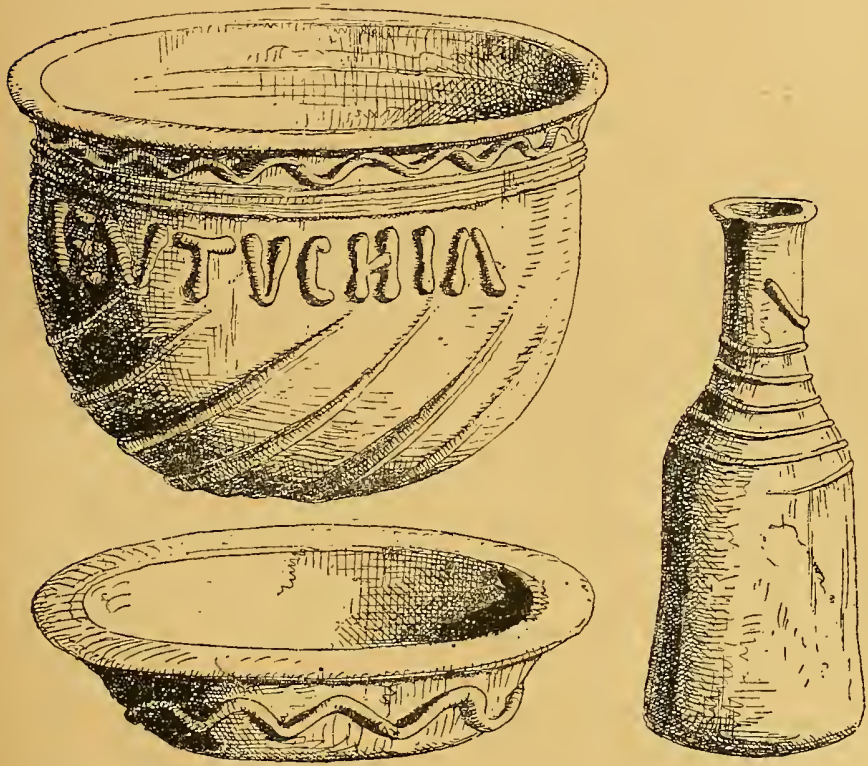

FIG. S6. - MOXEN AGE.

(Fouilles du Poitou.)

En rapprochant cette inscription de la légende

VIENNA DE OFFICINA LAVRENTI, qu'on lit sur une monnaie d'or du Cabinet des médailles

I. B. Fillon et de Rochebrune. Poitou et Vendée.

2. Deloche, membre de l'Académie des inscriptions et belleslettres. Revue archéologique, 1882. 
de la Bibliothèque nationale, portant le nom de l'empereur grec Maurice, gendre de Tibère II, qui régna de 582 à 602 , on peut conclure qu'à Vienne en Dauphiné, siège d'une ancienne colonie romaine, un fabricant du nom de Laurent était monnayeur et verrier vers la fin du $v^{\mathrm{e}}$ siècle. La fabrication de toutes ces pièces est celle de l'antiquité; le verre est blanc, verdâtre, rarement jaune; quelques pièces sont moulées, d'autres sont décorées de filets

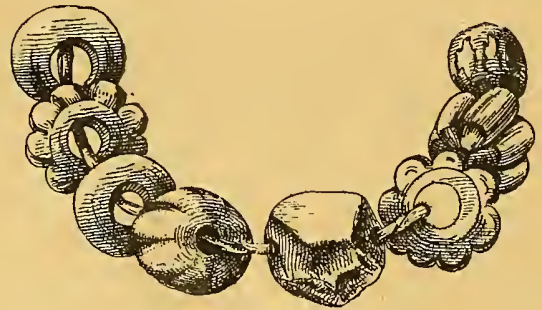

FIG. 57. - MOYEN AGE.

(Fouilles d'Envermeu, Seine-Inférieure.) d'un verre blanc laiteux. Les bracelets et les colliers sont unis ou à côtes moulées en verre blanc, brun, vert, bleu et en couleurs mélangées; on n'a trouvé qu'un seul bracelet en verre noir; il est d'une seule pièce. Le nombre d'objets dé. corés de pâtes de verre, boutons, fibules, boucles d'oreilles, armes, pièces de fantaisie est relativement considérable. Le tombeau de Childéric, fils de Mérovée, mort vers 482 , fournit une date; malheureusement, lorsqu'il fut découvert, en I653, à Tournay, près de l'église de Saint-Brice, l'opération fut conduite avec peu de soin; on reconnut néanmoins, au milieu d'autres pièces, une boule en cristal ou en verre de quatre centimètres de diamètre et divers objets, des boutons, des abeilles, la garde de l'épée, le fourreau de la même arme, décorés de feuilles transparentes de verre 
rouge grenat; l'application de la feuille de verre est sur des fonds d'or ou de métal; elle est découpée selon la forme à remplir. D'autres pièces, fibules, médailles, épingles à cheveux, boucles d'oreilles, découvertes ailleurs, sont ornées de verres opaques de différentes couleurs, retenus dans les creux, fixés par un mastic, rarement pris par le sertissage. L'observation a été faite que partout où nos ancêtres ont porté leurs pas, on trouve des bijoux du même genre. La matière rouge étaitelle du grenat ou du verre? Il est certain que les deux sub. stances ont été employées; lorsque la pâte est coulée dans

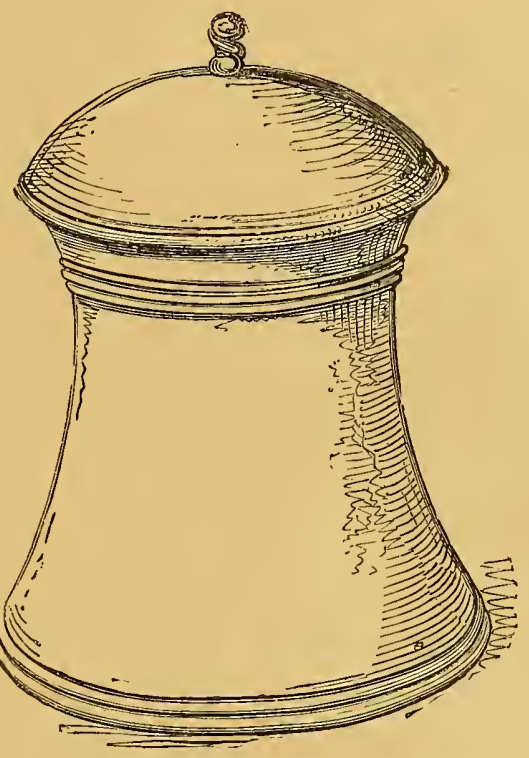

FIG. 58 . - MOYEN AGE.

(Fouilles d'Envermeu, Seine-1nférieure.) les réserves du métal, elle ne peut être que du verre; au contraire, lorsqu'elle est enchâssée à la manière des pierres précieuses ou appliquée à l'état de feuille mince contre le métal et retenue par une sertissure, elle peut être aussi bien une pierre naturelle que du verre fondu. La controverse a de l'intérêt, car si le grenat naturel était en usage, 
on pourrait admettre, comme le veulent quelques archéologues, que certains bijoux mérovingiens, et notamment l'épée de Childéric, conservée au musée du Louvre, seraient d'origine orientale. L'argument est tiré

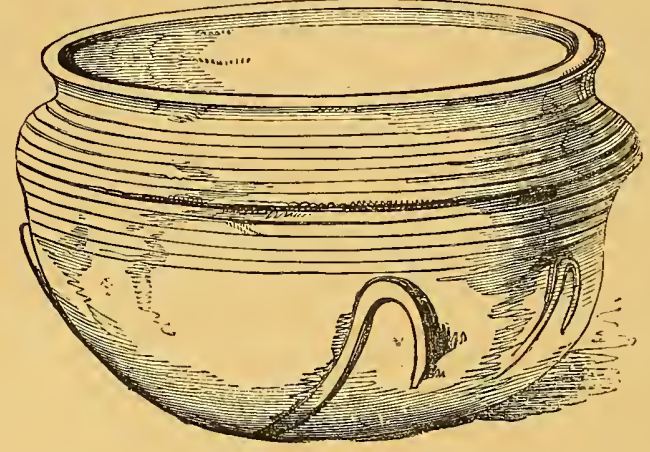

FIG. 59. - MOXEN AGE.

(Fouilles d'Envermeu, Seine-lnférieure.) de l'observation suivante: souvent les la meiles rouges incrusté es dans le métal son $\mathrm{t}$ d'une densité supé rieureà celle du verre, e 11 es le rayent, elles ont des rayons d'absorption particuliers au grenat syrien, qui vient non pas de la Syrie mais des environs de Syrian dans les Indes ${ }^{1}$. Quoi qu'il en soit, le goût des Mérovingiens pour le grenat véritable ou artificiel était à ce point prononcé et persistant qu'il est devenu l'une des caractéristiques de la race.

\section{I'}

Nous avons vu que les vitres en verre étaient connues de l'antiquité; les premières basiliques chrétiennes

I. A. Damour. Revue archéologique, 1882 . 
en furent pourvues; nous ne parlons pas ici de vitraux décorés de figures et d'ornements, mais seulement des fenêtres garnies de verre blanc ou coloré. Quoique les vitres de couleur semblent inutiles et mêême nuisibles dans les églises ornées de mosaïques, il paraît que les architectes les recherchaient néanmoins. Mais alors ils devaient certainement-les 'placer de façon à éviter que le reflet vint frapper les parties recouvertes de mosaiques. La basilique de Saint-Paul hors les murs a été édifiée par l'empereur Constantin, sur la demande du pape Sylvestre, qui la consacra en l'an 324; dès lors " aux fenêtres cintrées se déploient des verres de diverses couleurs, et cela reproduit la vue d'une prairie émaillée de fleurs ${ }^{1}{ }^{1}$. Lactance au $1 \mathrm{v}^{\mathrm{e}}$ siècle, saint JeanChrysostome, saint Jérôme, Sidoine Apollinaire au ve, mentionnent le verre à vitre blanc ou coloré. A la même époque, l'impératrice Galla Placidia, veuve de Constantin II, résidait à Ravenne et gouvernait l'empire d'Occident par délégation de son fils Valentinien III; la princesse, amie des arts, fit élever des églises somptueuses qui ont résisté aux ravages du temps et des guerres, et dont les fenêtres étaient garnies de vitres en verre. Grégoire de Tours écrit qu'en 62 I les soldats de Théodose pénétrèrent dans l'église de SaintJulien, à Brioude, en brisant le vitrage d'une fenêtre. Fortunat, évêque de Poitiers, contemporain de Grégoire, vante l'effet produit sur les murs par les vitres de couleur à Notre-Dame de Paris, à Saint-Martin de Tours, à l'église de la Vierge de Bordeaux.

1. Prudence. Carmina, hymne xis. 
$\mathrm{Au} \mathrm{vir}$ siècle, nos artisans français avaient acquis une telle renommée, que non seulement ils fabriquèrent des vitres pour la cathédrale d'York, sur la demande de l'évêque Jean Wilfrid, mais qu'en 670 ils furent appelés en Angleterre. Le roi Egfrid avait concédé á l'abbé Bénédict Biscopus un terrain à l'embouchure de la Wear; l'abbé y fit construire un grand monastère, mais comme il n'y avait pas de verrerie en Angleterre, il dut faire venir des verrriers de France; les vitres pour les fenêtres du couvent furent fabriquées sur place.

L'orfèvre, devenu ministre du roi Dagobert, employait le verre dans les travaux de son métier. La fameuse croix faite par "monsieur saint Éloi ${ }^{1}$ » pour l'église de Saint-Denis avait «au bas d'icelle, sous un grand verre à façon de tableau, une petite croix d'argent doré ............. Le champ de ladite croix tant devant que derrière était (couvert) de verres ressemblant à jacinthes, grenats, esmeraudes et saphirs. ”

Un évêque de Rouen se servait de burettes en verre. Isidore de Séville, qui fut évêque de 6 o I à 636, tout en constatant dans son livre, les Origines des étymologies, qu'autrefois on fabriquait du verre transparent en Italie, dans les Gaules et en Espagne, dit que le verre de couleur foncée est la meilleure matière pour les miroirs.

Le trésor de Guarrazar, du musée de Cluny, est, dans certaines parties, recouvert de pâtes de verre; ce trésor provient de Recesvinde, roi goth de l'Espagne,

1. Inventaire du trésor de l'abbaye de Saint-Denis en France en date, au commencement, du 27 mai 1634. Archives nationales. 
qui mourut en 672 . Vers 678 , il existait à Mayence une verrerie dont un ouvrier fut appelé en Angleterre.

-A la fin du viri siècle, l'abbé Gozbert remercie le comte Arnolt de l'envoi de fenêtres à plussieurs couleurs fait à un couvent de la Bavière.

Au $\mathrm{IX}^{\mathrm{e}}$ siècle, un calice en verre garni d'or se trouve dans la chapelle du comte Evrard, gendre de Louis le Débonnaire. C'est sans preuve que l'on attribue au même siècle le verre dit de Charlemagne, du musée de Chartres. En 8o3, le concile de Reims et plus tard le pape Léon IV, dont le pontificat eut lieu de 847 à 855 , interdisait l'usage des calices en verre cassant, en bois, en cuivre, "quia provocat vomitum ", et en corne impure; l'interdiction du verre ne semble pas avoir été généralement observée. Pendant le même $\mathrm{Ix}^{\mathrm{e}}$ siècle, l'abbé Ansigise fit don à l'abbaye de Fontanelle d'un grand vase à boire et de deux coupes en verre orné d'or. En Suisse, Salomon, abbé du monas. tère de Saint-Gall, possédait des vases en verre "plus précieux que les vases d'argent et d'or. " Près du monastère de Constance, il existait une verrerie. A l'abbaye de Fulda, en Allemagne, les religieux se servaient de verres à boire en verre. Louis le Débonnaire donna, en 825 , un diplôme à l'abbaye de Saint-Mesmin, près d'Orléans; dans le document, il est question d'un lieu appelé "portus vitrariæ ", port de la verrerie. Une charte de Charles le Chauve de 863, contenant donation en faveur de Saint-Amand en Pevèle, renferme les noms de deux verriers, Ragenut et Balderie. On a découvert, en Normandie, une aiguière que les archéologuent attribuent au $\mathrm{IX}^{\mathrm{e}}$ siècle; le verre est blanc, il est 
décoré en relief de filets et de rangs de perles en verre.

Le reliquaire de l'église de Saint-André, à Trèves, fabriqué dans le dernier quart du $\mathrm{x}^{\mathrm{e}}$ siècle, est garni en certains points d'un fond de verre rouge.

Saint Bernard, évêque d'Hildesheim, mort en ro22, avait, dit-on, fabriqué lui-même un calice en verre; Henri II, dit le Boiteux, empereur d'Allemagne, mort en 1025 , donna à l'église de Saint-Viton, à Verdun, des burettes et un calice en verre. Geoffroy de ChampAleman, évêque d'Auxerre, institua sous Henri I ${ }^{\text {er }}$, roi de 103 I à 1060, des prébendes pour des prêtres dont l'un serait peintre, l'autre vitrier et le troisième orfèvre.

Voilà donc le bien médiocre résultat de l'enquête; c'est à peine si elle prouve que le verre, dans ces temps obscurs et tourmentés, est resté en honneur, puisque nous le trouvons dans les objets précieux et sacrés et dans les cadeaux des souverains; c'est à peine si la verrerie était restée un métier en Occident : assurément elle n'était plus un art. Il n'y avait plus trace en Italie même de la belle production antique, et le pays doit recourir aux Grecs dont l'abbé Didier, supérieur du célèbre couvent du Mont-Cassin, avait remarqué l'habileté, lorsqu'il était légat du pape à Constantinople. De retour en Italie, il fit venir en I 066 , de l'Orient, des artistes non seulement pour décorer l'église du monastère, mais afin de former des ouvriers dans diverses branches des arts décoratifs. Léon, évêque d'Ostie, historiographe du couvent, consigne le fait en ces termes :

Et comme, depuis plus de cinq cents ans, le génie de ces arts s'était éteint en Italie, par ses soins, sous l'inspiration de Dieu, cet homme prudent (l'abbé Didier) s'appliqua à faire 
instruire les enfants du monastère en ces deux arts (la mosaïque et les incrustations); et il ne s'en tint pas là seulement, il fit former par les siens de très studieux ouvriers dans toutes les œuvres qui emploient l'or ou l'argent, l'airain, le fer, le verre, l'ivoire, le bois, le gypse ou la pierre.

\section{I I}

Le monde chrétien avait été pris de terreurvers la fin $\mathrm{du} \mathrm{x}^{\mathrm{e}}$ siècle; selon quelques lignes de l'Apocalypse ${ }^{1}$, mal interprétées par la superstition, on croyait à la fin du monde pour l'an mil. On a relevé, sur des actes authentiques du temps, ces mots mundi terminum appropinquante. Tout avait été abandonné, la culture de ia terre; les lettres, les arts. Vasari reconnaît que l'Italie ellemême :

La malheureuse Italie, avait vu disparaître, au milieu d'un déluge de calamités, tout ce qui portait le nom d'édifices et même les hommes qui cultivaient les arts.

Pour l'Italie, le « déluge de calamités » remontait au delà du $\mathrm{x}^{\mathrm{e}}$ siècle, et fut plus grand que dans les autres pays, car de la fin du pontificat de Pascal I ${ }^{\text {er }}$, qui occupa la chaire de saint Pierre de $8 \mathrm{I} 7$ à 824 , jusqu'à celui d'Innocent II, qui fut pape de I I 30 à I I 43, la mosaïque, si particulièrement protégée par les pontifes romains, fut abandonnée. Cependant, lorsque les peuples chrétiens furent convaincus de l'erreur qui les avait affolés,

I. Chapitre XX, versets 3 et 4 . 
ils songèrent à vivre; il y eut alors une reprise du mouvement humain dans toutes les branches du travail, et c'est dans cette renaissance sans doute que Théophile a puisé les enseignements qu'il nous a transmis.

Théophile, prêtre et moine, a écrit un essai sur divers arts, Diversarum artium schedula ${ }^{1}$. Le traité est en trois livres. Le premier donne les procédés de divers
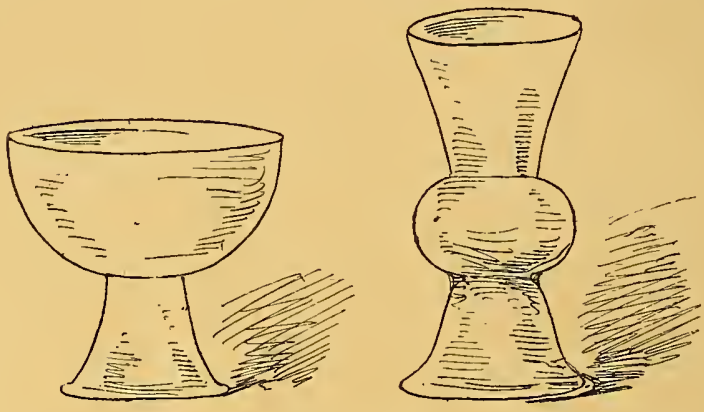

FIG. 60. - $\mathrm{XI}^{\mathrm{e}}$ SIÈ CLE.

(Peinture gréco-ruthénique.)

genres de peinture et notamment de la peinture à l'huile, non seulement sur les boiseries et les murailles, mais pour les teintes des figures et des draperies, " les animaux, les oiseaux et les feuillages ". Le second est consacré à la verrerie : verre à vitres, vitraux peints, mosaïque, vases en verre de couleur ou émaillés. Le troisième traite du travail des métaux simples, repoussés, émaillés appliqués aux objets en usage dans les célébra.

I. Traduction de M. le comte Charles de l'Escalopier, conservateur honoraire de la bibliothèque de l'Arsenal, précédée d'une Introduction par M. J.-Marie Guichard. Paris, $184^{3}$. 
tions du culte catholique : calices, burettes, encensoirs, orgues. On comprend l'intérêt qui s'attache à la question de savoir à quelle époque remonte le travail de Théophile, écrit en latin et non daté. Voịci les diverses opinions des savants qui ont tenté cette recherche : Lessing, fin du IXo siècle; Hendrie, première moitié du $\mathrm{xt}^{\mathrm{e}}$; Rapse, Morelli, Emeric David, de Montabert, Batissier,
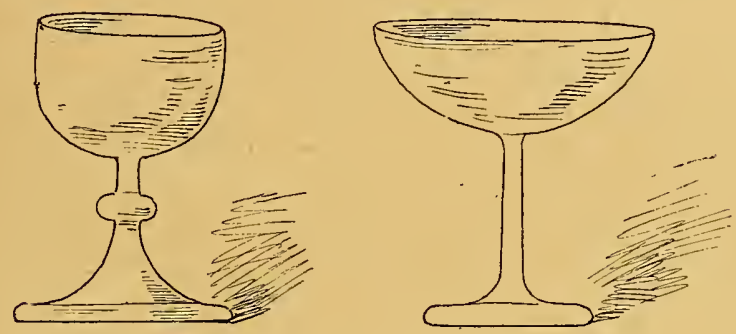

FIG. $61 .-\mathrm{XII}$ SIÈGLE.

(Manuscrit français du Vatican.)

$\mathrm{x}^{\mathrm{e}}$ ou $\mathrm{xI}^{\mathrm{e}} ; \mathrm{J}$. Labarte, fin du $\mathrm{xI}^{\mathrm{e}}$ siècle; M. Jlg, fin $\mathrm{du}$ $\mathrm{XI}^{\mathrm{e}}$ ou commencement du $\mathrm{xII}^{\mathrm{e}}$, au couvent des bénédictins de Helmershausen en Westphalie; l'abbé Boussaré, milieu du xiI $^{\mathrm{c}}$; Viollet-le-Duc, хII ; J.-M. Guichard, $\mathrm{xII}^{\mathrm{e}}$ ou $\mathrm{xIII}^{\mathrm{e}}$; l'abbé Texier, $\mathrm{xIII}^{\mathrm{e}}$. Nous penchons pour la fin du $x^{e}{ }^{e}$ siècle, et c'est dans l'histoire de la verrerie que nous trouvons nos arguments. Ainsi qu'on le verra plus loin, Théophile parle de la supériorité des Grecs dans l'art des verres et il ne fait pas la moindre allusion aux verreries italiennes; or nous avons vu qu'en. ro66 l'abbé Didier fit venir d'Orient des ouvriers verriers; nous pouvons donc supposer que Théophile 
écrivit avant l'arrivée en Italie de ces artisans. La nationalité de Théophile paraît être allemande, quoique des auteurs italiens la revendiquent pour l'I talie. Théophile dédie son livre :

A tous ceux qui veulent éviter ou dompter la paresse de l'esprit et l'égarement du cœur, en se livrant à l'utilité d'une occupation manuelle et à la douce méditation des choses nouvelles.
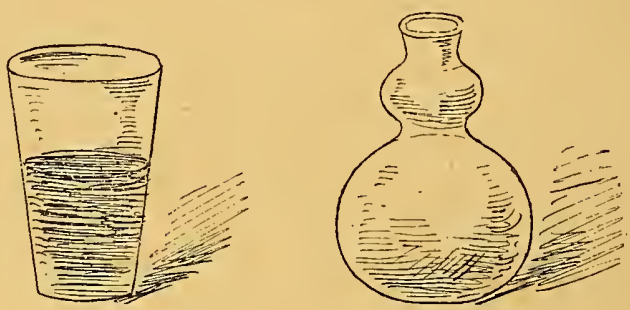

FIG, 62, - XIV SIÉGLE.

(Manuscrit latin du Vatican.)

\section{Il veut montrer :}

Combien il est honorable, combien il est parfait d'éviter l'oisiveté et de dompter la fainéantise et l'indolence; combien encore il est doux et délectable de se livrer aux exercices des divers arts utiles.

Il écrit sous forme de conseils à un élève "à qui Dieu a mis au cœur le désir d'exploiter le vaste champ des arts divers ". Avant d'aborder la technique, il indique l'état des arts dans les pays qui les cultivaient alors et explique le but de son travail :

Ainsi, mon bien-aimé fils, toi que Dieu a rendu parfaitement heureux, en ce sens qu'on t'offre ici gratuitement ce 
que beaucoup d'autres n'acquièrent que par de pénibles efforts, en fendant les flots de la mer au plus grand péril de leur vie, exposés aux rigueurs de la faim et du froid, ou bien assujettis au long esclavage de l'école, et tourmentés par l'insatiable désir d'apprendre; saisis avec des regards avides cet Essai sur diver's arts, lis-le avec une mémoire fidèle; embrasse-le avec un amour ardent. Si tu l'approfondis attentivement, tu trouveras là tout ce que possède la Grèce sur les espèces et les mélanges des, diverses couleurs; toute la science des Toscans sur les incrustations et sur la variété des nielles; toutes les sortes d'ornements que l'Arabie emploie dans les ouvrages faits au moyen de la malléabilité, de la fusion ou de la ciselure; tout l'art de la glorieuse Italie dans l'application de l'or et de l'argent à la décoration des vases, ou au travail des pierreries et de l'ivoire; ce que la France recherche dans l'agencement des précieux vitraux; les ouvrages délicats, d'or, d'argent, de cuivre, de fer, de bois et de pierres qu'honore l'industrieuse Germanie.

La leçon sur la verrerie commence par la construction des fours; il en faut trois : un four de travail pour la fonte, un four de refroidissement, un four de dilatation et de nivellement; les dimensions de la construction, la confection des creusets sont marquées avec précision. Elles nous apprennent que les fours étaient de quinze pieds sur dix, ce qui est une grande dimension et prouve une fabrication puissante. Puis Théophile continue en indiquant comment il faut s'y prendre pour faire un vase et des anneaux en verre, comment on se sert en fabrication des moules en fer et des moules en bois; nous n'hésitons pas à citer le texte même en omettant seulement ce qui se rapporte aux vitraux ${ }^{1}$. L'ou-

I. Nous préférons copier textuellement les auteurs qui marquent dans l'histoire des arts, plutôt que d'analyser leurs écrits, 
vrier prend un tube de fer et le plonge dans le creuset rempli de verre fondu.

Tournez le tube dans votre mairf jusqu'à ce que le verre s'agglomère autour en aussi grande quantité que vous voudrez; puis, le relevant, mettez-le à votre bouche et soufflez un peu et en l'éloignant aussitôt; tenez-le près de votre joue, pour ne point attirer la flamme dans votre bouche en reprenant haleine. Ayez une pierre unie devant la fenêtre (du four), sur laquelle vous battrez un peu le verre brûlant pour lui donner partout le même volume, avec rapidité soufflez et éloignez alternativement...... lorsque vous aurez soufflé selon la quantité que vous désirez, vous la détacherez en entier du tube avec un bois trempé dans l'eau; puis, chauffant le tube, vous le ferez adhérer au fond. Présentant le vase à la flamme, vous le chaufferez et avec un bois rond vous élargirez l'ouverture d'où vous avez séparé le tube, en travaillant et dilatant à volonté les bords. Vous agrandirez le fond autour du tube, en sorte qu'il soit creux à la partie inférieure. Si vous voulez faire au vase des anses pour pouvoir le suspendre, prenez un fer mince, plongez-le jusqu'au bout dans le verre; quand il en aura pris un peu, enlevez et placez sur le vase où vous voudrez; lorsqu'il aura adhéré vous chaufferez pour consolider. Faites ainsi un tel nombre d'anses qu'il vous plaira, tenant le vase près de la flamme, de façon qu'il se conserve chaud sans se fondre. Prenez aussi un peu de verre dans le four, de manière qu'il traîne un fil après lui, et le plaçant sur la partie du vase que vous préférez, roulez autour près de la flamme, pour qu'il adhère. Cela fait, selon l'usage, vous ôterez le tube, déposant le vase dans le fourneau de refroidissement. Vous opérerez ainsi tant que bon vous semblera.

Pour fabriquer des flacons à long col, faites ainsi. Après avoir soufflé du verre chaud, en forme de grande vessie,

une analyse pouvant paraître une sorte d'approbation au profit de celui qui la fait. 
fermez l'ouverture du tube avec votre pouce, de peur que l'air ne s'échappe, agitant le tube avec le verre qui y est suspendu, par derrière votre tête, comme si vous vouliez le jeter au loin. Le col s'étant développé en longueur, levez votre main en haut et laissez le tube avec le vase pendre audessous de peur que le col ne se courbe; alors séparant avec un bois humide, mettez dans le fourneau de refroidissement.

Les Grecs font aussi avec les mêmes pierres de saphir des coupes précieuses pour boire. Voici comment ils les ornent d'or. Prenant de la feuille d'or, dont nous avons parlé plus haut, ils en fabriquent des images d'hommes, d'oiseaux ou de feuillages, et ils les posent avec de l'eau sur la coupe partout où ils veulent. Cette feuille doit être un peu épaisse. Ensuite ils prennent du verre très clair comme du cristal qu'ils composent eux-mêmes, et qui, en sentant la chaleur du feu, se dissout. Ils le broient soigneusement sur une pierre de porphyre avec de l'eau et en appliquent avec le pinceau une couche très fine sur toute la feuille; lorsque cela est sec, ils le placent dans le fourneau dans lequel se cuit le verre pour les vitraux peints dont nous parlerons dans la suite, et mettent dessous du feu avec des bois de hêtre parfaitement séchés à la fumée. Quand ils voient la flamme pénétrer la coupe au point qu'elle prenne une légère rougeur, aussitôt, enlevant le bois, ils bouchent le fourneau jusqu'à ce qu'il soit refroidi, et l'or ne se détachera jamais.

Ils emploient aussi un autre moyen. Prenant de l'or moulu dans un moulin, dont on se sert pour les livres, ils l'étendent d'eau; de même pour l'argent. Ils en font des ronds et dans ces ronds des images, des animaux ou des oiseaux d'un travail varié; ils les enduisent du verre très brillant dont nous avons parlé. Ensuite prenant du verre blanc, du rouge et du vert, en usage dans les incrustations, ils broient sur une pierre de porphyre chacun de ces verres à part avec de l'eau, et ils en peignent de petites fleurs, des nœuds et autres petits ornements, à leur choix, avec un travail dẹ 
différentes couleurs entre les ronds et les nœuds, et la broderie autour du bord; et cela d'une épaisseur moyenne; cuisant dans le fourneau d'après les procédés déjà indiqués. Ils font aussi des coupes de pourpre et de saphir léger, et les fioles à col médiocrement allongé, les entourant avec des fils faits avec du verre blanc, et y plaçant des anses du même verre. Ils ornent encore à volonté leurs divers travaux d'autres couleurs.

Dans son impartialité, Théophile ne néglige aucune occasion de parler de l'habileté des Français. A propos de mosaïque, il dit :

On trouve dans les antiques édifices des païens, parmi les ouvrages de mosaïque, différentes espèces de verre, savoir : du blanc, du noir, du vert, du jaune, du saphir, du rouge, du pourpre. Il n'est pas transparent, mais opaque comme du marbre. Ce sont des espèces de petites pierres carrées dont on fait des incrustations dans l'or, l'argent et le cuivre.

On trouve aussi divers petits vases de ces mêmes couleurs qui sont recueillis par les Français, très habiles dans ce travail. Ils fondent dans leurs fourneaux le saphir en y ajoutant un peu de verre clair et blanc, et ils fabriquent des feuilles de saphir précieuses et assez utiles dans les fenêtres. Ils en font autant du pourpre et du vert.

On le voit: Théophile s'exprime en termes clairs et précis, il parle en homme qui a vu et qui sait; il l'avoue du.reste. Dans une de ses exhortations, il dit qu'il s'est livré à de scrupuleuses expérimentations et aux investigations de l'œil et de la main. Dans notre pensée il n'y a aucun doute: Théophile a été peintre de figures et de manuscrits, verrier, orfèvre et facteur d'orgues; pour un moine instruit, passionné au travail, dégagé 
des préoccupations de la vie matérielle, la pratique de ces divers arts était chose aisée et chose sainte, car elle tournait à la glorification de son Dieu. Théophile nous représente, en plein moyen âge, le type parfait de ces artistes à la fois peintres, sculpteurs, orfèvres, graveurs, qui plus tard, pendant la Renaissance, ont, à Florence et à Nuremberg, élevé à un haut degré les arts décoratifs. 


\section{VENISE}

Il est très difficile de déterminer, même approximativement, l'époque où les premières verreries furent établies à Venise. Les historiens italiens veulent les faire remonter à la fondation de la ville, au $\mathrm{v}^{\mathrm{e}}$ siècle ; si, en effet, il y eut des verreries alors, elles n'étaient que de médiocre importance et n'ont pas marqué dans l'histoire. Les plus anciennes mosaiqques de la cathédrale de SaintMarc se trouvent à l'intérieur, au-dessus de la porte d'entrée; elles représentent le Christ, la Madone et Saint-Marc et datent du $\mathrm{x}^{\mathrm{e}}$ siècle; or, une verrerie qui fond les émaux pour la mosaique est certainement en état de fabriquer aussi des pièces de service. Mais les émaux des mosaïques primitives de Saint-Marc, les smaltes, comme on dit en Italie, proviennent-ils d'une verrerie vénitienne? $\mathrm{La}$ question peut se discúter. $\mathrm{Au}$ $\mathrm{Ix}^{\mathrm{e}}$ siècle, Charlemagne fit décorer de mosaïques la chapelle palatine du dôme d'Aix-la-Chapelle, au moyen de matériaux italiens; de notre temps, les mosaiqques décoratives du théâtre de l'Opéra de Paris ont également été exécutées avec des matériaux italiens. Il est 
donc possible que les smaltes des premières mosaiques de Saint-Marc soient venus d'Orient : à l'appui de cette hypothèse, nous pouvons citer le texte de Léon, évêque d'Ostie, qui assure qu'en ro66 Didier, abbé du Mont-Cassin, fit chercher en Orient des ouvriers habiles dans l'art de la mosaïque pour apprendre aux enfants du monastère le travail des métaux, de l'ivoire, de la pierre et du verre. Théophile, dans l'énumération qu'il fait des arts pratiqués par " la glorieuse Italie» ne mentionne pas le verre. On prétend avoir trouvé, dans les archives d'une famille patricienne de Venise, mention d'un certain Petrus Flavianus qui, en rogo,

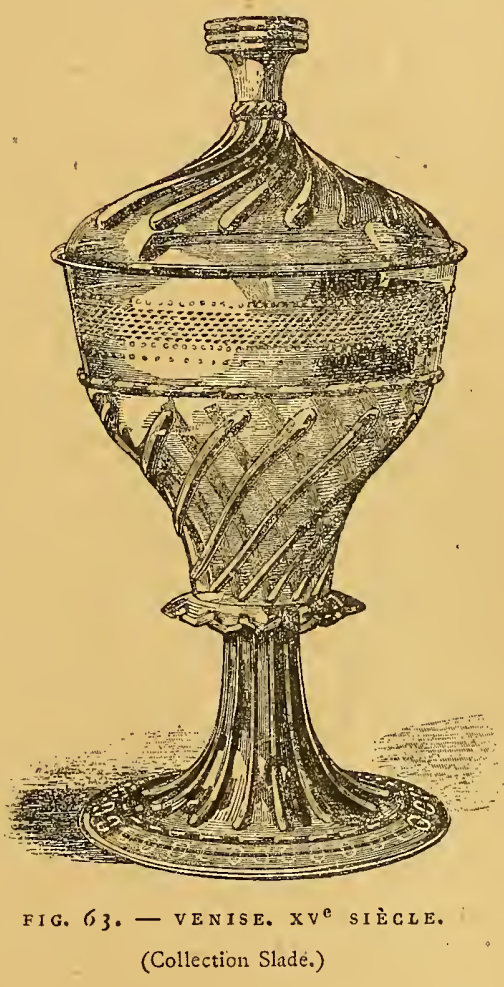
était phiolarius. Cette inscription n'a pas une grande valeur, car, s'il existait des verreries à Venise au $x^{\mathrm{e}}$ et au $x^{e}{ }^{e}$ siècle, ce qui n'est ni prouvé ni dénié, elles étaient certainement fort peu productives, et, à cette 
époque, c'était toujours à l'Orient qu'appartenait la fabrication. Les soldats de Venise firent partie de l'expédition dont le résultat fut la prise de Constantinople en 1204 ; le gouvernement, toujours attentif au développement des intérêts matériels de la République, sut attirer à Venise les verriers orientaux et, dans le cours du xIII siècle, l'industrie de la verrerie prit une très grande extension dont nous trouvons la preuve dans les actes officiels.

Le plus ancien document authentique est un article du traité conclu, le $1^{\text {er }}$ juin 1277 , entre Bohémond VI, prince d'Antioche et comte de Tripoli, d'une part, et J. Contarini, doge de Venise, d'autre part. L'article renferme la stipulation suivante: " Et si Venicien trait verre brizé de la ville, il est tenuz de payer la dhime ». Le verre cassé, le groisil en terme du métier, est nécessaire à une bonne fabrication de verrerie; il provient, non seulement des objets brisés, mais encore des déchets de la fabrication. Nous avons dit qu'à Rome, au temps de l'empire, les juifs et d'autres marchands ambulants échangeaient des allumettes contre du groisil; les verriers de Venise avaient donc reconnu la nécessité de l'emploi de cette matière dont l'usage leur avait été sans doute enseigné par les Orientaux, et ils en consommaient en si grande quantité que les déchets de leur propre industrie ne leur suffisant pas, ils durent recourir à l'importation. Le traité prouve que les verreries vénitiennes étaient déjà, en 1277 , en plein fonctionnement et que les verreries orientales travaillaient encore avec activité.

La Sérénissime République avait un goût très pro. 
noncé pour la réglementation, non seulement dans un but de sécurité publique, mais ausși en vue du développement de l'industrie et de la qualité des produits; elle pensait que le système des privilèges, des corporations, des inspections, était de nature à favoriser le travail et le commerce. C'est par cette raison que la verrerie « qu'elle

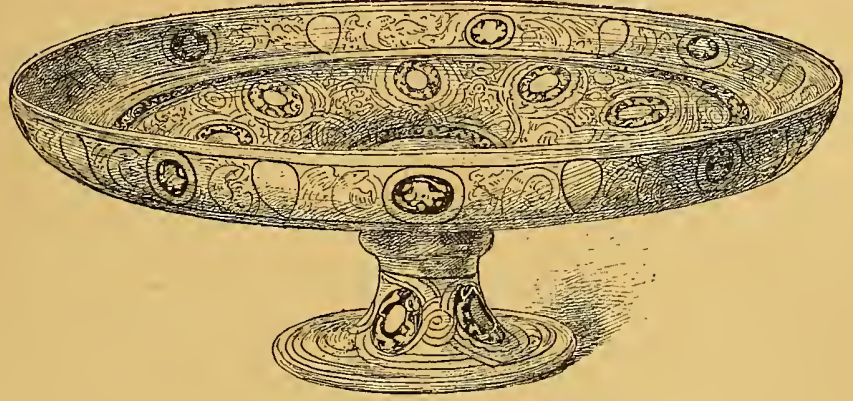

FIG. $6_{4}$. - VENISE, XVE SIĖCLE.

(Musée de Cluny.)

aimait comme la prunelle de ses yeux ${ }^{1}$, fut soumise à des règlesıtrès sévères.

La verrerie a été de tout temps ce que le gouvernement avait de plus précieux. Une infinité de mesures ont été prises pour en augmenter, pour en perfectionner les travaux, et pour en avoir autant que possible un débit exclusif dans les pays voisins comme dans les contrées les plus lointaines.

Dès 1289, un ordre du Grand Conseil, Maggior Consiglio, interdit d'établir des fours de verrerie dans

I. Carlo Marin. Histoire civile et politique du commerce des Vénitiens. Venise, I800. 
la ville, à moins que le verrier ne fût propriétaire de la maison affectée à la fabrique. Cette mesure ne suffit pas pour empêcher les incendies et, le 8 novembre i 29 I, une nouvelle délibération ordonna la destruction de tous les fours existant dans la cité et dans l'évêché de Rialto, défendit d'en construire de neufs sous peine d'une amende de cent livres, et relégua l'industrie dans l'île de Murano. Peu de temps après, le Y I août I 292, le Grand Conseil modifia le décret et autorisa l'établissement dans la ville de fours de petite dimension, à la condition qu'ils seraient isolés des maisons, de tous les côtés, par une distance de quinze pas au moins; la fabrication dans l'intérieur de Venise fut ainsi limitée aux menus objets et à la fonte du verre coloré. Dès le $\mathrm{x}_{11}{ }^{\mathrm{C}}$ siècle, la République prohiba, sous des peines très sévères, l'exportation du verre cassé et des matières premières nécessaires à la fabrication, et, ce qu'il était plus difficile d'empêcher, la divulgation des procédés de fabrication.

L'intelligence et l'activité d'un citoyen de Venise, Marco Polo, ouvrit à la verroterie vénitienne des débouchés nouveaux. Son père, Nicolo Polo, et son oncle, Matheo Polo, étaient d'une famille patricienne; en 1250 , ils partirent pour Constantinople où leur frère aîné, Andrea, avait une maison de commerce; ils trafiquèrent dans les ports de la mer Noire, dans la région du Caucase et du Volga et se rendirent auprès de Khoubilaï-Khâan, empereur mongol de la Chine. Dix ans après, ils retournèrent à Venise, pour en repartir bientôt avec Marco Poloqui fut présenté à Khoubilai, en 1275 . Le jeune Vénitien sut gagner la confiance de l'empereur 
VENISE.

qui le chargea de nombreuses et importantes négociations. Il visita successivement la Cochinchine, la Bir-

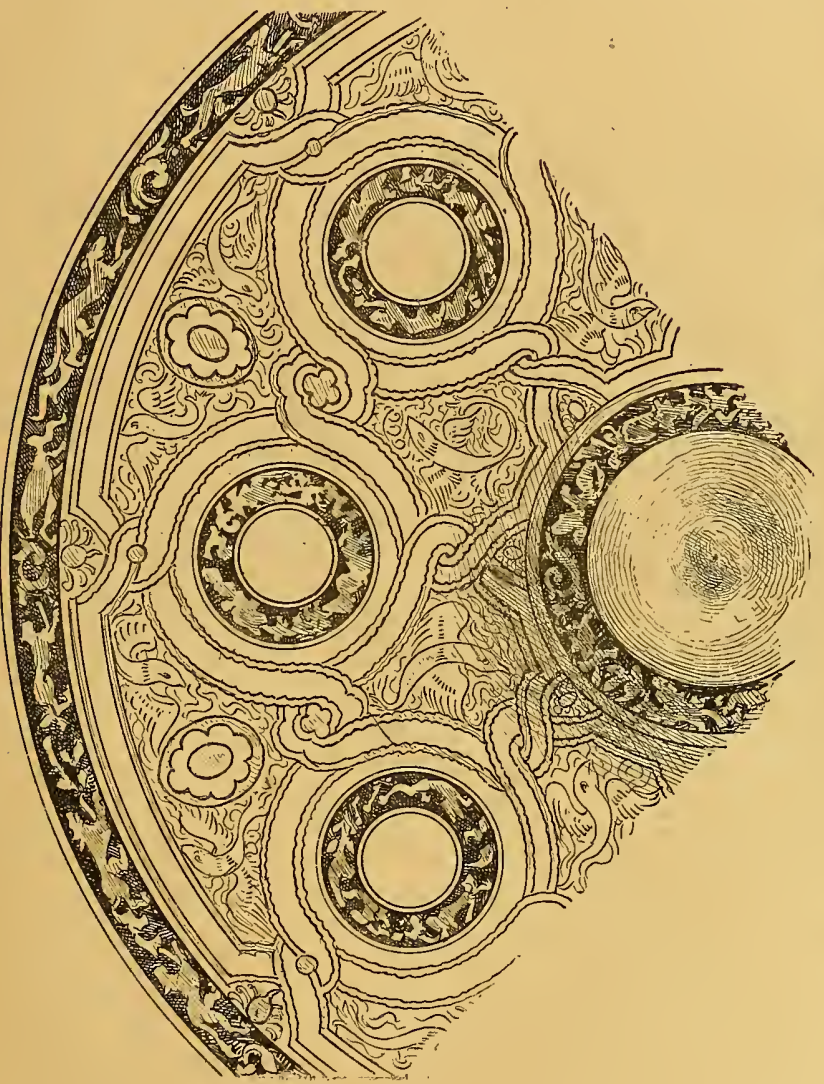

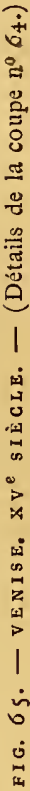

manie, diverses provinces de la Chine actuelle, la Perse, les Indes, Java, Sumatra, Ceylan, Madagascar, l'Abys- 
sinie, l'Égypte et tout le bassin oriental de la Méditerranée. Marco Polo avait tantôt la fonction de commissaire en second du Conseil privé, tantôt celle de gouverneur de province; il fit des expéditions militaires

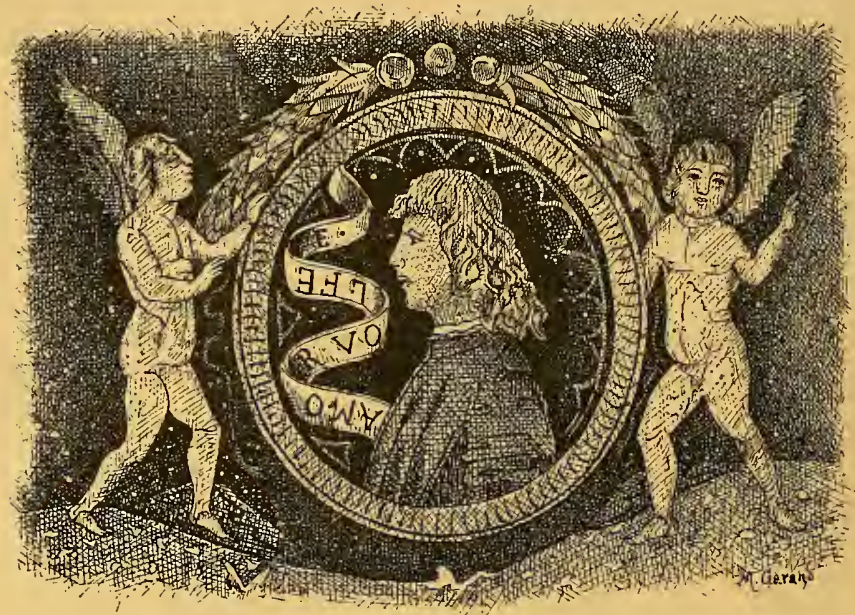

FIG. 66. - VENISE. X甲 SIÈCLE.

(Décoration émaillée d'un verre à boire.)

et remplit des missions diplomatiques ou commerciales; de retour à Venise, en $\mathrm{I} 295$, il tint, avec ses parents, un rang distingué dans la société, et mena l'existence fastueuse que lui permettaient les richesses et les objets précicux rapportés d'Asie. La guerre éclate entre Venise et Gênes. Marco Polo arme une galère à ses frais, est fait prisonnier à la bataille de Layas, en I296, et emmené à Gênes; durant sa captivité, Rusta Pisan écrit 
en français sous sa dictée la relation de ses voyages. Rentré à Venise, Polo est nommé mem. bre du Grand Conseil et meurt en 324 . On le désignait dans son pays comme “ le meilleur citoyen de $\mathrm{Ve}$ nise ». C'est par son influence, par ses récits de voyages, par les renseignements commerc iaux qu'il fournit, par les it in éraires qu'il a tracés, que les verriers de Venise ont été déterminés à exploiter à

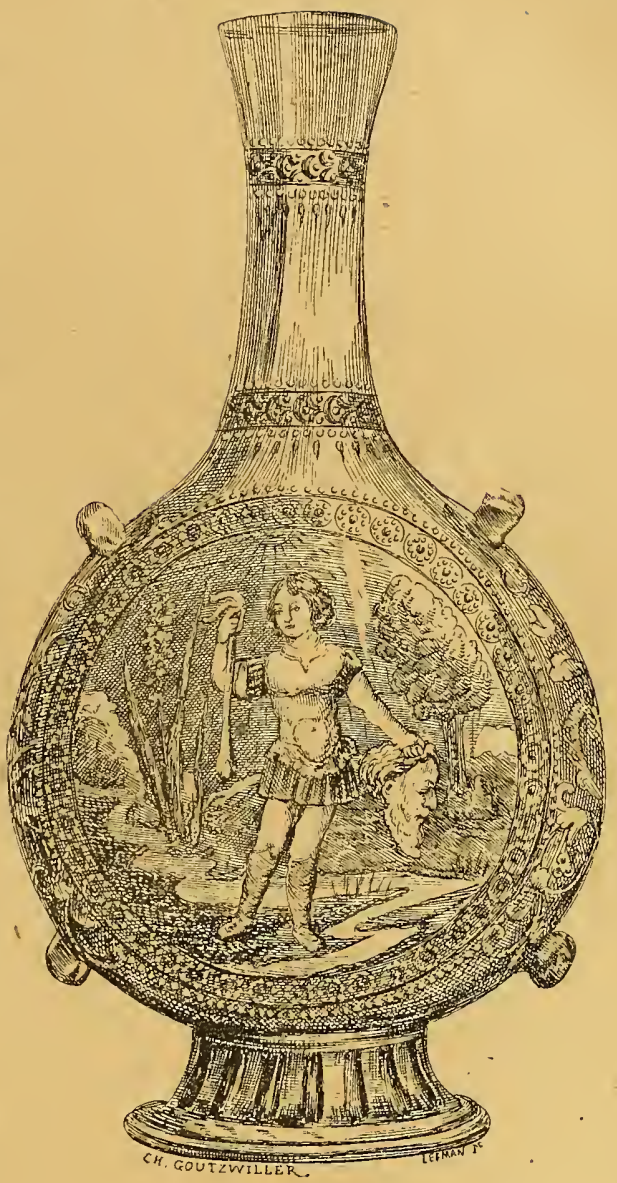
FIG, 67. 一VENISE. - XVIC SIËCLE. BOUTEILLE ÉMALLÉE ET DORÉE. (Collection Spitzer.) leur profit le goût des peuples orientaux pour la verLA VERRERIE. 
roterie, le clinquant et les pierres précieuses factices. Il ne semble pas que Marco Polo ait engagé ses compatriotes à faire concurrence aux verreries orientales pour les verres émaillés dont ces fabriques avaient le

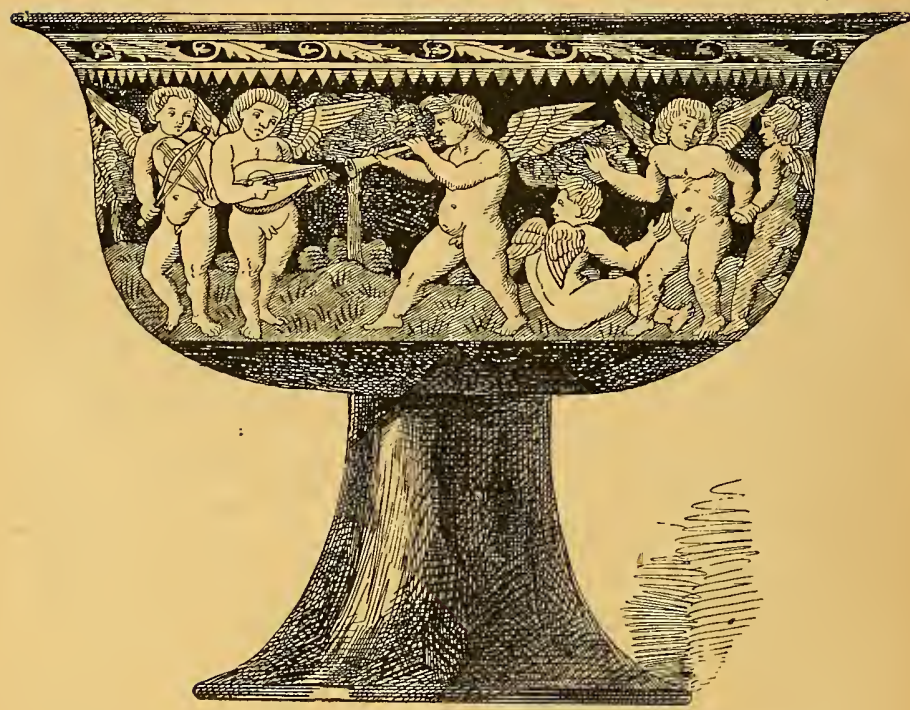

FIG. 68, - VENISE, XVI SIÈCLE.

(Décor émaillé.)

monopole, car les Vénitiens limitaient alors leur ambition à la production de menus objets de fantaisie. Deux verriers, Chistoforo Briani et Domenico Miotto, s'étant mis à l'œuvre, réussirent à retrouver les procédés de coloration du verre, connus de l'antiquité, et à imiter ainsi les pierres précieuses. Une première expédition fut dirigée vers Bassora, sur l'Euphrate. Elle réussit; 
dès lors, le chemin était ouvert et bientôt les verroteries de Venise se répandirent dans les ports de l'Asie Mineure, de la mer Noire, sur les côtes de la mer Caspienne et en Ëgypte. De ces points, les marchands et les caravanes les transportaient dans l'intérieur jusqu'en Chine, où elles servirent à faire les boutons de mandarins, dans les îles de l'océan Indien, sur les rivages de la mer Rouge, en Éthiopie et en Abysinie. Ce mouvement commercial donna une très grande extension à l'industrie nommée arte del margari-

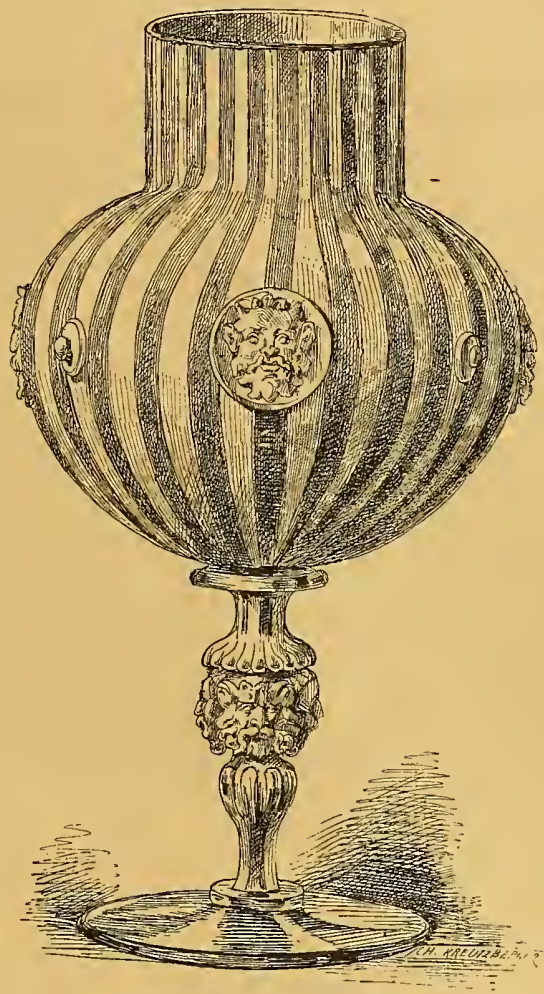

FIG. 69. - VENISE. XVI EIÈCLE.

(Musée de Cluny.)

taio, les grenats et autres pierres précieuses étant, à cette époque, connus sous le nom de margarita. Le mot venait de l'antiquité : on appelait ả Rome, margaritarii, 
les joailliers. Les margaritaires se bornaient à la verroterie, aux grains de couleur et aux menus articles de verre dont les peuples de l'Asie et de l'Afrique ont toujours aimé à parer leur corps et leurs vêtements,

La division du travail paraissait au gouvernement une nécessité absolue et, dès r 3 r 8 , les verriers de Murano furent classés en un certain nombre de catégories dont chacune avait des lois spéciales. Le i 5 mars r 383, le Sénat de Venise prit de nouvelles mesures pour affermir à Murano "le noble art " de la verrerie " $U t$ ars tam nobilis semper stet et permaneat in loco $\mathrm{Mu}$ riani ». En $\mathrm{I}_{44}$, les citoyens de Murano obtinrent le privilège d'élire un chancelier prétorien pour rendre la justice dans l'île et de nommer un nonce en résidence à Venise, à l'effet de traiter les affaires. Les privilèges commerciaux, politiques et municipaux de Murano résultaient d'actes épars; on résolut, en 1502 , de les réunir sous le nom de Statuto di Murano. Voici les principales dispositions de ce code qui est resté en vigueur sans modifications sensibles, jusqu'à la chute de la République :

Les habitants de Murano avaient le titre de citoyens originaires de Venise et étaient comme tels admis aux premiers emplois du gouvernement. - L'île possédait son "Livre d'or » pour l'inscription des familles qui en étaient originaires et de leurs descendants. - Elle avait le privilège de faire frapper monnaie à la "Zecca " de 
Venise. - Les provéditeurs de Venise n'avaient pas le droit de s'occuper des ponts, des rues et des canaux de Murano; ce soin était confié aux surveillants soprastanti des verreries. - Il était interdit à la police de Venise de débarquer à Murano. - Seuls les fils des propriétaires de verrerie ou les chefs d'atelier pouvaient établir une verrerie. - Tous ceux qui travaillaient dans les verreries pouvaient porter sur eux deux couteaux dans une gaine unique. - L.es filles des maîtres de verrerie pouvaient se marier à un noble patricien de Venise, et les descendants de cette union conservaient leurs titres de no-

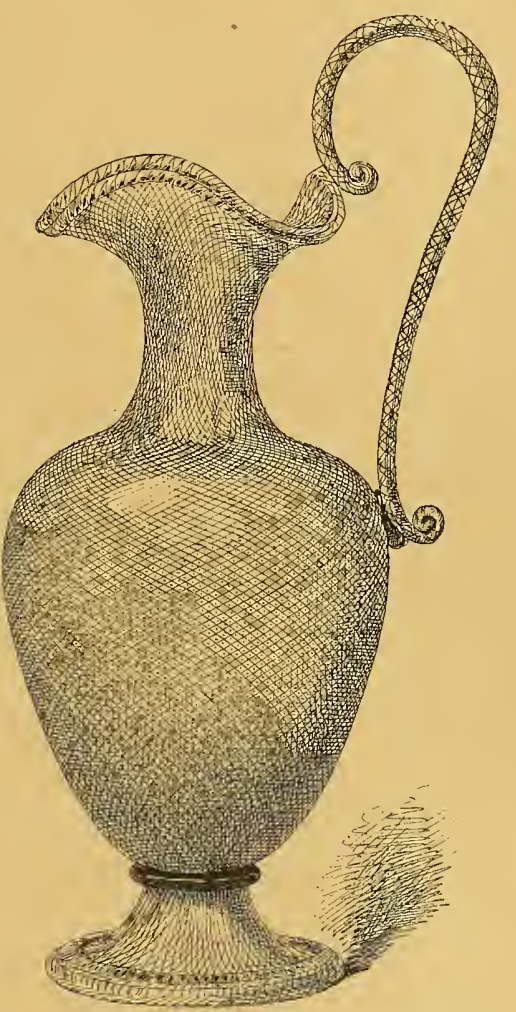

FIG. 70 , - VENISE. XVI E SIÈCLE. blesse; cette faveur datait de 1376 . En 1574, Henri III, roi de France, visita Murano et donna la noblesse aux principaux verriers. 
La surintendance des verreries était dans les attributions des chefs du Conseil des Dix. Cette disposition résultait d'un décret du 23 février I 490, et ne constituait pas, comme on pourrait le croire, une atteinte aux privilèges des verricrs de Murano. Le Conseil des Dix était chargé des intérêts de l'Etat et, en cette qualité, i] prit les mesures les plus sévères pour conserver à la République la fabrication exclusive de la verrerie. L'article 26 du décret du 27 obtobre 1547 était ainsi conçu ${ }^{1}$ :

Si un ouvrier transporte son art dans un pays étranger au détriment de la République, il lui sera envoyé l'ordre de revenir; s'il n'obéit pas, on mettra en prison les personnes qui lui appartiennent de plus près... Si, malgré l'emprisonnement de ses parents, il s'obstinait à vouloir demeurer à l'étranger, on chargera quelque émissaire de le tuer.

Déjà, au xıı e siècle, le gouvernement avait pris des mesures pour empêcher l'émigration des verriers, mais ni les lois ni les règlements ne tiennent contre l'appât du gain et le goût des aventures. Dès I 438 , on trouve à Vienne un verrier de Murano, Onofrius de Blondio, et, en 1486, un autre, Nicolas Valche. En 1459, Angeli Beroviero avait un engagement avec la seigneurie de Florence, puis il se rend à Naples. Guido di Savino est à Anvers dans les dernières années du $x^{2} I^{e}$ siècle et un verrier italien dont le nom est inconnu se trouve, en I 59o, à Chiraz, en Perse. Sous Henri II, Mutio, d'origine italienne, s'établit à Saint-Germain-en-Laye ; Ambrosio de Mongarda, puis Philippe de Gridolphi

I. Daru. Histoire de la république de Venise. 
sont dans les Flandres à la fin du xvi ${ }^{\mathrm{e}}$ siècle. Henri IV autorisa des Italiens à fabriquer à Paris, à Nevers et à Rouen. Côme II, qui gouverna de I 608 à I620, accueillit à Florence Girolamo et Alvise Lủna. En I623,

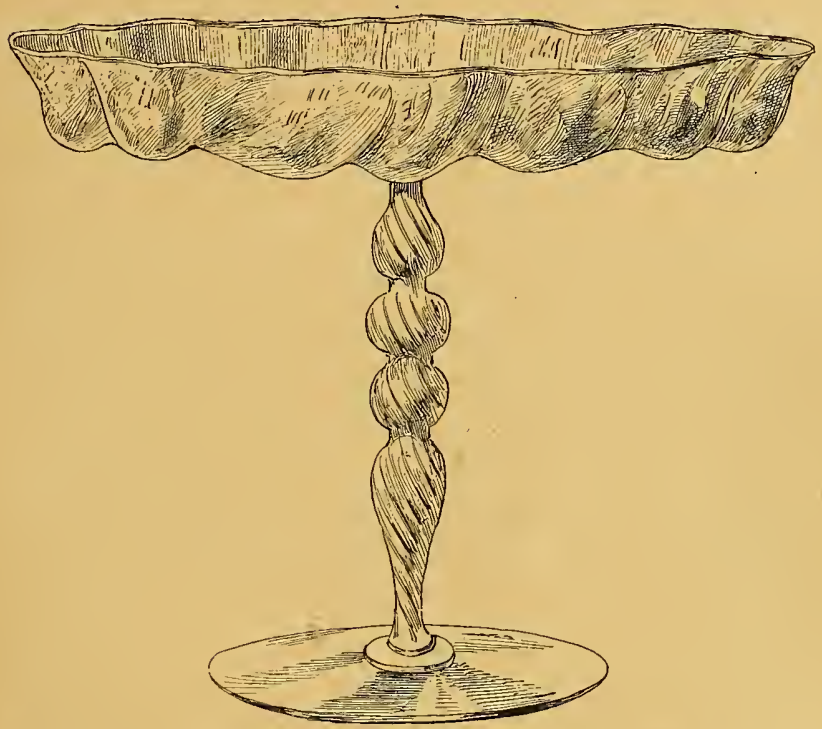

FIG. 7 I. - VENISE. XVI E SÈ GLE. - (Musée de Cluny.)

Antonio Miotti reçut le privilège de s'établir dans les Flandres; à la même époque, les verres de Venise se fabriquaient à Milan et à Vérone. En i 640 et i 643 , Ludovico Caponago, Jean Savonetti, "gentilhomme de Murano et de Venise ", Francesco Savonetti sont à Bruxelles. Louis XIV attira des Vénitiens en France. En r670, le duc de Buckingham installa en Angleterre 
une manufacture de verre avec des ouvriers italiens. En Allemagne, en $\mathrm{x} 679$, on rencontre Marinelli, Ludovico Savonetti et Joselli; les Italiens, en un mot, se rendent dans presque tous les pays d'Europe où la fabrication du verre paraît avoir quelques chances de réussir ${ }^{1}$. Cette émigration continue alarmait le gouvernement et le décret du 27 octobre 1547 ne resta pas toujours à l'état de lettre morte ; deux verriers appelés en Allemagne par l'empereur Léopold Ier, qui régna de I 658 à I 705, furent assassinés par les sbires de Venise, et on décréta de nouveau, le 22 mars 1705 et le 13 avril I762, " que les chefs du Conseil des Dix devaient prendre soin de l'art en se prévalant des moyens les plus secrets et les plus sévères, que dans leur sagesse ils croiraient nécessaires, pour veiller attentivement à ce qu'aucune personne employée dans les verreries ne sortît de l'État pour passer dans les pays étrangers ". Les peines les plus rigoureuses furent édictées contre ceux qui dévoileraient l'art du verrier, et la peine de mort prononcée de nouveau contre les verriers qui quitteraient le territoire de la République sans la permission du Conseil des Dix ou à son insu. En 1754 , Pietro de Vetor fut tué à Vienne par ordre du Grand Conseil.

Le gouvernement avait réglé même le travail intérieur des fabriques; les corporations n'étaient pas maîtresses chez elles. Une décision du Grand Conseil du I 3 avril I762 ayant déclaré à nouveau " qu'il ne devait appartenir qu'au Sénat de statuer par voie administra-

I Nous ne citons pas ici tous les verriers italiens qui s'expatrièrent; on trouvera d'autres noms dans la suite de ce livre. 
tive sur toutes les affaires relatives à l'art du verrier ", le Conseil des Cinq sages fut invité, le même jour, à faire un rapport sur l'état des diverses fabriques de verre et à proposer des modifications, s'il y avait lieu; à la suite

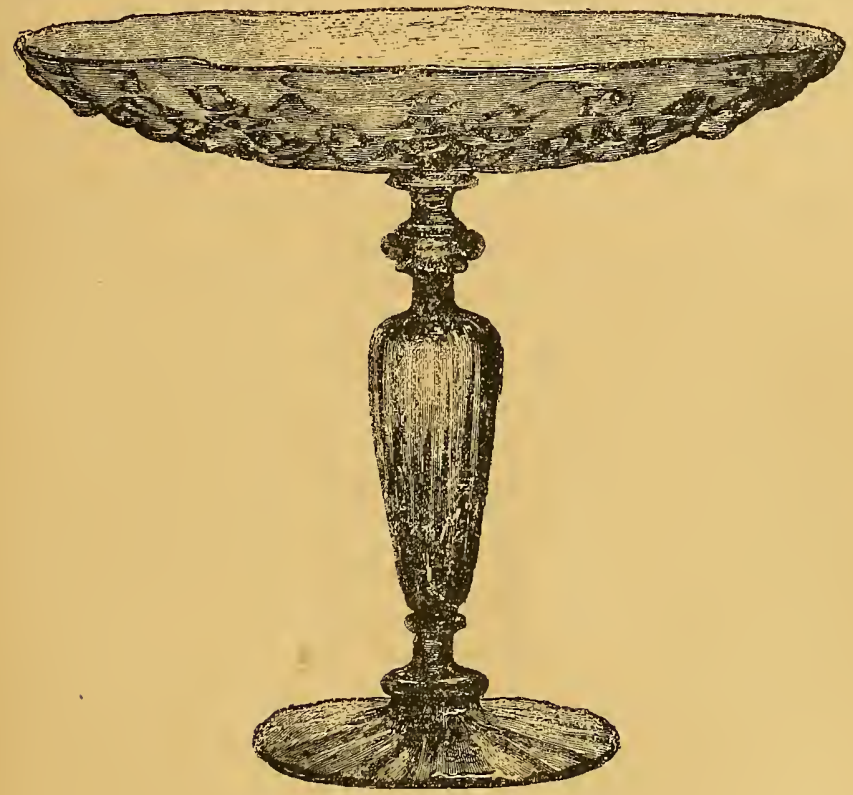

FIG. 72. - VENISE. XVI SIÈCLE.

de ce rapport, le Conseil des Censeurs, renforcé de l'un des trois inquisiteurs d'État, fut chargé de la surintendançe des verreries. Les règlements étaient inscrits sur le Capitolare o matricola, registre officiel des professions. Les verriers de Murano et ceux de Venise avaient un mariegola spécial; c'est ainsi qu'on appelait vul- 
gairement le registre. Les fabriques étaient divisées en quatre catégories :

Fabriques de verres et cristaux;

Fabriques de vitres et glaces;

Fabriques de canne ordinaire pour conteries;

Fabriques de canne pour margaritaires et perlaines et d'émaux en pains.

Nous donnons plus loin quelques détails sur ces divers genres de travaux. Il était absolument interdit de passer sans autorisation de l'une de ces catégories dans l'autre. Les travaux étaient minutieusement surveillés par les inspecteurs du bureau de répartition " del Comparto ". Le nombre des membres du bureau pour $\mathrm{Mu}$ rano était de neuf, dont cinq élus par les maîtres verriers et quatre par les ouvriers. Le bureau était sous la juridiction du Conseil des Censeurs; il déléguait l'inspection à deux inspecteurs, Soprastanti, qui avaient le droit d'entrer dans les verreries à tout moment du jour et de la nuit. Les inspecteurs vérifiaient la qualité des marchandises et avaient mission d'empêcher la sortie des produits de mauvais aloi. "On fait publiquement savoir et entendre, dit un décret du Conseil des Censeurs en date du 20 mars I 764 , que les contrefaçons, de quelque genre que ce soit, dans les verreries de Murano seront irrémissiblement suspendues moyennant le transport préalable des objets fabriqués. Les coupables fugitifs seront poursuivis criminellement et l'on ouvrira un procès d'inquisition toujours permanent, pour arriver contre eux inexorablement aux plus sévères châtiments, en réparation de tant de dommages publics et privés $n$. Si le décret prouve le souci que témoignait le 
gouvernement pour la réputation de la verrerie de Venise à l'étranger, il permet aussi de supposer que les verreries exportées n'étaient pas toujours de premier

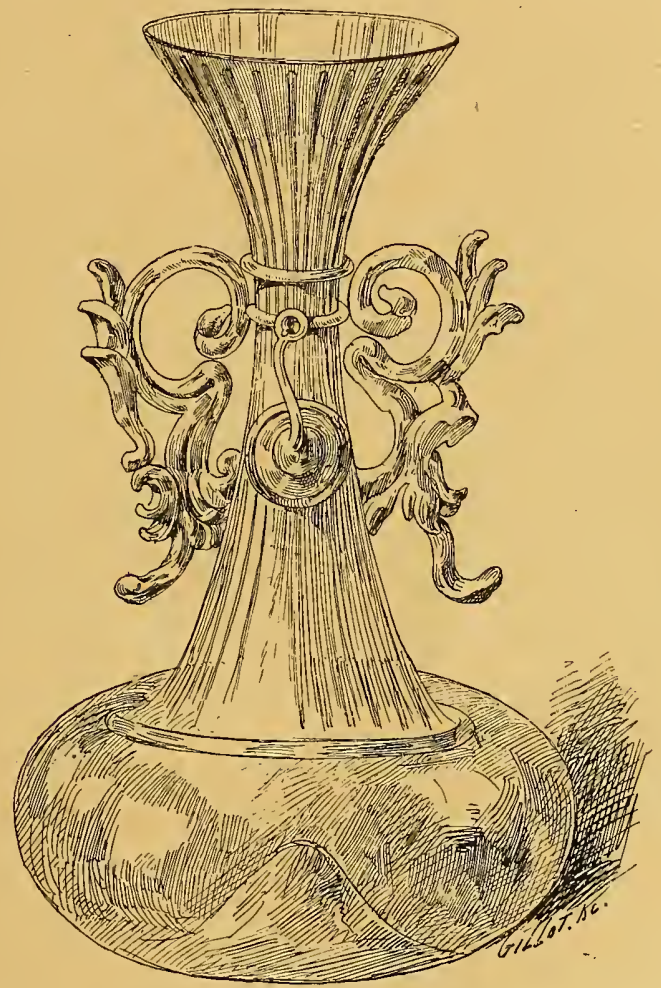

F1G. 73. - VENISE. XVI ${ }^{\mathrm{e}}$ SIÈCLE. - (Musée de Cluny.)

choix. Non seulement la qualité du travail était l'objet d'une surveillance, ce qui peut se comprendre, mais la quantité elle-mème était fixée. Au commencement de 
chaque année, le maître verrier était obligé de déclarer combien de creusets de fonte il avait l'intention de chauffer, et quelle espèce de produits il allait fabriquer dans la catégorie qui lui était assignée; de sorte qu'il devait refuser les commandes

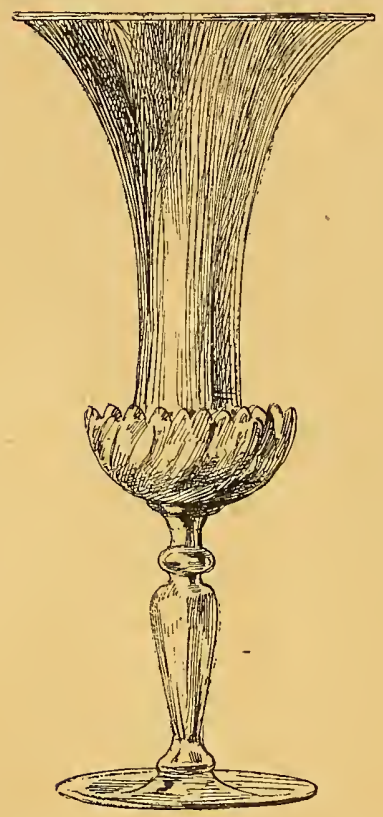

FIG. 74 - VENISE. XVI SIÈCLE. si elle lui arrivaient au delà de ses prévisions. L'année de travail comprenait quarante-quatre semaines, du $I^{\text {er }}$ octobre au 3 i juillet; les mois d'août et de septembre étaient réservés pour les réparations dont les fours de verrerie ont besoin régulièrement ; l'apprentissage, l'accès dans les corporations et les maîtrises étaient réglés sévèrement et de façon à former de bons ouvriers.

\section{I I}

Nous avons dit que Venise avait débuté dans l'exploitation de la verrerie par la fabrication des menus objets en verre, perles, grains, colliers, pierres factices, etc., rentrant dans la catégorie de l'arte del margaritaio. On ne peut préciser l'époque où, à côté de cette industrie spéciale, commença celle di vasselami o recipiendi di vetro e cristallo, c'est-à-dire des 
vaisseaux et des récipients en verre qui éleva si haut le renom de Venise dans l'art de la verrerie; cependant le xIve siècle fournit à ce sujet quelques renseignements. Un document de ce temps, conservé dans une bibliothèque de Venise, indique les moyens employés par les Grecs pour donner au verre la pureté, la couleur et la décoration par la peinture; les Vénitiens surent-ils immédiatement tirer parti de ces renseignements ? Cela est possible, car, dès ce xive siècle, il est question à Cracovie de verres de Venise et, à Vienne, en I 354 et en s 36o, un règlement détermine la place réservée sur le marché à la vente des verres vénitiens, tandis que les verres du pays pouvaient se vendre partout; il y avait donc une sorte de concurrence entre les deux fabrications et, à cette époque, les verres allemands n'étaient certes pas des conteries. Un ordre de payement de Philippe le Bon, duc de Bourgogne, dit :

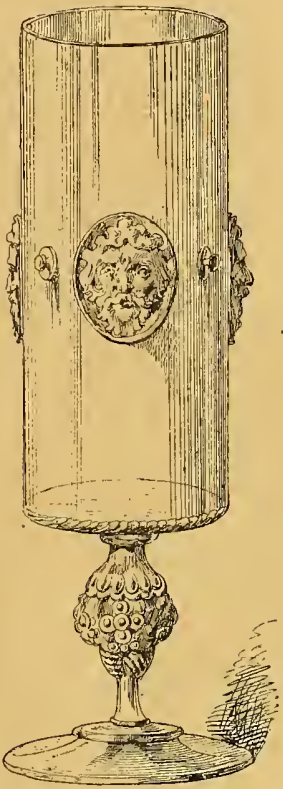

FIG. 75. - VENISE. $X V I{ }^{c}$ SI È CLE.

(Musée de Cluny.)

Voulons que vous paiez pour seze voirres et une escuelle de voirre que les galées de Venise ont avan. apportez en nostre pays de Flandres, quatre francs. Donné à Paris, le VIe jour de juillet de l'an mil CCC IIII XX et quatorze 1.

I. M. De Laborde. Les ducs de Bourgogne. M. Labarte suppose 
Nous ignorons s'il existe dans les colleclions des pièces authentiques antérieures au $\mathrm{xv}^{\mathrm{e}}$ siècle, mais dès cette époque, la fabrication des verres soufflés était en plein développement. Le Livre d'or de Murano mentionne, en I458, Angelo Beroviero qui, avec l'aide d'un chimiste, Paolo Godi de Pergola, fabriquait des verres de couleur; le célèbre verrier fut trahi par un de ses ou. vriers, Giorgio dit Ballerino, qui déroba à son maître son livre de formules, le copia, le remit en place et s'établit à son tour après avoir vendu les secrets à un fabricant étranger ${ }^{1}$.

L'architecte Antonio Averlino écrivit, vers le milieu du $\mathrm{xv}^{\mathrm{e}}$ siècle, un traité d'architecture, et lui donna la forme d'un dialogue; nous reproduisons la conversation tenue entre deux artistes à propos de la décoration d'un palais :

- Mais, dis-moi, en quoi se fera ce pavé?

- Pour qu'il soit beau, nous le ferons en verre coloré dans le genre des mosaïques et, à côté, nous placerons d'autres verres qui ressembleront au jaspe, et d'autres encore de diverses manières; c'est ainsi que nous ferons le dessus du siège des verres qui te paraîtront beaux : ils seront plats, et, à l'intérieur, on verra des figures en relief, des animaux et diverses autres choses dignes d'admiration.

- Cela me plaît; mais qui fera ces verres et ces mosaïques?

- Qui les fera? Un de mes chers amis qui s'appelle maestro Angelo de Murano.

que ces verres étaient des produits orientaux apportés dans les Flandres par des vaisseaux vénitiens; c'est une simple hypothèse.

I. A: Sauzay. La verrerie depuis les temps les plus reculés jusqu'à nos jours. 
- Celui qui fait ces beaux objets en verre cristallin?

- Oui.

- Mais les autres verres dont tu parles, qui paraîtront comme s'ils avaient des figures sculptées à l'intérieur et ceux ressemblant au jaspe?

- Ceux-ci, je les ferai, moi.

- Tu sais donc les faire?

- Oui.

- Oh! dis-moi de quelle manière on fait ceux qui ont des figures à l'intérieur qui paraissent en relief, ainsi que les autres. Je tiens beaucoup à le savoir.

- Je ne veux pas l'enseigner maintenant, mais plus tard ${ }^{4}$.

De ce genre de verrerie, d'une extrême rareté, il existe dans la collection de $M$. Piot une pièce : c'est une tablette de verre blanc coulé sur un bas-relief représen-

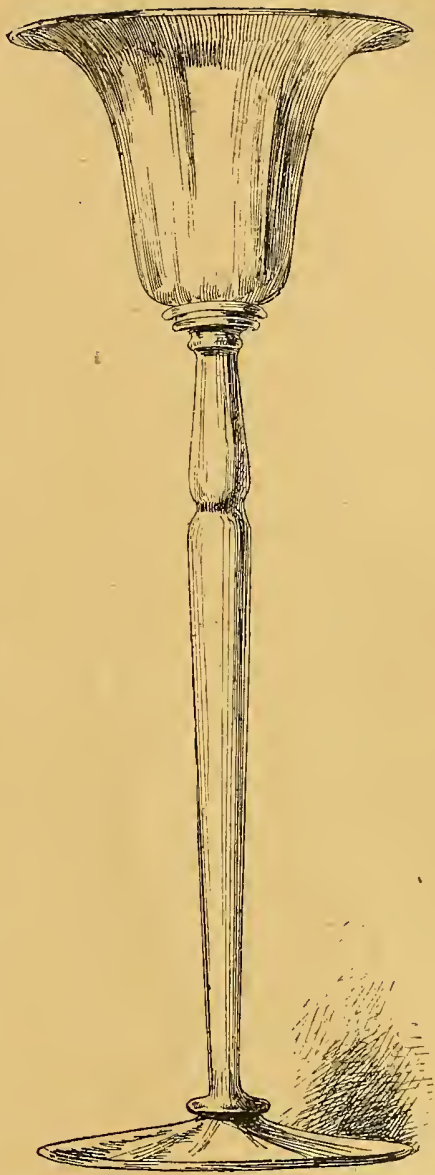
tant deux génies ailés fig. ᄀ O. - VENISE. XVI é Sİ̀CxE. soutenant les armoiries (Musée de Cluny.) de la famille Oddi de Pérouse; les génies sont doI. E. Piot. Le Cabinet de l'amateur. 
rés à l'intérieur; l'écusson est argenté et peint en bleu.

L'Italie a produit aussi des décorations sur verre qu'on ne peut passer sous silence, quoiqu'elles ne rentrent pas dans les œuvres de la verrerie proprement dite; ce sont des dessins tracés à la pointe sèche sur des feuilles d'or collées ensuite contre une surface de vérre, et des peintures à l'huile, à l'eau ou à l'œuf exécutées sur le dessous d'une coupe et garanties quelquefois par un vernis appliqué sur le revers. Les dessins par enlevage étaient connus des premiers chrétiens, qui plus soucieux de leur durée les engageaient entre deux feuilles de verre. Les compositions des peintures sur verre sont empruntées à la mythologie et aux Écritures saintes; de semblables travaux ont été exécutés en Allemagne; ils tirent leur prix de la rareté, car le procédé, fort discutable du reste, n'ajoute rien à leur valeur comme œuvre d'art ${ }^{1}$.

Les ducs de Bourgogne possédaient, en 1470, "ung pot de voirre de Venise, jaune, garni d'or hault et bas et de vingt perles pendans autour du col, à devise de fusilz ». En 1480, Maximilien d'Autriche donne en garantie d'un emprunt contracté à Bruges « ung pot de voirre de Venise, jaune, garny d'or „. Un historien de Venise, Marco Antonio Coccei Sabellico, né à Vicovaro en 1436 , bibliothécaire de la cathédrale de

I. On a donné récemment à ce genre le nom de verres églomisés ou agglomisés; c'est une expression de fantaisie que les collectionneurs ont adoptée sans motifs connus. Peut-être vient-elle de Glomy, encadreur de dessins sous verre, connu au xviri siècle?

2. M. De Laborde. Les ducs de Bourgogne. 
Saint-Marc en I 484 , mort en I 506, s'exprime ainsi sur l'île de Murano :

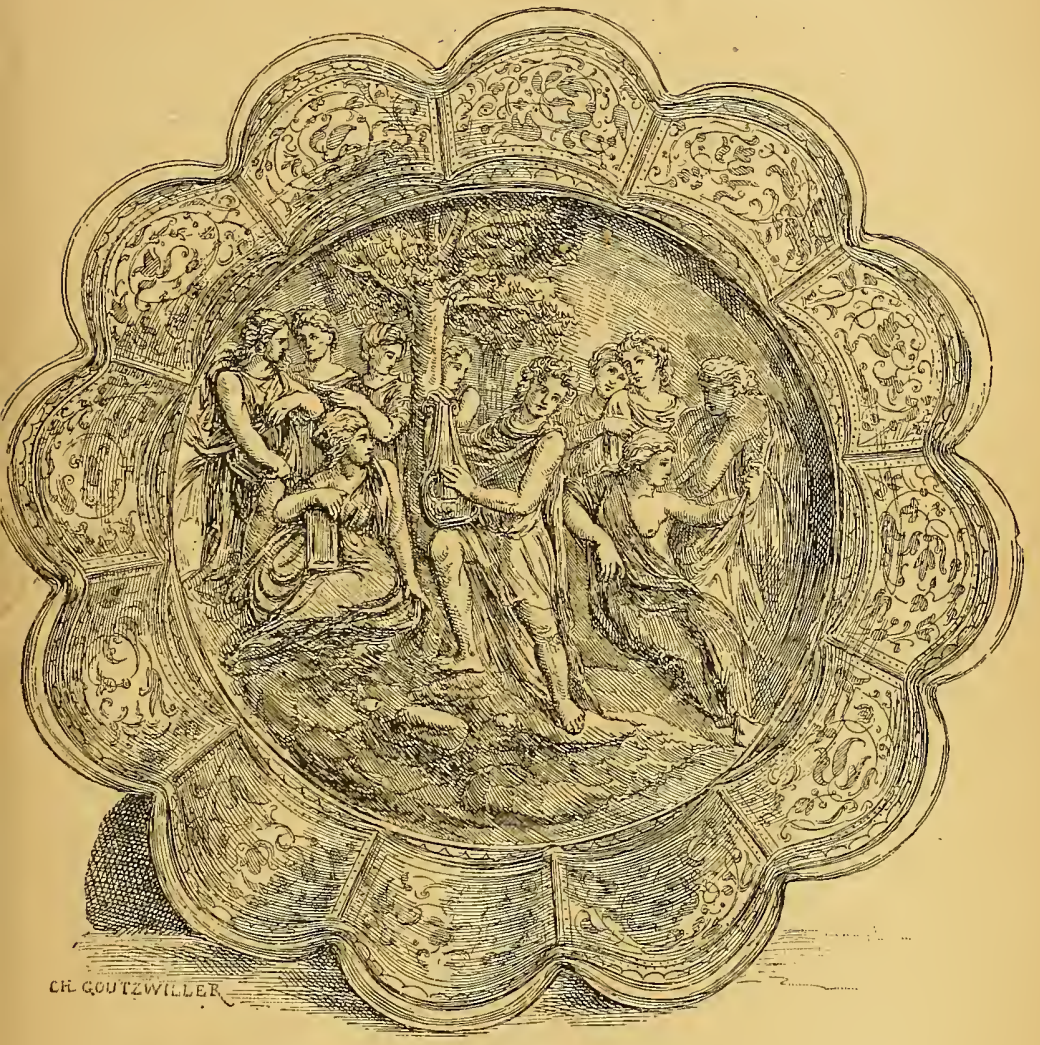

FIG. 77. 一 VENISE. XVI ${ }^{\text {e }}$ IÈ CLE.

COUPE PEINTE, BORDS DORÉS. - (Collection Spitzer.)

Elle est surtout célèbre par ses fabriques de verres... le génie humain entreprit de donner à la matière mille cou- 
leurs variées et d'innombrables formes: de là, calices, fioles, canthares, lebetes, cadi, candélabres, animaux de tous genres; cornua, sequienta, monilia; de là, toutes les élégances humaines; de là, tout ce qui peut charmer les yeux des mortels et tout ce que la vie serait à peine en droit d'espérer. Il n'est pas d'espèce de pierre précieuse que l'industrie du verre n'ait imitée. Suave combat de la nature et de l'homme!...

\section{Voici encore un récit du temps :}

Le 14 janvier (1484), j'ai été à Murano avec les marchands et je suis revenu à Venise en barque, avec les verres qu'on y avait achetés. Vraiment on ne voit nulle part au monde des verreries aussi précieuses que celles qui se fabriquent là chaque jour, et il n'existe pas ailleurs d'artistes capables de faire, avec une matière aussi fragile, des vases d'une élégance telle qu'ils l'emportent sur les vases d'or et d'argent et même sur ceux qui sont ornés de pierres précieuses. S'ils étaient aussi solides que ceux de métal, ils auraient une valeur bien plus grande que celle de l'or; mais leur fragilité, malgré leurs formes élégantes et leur aspect charmant, les rend vils et sans valeur. C'est ce que fit bien voir l'empereur Frédéric III, lors de son voyage à Venise, il y a quelques années (1468). Le doge et le Sénat lui ayant porté, pour son plaisir, certain vase de verre admirable, l'empereur, après l'avoir considéré un moment et avoir loué l'excellence de l'artiste qui l'avait exécuté, laissa tomber de ses mains, comme par mégarde, mais il le faisait à dessein, le vase, qui se brisa en mille morceaux sur le pavé : "Hélas! qu'est-il arrivé? s'écria l'empereur désespéré, en ramassant les inutiles débris de ce chef-d'œuvre. Voilà, dit-il en les leur montrant, en quoi les vases d'or et d'argent surpassent les vases de verre; les morceaux même sont bons. "Les Vénitiens comprirent bien la plaisanterie de l'empereur et ce qu'il voulait : ils ne lui présentèrent plus à boire, par la suite, que 
dans des vases d'or, qu'il prit et qu'il ne laissa jamais tomber à terre 1 .

Le moine d'Ulm auquel nous empruntons cette

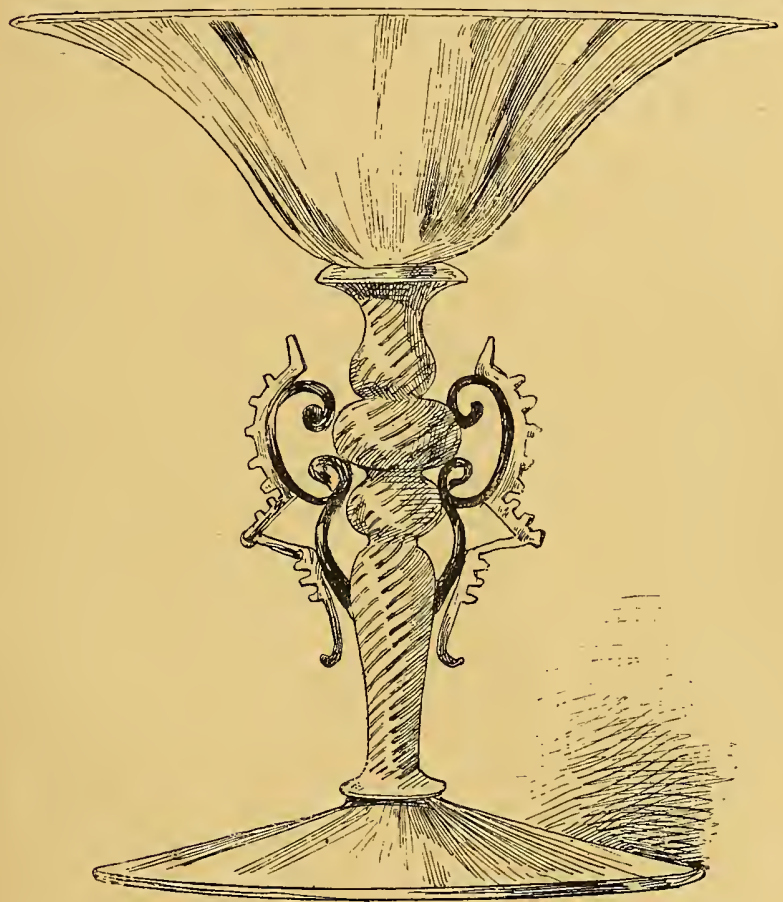

FIG. 78. - VENISE. XVI SIÈGLE. - (Musée de Cluny.)

anecdote aurait pu ajouter que la plaisanterie était d'assez mauvais goût; si nous la reproduisons, c'est

1. Fr. F. Fabro. Evagatorium in Terra sancta, Arabiae et Egypti peregrinationem. 
pour montrer le mépris que certains souverains avaient pour la verrerie et expliquer ainsi sa rareté dans les trésors et les inventaires du temps.

Vers le commencement du xvie siècle, les Vénitiens avaient déjà le verre gravé au diamant. Le Grand Conseil accorda, en I 5o3, à Andrea et à Domenico de Anzolo del Gallo le privilège pour vingt-cinq ans de la fabrication des miroirs. La requête était ainsi rédigée : "Que connaissant le secret de faire de bons et parfaits miroirs de verre cristallin, chose précieuse et singulière et inconnue du monde entier, si l'on excepte une verrerie d'Allemagne qui, associée à une maison flamande, exerçait le monopole de cette fabrication et écoulait ses produits du levant au couchant à des prix excessifs, et désirant mettre Murano à même d'établir une coricurrence qui ne pouvait qu'être profitable à la République, ils demandaient qu'on voulût bien leur donner un privilège exclusif dans tout le territoire de la République pendant vingt-cinq ans ${ }^{1}$. En 1564 , les miroitiers, specchiai, avaient pris assez d'importance pour former une corporation réglée, selon l'usage, par un code spécial.

La réglementation excessive imposée aux fabricants n'empêchait pas les perfectionnements; en 1528 , Andrea Vidaore obtint du comité de surveillance des arts et métiers une matricule pour le travail des perles soufflées à la lampe d'émailleur; l'industrie des perlaires prit alors le nom de supialume, souffle-lumière. Le I I février 1604 et le 13 mai 1605 , le Conseil des Dix rendit en faveur de Gérolamo Magagnati, qui n'était pas im-

I. Lazari. Notizia delle opere d'arte d'antichità. 
matriculé à Murano, des décrets l'autorisant à faire des verres en topaze et en jacinthe et à exploiter son invention de verre à vitres; Magagnati fabriquait de grands carreaux de verres et des glaces sans tain que les personnes riches mirent à leurs fenêtres à la place des rui, rouleaux, disques épais employés précédemment. Murano se livra à cette industrie avec succès et fournit des vitres de couleur aux églises et aux mosquées; on croit que les fenêtres de verre bleu et or du tombeaú du shah Abbas II, mort en I666, étaient de cette provenance. En I 7 r 7 , Vincenza Miotti, Danielo et ses fils reçurent le privilège de fabriquer la calcédoine, l'émail; les verres pour la mosaïque; il semble que ce fut ce Miotti qui inventa l'aventurine ou qui en reprit la fabrication, car quelques auteurs en attribuent l'invention à Christophe Briani, vers 1530 . $\mathrm{Au}$ commencement du $\mathrm{xvIII}^{\mathrm{e}}$ siècle, les verreries de Venise étaient peu prospères, car l'Allemagne, les Flandres leur faisaient concurrence sur les marchés étrangers, à ce point

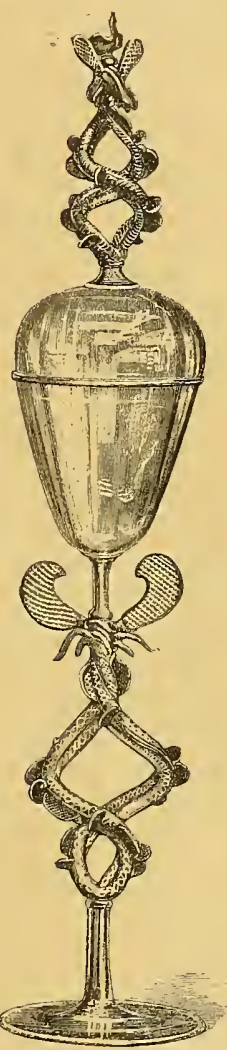

FIG. 79. - VENISE. $X I^{e}$ SIÈCIE. qu'en 1736 Jacobus Busenello obtint pour dix ans le privilège de fabriquer à Murano des verres de Bohême. 
La fabrication des bottiglie d'Inghilterra, bouteilles à la façon anglaise, fut aussi autorisée en I79o, quoique ce genre ne prête guère à la fantaisie. Ce fut là sans doute une des dernières inscriptions sur la mariegola. En I797, l'armée française occupa Venise; l'année suivante, le Directoire ordonna au général Berthier d'envoyer en France des ouvriers verriers; le général échoua dans la tentative et il écrivit :

C'est avec peine que je dois vous apprendre que je n'ai pu réussir, comme vous m'en aviez chargé par votre lettre du 5 nivôse, à enlever à Venise la fabrique des marguerites. Je compte vous envoyer, par le prochain courrier, le rapport des personnes que j'avais chargées de cette affaire ${ }^{1}$.

A cette époque, il y avait cependant encore, à $\mathrm{Mu}-$ rano, près de cinquante verreries, dont quatorze pour marguerites, perles, etc., quatre pour glaces et miroirs, trois pour verres de fantaisie, vingt et une pour verres à vitres et quelques-unes pour verres ordinaires. En I806, toutes les corporations furent abolies et trente ans après le nombre des verreries était réduit à une douzaine.

Aux noms des verriers distingués de Venise et de Murano que nous avons cités, on peut ajouter Francesco Ballarino, Muro, Motta, miroitier, Seguso, Vistosi, Nicolas de l'Aigle, connu pour les formes de fantaisie, Movelli, G. Briati, Barbaria; ces deux derniers furent autorisés au $\mathrm{xvH}^{\mathrm{e}}$ siècle et par exception à établir leurs fours à Venise même; G. Briati était fort habile. Ces noms, du reste, ont peu d'inté-

ı. D'Artaud. Vie du pape Pie VII. 
rêt, car les ouvrages de verrerie ne sont pas signés et il est fort rare que par son caractère spécial une pièce puisse être attribuée avec certitude au fabricant qui l'a produite, à l'artiste qui l'a décorée ou à celui qui a dessiné le modèle. Nous avons tenté de rechercher la part que les peintres $\mathrm{du} \mathrm{xvI}^{\mathrm{e}}$ siècle avaient pu prendre à la verrerie vénitienne; nos investigations ont eu un

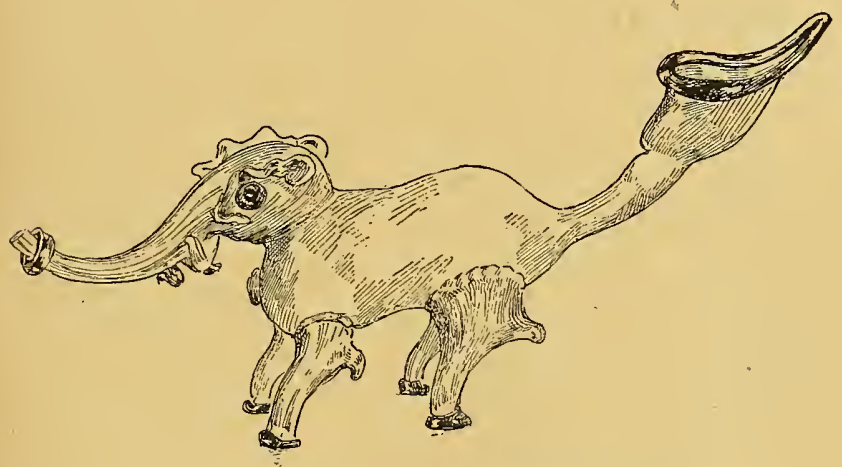

FIG. 80. - venise. - (Musée de Cluny.)

résultat à peu près négatif. Jean d'Udine, l'élève de Raphaël, aurait cependant fourni le modèle de certains vases de Murano que Pierre l'Arétin a offerts au marquis de Mantoue ${ }^{t}$.

\section{V}

La verrerie vénitienne peut se diviser en cinq grandes catégories principales:

La verroterie;

I. E. Müntz. Le tour du monde. - A travers la Toscane. 
La verrerie de fantaisie et de service;

Les glaces, miroirs et lustres;

Les verres à vitres;

Les émaux pour la mosaïque et la bijouterie.

La verroterie comprend les perles pour la broderie, margaritines, également appelées charlottes dans le commerce, et les perles en émail ou en verre pour les chapelets, boucles d'oreilles, têtes d'épingles, colliers, etc. La fabrication de tous ces menus objets est désignée

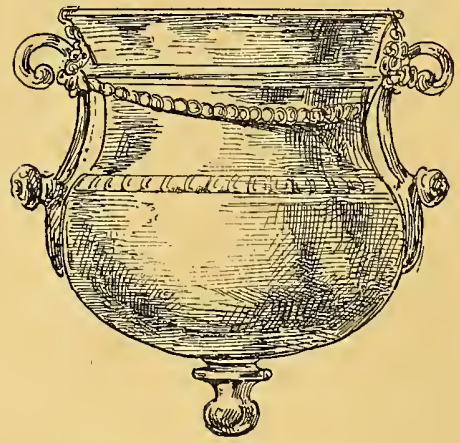

FIG. 8 I. - VENISE.

IAMPE EN VERRE. sous le nom général de fabbriche di conterie; ils sont en verre de couleur transparent ou opaque ou en verre filigrané. Cette fabrication s'opérait sous le régime de division du travail en trois ateliers différents : l'atelier de composition et de fonte, celui du margaritaio, où la matière était réduite en perles, et celui des perlai patenotriers, où les perles étaient façonnées à la lampe d'émailleur.

Si les conterie ont fait la fortune des verriers vénitiens, les pièces d'apparat, de luxe, de fantaisie et les verres de services de table ont fait leur gloire. Les Vénitiens ont, à fort peu d'exceptions près, mis en œuvre toutes les ressources que leur offrait la matière; ils ont produit des verres incolores, unis ou craquelés, des 
verres teints dans la masse, des verres sablés d'or, des verres filigranés, gravés, dorés, émaillés. Selon le goût du décorateur, les verres en verre blanc ou teint étaient homogènes ou avec des anses et des pieds d'autres couleurs, des godrons et des masques dorés; on usait, en un mot, de toutes les combinaisons pour embellir l'objet.
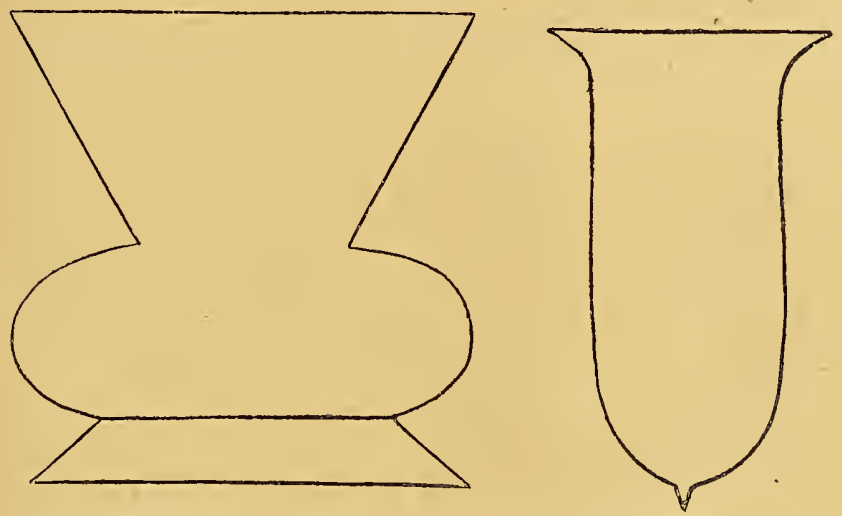

FIG. 82. - MODẼLES DE LAMPES COMMANDÉES A VENISE

PAR MOHAMMED-PACHA EN I $569^{\circ}$

Sous ces aspects multiples, les verriers ont constitué un genre, le verre de Venise, qui est resté le type de la finesse et de l'élégance; il n'est pas possible de décrire toutes les formes qu'ils ont données à leurs produits, coupes, calices, buires, hanaps, aiguières, verres cylindriques, coniques et toutes les variétés de leurs décors. Il ne faut pas perdre de vue que Venise travaillait surtout en vue de l'exportation et devait, par conséquent, 
approprier les formes à l'usage des pays de destination; si les verres à boire longs, effilés étaient pour les vins mousseux, les coupes largement ouvertes servaient aux vins dont le bouquet devait être apprécié, et les hauts verres cylindriques chargés de bagues ou de boutons en relief étaient destinés aux pays où la bière était en honneur.

Voici un exemple de l'importance de l'exportation vénitienne: dans une dépêche datée de Péra, le I I juin I 569, Marc-Antoine Barbaro, ambassadeur de Venise à Constantinople, annonce que Mohammed pacha, le grand vizir, l'a prié de faire exécuter à Murano un fanal et neuf cents lampes de mosquée; l'ambassadeur joint à sa dépêche le dessin de ces lampes; nous en reproduisons les profils réduits. M. Yriarte, à qui l'on doit cette curieuse découverte, a pris un calque sur la dépêche même de l'ambassadeur conservée aux archives des Frari ${ }^{1}$.

La fantaisie tenait une place importante dans la fabrication; René François, chapelain de Louis XIII, l'a plaisamment décrite :

Mourano de Venice a beau temps d'amuser ainsi la soif et remplissant l'Europe de mille et mille galanteries de verre et de chrystal, fait boire les gens en dépit qu'on en ait; on boit un navire de vin, une gondole; on avale une pyramide d'hypocras, un clocher, un tonneau, un oiseau, une baleine, un lion, toute sorte de bestes potables et non potables. Le vin se sent tout étonné, prenant tant de figures, voire tant de couleurs, car, dans les verres jaunes, le vin clairet s'y fait

I. Ch. Yriarte. La vie d'un patricien de Venise au $\mathrm{xvI}^{\mathrm{e}}$ siècle. Paris. Rothschild. 
tout or et le blanc se teint d'écarlate dans un verre rouge. Ne fait-il pas beau voir avaler un grand trait d'écarlate, d'or, de lait ou d'azur ${ }^{1}$.

Mais c'étaient là des exceptions et même dans la vie somptueuse des patriciens, le service était réglé d'une façon plus rationnelle. On remarque, par exemple, dans le tableau des noces de Cana, où Véronèse semble avoir réuni tout le luxe de table d'une grande fète, que les convives ont de larges coupes sur pieds élevés, sans décor aucun, d'une forme simple et pratique; sur la table, on ne voit ni flacon ni aiguière; le vin est conservé à la façon antique dans de grands vases que les servants apportent dans la salle pour le verser dans des récipients plus faciles à manier et aller remplir à la ronde les coupes des convives. Les verres à couvercles, les verres ouverts munis de ces anses en forme d'oreilles, d'ailes, d'élytres, de dragons, d'hippocampe, de papillons, contournées, aplaties, pincées; les verres à bords lobés, ondés, renversés, étaient évidemment des pièces destinées aux crédences et aux desserts, trionfi. A plus forte raison en était-il ainsi lorsque la pièce, au lieu d'être en verre transparent, était filigranée, c'est-à-dire que dans la pâte de fond le verrier avait incorporé des fils torses, canne ritorte, soit de couleur blanche, opaque, latticinio, soit de colorations diverses; ce réseau, dont les combinaisons sont multiples, contrariant la transparence de la matière, était un ornement agréable à la vue, mais peu fait pour laisser apprécier la couleur du

I. René François. Essay des merveilles de la nature et des plus nobles artifices. 
liquide. Par un arrangement spécial qui consistait à appliquer lune sur l'autre deux feuilles de verre filigra. nées en sens inverse, les verriers formaient un réseau, reticella, qui, entre chacune de ses mailles, laissait une petite bulle d'air retenue entre les feuilles superposées. Le filigrane était aussi, mais plus rarement, posé en relief sur l'extérieur du verre.

Les pièces décorées de peintures en émail étaient par excellence des objets d'art et de luxe; ce sont même les seules avec les verres gravés qui se prêtaient à une composition d'artiste. Venise nous a laissé dans ce genre des portraits, des scènes d'amour, des sujets votifs, des écussons et des moţifs d'ornement. Le champ sur lequel une composition peut être fixée est toujours très limité en verrerie; aussi les Vénitiens ont-ils généralement adopté, pour les verres émaillés, des formes simples: plateaux, gourdes, gobelets, coupes; pour augmenter la valeur de la décoration, les verres étaient parfois ornés de boutons, de perles factices en relief et de parties dorées.

Un autré genre excite la curiosité plutôt qu'il n'attire l'attention; ce sont les vasi fioriti ou millefiori, qu'on a appelés fort improprement les verres mosaïques au lieu de les nommer verres millefiores, par exemple. La décoration consiste en un faisceau de baguettes de diverses couleurs coupées par sections et vues par la tranche; la combinaison des baguettes donne lieu à des dessins variés et peut s'appliquer à des pièces soufflées ou moulées. Dans les temps modernes, on a abusé de ce genre pour les boules, presse-papiers et autres objets d'un goût médiocre. 
Nous n'avons pas à insister sur les verres à vitres blancs ou de couleur, ni sur la fabrication des émaux pour la mosaïque et la bijouterie, car le verre à vitre ne laisse rien à l'artiste et les émaux de mosaïque et de bijouterie ne prennent leur valeur qu'entre les mains des mosaïstes et des bijoutiers; mais il est deux sortes de produits de Venise qui méritent tout particulièrement l'attention : les lustres et les glaces.

La composition d'un lustre est une ouvre d'art. Le lustre doit, non seulement se prêter le mieux possible à sa fonction principale, l'éclairage de l'appartement, mais être aussi un ornement de jour, et comme il est suspendu au plafond, il ne doit point contrarier la vue des panneaux ni solliciter le regard au détriment des autres objets d'art. Le Iustre de verre de Venise nous paraît réunir ces conditions infiniment mieux que tous les autres genres qu'on a créés depuis; il est homogène, l'emploi du métal étant réservé aux armatures rigoureusement nécessaires que le verrier a eu d'ailleurs le soin de dissimuler dans des manchons de verre; il est svelte et léger. L'usage exclusif de la cire facilitait, du reste, ces conditions; toutes les parties, larges bobèches, branches tordues, feuilles renversées et striées, fleurs découpées, reçoivent la lumière avec une égale intensité. Le soir, le lustre de Venise allumé est un rayonnement harmonieux sans reflets discordants; le jour, stalactite ciselée, il égaye l'appartement comme une note claire et joyeuse.

Les glaces de Venise nous paraissent également constituer le type par excellence de la glace d'appartement; en adoptant la bordure en verre, les Vénitiens 
ont compris que dans une glace comme dans une tapisserie, :une plaque céramique, un panneau de mo-

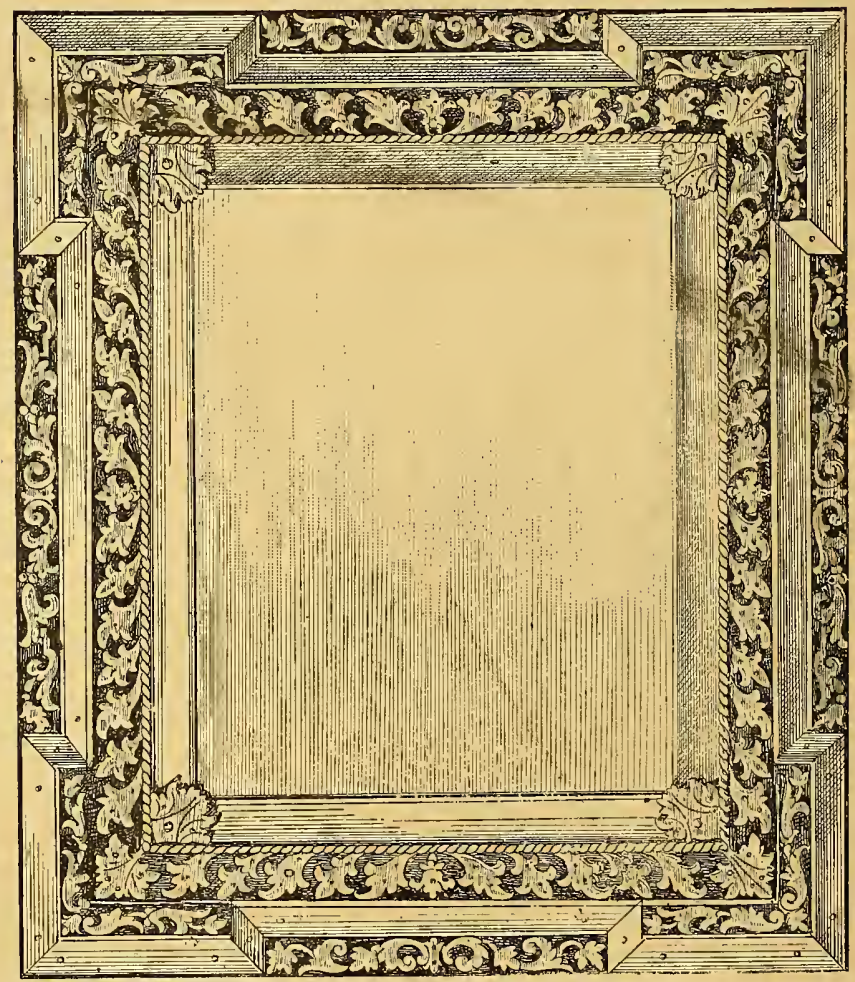

FIG. 83. - VENISE. XVI SIÈcLE.

GLACE AVEC GADRE EN VERRE. - (Musée de Cluny.)

saïque, l'encadrement doit être composé des mêmes éléments décoratifs que le fond qu'il entoure; ils ont 
poussé l'intention jusqu'au scrupule en arrètant la glace par une bande en biseau qui sert de transition

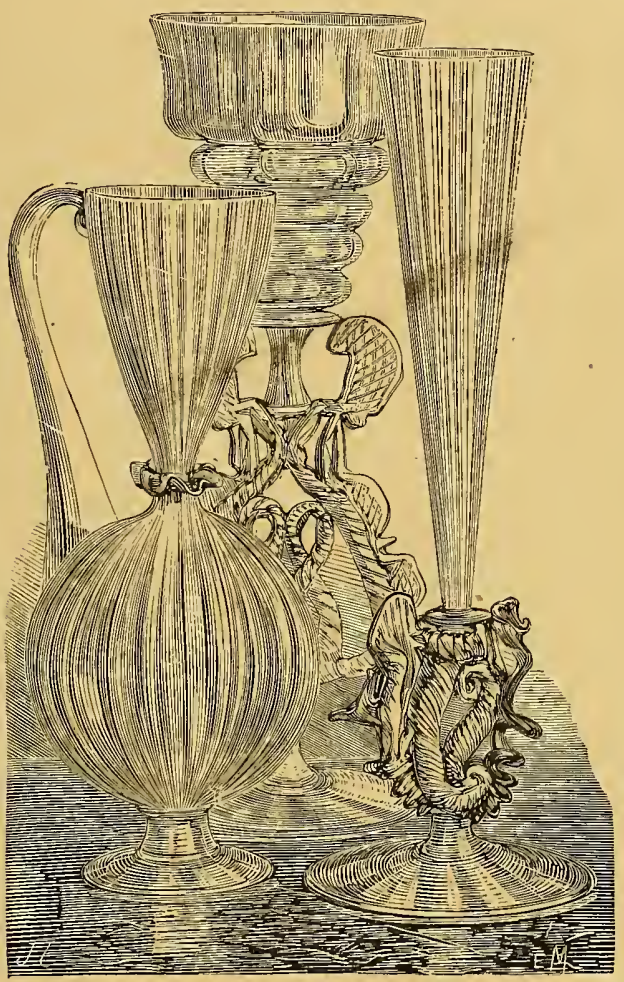

FIG. 8 4. - VENISE, XVI

entre la surface plane et le cadre découpé nécessaire pour relever l'uniformité du fond.

$\mathrm{Au}$ point de vue de l'invention et en poussant les choses à l'extrême, on' pourrait prouver que les Véni- 
tiens n'ont rien innové en verrerie : la verroterie était connue des Égyptiens; le filigrane était employé par les verriers romains; la peinture en émail était largement pratiquée en Orient; les glaces se fabriquaient en Allemagne; mais peu importe, car, si la priorité a de l'intérêt pour l'archéologie, elle en a infiniment moins pour l'art. Et du reste, les Vénitiens non seulement ont créé le lustre en verre et donné à la glace son véritable caractère, mais par les modifications qu'ils ont apportées aux formes usuelles, par les combinaisons du décor, ils ont également inventé de nouveaux types de verres de service et de luxe; c'est bien ainsi que leurs contemporains l'ont compris, car partout en Occident les modèles de Venise ont été adoptés et imités. Les verriers vénitiens étaient des artistes; il est vrai qu'ils se souciaient assez peu de la qualité de la matière; souvent le verre manque de blancheur et de finesse, et les formes n'ont pas une régularité mathématique, mais la pièce reste toujours dans ses proportions et porte le cachet d'un tour de main original. L'élégance, la grâce et la légèreté ne font jamais défaut, et si la fantaisie est quelquefois poussée un peu loin, c'est avec intention et non par manque de goût. Les Vénitiens ont compris les qualités expressives du verre, et c'est là la véritable raison de leur supériorité dans cet art difficile.

Il est certain que Venise avait le monopole presque exclusif de la fabrication du verre en Italie; cependant, à l'époque même de sa plus grande prospérité, il exis. tait des verreries à Florence, où l'on fabriquait " pour la Cour et pour le peuple», à Rome, à Milan, dans le duché de Montferrat, à Mantoue. On prétend que les 
lunettes ont été inventées à Florence, en s'appuyant sur l'inscription suivante tracée sur une pierre tombale ${ }^{1}$ :

\author{
QUI GIACE \\ SALVINO D'ARMATO DEGLI ARMATI \\ DI FIRENZE \\ INVENTOR DEGLI OCCHIALI \\ DIOGLI PERDONIE A PECCATA \\ ANNO MCCCXVII ${ }^{2}$.
}

Cependant déjà vers la seconde moitié du XIre siècle, on remarque des besicles suspendues à des attaches, dans les personnages figurés en sculpture. Un manuscrit italien de 1299 parle de "vetri appelati occhiali " et en 1305 , le frère Jordan de Rivalto rappelle dans un sermon que les lunettes sont en usage depuis vingt ans à peine. L'emploi des lunettes se répandit promptement et dans l'inventaire dressé en 1372 de la "Royne Jehanne d'Évreux ", sont inscrits ces mots : " un véricle encerné en manière de lunettes ».

I. Léopold de Migliore. Florence illustrée.

2. Ci-gît Salvino d'Armato d'Armati, de Florence, inventeur des lunettes. Dieu lùi pardonne ses péchés. An 13 I 7 . 


\title{
LA FRANCE
}

\author{
L'USAGE ET LE GLOSSAIRE DE LA VERRERIE \\ JUSQU'AU XVI SIÈCLE.
}

\section{I}

Avant d'aborder l'étude de la verrerie en France pendant le Moyen âge et la Renaissance, il est nécessaire de se rendre compte des expressions employées dans les documents et par les écrivains du temps. Nous avons essayé d'établir dans ce but une sorte de glossaire de la verrerie; toutefois nous reconnaissons sans peine que la nomenclature que nous tentons est incomplète et loin de résoudre tous les points obscurs.

Le mot cristal vient du grec $\mathrm{X}$ púos, froid, qui a fait

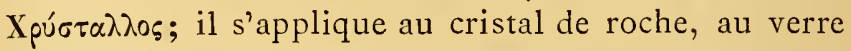
de qualité supérieure et enfin à une composition de verre à base de plomb connue de l'antiquité, puis complètement abandonnée jusqu'au xvir ${ }^{\mathrm{e}}$ siècle. Appliqué au cristal de roche, il a pour équivalent le mot bericle; on disait indifféremment, au XIv siècle, une " esguière- 
de bericle» ou une " esguière de cristal ». Lorsque le mot cristal est accompagné du mot émaillé, ou d'une désignation de couleur, il signifie absolument le verre, car le cristal de roche ne peut être émaillé. Ainsi « le verre de cristal fait en cloche, garny d'or, esmaillé de rouge clair avec de grandes flambes ", appartenant à Gabrielle d'Estrées, n'est assurément point du cristal de roche, pas plus que le " bouton azuré de cristal » d'un " voirre, dont la coupe est de cristal » du trésor du duc d'Anjou, inventorié en I 360 .

Le mot vouarre, vouerre, voirre se prête à diverses applications. Il est évident que le «voirre d'argent doré à coste ", de l'inventaire de la reine Clémence, dressé en 1328 , est un gobelet en argent et que le " hannap de voirre au fond duquel il y a un las d'amour ", de l'inventaire du duc de Berry en 1416, est un hanap en verre; mais il ne faudrait pas conclure de ces exemples que l'expression très usitée de "voirre de cristal » veut littéralement dire un verre à boire en cristal de roche, car, nous le répétons, on a très fréquemment appelé cristal le verre blanc de belle qualité.

Plus tard on a inventé une désignation nouvelle; l'inventaire des ducs de Bourgogne, fait en 1467 , donne " ung voirre cristallin, couvert, garny d'or ", ce qui veut dire: un verre en verre blanc ayant l'apparence du cristal. Les mots "verre chambouirin » et "verre de fougère » signifient que, dans le mélange des matières premières, on mettait des cailloux broyés nommés chambourins ou des cendres de fougères.

Le verre de France est un verre à vitre en plateau, ayant au centre une boudine ou bosse; on le nommait 
aussi " plast de verre", et la Normandie le fabriquait dès 1330 .

Soit par ignorance, soit pour mettre plus de valeur à l'objet, on a souvent donné au verre de couleur le nom de la pierre précieuse correspondante; mais il était aussi d'usage de faire de même en connaissance de cause et sans l'intention de tromper; ainsi, dans les vitraux peints, il est souvent question de saphir et de rubis, alors qu'il est bien évident que le vitrail ñ'était qu'en verre coloré, car matériellement il ne pouvait être en pierre précieuse. Théophile, par exemple, dit en parlant des Français : "Ils fondent dans leurs fourneaux le saphir en y ajoutant un peu de verre clair, et ils fabriquent des feuilles de saphir précieux et assez utile dans les fenêtres. " Mais les experts chargés d'inventorier les trésors y mettaient plus de scrupule; en $\mathrm{I}_{3} 72$, dans les comptes du testament de Jehanne d'Évreux, on trouve " un chapel d'esmeraudes de vouaerre et de besans, chascune de IV perles et à un rubit de vouarre. "Dans ce cas, il n'y a pas d'erreur possible, le chapelet était en pierres fausses, c'est-á-dire en verres de couleurs.

On peut discuter sur la valeur de la désignation “ voirre à la façon de Damas. ) Veut-on dire par là, verre provenant de Damas, ou bien, verre fabriqué à l'imitation des verres de Damas? Si la désignation est antérieure au $\mathrm{xv}^{\mathrm{e}}$ siècle et se rapporte à des verres émaillés, il n'y a pas à hésiter, les verres sont orientaux, car l'Occident n'en connaissait pas la fabrication. Si elle est des $\mathrm{xv}^{\mathrm{e}}$ et $\mathrm{xvl}^{\mathrm{e}}$ siècles, il y a doute, car Venise imitait la verrerie émaillée d'Orient.

L'aiguière, esguière, acuère, est un vase sans forme 
déterminée; en principe, c'est un vase à eau, son nom venant de aigue, eau, et de aiguier, réservoir d'eau; mais, en fait, l'aiguière servait à des usages très divers et affectait des formes extrêmement variées, depuis la forme ronde à anses, au col allongé, jusqu'à celle des simples gobelets et pots à biberons; d'autres avaient
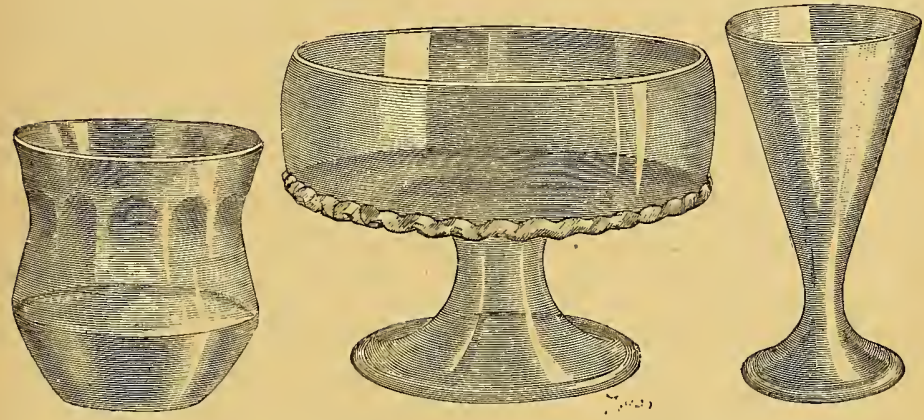

F1G. 85. FRANCE. XIV $\mathrm{XV}^{*}$ SIÈCLES 1 .

" d'estrangue façon ", par exemple " de femme assise » "; d'autres enfin étaient des petits meubles, ainsi " une esguière, où a dedens six gobeletz, trois sallières, six cuillers neslées ", appartenant aux ducs de Bour-gogne.

Le bassin, bacin, est une cuvette ou un plat creux pouvant former le dessous de l'aiguière.

La canne et la canette sont une grosse et une petite cruche.

I. Ces dessins sont extraits du Dictionnaire du mobilier de Viollet-le-Duc. Paris, Ve Morel et $\mathrm{C}^{\mathrm{ie}}$.

2. De Laborde. Notice des émaux, bijoux et objets divers exposés dans les galeries du Musée du Louvre. 
Les mots flasque, flacon, bouteille sont à peu près synonymes; si quelques "flascons ) sont à panse plate, d'autres ressemblent aux bouteilles. Tabourot ( 1547 † r 590$)$ a écrit : "On ferme bouteilles à bouchons et flaccons à vis ", mais c'était un écrivain humoristique et sa définition n'a rien d'absolu.

Le hanap, hennap, est un vase à boire dont il n'est pas possible de déterminer la forme avec certitude. Le hanap de saint Louis était "en forme de petit bacin". Charles V en possédait " en façon de calice» — "à façon de tour de lampe \# — " pareilz à une rose ». Le duc de Normandie avait "un hanap de coupe sans pié "; d'autres étaient en forme de tasses et de tonnelets. Les hanaps étaient avec ou sans couvercle, anses et pieds; en principe, c'était un verre à boire d'honneur.

La nef était un vase primitivement en forme devaisseau; elle contenait le couvert, les épices, les verres à boire et était placée sur la table, en face du seigneur. La forme des nefs varia souvent; on en fit des châteaux, tout en leur conservant leur nom; vers la fin du $\mathrm{xvIII}^{\mathrm{e}}$ siècle, on les appelait "cadenas », prenant la partie pour le tout.

Le barris, bariz, barillet, baril est un petit vase en forme de tonneau qui figurait sur les tables et les dressoirs.

La forme du poz, pot, n'est pas bien déterminée; il y avait des pots carrés, ronds, à biberons; le pot est quelquefois opposé à l'aiguière.

Les plats en verre étaient servis sur table pour "mettre viandes». L'usage était ancien; on veut qu'au $\mathrm{vl}^{\mathrm{e}}$ siècle Fortunat, évêque de Poitiers, ait assisté à un 
repas où la volaille était servie sur des plats en verre.

Le gobel, gobelet, est un vase à boire, avec ou sans pied, avec ou sans couvercle; il offre diverses formes, conique, ronde, de calice, en coupe, à biberon; il y en avait même " en manière d'un chandeller ».

Le godet est une sorte de gobelet évasé et « en manière de coupe »; on le nommait aussi "aumosnière. »

Le dragier, dragoer, drageoir, servait aux épices de chambre et à la confiserie; il n'avait pas de forme déterminée; quelquefois c'était une simple coupe.

Le godeffle, godofle, guedoufle, était une fiole à col très mince; on en connaît qui formaient deux vases réunis en un seul; c'étaient sans doute des huiliers.

L'ampulle, ampoule, était d'abord un vase sacré; sa forme essentielle est une panse large avec un col étroit et allongé, mais elle a été souvent modifiée et le nom a été donné à des flacons en usage dans la vie privée.

Le nom de mirour, mirouer, miroer, miroir se donnait aussi à de petites plaques de verre doublées d'une feuille métallique enchâssée de perles et de pierres précieuses.

\section{I}

Pendant la durée du moyen âge, la verrerie de luxe et la verrerie de table n'étaient pas en grande faveur en France; le verre à vitres était relativement plus répandu, ainsi que la verroterie appliquée aux bijoux et à l'ébénisterie; nous allons enregistrer une série de documents contradictoires qui témoigneront tour à tour en faveur du verre et contre lui. La verrerie commune a laissé 
fort peu de traces, et les pièces de luxe inventoriées dans les trésors des princes sont en petit nombre par rapport à la vaisselle d'or; même au xIve siècle, alors que déjà quelques verreries françaises étaient en pleine activité, les coupes d'or de Tours et les hanaps d'argent de Pontarlier étaient fort à la mode, et

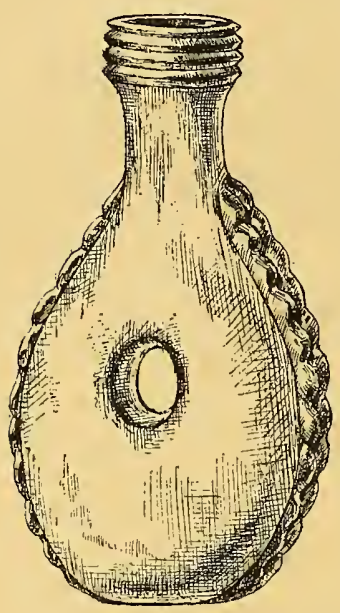

FIG. 8\%. - FRANCE. ( si alors les verres deviennent moins rares, ils ne paraissent avoir été estimés qu'en raison de leurs garnitures d'or émaillé et semé de pierres précieuses.

$\mathrm{Au}$ temps des Gaulois, un guerrier qui avait tué un taureau sauvage en conservait les cornes comme un glorieux trophée, les décorait d'anneaux d'or et d'argent et les présentait à ses convives dans les repas de fête, les invitant à y boire à la ronde ${ }^{1}$. Cette coutume subsista longtemps. Guillaume le Conquérant (1027 + 1087), dans un festin qu'il donna à Fécamp pour la fête de Pâques, avait sur sa table des vases d'or et d'argent et des cornes à boire garnies des mêmes métaux à leurs extrémités. On pensait sans doute alors que la corne convenait mieux aux gens de guerre, parce que le mouvement par lequel on la porte aux lèvres est d'une allure noble et fière; les poètes des $\mathrm{XII}^{\mathrm{e}}$ et

I. Mézeray. Histoire de France avant Clovis. 1696. 
$\mathrm{XIII}^{\mathrm{e}}$ siècles n'hésitent pas à la mettre aux mains de leurs héros, et nous en retrouvons la forme en or, en argent et en verre.

Philippe de Valois (1 293 † I 35 o) donne un dinner de gala aux rois de Majorque, d'Écosse, de Bohême et de Navarre. "Il avoit sur sa table tant seulement deux

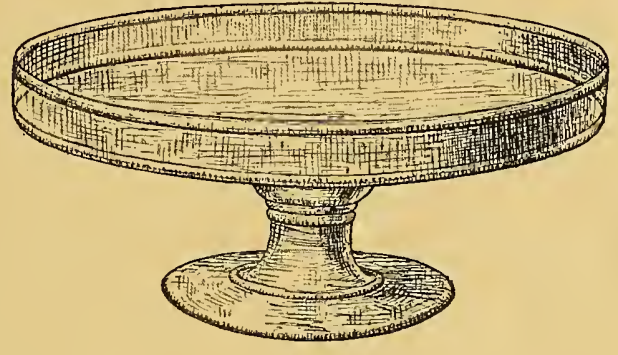

FIG. 87. - FRANCE. (POITOU.)

quartes dorées pleines de vin, une esguière et la coupe à quoi il buvoit; sur-le dressouer royal, n'avoit aultre vaisselle d'or et d'argent, flascon ou ydre, fors que tant seulement un oultre de cuir auquel oultre estoit le vin du Roy et des Princes et Roys qui seyoent à la table, chascun avoit sa propre coupe en laquelle il buvoit et son esguière tant seulement. »

Il est mention aussi de "dressouers » - le dressoir a pris le nom de buffet au $x^{2} I^{e}$ siècle - dans le festin donné par Charles V, dit le Sage ( 337 i 380 ), à Charles IV, empereur d'Allemagne. Il y avait dans la salle trois dressoirs, l'un en or, l'autre en argent, le troisième doré, chacun étant exclusivement garni de vaisselle en mème matière que le meuble. 
Eustache Deschamps (1325 + I42 I), huissier d'armes de Charles $\mathrm{V}$ et de Charles VI, était poète; il écrivit notamment le Miroir du mariage, satire très vive dirigée contre les femmes et leurs exigences; en parlant du mariage il dit : "Il vous faudra pintes, pots, aiguières, dressoirs avec beaucoup de vaisselle, sinon d'argent, au moins de plomb et d'étain. »

D'autre part, le dominicain Vincent de Beauvais assure, dans son livre de i 250 sur les Connaissances de son temps, que les meilleurs miroirs sont ceux de verre et de plomb, ex vitro et plumbo. Les us des métiers recueillis par le prévôt de Paris en I 260 interdisent aux orfèvres de joindre "voire en couleur de cristal », ce qui prouve que le verre blanc était de belle qualité; ils disent aussi : "Nul ne peut metre aucunes finnes pelles fausses, pelles blanches ne dorées, s'elles ne sont d'argent ", ce qui prouve que le travail de la verroterie était pratiqué. Le Vendômois, le Berry, la Provence, le Languedoc avaient des fours à verre: dans un dicton populaire au $x_{n}{ }^{\mathrm{c}}$ siècle se trouvent les mots "voirre de Vendôme ", et dans l'héritage du comte d'Artois, mort en r 302, on constate "Grant planté de poz de voirre et voerre d'Aubigny et de Provence et d'autres pais et de diverses couleurs et bocaux et bariz ». Les Us et couttumes des métiers d'Estienne Boileau (1300) prescrivent "que les chatons et les épingles soient percés de verre de Montpellier au cas que l'on en pourrait à Paris, car autre voerre n'y est pas suffisant."

Joinville nous apprend dans ses Mémoires (130o) que " le comte d'Eu dressoit sa bible le long de nostre table et nous brisoit nos pots et nos vouerres. » 
Les huchiers trançais de la fin du $x_{n}{ }^{e}$ siècle fabriquaient des meubles qu'ils livraient ensuite aux imagiers chargés de les décorer. Le verre était quelquefois employé à cette décoration; voici de quelle façon, selon M. Viollet-le-Duc ${ }^{1}$, qui s'en rapporte pour les détails au moine Théophile: On colle de place en place des pâtes de verre de diverses couleurs en forme de cabochons ou de plaques; sous chaque pièce on pose une feuille d'argent battu. Sur le verre on peint des ornements avec de l'huile de lin mêlée à la cire, de l'essence de térébenthine et de la sanguine; on fait cuire à un feu modéré; sur cette assiette un peu molle on applique l'or en feuille; après durcissement, on brosse l'or et il ne reste que l'ornement, puis on colle la plaque sur le meuble; l'ornement doré extérieur projette une ombre sur la feuille d'argent du dessous; cela donne une grande élégance et du relief à l'ornement; d'autres fonds sont peints de diverses couleurs rehaussées de dorures sous un verre blanc verdâtre. On décorait ainsi des plafonds, des armoires et des dressoirs; le retable de l'église de Westminster est la pièce la plus importante dans ce genre; elle est peut-être de fabrication française.

Et cependant, malgré l'absence constatée du verre dans les festins de Philippe de Valois et de Charles V et sur les tables plus modestes des ménages d'Eustache Deschamps, la fabrication du verre de service était en pleine activité dans le Dauphiné, comme le prouve un privilège accordé en 1338 par Humbert II, dauphin du Viennois, à Guionet, maître de verrerie; le dauphin

I. Viollet-le-Duc. Dictionnaire raisonné du mobilier français. 
abandonna l'exploitation d'une partie de la forêt de Chamborant à la condition que Guionet lui fournît chaque année pour sa maison les pièces de verrerie dont voici le détail : 240 coupes à pied, forme hanap, I44 amphores, 432 urinals, 144 grandes écuelles, 72 plats, 72 plats sans bords, I 44 pots, 144 aiguières, 60 gotteffles, i 2 salières, 240

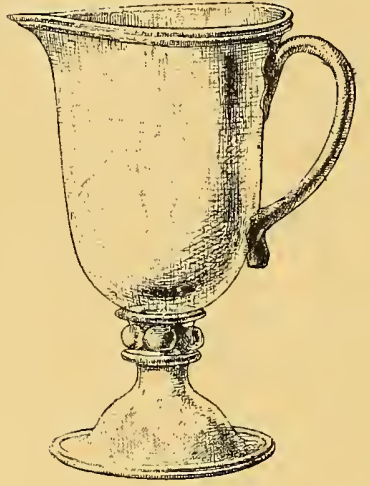

FIG. 88. - FRANCE.

(роттол) lampes, 72 chandeliers, I 2 tasses larges, I 2 petits barils, 6 grandes bottes pour transporter le vin, I grande nef. Cette quantité d'objets fournie chaque année à une petite cour d'un fort petit pays ${ }^{1}$ prouve peut-être moins le goût du dauphin pour le luxe de la table que le désir de se pourvoir d'une ample provision. En cette même année I 338 il y a déjà dans la grande salle du "chastel " de Rouen " v1 piés de verre assis entre deux chassis de fer ", le verre était de provenance normande.

Jean II, dit le Bon, avait en I 353 " deux petites bouteilles de voirre grinelé garnies d'argent. "

Dans l'inventaire du duc d'Anjou, dressé en I 360 , on ne compte que trois " voire de cristal et le couvercle de mesme " sur sept cent quatre-vingt-seize objets pré-

I. Le Viennois était compris entre le Grésivaudan, l'Isère et le Rhône; le Dauphiné fut réuni à la France en r 343 . 
cieux, et encore est-il possible que ces verres aient été en cristal de roche. Le duc de Normandie, vers le même temps, avait " une choppine de voirre rouge garnie d'argent blanc ». Charles V, dont l'inventaire date de r 38o, possédait " des grands plats de voirre ouvrez et peinds et escuelles de même, " - " une pairre de voire azuré garni d'un pou d'argent doré au bout dessus »-un pied de verre riollé » - « un miroir d'argent dont au doz à un roy séant peint sur verre."

La fabrication des pierres fausses continue toujours. L'auteur du Propriétaire des choses (1372) met en garde les connaisseurs : "Aulcunes foys les faulces pierres sont si semblables aux vrayes que ceulx qui myeulx si cognoissent, y sont bien souvent déceulz. " Les princesses ne dédaignaient pas de s'en servir; la reine Jehanne d'Évreux, parmi ses chapelets, avait « un autre chapel d'esmeraudes de vouarre et de besans, chascune de iv perles et à un rubis de vouarre », et la reine Jehanne de Bourbon " une attache garnie de pierres faulces, c'est assavoir doublez rouge et voirres verds».

Les " tailleurs d'ymages » inscrivent dans leurs statuts de r 39 I cette condition : "Et doivent estre (les tabernacles à mettre corpus Domini) envoirez et fermans à clef et doit être le verre assis et ouvré et enclavé bien et souffisament. »

Les inventaires $\mathrm{du} \mathrm{xv}^{\mathrm{e}}$ siècle font connaître quelques pièces intéressantes; dans celui du duc de Berry, dressé en 1416 , on constate " un gobelet et un pot de voirre en manière d'émail blanc garni d'or, - un hanap de voirre au fons duquel à un i couronné et un las d'amour, estant en un estuy de cuir, - un voirre fait en guise de 
burette garni d'or, pendant à trois petits chayennes d'or, - une autre burette de voirre garnie et pendant à cinq chayennes d'or, - une aiguière sanz couvercle, large par dessus, qui est de voirre taint sur la couleur du bassin que le grant prieur de Thoulouse donna à M. D. S. au mois de décembre l'an mil ccc et sept - une aiguière de voirre tainte en manière d'agathe sans couvercle ». Cette pièce pouvait venir des verreries du Poitou, qui avaient la spécialité de ce genre, comme il sera dit plus loin. - " Deux grans ampoules ou fioles de voirre taintes sur couleur de pierre serpentine, l'une en façon de poire, l'autre en façon de coucorge, garnies d'argent doré pendant chacune à un tixu de soye noire. " Cette description se rapporterait assez exactement aux verres de l'antiquité striés de bandes longitudinales et flexueuses de diverses couleurs; les formes antiques de ce genre de verre se rapprochaient aussi de la poire et de la courge, mais elles étaient de petites dimensions; on peut également supposer que ces deux ampoules étaient en porcelaine.

L'usage de couvrir de verre les tableaux continuait à être pratiqué; nous l'avons constaté à Jérusalem au $\mathrm{xI}^{\mathrm{e}}$ siècle; nous retrouvons dans la collection du duc de Berry un tableau de bois dont les dix images sont " couvers d'un grant pièce de voirre plate et les bords dudit tableau sont pains d'or bruni » et "uns petis tableaux dorez garny d'un des costez de voirre bleu où il a par dessoubz un crucefiement d'argent, saint JeanBaptiste et saint Jean l'Évangéliste, et de l'autre costé de voirre vermeil où il y a dessoubz un ymage de Notre Dame, sainte Catherine et la Magdelaine. » Le 
duc ne dédaignait pas les fausses pierres; il possédait “ un gros saphir sur couleur, de voirre, pertuisé pendant à un annelet, - une pierre de voirre, contrefaicte en manière d'esmeraude, assise en cire noire, - un onis d'esmail ou voirre taint de couleur desmeraude enchassé en or en manière d'un fermaillel. »

Les ducs de Bourgogne brillaient par leur faste. Dans une fête donnêe par Philippe le Bon $(\dagger 1467)$ on voyait sur table " une jeune fille, faite d'or émaillé. Elle était nue et tenait ses mains baissées et serrées contre son corps comme pour s'en couvrir. De dessous ses mains sortait une fontaine de vin délicieux qui était reçu dans un vase transparent. " A la mort de ce prince, l'expert constate dans son service de table " une coupe de voirre jaune, garnye d'or de $\mathrm{xxv}$ perles pendans dessoubz et de xII perles dessus le fretelet (bouton) du couvercle et ledit fretelet ouvré à fusilz, - une couppe de voirre vert, - une couppe de voirre blanc, - ung pot de voirre, - un pot de voirre de couleur vert, - une aiguière de voirre vert torsée, - un gobelet couvert de plusieurs couleurs de verre fondu et a fachon de barres, - sept trompes de verre ${ }^{1}$ )。

Le verre torsé devait être, comme le nom l'indique, une sorte de bouteille à col tordu qui fut longtemps en usage en Allemagne; les trompes étaient des verres à boire en forme de corne.

Nous trouvons au $\mathrm{xv}^{\mathrm{e}}$ siècle quelques mentions de verrres à vitres. Claude Le Leu, " voeirier à Paris ", répare, en 1405 , les vitres de l'hôtel du duc d'Orléans,

I. De Laborde, Histoire des ducs de Bourgogne, 
frère de Charles VI, situé à Chaillot; Philippe Blancart, "voerrier à Soissons ", fait une semblable réparation, la mème année, à l'église des Célestins de Villeneuve-les-Soissons 1. Dans le Songe de Polyphile, publié en Italie, on lit: "Entre deux piliers y avait une fenestre vitrée de lames de Bologne en France». Antoine de La Salle parle de " chambre chauffée qui estoit bien tendue et necte, tapissée, verrée ", c'est-à-dire garnie de verres aux fenêtres. Jacques Cœur, l'argentier de Charles VII, avait dans son logis " du beau verre clair qui résiste aux rayons du soleil, sans empescher la clarté » 2. Mais l'usage des fenêtres vitrées était loin d'être répandu, car, dans les comptes du receveur de l'Auvergne, libellés en I4I3, figure une dépense " pour la venue de Madame la duchesse de Berry pour aller à Montpensier faire faire certains chassitz aux fenaistrages dudit chastel pour les ansires de toilles sirées par défaut de voirrerie ", et dans le palais du roi Charles VIII, qui régna de 1483 à 1498 , les châssis de certaines fenêtres étaient garnis de papier.

Nous arrêtons ces recherches à la fin $d u x^{e}$ siècle. Désormais nous serons quelquefois en présence de verres réels ou figurés, mais assez fréquemment encore nous resterons dans l'incertitude; la verrerie n'est pas de nature à bien se conserver, et s'il devient relativement plus facile de retrouver la trace des fabriques françaises, il arrive trop souvent que les objets fabriqués aient disparu, quoiqu'ils aient été en assez grand nombre, comme l'in-

I. Nouvelles Archives de l'art français.

2. Jonathas Petit. L'Antihermaphrodite. 
dique Bernard Palissy vers I 580 dans cette note extraite de ses écrits : " Il y a plusieurs gentilles inventions, lesquelles sont contaminées et mesprisées pour estre trop communes aux hommes. Aussi plusieurs choses sont exaltées aux maisons des princes, que, si elles estoient communes, on en feroit moins d'estime que de vieux chaudrons. Je te prie, considère un peu les verres qui, pour avoir esté trop communs entre les hommes, sont devenuz à un prix si vil que la plupart de ceux qui les font vivent plus méchaniquement que ne font les crocheteurs de Paris..., et ces verres sont venduz et criez, par les villages, par ceux mêmes qui crient les vieux chapeaux et les vieilles ferrailles... » 


\section{LA FRANCE}

LES VERRERIES DE L'OUEST, DU MIDI, DU CENTRE ET LES VERRERIES ÉPARSES SUR LE TERRITOIRE.

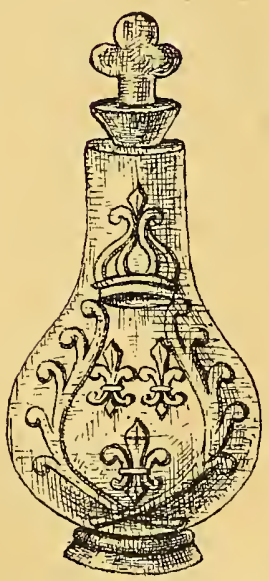

FIG, 89, - FRANCE. (ORIÉANAIS.) X̃VII

Nous devons maintenant rechercher les verreries françaises. Pour simplifier cette tâche difficile, nous les diviserons en trois groupes :

- Les verreries de l'Ouest, du Midi, du Centre et les verreries éparses sur le territoire;

- Les verreries de la Normandie et du Nord;

- Les verreries de l'Est et de la Lorraine.

Il n'entre pas dans notre programme de dresser la nomenclature de toutes les verreries dont l'existence a été reconnue, mais seulement de signaler les centres de fabrication qui ont eu une influence sur la production nationale ou qui ont été l'objet de la protection spéciale du souverain. Nous n'insisterons pas sur les 
fabriques de bouteilles communes et de verres à vitres ordinaires, à moins que ces établissements ne soient devenus le point de départ d'une industrie plus intéressante.

XIII $^{\mathrm{e}}$ siècle. - Willelmus Géraud et Simon la Joui sont verriers à $\mathrm{La}$ Roche en $\mathrm{I} 207$; cette localité est $\mathrm{La}$ Roche-sur-Yon (Vendée) ou La Roche-Corbon. - Guillelmus Gaudin est verrier en I 249 aux Moutiers (DeuxSèvres) ${ }^{1}$. - La verrerie de Quiquengrogne (Aisne) est fondée en i29o. - Vers la fin de ce siècle, il existait aussi des verreries à Vendôme, à Aubigny, à Montpellier, en Provence et à Moulchamp (Vendée).

xIV $^{\mathrm{e}}$ siècle. - André Basge, dit Calot, est verrier en I33 I à Aulnay, dans la forêt de Mervent (Poitou). Nous avons précédemment indiqué l'importante verrerie de Guionet, fondée en I 338 à Chamborant en Dauphiné; cette fabrique exportait encore dans les Flandres, en 16 i 8 , ses verres cristallins en grande quantité. - Le roi Charles VI fait, en r 382 , dons en argent " à Guillaume le voirrier, » à « Jehan le voirrier de la forest Dotte, lequel avoit présenté au Roy voirres par plusieurs fois», aux " voirriers près la forest de Chevreuze où le Roy etoit alez veoir faire des voirres ». - Le même prince concède, le 24 janvier $\mathrm{x} 399$, à Philippon Bertrand,

1. Tous les renseignements que nous donnons sur les verreries du Poitou sont tirés des intéressants travaux de M. Benjamin FilIon : l'Art du verre chez les Poitevins. 
maître de la verrerie du parc de Moulchamp (Vendée), pour lui et les autres verriers du même lieu, "à cause dudict mestier de verrier, de toute ancienneté ", les privilèges et libertés dont sont accoutumés de jouir les nobles du pays, car les verriers "à cause dudict mestier soient et doivent estre tenus et reputez pour nobles». Les privilèges octroyés interdisaient l'établissement de verrerie à celui qui n'était pas « nez et extraict de par son père d'autres verriers », et rendaient les verriers "francs, quittes et exempts de toutes tailles et fouages». $\mathbf{x v}^{\mathrm{e}}$ siècle. - Colin Bonjeu, Pierre Musset, Katherine Chauvigné, verriers à Bichat (Vienne), sont preneurs d'un bail en I442. - Denis Lasne, verrier à Bourges (Cher), garnit de fenêtres blanches la grande salle du palais épiscopal de Poitiers, en I444. - Jean Le Pelletier, de Paris, et Jaquin de Bensinghen, de Boulogne, font une semblable fourniture pour la chapelle de l'évêque de Poitiers. - Le roi René donne permission, le i 9 novembre I456, à Lucas Rillet, Jehan Bertran et Pierre Maigret, demeurant dans la forêt de La Roche-sur-Yon, d'exploiter les bois " au lieu le moins dommaigeable", en considération de "la gentillesse et noblesse qui est l'ouvrage de verrerie, et que aussi c'est le bien du pays et de la chose publique ». - La seigneurie de Vasle paye, en septembre 1463 , “ quatre douzenes de voyres et sept acuères " à Musset, maître de la verre. rie de Courlac (Vienne?). - En 1466, un compte semblable est réglé aux verriers de La Ferrière (Deux-Sèvres). - Philippon et Jehan Boissière sont "verroiers", en I468, à La Puye en la forêt de Gatine (Vienne); la même verrerie était tenue, en I 562, par François Gal- 
liot, écuyer, seigneur de Vangenille. - Sous le roi René ( $1408+\mathrm{r}_{480}$ ), un nommé Ferré est autorisé à établir une verrerie à Apt (Vaucluse); une autre verrerie exis-

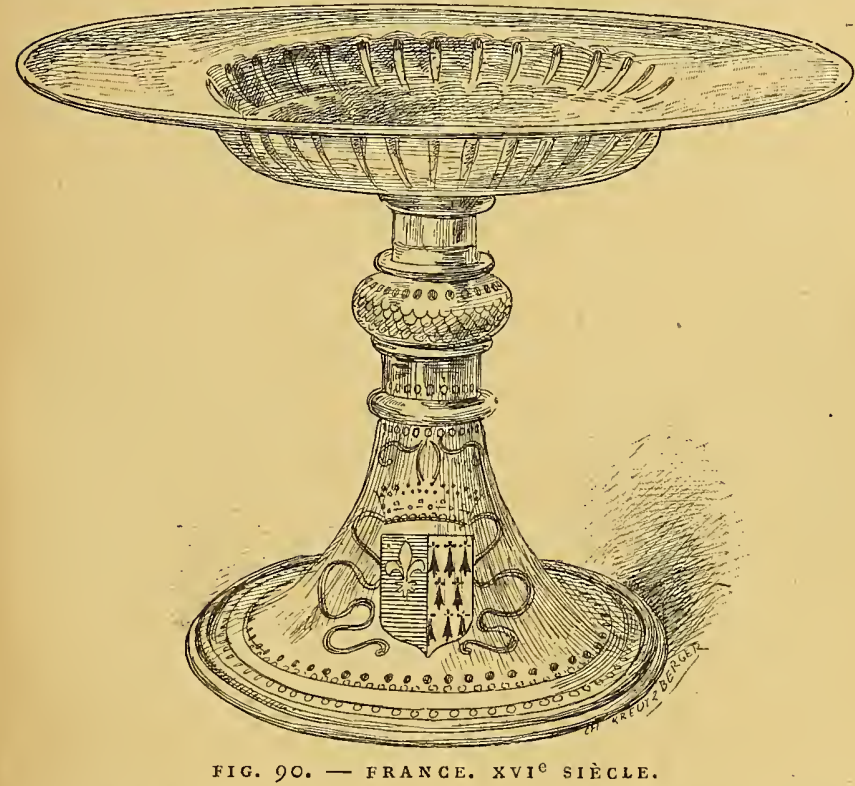

ÉCUSSON ÉMAILLÉ DE LOUIS XII ET D'ANNE DE BRETAGNE.

(Musée de Cluny.)

tait à Goult dans le même pays; elle fournit les verres " moult bien variolés et bien peints" que le roi acheta moyennant cent florins pour les offrir à Louis XI; le roi René était un protecteur éclairé des lettres et des arts, mais c'est à tort qu'on lui attribue la fondation de la première verrerie française. - Vers la fin de $\mathbf{r}_{4} 55$, 
le roi Louis XI écrit la lettre suivante à Étienne Achart, résidant à Grenoble: "Estyenne, je vous prye, envoyés moy un bon ouvryér de fayre voyrines car j'an veux fayre fayre et les luy veux devysér, et le m'anvoyés en ceste vylle, mès que se soyt uncontynant et qu'y n'y èt poynt de faulte. Escryt de ma mayn. Loys. " - En I486, Jacques Bertrand, seigneur de la Vrignonnière, prend à bail un terrain au Rorteau (Vendée) pour y construire une verrerie; la verrerie fut exploitée par la famille de Roussy depuis 1696 jusqu'à la Révolution.

$\mathrm{xvl}^{\circ}$ siècle. - Geoffroy Poussart est, en I 507, maître de verrerie à la Motte, dans la forêt de Chizé (DeuxSèvres). - Maurice Gazeau, sieur du Retail, Jacob Morisson et François Gaudin, fondent la verrerie Neuve près de Talmond, en $\mathbf{5} 543$; déjà un nommé Gaudin avait été verrier, en 1 249, aux Moutiers (Deux-Sèvres). - La verrerie de la Court, dans la forêt de Prinçay (Loire-Inférieure), existait en I 545. - Giovani Ferro " gentilhomme en l'art et science de verrerye, natif d'Altare, au marquisat de Montferrat ", parait avoir exercé son art à Lyon et à Nevers dès le milieu du siècle. - Henri II, étant à Châteaubriant, le I 3 juin 155 , accorde à Theseo Mutio, né à Bologne en Italie, le privilège pour dix ans de fabriquer dans le royaume des ouvrages de verre « dẹ la même beauté et excellence que ceux qu'on vouloit apporter de Venise ». Mutio s'établit à Saint-Germain-en-Laye; il ne paraît pas y avoir prospéré, et la fabrique disparaît vers i 560. - Girolamo Matteo, natif du Piémont, possède, en r 557, une verrerie à Amaillou. - En r 560, les verreries de Bourgogne, de Lorraine et de Normandie étaient connues pour la 
qualité de leurs vitres, à ce point que Philippe II en fit venir des échantillons en Espagne pour les fenêtres du palais de l'Escurial; les verres de Normandie furent

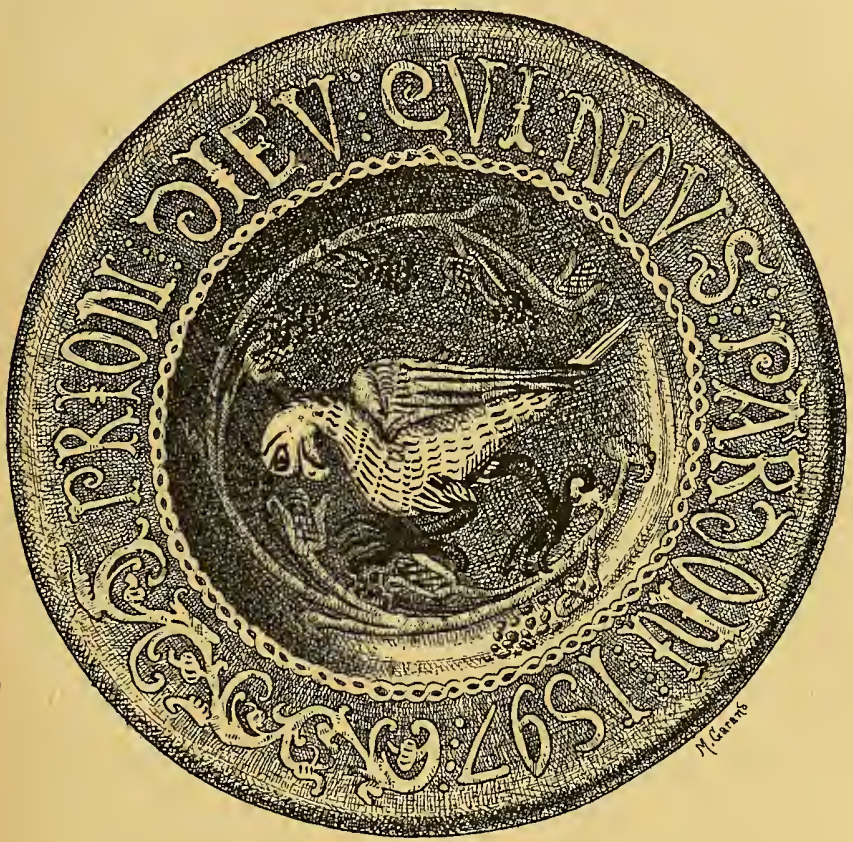

FIG. 9 I. - FRANCE. I 597. VERRËÉMAILLÉ.

Musée de Rennes.)

jugés les meilleurs. - Vers $\mathrm{x} 568$, il y avait dans les environs de Parthenay une famille de verriers du nom de Cruzeron. - Le comte du Lude, gouverneur du Poitou, prend, en $5_{72}$, sous sa protection " Fabian Salviate, escuyer, gentilhomme de Myrane, païs de Venize, 
venuz, lui et sa famille, en ce païs de Poictou pour praticquer l'art de la verrerie ". Le gouverneur commande à tous les officiers "que vous n'aiez à loger, ne souffriez estre logez aulcuns gens de guerre en sa mayson de l'Argentière, laquelle mayson nous avons exempté et exemptons, par ces présentes, de toute garnison ". Un acte notarié de I 590 constate la présence à Machecoul (Loire-Inférieure) de Jacques et Loys Ridolfe, « escuyers, frères, gentilz hommes de l'art de verre et de terre de Faenze natifz de Caffagiolo ». - Vers la même époque, Giovanni Ferro, que nous avons déjà cité, était à Machecoul "où, avec des amis, il a dressé une verrerye à faire verre et christal "; Henri IV, en 1596 , lui donna ses lettres de naturalisation. - Agostino Ferro obtint la même faveur en I 598 . - Henri IV donne, en août $\mathrm{I} 597$, le privilège d'une fabrique de cristaux à Melun à Jacopo et Vincentio Sarode, et Horacio Ponti, originaires de l'Altare en Montferrat, en récompense de ce qu'ils " avoient cy devant et depuis longtemps tenu les fournaux et verrerie de cristal dans les villes de Lyon et Nevers et avoient acquis telle réputation en la perfection de leurs ouvrages que la plupart des verres du dict cristal, dont on se servoit à la cour et suite et partout le royaulme, estoient apportés des dites villes de Lyon et de Nevers ». -- Vincentio Sarode est autorisé, le 4 mai r6oo, à s'établir à Paris, Orléans, Rouen, Caen, Angers, Poitiers, Bordeaux, Toulouse, Lyon, Marseille et généralement partout, pour " $y$ faire toutes sortes d'ouvraiges de verre, comme ils faisoient et pouvoient faire à Venise et tous aultres lieux, sans brusler bois ou charbon "; le nombre des verreries et la clause 
relative au combustible indiquent qu'il ne pouvait être question que de verroterie ou d'émaillage.

xvme siècle. - Guillaume Bicheux, fils d'un verrier normand, maître patenôtrier de Paris, inventa en r6o3, selon son dire, une sorte de moulure en pâte de verre qui lui permettait de reproduire les empreintes des verres antiques; nous ne pensons pas qu'il s'agisse ici du verre proprement dit, mais seulement d'une pâte vitrifiable "sables et terres de toutes façons ${ }^{1}$. - En r607, une verrerie importante existait à Mézières; nous estimons quìil s'agit de la ville située dans les Ardennes, car le maître de l'établissement avait embauché des verriers d'Anvers afin de fabriquer des verres à la façon de Venise. - Anthoine de Cléricy, le céramiste de Marseille, était logé au Louvre sous la régence de Marie de Médicis; do I6I 2 à I625, il obtint des brevets pour établir des verreries dans le royaume; il était, dans ces actes, qualifié de " escuier, maître de la verrerie royalle et nostre ouvrier en 'terre sigillée ». Nous n'avons sur la fabrication de Cléricy que le renseignement suivant, fourni par un écrivain du temps : "Proche de cette église (Saint-Pierre d'Avon, paroisse de la ville), vers le septentrion, et immédiatement au bout du parc de ce chasteau, est la maison seigneuriale de Monceau, où l'année passée r64I a esté establie une verrerie royale par lettres patentes du Roy, données au mois de mars I640, et par arrest du conseil privé de Sa Majesté, tenu à Paris le cinquième jour de juin $\mathrm{r}_{4} \mathrm{I}$; et ce en faveur du sieur Antoine Clericy, ouvrier en terre sigillée, et de

I. Nouvelles A rchives de l'art français. $2^{\mathrm{e}}$ série. Tome II. 
ses associez; leur donnant pouvoir d'y faire des verres, miroirs, glaces et autres ouvrages de verrerie, et les vendre et distribuer par tout le royaume et mesme les transporter hors d'iceluy: le sieur Clericy a déjà si bien réussi en son entreprise qu'il s'y fait des verres de cristal des plus beaux et des plus fins qui se fassent point partout ailleurs et des ouvrages en terre sigillée » ${ }^{1}$. En I653, on trouve Cléricy à la foire de Saint-Laurent au faubourg Saint-Martin. - Georgio et Antonio Bianca; verriers, sont naturalisés français en r 6 I I par acte enregistré au parlement de Nantes. - Même constatation en faveur de Antonio Ribre ou Ribé, verrier, en r 626. - Lorenzo Rossi, naturalisé français par Louis XIII, associé avec Jean-Marie Perrot, est autorisé, en I 626, a établir des verreries en Poitou, Saintonge et Angoumois. - Horacio Borniola, gentilhomme verrier de Noli, était, en I 627, établi au Croysic près de Nantes, comme fabricant de verreries et de faïences. - Gérard Demigennes de Gand était, en 1627 , verrier et faïencier au Croysic. - En r640, Robert de Verrière, écuyer, sieur de Fandôme, fabriquait des verres à vitres à Montelle (Vienne). - Castellan était, en r 665 , subventionné par le roi pour un établissement de glaces de Venise fondé à Nevers. Le parlement de Nantes enregistre successivement les lettres de naturalisation des verriers italiens : E. Buisson et Heric, en 1635; César Racheto, à Riaillé, en I 653; Giovanni Marino, sieur du Chastelet, et Giovanni Sarode, en I 654; Damiano Racheto, à Saint-Magon, évêché de Saint-Malo, en r654; Carlo Borniola, sieur de

I. Le Père Dan. Trésor des merveilles de la maison royale de Fontainebleall. Paris, 1642. 
la Grandmaison, à Fercé, en r 668; Francesco-Ambrosio Massart, en r 697 . Tous ces Italiens étaient originaires du duché de Montferrat; la famille Sarode, de souche de gentilshommes, exerçait la verrerie dans le duché en I 552 ; elle continua en France pendant près de deux siècles à la Fosse de Nantes et à Vandrennes en bas Poitou; elle se livra aussi à la fabrication de la faience.

\section{I}

Nous avons établi cette aride, longue et cependant encore incomplète nomenclature dans l'espoir de faciliter la recherche des attributions, car, à peu d'exceptions près, l'archéologie a dû s'en tenir à des données assez vagues sur l'origine des verres français antérieurs au règne de Louis XIV et conservés dans les collections.

La désignation des produits de la verrerie de Guionet à Chamborant nous apprend que, dès le xive siècle, le service de table était bien compris et bien composé; les verreries du pays d'Avignon paraissent avoir produit des œuvres d'art vers le milieu du $\mathrm{xv}^{\mathrm{e}}$ siècle. Le roi René possédait un verre à boire fabriqué à Goult, décoré dans le fond de la Madeleine aux pieds du Christ debout sur les parois, avec l'inscription ${ }^{1}$ :

Qui bien boira

Dieu verra, Qui boira tout d'une haleine Verra Dieu et la Madeleine.

1. E. Piot. Le Cabinet de l'amateur. 
Les verreries du Poitou nous ont laissé quelques pièces très intéressantes ${ }^{1}$. Jusqu'au xvie siècle, la production, sauf quelques cas particuliers, consistait en verres communs, légèrement teintés de jaune ou de vert et peu raffinés; cette médiocre fabrication tenait à la mauvaise qualité des matières premières; dès le milieu du $\mathrm{xvI}^{\mathrm{e}}$ siècle, un progrès très sensible a lieu : il vient de l'emploi d'un sable plus pur. Belon, le naturaliste, le constate en 1553 : “Les François ayant, n'a pas longtemps, commencé à faire les verres crystallins, ont faict servir le sablon d'Estempes au lieu des cailloux du Tessin, que les ouvriers ont trouvé meilleur que ledict caillou de Pavie. Mais ils n'ont encores sceu inventer chose qui puisse servir au lieu de la susdicte cendre. » La « susdicte cendre » était la soude d'Égypte, et, à cette époque, les verriers français employaient comme fondant le sel provenant des fougères coupées au mois de juillet en pleine sève; ces plantes produisaient environ un dixième de sel alcali, c'est-à-dire de carbonate de potasse. Le sable d'Étampes est très pur eí très blanc; les gisements s'étendent jusqu'à la forêt de Fontainebleau et sont encore exploités de nos jours. Avec un verre plus blanc et plus fin, le décor devient plus facile et la coloration plus nette; nous sommes obligés de reconnaître que le perfectionnement considérable introduit dans la décoration vers le milieu du $\mathrm{XVI}^{\mathrm{e}}$ siècle coïncide avec l'arrivée des Italiens. A partir de ce moment, la forme gagne en légèreté, les proportions deviennent plus gracieuses, et le décor émaillé de

I. B. Fillon. L'Art de la terre chez les Poitevins. 


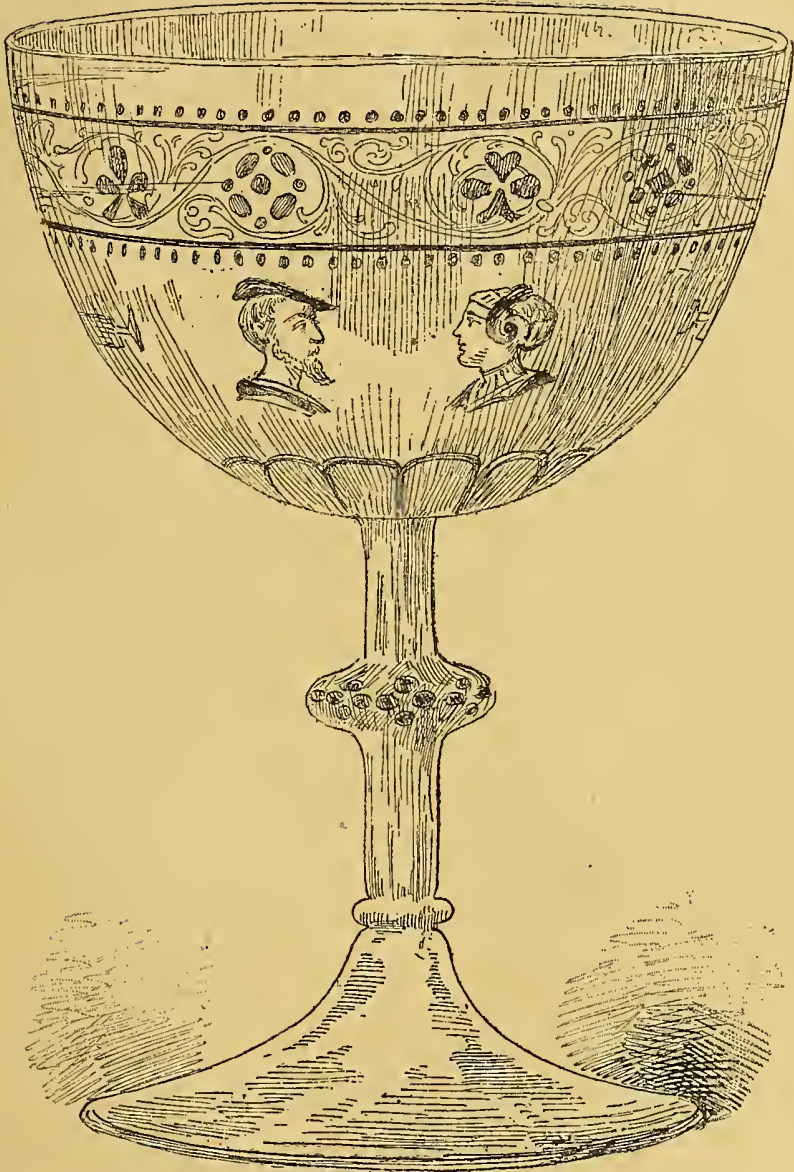

FIG. 92. FRANCE, XVIE SIÈGLE. D PORTRAITS ÉMAILLÉS DE PIERRE TALLON ET DE MARIE MARCEL.

(Musíe de Cluny.)

diverses couleurs se manifeste en perles, torsades, armoi- 
ries et autres ornements, ainsi que par des inscriptions et par la peinture au naturel de la figure humaine et des fleurs. Nous reproduisons quelques-uns de ces verres.

Le verre à pied du musée de Cluny montre en émaux de couleur (fig. 92), sur une face, les portraits de Pierre Tallon et de Marie Marcel, sa femme; sur l'autre, l'écusson de la famille, qui porte trois léopards d'or sur champ d'azur, la devise pour noble et la légende PIERrE TALLON; à l'entour règnent des arabesques d'or rehaussées de croix rouges; la frise est de fleurons de couleurs et de branches d'or. Pierre Tallon était conseiller, notaire et secrétaire du roi, contrôleur général de son artillerie; plusieurs actes, de $\mathrm{I} 542$ à $\mathrm{I} 55 \mathrm{I}$, prouvent son existence. Le verre peut être de la fabrique de SaintGermain; les dates et les fonctions remplies par Tallon auprès de Henri II rendent l'hypothèse vraisemblable.

Les inscriptions sont des devises, des souhaits, des proverbes, des dédicaces, des vers, des maximes religieuses; en voici quelques-unes. - Sur un verre à pied, élégant de forme et très évasé, on lit (fig. 93) :

A. BON, VIN, NE. FAVLT, POINT. ENSEIGNE,

Sur un autre :

QVI EN. CHRIST. CROY EST HEVREVX.

Le verre appartenait sans doute à un protestant dont le nom est peint dans un cartouche entouré de rinceaux et de fleurs : ives PINEAv.

Un verre présente, d'un côté, une dame en costume 
du temps de François II chassant le cerf, et, de l'autre, le même personnage à cheval, suivi d'un écuyer; elle lance le faucon près d'une fontaine. Deux vers des métamorphoses d'Ovide sont inscrits sur la frise supérieure :

HIC. DEA. SYLVRARV. VENATV. FESSA. SOLEBAT. VIRGINOS. ARTVS. LIQIDO.

PERFVNDERE. RORE.

On voit sur un beau verre du musée de Cluny (fig. 94), dont la forme et l'époque sont celles de la pièce précédente, trois hallebardiers en faction dans des compartiments séparés par des bandes d'arabesques; la bande supérieure porte les mots gravés en clair :

\section{EN LA SVEVR.}

DE. TON. VISAIGE

TV MANGERAS, LE. PAIN.
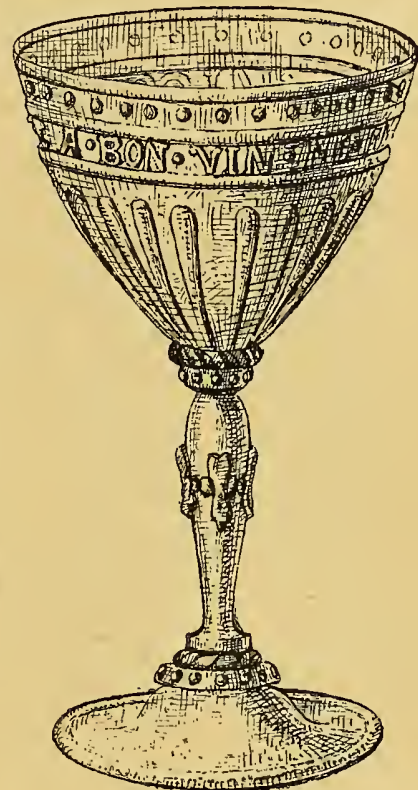

FIG. 93. - FRANCE. (POITOU.) $\mathrm{XVI}$ e sIÈcLE.

Ce qui veut dire que le métier de soldat était fort dur à cette époque.

Le verre de la collection Fillon (fig. 95) portait jadis les armoiries de la famille des Tavaux de Mortemer; les quatre écussons dont le thamp a été passé à la roue pendant la Révolution sont posés sur un décor très fin, 
bordé de feuillages dorés et de perles en émail blanc.

Les verres gravés semblent postérieurs aux verres émaillés; on cite, dans cette manière, un drageoir de fiançailles couvert de

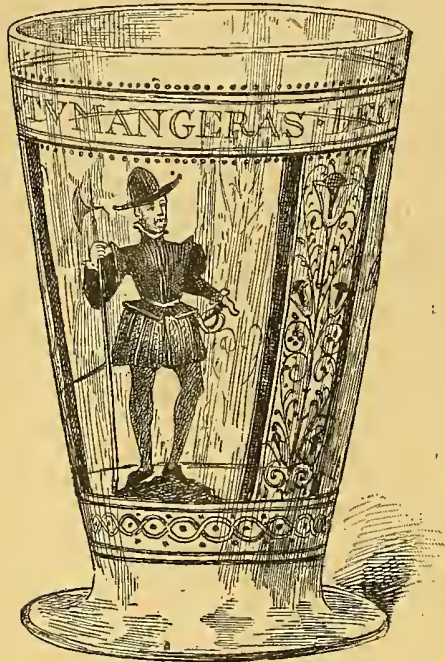

FIG. 94. - FRANCE. (POITOU.)

XVI S SI Eे CLE。

(Musée de Cluny.) feuillages enlacés autour de trois écussons, l'un aux trois fleurs de lys, l'autre avec un cour percé de deux flèches et la date de 1578 , le troisième avec une dédicace en abréviation :

\section{.A.}

M. M.

D. L. P

D'autres verres portent des armoiries gravées dans le fond ou une inscription :

NICOLAS TVTAVLT I 583

On a.trouvé au château de Talmont des verres décorés de têtes de lions, et des vitres avec des bordures en aräbesques gravées.

Dans la verrerie du Poitou comme ailleurs, les verres émaillés et gravés sont des objets de grand luxe, et dès lors beaucoup plus rares que les coupes, aiguières, bouteilles, salières en verre blanc rehaussé de quelques applications en relief, colorées ou dorées. 
Une fabrication spéciale en France aux contrées de l'Ouest est celle des verres colorés dans la pâte; les uns sont opalisés, d'autres marbrés de rouge, de rose, de bleu, de violet et de vert, ce qui leur donne l'aspect des agates; ce travail est manifestement imité de Venise et produit par les Italiens du Poitou et leurs successeurs; dans l'inventaire du roi Henri II, fait en I 560 , il se trouvait " deux autres vases de voerre retirans à agathe " qui pourraient bien être du Poitou. Le même prince possédait "ung voerre d'email blanc sur fond violet; ung petit vase de cristallin blanc,

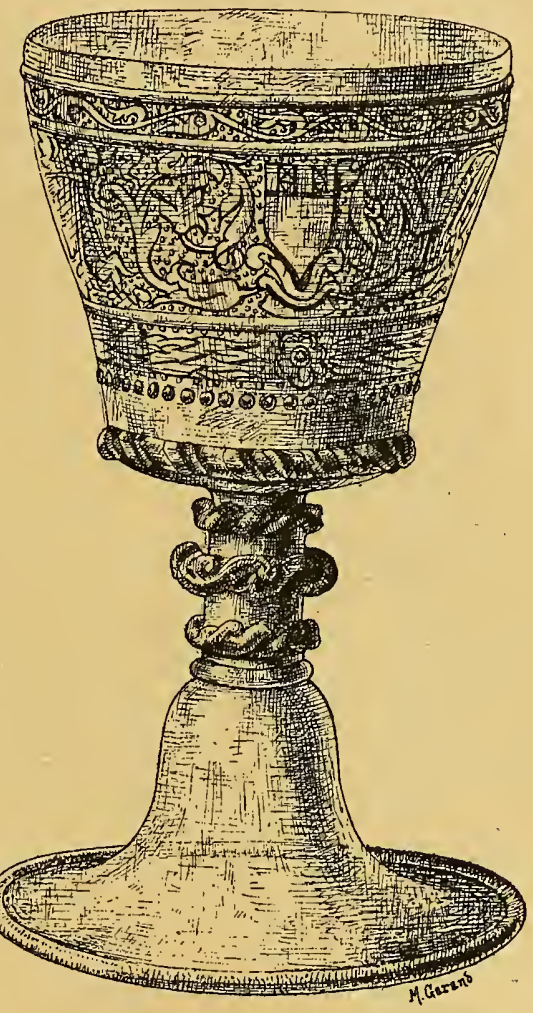

FIG. 25. - FRANCE. ( POITOU.) $\mathrm{XVI}{ }^{\circ}$ SIÉGIE. - (Collection Fillon.) garny d'argent "; il est logique de supposer que ces pièces provenaient de la fabrique de Saint-Germainen-Laye, fondée par le roi et alimentée par ses deniers. 
On peut aussi rapporter à la même fabrication un gobelet de verre jaune émaillé, du British Museum, de forme conique (fig. 96), dont le décor montre un gentilhomme en costume Henri II, offrant un bouquet à une dame; le compliment qu'il prononce est inscrit sur une banderole :

JE SVIS A VOVS.

La dame tient un cœur cadenassé et répond : MŌ CVER AVÉS.

Plus loin, on voit un bouc léchant un vase rempli d'eau, et vers le bord du verre on lit l'in. scription circulaire :

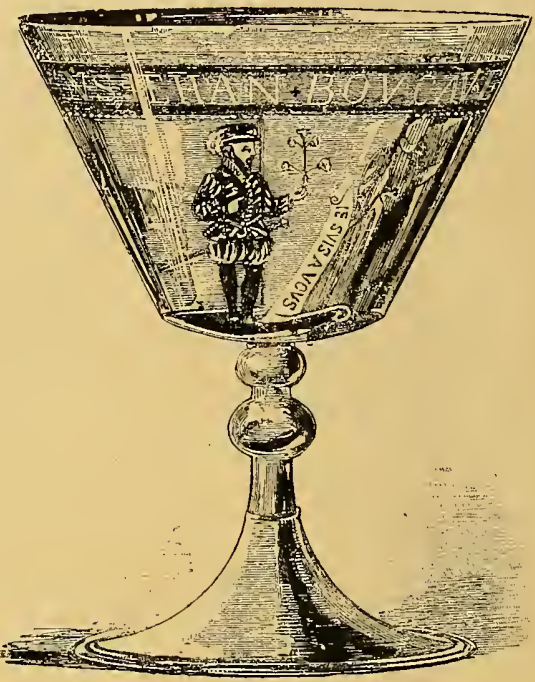

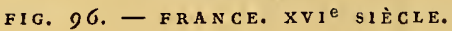
VERRE ÉMAILLÉ. (Collection Slade.)

JE SVIS A VOVS JEHAN BOVCAV ET ANTOYNETF BOVC.

Le verre de la collection du baron Davillier (fig. 97) rentre dans le même ordre de production.

Le plateau du musée de Rennes (fig. 9r) porte sa date; le décor émaillé est sur un fond bleu, l'inscription est en émail blanc; le corps de l'oiseau, très sail- 
lant, est blanc, tacheté de brun, les pattes brunes et la branche d'un gris bleuté; on ne connaît pas l'origine de cette pièce intéressante, mais il n'y a aucune témérité à l'attribuẹr à un verrier italien établi en Poitou.

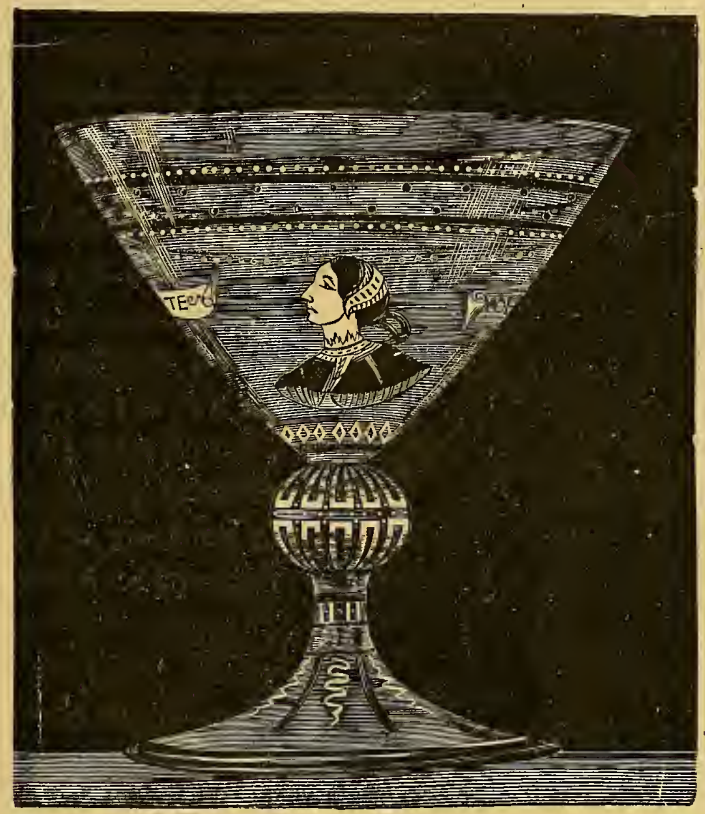

FIG. 97. - FRANCE. XVI SIÈCLE. VERRE ÉMAILLÉ. (Collection du baron Davillier.)

Il reste deux types authentiques des verreries françaises sous Louis XIII : une aiguière et un bassin de la collection d'Huyvetter; ils sont émaillés; on voit sur l'aiguière un boulanger pétrissant le pain, avec les mots :

VIVE LA BELLE QUE MON COEUR AIME. 
Et sur le bassin la même acclamation et la date 1625 . Toutes ces pièces sont manifestement d'un caractère italien pour le décor; elles n'ont de français que le costume des personnages et leur galanterie.

Les verreries du centre de la France et de l'Ouest ne semblent pas avoirpros-

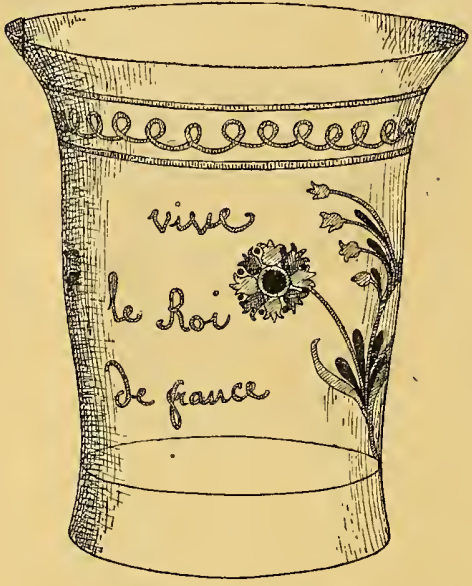

F!G. 98 . - FRANCE.

XVIII S SIÈCLE. VFRRE ÉMAILLÉ. (Collection Champleury.) péré sous Louis XIV; il est surprenant que le génie de Colbert ne leur ait pas accordé la même protection qu'aux manufactures de glaces; ce grand homme paraît, en verrerie, n'avoir donné son estime qu'aux grandes pièces de faste et de luxe, qui répondaient sibien aux goûts somptueux de son prince. En 1662 cependant, il fit accorder à Jean Castelon le privilège pour trente ans d'établir le long de la Loire, depuis Nevers jusqu'à Poitiers, des fabriques de toutes sortes de verres, de cristal et autres marchandises de verreries. La même année, fut également breveté Bernard Perrot, écuyer, maître de verrerie à Orléans; le privilège fut prorogé à plusieurs reprises, à cause d'une invention tenue pour extraordinaire. "Il a inventé un moyen inconnu jusques à présent de couler le cristal en tables, comme on 
fait les métaux, luy donnant telle couleur que l'on veut, mesme de rendre lesdites tables creuses à la manière de camayeux et d'y représenter des portraits, d'y graver des lettres et toute autre sorte de figures, comme pareillement de faire toute sorte de bas-reliefs, corniches et moulures. „Le privilège fut confirmé en I 668 et de nouveau en ${ }_{1} 672$, à la suite d'une réclamation introduite par Perrot contre Paul Massolay de la Motte, qui avait obtenu " par surprise » du duc d'Orléans, frère du roi, l'autorisation d'établir une verrerie à Orléans. Dans les considérants de la dernière concession, il est dit que Perrot a su

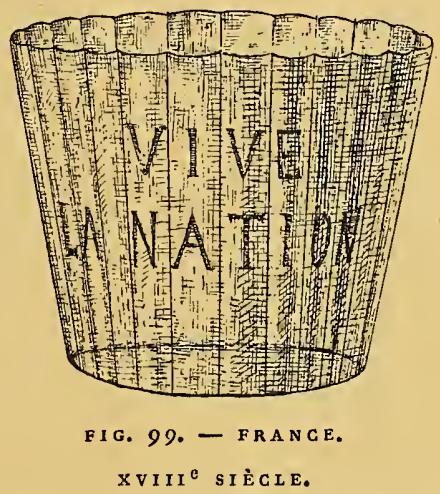
" rendre le verre intérieurement et dans sa substance en couleur rouge, transparent, mesme faire un riche émail qui s'applique sur toutes sortes d'ouvrages de cuivre et autres matières. " En conséquence, il est autorisé de faire pendant vingt ans " toutes sortes d'ouvrages de cristal, de verre commun, de verre teint et d'émail et autres sortes de verreries, en telles figures, fassons, manière et grandeur qu'il conviendra pour la commodité publique ". Perrot avait un magasin à Paris; il est cité dans la liste des adresses de cette ville pour l'année I69I, par du Pradel. Nous reproduisons une burette fleurdelysée qui lui est attribuée (fig. 89). 
Au cours du xvili e siècle, les verreries de la région de l'Ouest éteignirent successivement leurs feux, à cause de la concurrence étrangère; la Révolution en trouva peu en activité; cependant il reste, comme types de la verrerie du Poitou de ce temps, un verre blanc à côtes avec une inscription en lettres rouges :

\section{VIVE LA NATION.}

Et un autre semé de fleurs rouges et jaunes entourant le nom du CITOYEN BONNARD.

La verrerie révolutionnaire n'est pas aussi répandue que la faïence de la même époque; c'est la raison qui nous a fait citer ces deux pièces. 


\section{LA FRANCE}

LES PROVINCES DE L'EST.

Les verriers des provinces de l'Est jouissaient déjà de certains privilèges au xıvo siècle. Ceux de la Champagne adressèrent à Philippe le Bel, qui régna de 1285 à ${ }_{3}{ }_{14}$, des réclamations au sujet de la confirmation de leurs droits; cependant l'histoire de ces établissements est très obscure, l'époque de leur production est incertaine, et ce n'est qu'au $\mathrm{xv}^{\mathrm{e}}$ siècle que la lumière commence à se faire sur certains points.

Jean de Calabre, gouverneur des duchés de Lorraine et de Bar, en l'absence de René d'Anjou, son père, signa, en I448, "la Charte des verriers"; ce document, brûlé à Fontenoy, fut authentiquement recopié et expédié à Nancy, le 15 septembre 1469 . Nous en donnons l'analyse avec quelques citations ${ }^{1}$.

"Jehan, filz du roy de Hiérusalem et de Sicile, etc.,

I. M. Beaupré. Les Gentilshommes verriers dans l'ancienne Lorraine. Nancy, 1846 . 
duc de Calabre et marquis du Pont, lieutenant de Monseigneur en ses duchez de Bar et de Lorraine, à tous ceux qui ces présentes verront, salut. La supplication de nos âmez Pierre Brysonale, filz de Jehan Brysonale, Henry filz, Nycholas Mengin, Jacob Guillaume du Tyson et Jehan son filz, tous verriers et ouvriers ez verrières de Jehan Brysonale, en la verrière des Aufans, en la verrière Jacob et en la verrière Jehan Hendel ${ }^{1}$ qui à présent est vague, icelles verrières estant ez bois et forest de Monseigneur, en sa prevosté de Darney, en son duchié de Lorraine avoir oye ". Suit l'explication de la perte des lettres de 1448 par le fait des "guerres qui par longue espace de temps ont reigné audit pays ", et le désir de reconnaître " plusieurs beaux droitz, libertez, franchises et prérogatives, et dont eulx et leurs prédé-. cesseurs ayant joui et usé de tous temps passez et esté tenus et réputez en telle franchise comme chevaliers estimez et gens nobles dudit duchié de Lorrainne ». La Charte exempte les verriers, leurs hoirs et successeurs de "toutes tailles, aydes, subsides, d'ost, de giste et de chevaulchiées et de tous débits, exactions et subventions quelconques qui pourroyent estre imposez sur le duchié de Lorrainne ". Les aydes et subsides étaient les impôts levés extraordinairement en temps de guerre, mais qu'on laissait subsisteraprès; les droits d'ost et de chevauchée exercés par le seigneur, forçaient le vassal à le suivre à la guerre; l'exemption du gîte assurait la demeure contre l'obligation de loger le prince et les gens de sa suite;

r. Les noms de Tyson et de Hendel sont ailleurs écrits Tysal ou Thysal, Hennezel ou Henezel; ces changements d'orthographe sont très fréquents alors et plus tard. 


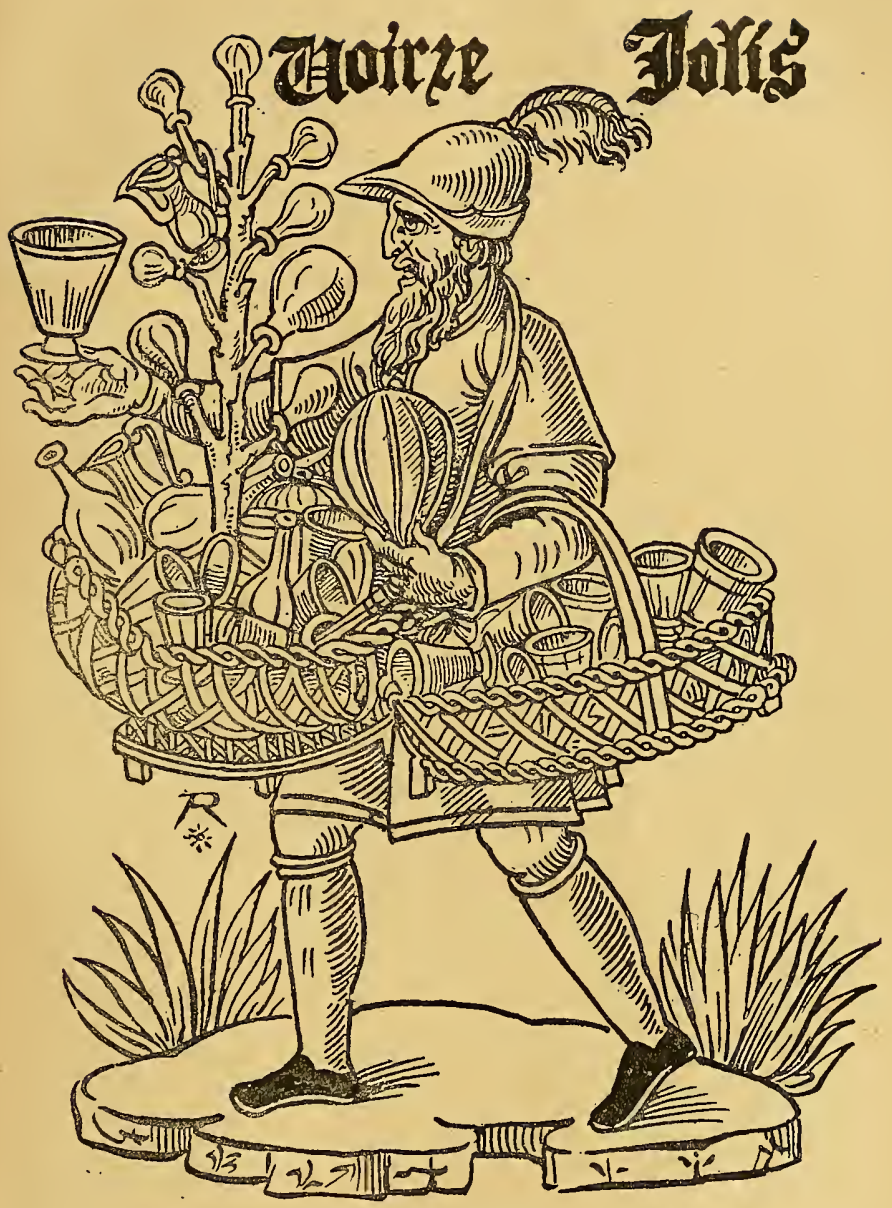

FIG. IOO. - FRANCE. - ESTAMPE DU XVI SIÈCLE.

ces avantages étaient donc considérables; ils allégeaient 
le fardeau de l'impôt personnel et professionnel et donnaient sécurité au travail. La marchandise était également protégée : "Iceulx lesdits ouvriers pourront faire, ez dites verrières, verres tels et de telle couleur qui leur plaira, et les faire mesner et pourront les vendre par tous les pays de Monseigneur, où bon leur semblera, sans que eulx ou ceulx qui mesneront ou qui porteront lesdits verres soient tenuz à cause desdits verres, payer aulcun passaige, gabaile, ni tributz quelconques». Les transactions étaient, à l'époque et longtemps après encore, entravées par des droits de passage, de péage, de gabelle, etc., sortes de douanes intérieures et d'octroi; l'affranchissement de ces taxes constituait donc un notable dégrèvement de l'impôt sur la marchandise fabriquée. Les verriers avaient le droit de faire paître dans les forêts cent porcs, soit vingt-cinq par verrerie, de couper le bois nécessaire à la consommation de leur ménage, à la construction et au chauffage des fours; ils pouvaient aussi cueillir et emporter "fouchières et toutes aultres herbes propres et convenables pour le fait de leur mestier", le tout moyennant une redevance annuelle, "six petits florins au comptant, chacun florin de deux gros, monnoye courant audit duchie de Lorraine ", ce qui était une valeur d'environ cent cinquante francs. A cette époque et pendant plusieurs siècles èncore, on cherchait dans les cendres des "fouchières", fougères, le carbonate de potasse pour fondre le verre. Pour affranchir les verriers de faire moudre leur blé au pays de Bourgogne, ils purent élever un moulin et enfin ils eurent la facilité de " chasser ez bois et forestz de Monseigneur, à l'environ desdites verrières, à bestes 
grosses et rousses, à chiens et harnois de chasses, quand il leur plaira " et de " pescher à filet et harnois et prendre poissons ez rivières et ruisseaux ". Les'quatre verreries privilégiées étaient tenues, l'une par les familles du Tyson et Colin, l'autre par Mengin et son fils, la troisième par Jehan Henezel, la quatrième, par Claude Bysenate et Chelizot.

Ces privilèges constituaient un monopole, non seulement pourl'exploitation des verreries, mais pour l'exercice mêmedu métier; François du Tysal, concessionnaire dans la forêt de Darney, ayant pris, en r 516 , comme apprenti un nommé Dardenay, originaire de la Bourgógne, et Du Preys, natif de Bonpairre, en Lorraine, fut dénoncé au duc par ses ouvriers, qui demandèrent "que nul d'entre eux dès maintenant, comme pour lors, apprendra ou pourra apprendre le métier de verrier à besongner de mêmes verres à aucun qui qu'ils soient, sinon à leurs hoirs mâles légitimement prouvés de leur mariage, sous peine de parjurement, d'amende arbitraire et d'encourir l'indignation de nous et de nos successeurs de Lorraine ". Le prince approuva cet appointement "en considération du bien et utilité qui précède d'avoir verrières en nos pays, désirant l'entretiennement d'icelles et des verriers y demeurant, et aussi la conservation de leurs droits, usages et privilèges ${ }^{1}{ }^{1}$. Le bien et l'utilité d'avoir des verreries eût été mieux compris en facilitant l'apprentissage à tous qu'en le limitant aux enfants des verriers.

L'acte du duc Jean de Calabre reconnaît aux maîtres

I. H. Lepage. Recherches sur l'industrie lorraine. 
verriers leur état antérieur de noblesse, mais la noblesse était-elle acquise par le seul fait de l'exercice de la profession de verrier en tant que patron et ouvrier?

La question donna

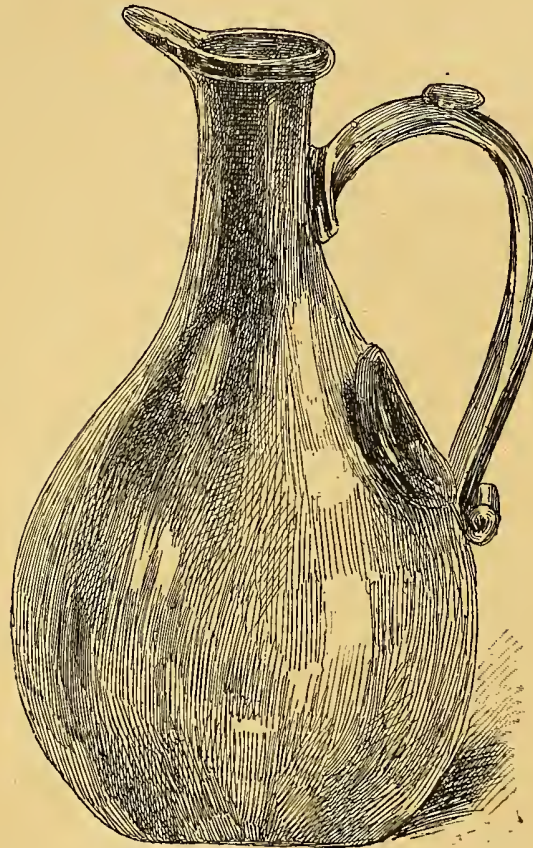

FIG. IOI. - FRANCE. XVII SIÈCLE. A IGUIÉRE A RAFRAICHIR LES VINS AVEC RÉSERVOIR INTÉRIEUR lieu à des controverses et à des procès. La Verrerie est-elle un art noble, comme l'avait proclamé le grand conseil de Venise en 1383 ? Les verriers soutenaient naturellement l'affirmative et l'opinion de Lulli, le plus célèbre chimiste du temps, était avec eux, car il proclamait que le verre était le premier produit de la philosophie chimique; les opposants prétendaient le contraire, car, disaient-ils " il n'y a rien qui gâte le corps et corrompt plus l'esprit que la force du feu". La querelle dura longtemps. Henri IV et Charles III, duc de Lorraine, la résolurent: il fut décidé que les nobles qui feraient à 
l'avenir de la verrerie ne dérogeraient pas; que les verriers d'extraction noble seraient tenus pour nobles et qu'il en serait de même des descendants des anciens verriers lorrains. Cette situation devint à peu près générale en France; les rois conférèrent des titres de noblesse à certains verriers français et italiens, mais expressément à titre de faveur. La noblesse de race, d'épée et de robe affectait de dédaigner les gentilshommes verriers, et François Maynard, l'un des premiers membres de l'Académie française, leur lança cette épigramme :

Votre noblesse est mince;

Car ce n'est pas d'un prince,

Daphnis, que vous sortez.

Gentilhomme de verre, $\mathrm{Si}$ vous tombez à terre, Adieu vos qualités.

Aux noms des gentilshommes verriers lorrains cités il convient d'ajouter ceux de Finance, r 492 ; Thierry ou Thiétry, I496; Desprez, I554; du Houx ı63ı; de Mussel r633. Les maîtres portaient généralement le titre d'écuyer; quelques familles ont tenu les verreries pendant plusieurs siècles, d'autres les possèdenț encore de notre temps.

Nous manquons de détails précis sur le développement successif des verreries dans l'Est; avant le xvir ${ }^{e}$ siècle, il s'en établit en Lorraine, à Darney, à la FontaineSaint-Lambert, au Faye, à Martinville, au Torchon, à la Haute-Frizon, à Neumont. Voici cependant quelques dates; deux verreries à bouteille existaient, en $\mathrm{s} 5$ r 8 , à 
Chatrice et au Bois-Japin dans l'Argonne française, surles confins de la Champagne; dans la forêt de l'Argonne, au bailliage de Clermont (Meuse), il y avait «forges à faire mirouers, voirres fins et communs, avec voirreries de gros voirres". On y fabriquait " plusieurs sortes de voirres fins en la semblance de christallins, et d'autres voirres communs, autant que l'on sçauroit soubhaiter; et pour chose nouvelle venue de nostre temps, au lieu du Pont-à-Mousson, quinziesme jour de juing environ, le maistre voirrier fit présent au prince (le duc Antoine), modérateur dudict parc, d'ung crucifix mis sur une grande croix de voirre, en grosseur de la cuisse d'ung homme, accoustré si richement de couleur, que l'on estoit aveuglé de la beauté et lueur. Joinct semblablement à Raon au pays de Vosges, et à Saint-Quirin, l'on faict des mirouers qui se transportent par toute la chrestienté. Ce que l'on racompte avoir esté faictau lieu de Bainville surnommé aux mirouers, essir sur la rive de Mezelle, entre Charme et Bayan ${ }^{1}$ ». Vers I553, Josué Hennezel quitte la Lorraine pour aller établir à Bruxelles une fabrique de verres à vitres. En 1555, on trouve des verreries à Attigny, Belrupt et à Conrupt. Les établissements d'Attigny et de Belrupt, au nombre de cinq, fabriquaient le verre à vitre; ils n'observèrent pas les clauses de la concession accordée par Nicolas de Vaudemont, régent de Lorraine; ils " faisaient verres sans mesure et louyauté, contrevenant à leur art et estat de noblesse "; aussi une ordonnance de 1557

I. Volcyr de Serouville. Cronicque abrégée par petits vers huytains des Empereurs, Roys et Ducs Daustrasie. 1530. 
les rappela à leurs devoirs qui étaient de fabriquer chaque jour une quantité de verre, "bons léaulx et marchands » et de le marquer d'une marque de fabrique; ils furent soumis á un inspecteur "regardeur " chargé de s'assurer de la bonne qualité de la fabrication. Ces prescriptions, qui rappelaient, toute proportion gardée, les édits du Conseil des Dix de Venise, avaient pour objet de faciliter l'exportation du verre qui se faisait exclusivement en Suisse, au profit d'un concessionnaire attitré, Jean Lange de Bâle, d'où la marchandise était expédiée dans les autres pays. En 1560, Philippe II fit venir pour l'Escurial des échantillons de verre à vitres de la Lorraine; ce qui prouve encore que le produit était connu et apprécié, c'est une association conclue en r 568 entre Thomas et Balthasar de Hennezel et des verriers anglais, pour faire venir les Lorrains en Angleterre. Vers la fin du siècle, les verreries étaient nombreuses; on en comptait dix-huit dans la recette de Darney et quatre dans celle de Bompaire; un malencontreux impôt vint arrêter cet essor. A Nancy, il existait alors un centre important de maîtres verriers qui se constituèrent en corporation; on trouve parmi leurs noms ceux de Jean Martin, établi à l'hôtel du duc de Lorraine, Ydoolf Olivier, Jean Thierry, Vincent Claudot, Jean Clément. Le 16 octobre $160 \mathrm{I}$, ils firent approuver leurs statuts; selon l'usage du temps, le métier était réglementé à l'effet d'obtenir la qualité des marchandises, des garanties de capacité et de moralité de la part des maîtres et compagnons, une bonne gestion des deniers de la confrérie, qui s'augmentaient au moyen des amendes 
et d'un droit d'entrée. La corporation de Nancy paraît ne comprendre que les vitriers; mais, outre les verres à

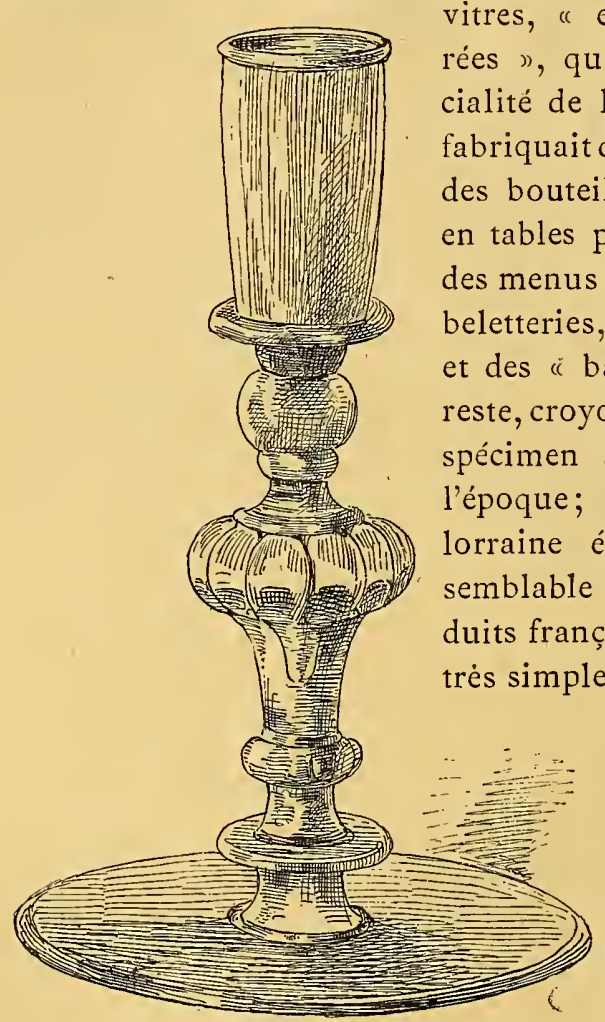

FIG. IO2. - FRANCE. XVII SIËCLE。

SUPPORT DE IAMPE。

(Musée de Cluny.) vitres, " en tables quar"es ", qui étaient la spécia Lorraine, on fabriquait dans la province bouteilles, des verres tables pour miroirs et derres pour gobeletteries, des "phiolles» (bassins ): Il ne reste, croyons-nous, aucun spécimen authentique de lépoque; la gobeletterie était sans doute chlable aux autres produits français, c'est-à-dire mode à l'usage et rarement décorée par la taille ou la gravure.

LexvII siècle ne fut pas propice aux verreries de Lorraine. Un nouvel impôt établi en r6o6, mal calculé, produisit peu et entrava la fabrication; l'exportation semble avoir cessé, et nous 


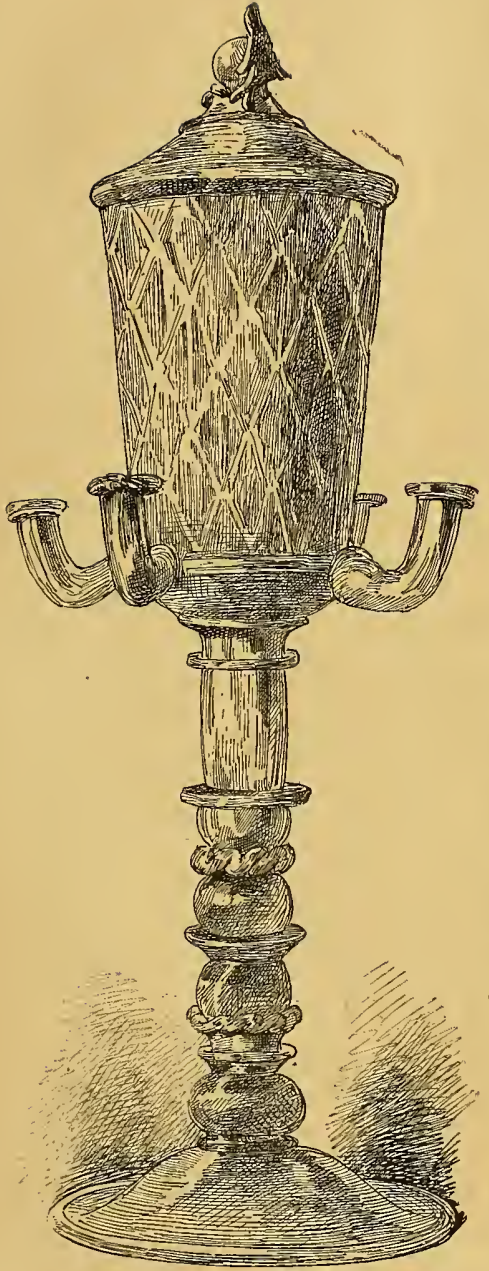

FIG. 103. - FRANCE. XVII SIÈCLE. LAMPE A QUATRE BECS.

(Musée de Cluny.)

constatons qu'en i 660 Paul d'Hennezel établissait une fabrique de verres à vitres à Fourmies dans le Hainaut. Un rapport du temps constate que les verreries de la forêt de Darney, du voisinage de Saint-Mihiel, et du village de Tonnoy, près de Nancy, "fournissent le pays de verre ". La verrerie de Munzthal, de l'ancien comté de Bitche, fut détruite pendant les guerres de la fin du siècle; elle existait depuis très longtemps.

Le Xviri siècle fut plus favorable; l'ancienne verrerie de Saint-Quirin ou Leutenbach fut réorganiséer, une société loua l'établissement aux moines qui en étaient propriétaires et y entreprit, en $\mathrm{I} 738$, la fa- 
brication des verres à vitres au moyen du soufflage en cylindre; la méthode était pratiquée en Bohême, mais non en France, où l'on continuait l'usage des verres en plateaux, appelés aussi verres à boudins; plus tard, Saint-Quirin reçut le titre de Manufacture royale et fabriquait " de beaux verres de table, verres de Bohême et cristaux ». D'autres verreries qui avaient éteint leurs feux les rallumèrent, et de nouveaux établissements furent fondés qui subsistent encore et sont à la tête, comme production et qualité, des cristalleries françaises; nous avons nommé ceux de Baccarat et de Saint-Louis. Baccarat fut fondé, en i 765 , sous le nom de verrerie de Sainte-Anne, par l'évêque de Metz, $\mathrm{M}^{\mathrm{gr}}$ de Montmorency-Laval, et par Antoine Renault, avocat au Parlement, conseiller du roi, receveur des bois et domaines à Nancy. Renault resta directeur jusqu'en I 806 ; dix ans plus taid, d'Artigues, fabricant de cristaux à Vonèche, en Belgique, transporta sa fabrication à Baccarat, la prohibition l'empêchant d'écou. ler en France ses produits belges. La cristallerie de Saint-Louis a été fondée, en 1767 , dans la vallée de Munzthal, par MM. de La Salle, Olivier, Anthoine et Joly; elle débuta par le verre à vitre et la gobeletterie commune; en I $78 \mathrm{I}$, M. de Beaufort, directeur de la verrerie, fit des essais sur la fabrication du cristal qui venait alors exclusivement de l'Angleterre, et, le i 2 janvier I782, l'Académie des sciences inscrivit la découverte dans ses procès-verbeaux, sur le rapport de Macquer et de Fougeroux de Bondaroy. C'est à tort que l'on a attribué les premières fontes de cristal sur le sol de France à Lambert; ce verrier ne s'établit à Saint-Cloud 
qu'en 1784 , pour transporter en $\mathrm{i} 787$ son industrie à Moncenis, près du Creusot, avec le titre de Verrerie de la Reine.

\section{I}

Nous venons de parler de l'Académie des sciences; cette illustre compagnie se préoccupait beaucoup des industries françaises; elle constata l'état fort médiocre de nos verreries et, en 1760 , elle mit au concours cette question : «Quels sońt les moyens les plus propres à porter l'économie et la perfection dans les verreries de France?" Le docteur Bosc d'Antic remporta le prix; son mémoire donne quelques renseignements sur la situation des verreries en Europe. Les glaces de Murano sont les plus mauvaises. L'Angleterre en fabrique des quantités considérables en cristal, verre blanc et verre commun; la matière n'est pas belle, elle tire sur le jaune et le brun et est mal raffinée; malgré ces défauts, la marchandise anglaise entre pour les quatre cinquièmes dans la consommation de l'Europe. L'Allemagne, Nuremberg et Neustad notamment, fabriquent des glaces supérieures aux produits anglais; la Saxe, la Bohème, la Franconie, le Palatinat, importent en France les lustres, les bras de cheminées, les flacons, les carafons, la verrerie de table, les verres à vitres, à cadrans, à estampes. La France est tributaire de l'étranger, à cause de l'ignorance des maîtres verriers et de la mauvaise qualité des matières premières. Bosc d'Antic passe en revue la fabrication tout entière; il donne de nouvelles 
formules de composition, des profils de fours et de creusets; il étudie l'emploi des terres réfractaires et des divers combustibles. Son mémoire est apprécié par les praticiens, et, quelques années après, la verrerie française est de meilleure qualité et à meilleur marché. 


\section{LA FRANCE}

LA NORMANDIE. - SAINT-GOBAIN.

Les curieuses recherches de l'un des descendants des anciens gentilshommes verrier's ${ }^{1}$ ont prouvé que, depuis le commencement du xiv ${ }^{e}$ siècle jusqu'à nos jours, on a installé en Normandie soixante-dix verreries. Les plus anciennes existaient: celle de la Haye, dans la forêt de Lyons en $\mathrm{r} 302$, et celle du BoisMallet en $\mathrm{r} 3 \mathrm{r} 3$. Voici quelques autres dates de fondation ou d'existence constatée: Caudel I 497, Gast I 532, Varimpré I 573 , Courval I623, Grand-Vallée I640, Beaumont-le-Roger 1678 , Romesnil 1776 , Belle-Vue I796. Au moment de la Révolution, il y avait vingtcinq verreries en fonctionnement; quelques-unes ont continué à travailler après la suppression des privilèges. Dans l'origine, le privilège des verreries normandes fut accordé à quatre familles verrières nom-

I. O. Le Vaillant de La Fieffe. Les Verreries de la Normandie. Rouen, 1873 . 
mées de Cacqueray, Le Vaillant, de Brossard et de Bongars, dont on trouve mention dans les archives de quelques verreries jusqu'à la Révolution et même plus loin; il est inutile d'ajouter que ces familles ne furent pas les seules qui obtinrent des privilèges.

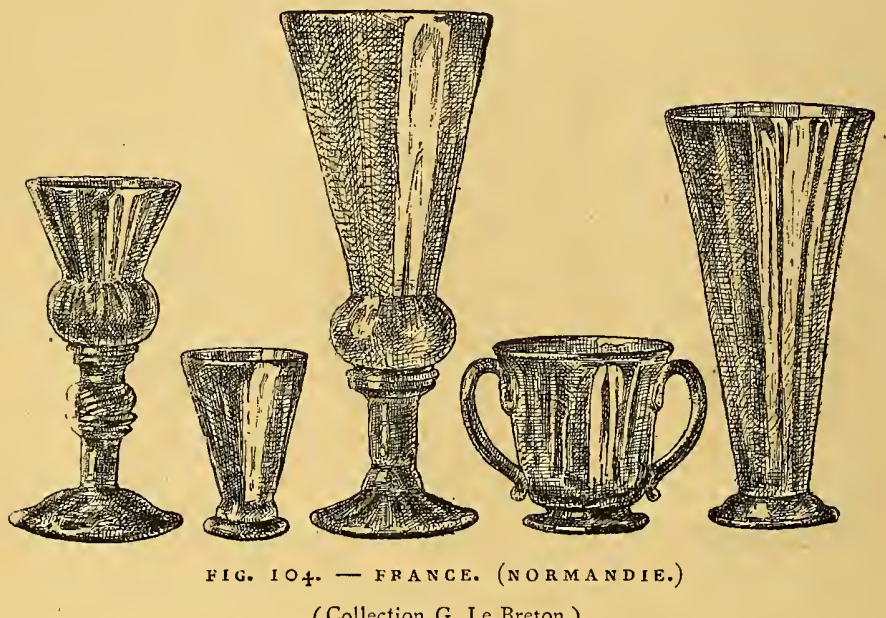

(Collection G. Le Breton.)

On admet que la verrerie de la Haye, exploitée d'abord par maître Gobert pour le compte du roi Philippe le Bel, fut concédée à Philippe de Cacqueray en 1330 , parce que ce gentilhomme avait inventé, dès le commencement du siècle, une sorte de verre à vitres, le "plast de verre " ou "verre de France ». Nous avons vu, au cours de cette étude, que l'usage de garnir les fenêtres avec du verre était fort ancien et n'avait jamais été complètement abandonné. Cacqueray facilita cet usage par son "plast de verre ", qui était une vitre 
en disque ou en plateau ayant au centre une loupe ou boudine; le produit était le résultat du soufflage et provenait d'un globe ouvert et aplati. Dès I338; on constate dans la grande salle du "chastel » de Rouen "vi piés de verre assis entre deux châssis en fer »; en
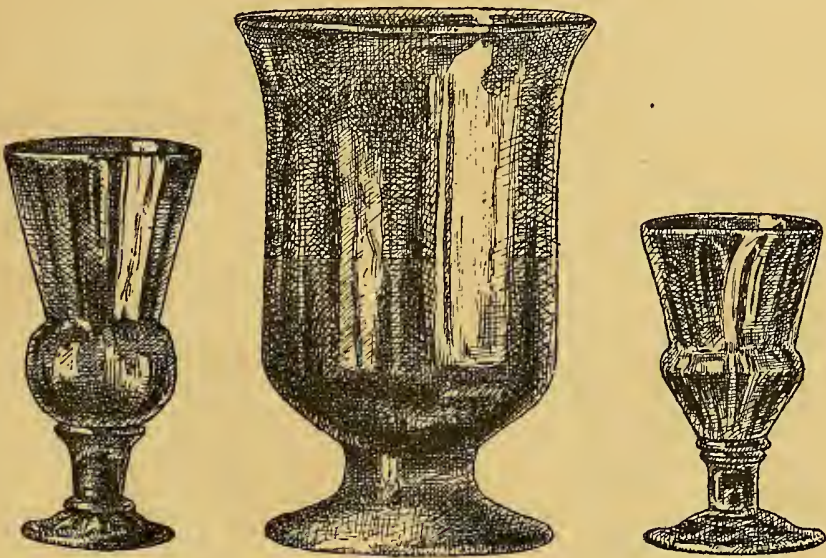

FIG. 105 . - FRANGE. (NORMANDIE.)

(Collection G. Le Breton.)

I 485 , le verre à vitre normand est connu en Angleterre et, en r 56o, il entre en concurrence en Espagne avec les verres de Bourgogne et de Lorraine, pour être jugé le plus clair de tous.

Les verreries normandes étaient de deux sortes : les grosses verreries, qui fabriquaient les vitres en plat, appelées aussi verre à férule, et les petites verreries, d'où sortaient les verres à boire, carafes et autres ouvrages de verre blanc, Les grosses verreries firent aussi des 
bouteilles, surtout après que le privilège exclusif des glaces eut été concédé à l'établissement qui devint plus tard la manufacture de Saint-Gobain. En I647, on trouve en Normandie des « verryers bouteillers» et, en
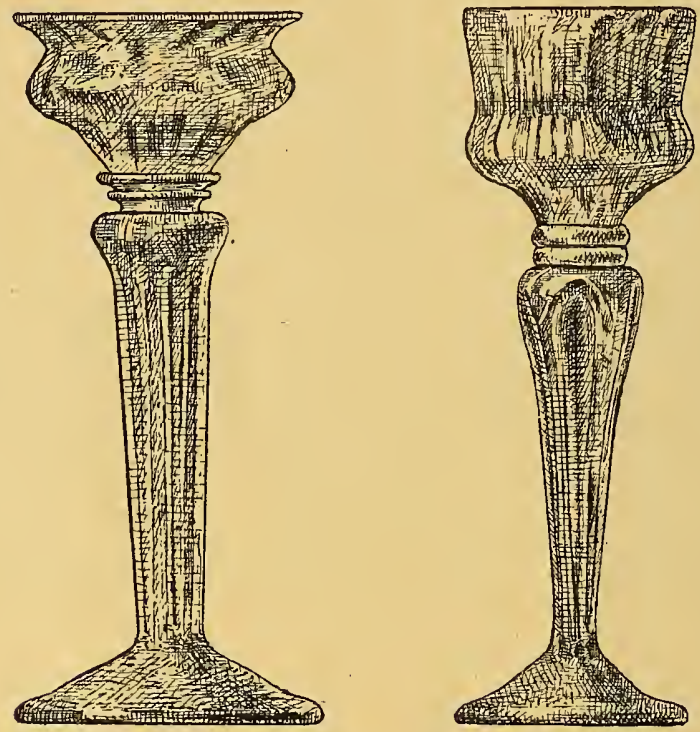

FIG. IOG. - FRANCE. (NORMANDIE.)

(Collection G. Le Breton.)

I664, des fabricants de "toutes sortes de verres et verreries, même verres de cristal, émaux et glaces à miroirs $).$

Les verreries de Rouen et des environs présentaient un intérêt spécial. Au xvi siècle, il existait dans la ville des patenostriers qui, à l'imitation de Venise, fabri- 
quaient des chapelets, perles, boutons, grains et autres
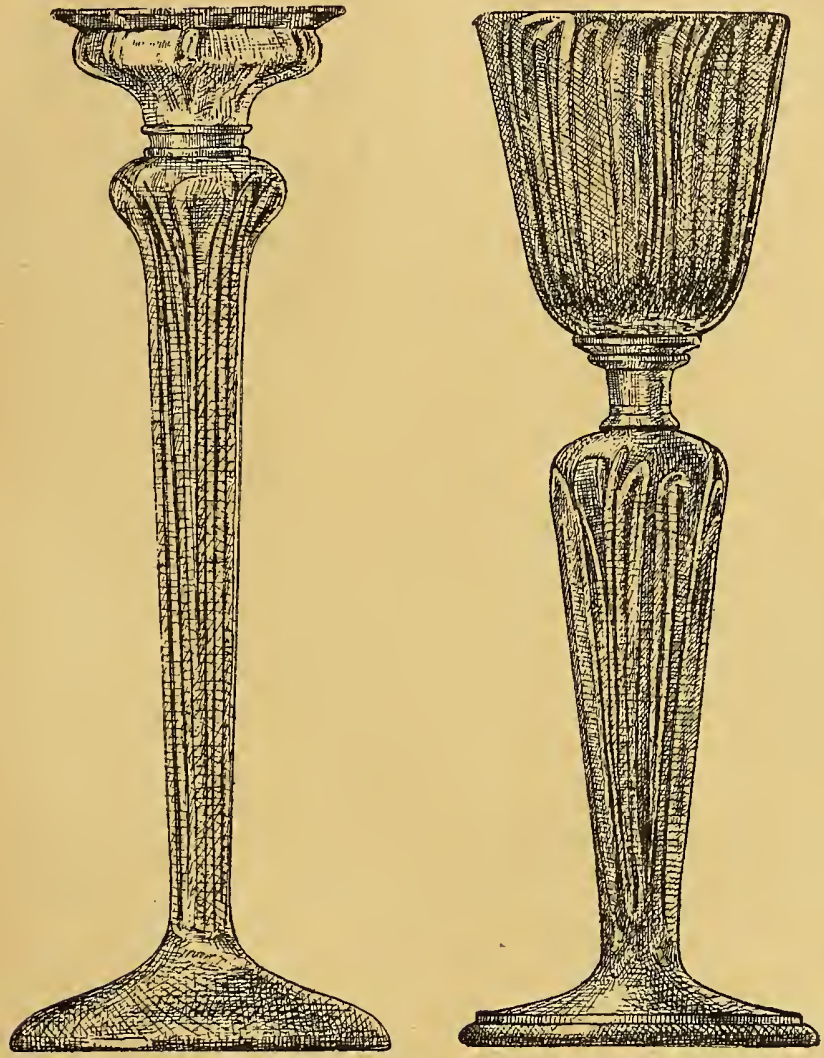

F1G. 107 . - FRANCE. (NORMANDIE.)

(Collection G. Le Breton.)

menus objets en verre de couleur; ils tiraient leurs cannes de verre des verreries de la ville ou de celle de 
la Mailleraye; leurs statuts de I 593 , confirmés par lettres patentes du roi en 555 , disaient que " les maistres du dict mestier pourront faire patenostres et boutons d'esmail et de verre, chaisnes, colliers et braceletz passantz par le feu et fourneau " ${ }^{1}$. Le 24 janvier 1598 , Henri IV, "voulant donner à ses sujets du pays de Normandie l'usage commun des ouvrages de verrerie comme chose qui leur est nécessaire ", autorisa Vincent Buson et Thomas Bartholus, verriers originaires du duché de Mantoue, à établir à Rouen ou dans les faubourgs une verrerie pour "verre de cristal, verres dorés, émaux et autres ouvrages qui se font à Venise et autres lieux et pays étrangers, et autres qu'ils pourront de nouveau inventer ". Le privilège semble ètre resté à l'état de lettre morte, car, le 8 mars r 605, Françoịs de Garsonnet, d'Aix en Provence, fut autorisé, par lettres patentes, à établir à Rouen, au faubourg de Saint-Sever, où il n'y avait aucune verrerie de cristal, une verrerie avec des ouvriers étrangers et, de plus, il fut interdit pendant dix ans de fonder dans le ressort du Parlement de Rouen aucun autre établissement du même genre; le 4 mai r 6 r 3 , le privilège fut prolongé pour dix ans, Garsonnet n'ayant que médiocrement réussi, quoique, disent les lettres patentes, " on ne sçauroit faire élection d'homme plus intelligent et capable, par le témoignage qu'il en a déjà rendu en l'art de la dite manufacture de verre de cristal ordinaire et rafiné, que aussy aux ouvrages de canons et d'émaulx de verre de belles et riches couleurs non encore usitées. "Garsonnet em-

I. A. de Girancourt. Revue de Normandie. 1867. 
ploya, en 16 I 6 et en 1619 , le charbon de terre anglais pour le chauffage de ses fours, le bois étant devenu rare ${ }^{1}$. A près quatorze ans de fabrication, le maître céda son privilège moyennant 7,500 livres tournois et son matériel et magasin moyennant 22,307 livres à Jean et Pierre d'Azemar, qui eurent pour bailleur de fonds Antoine Girard du faubourg de Saint-Sever; ce dernier devint plus tard le beau-frère de Pierre d'Azémar. L'homologation de la vente par le Parlement de Rouen fut faite en $16 r 9$, à la condition que le verrier userait à l'avenir de charbon de terre. Rouen a ainsi suivi de très près l'Angleterre dans l'emploi de ce combustible,

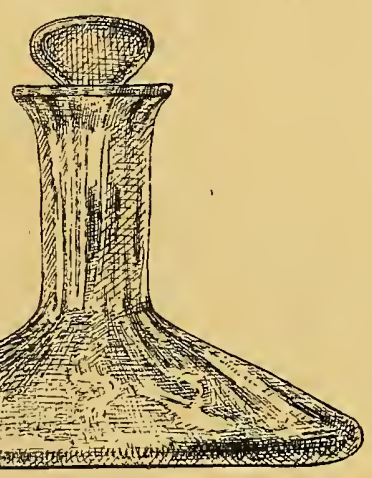

FIG. 108 . - FRANCE. (NORMANDIE.)

(Collection G. Le Breton.) car la plus ancienne mention connue de cet usage en Angleterre est une patente de 16 II; en 1615 , une ordonnance de Jacques Ier prohiba le bois dans les verreries. La fabrique de Saint-Sever avait vu son privilège temporaire changé en privilège perpétuel, mais bientôt les réclamations furent si nombreuses, qu'en i65o le roi autorisa les anciennes familles verrières de Normandie à

I. Arrêt du parlement de Rouen du 4 août 6 I6. (Garsonnet contre les mesureurs de Rouen.) 
faire du cristal. En 1753 , la verrerie de Saint-Sever a encore ses feux allumés; de la famille d'Azemar, elle

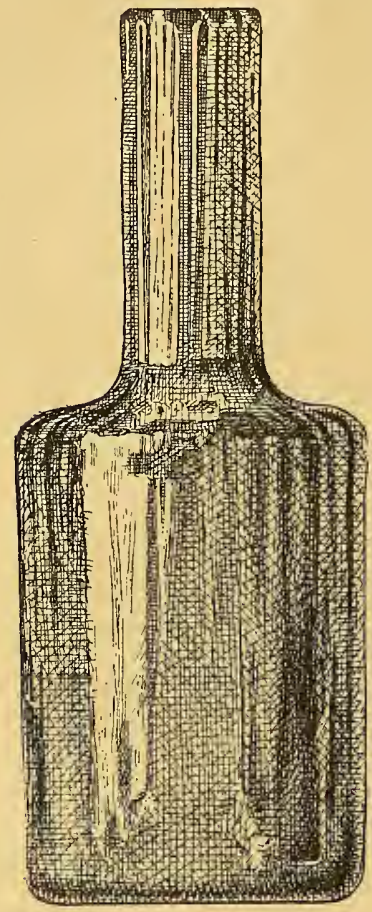

FIG. 109. - FRANCE.

(NORMANDIE.)

(Collection G. Le Breton.)

passa entre les mains de Jean-Baptiste Cardon et ensuite de A.-F. Hubert.

La verrerie du faubourg de Saint-Sever ne fut pas la seule en Normandie qui fabriqua du verre blanc de service de table. Vers 1634 , on constate au Caule, dans la forêt d'Eu, une verrerie tenue par Henri de Virgille, qui semble être venu du Languedoc avec la famille d'Azémar, chez laquelle il a travaillé jusqu'à l'époque de son établissement. Fn I 784, Mayer Oppenheim, Hongrois de naissance, fut autorisé à établir au PetitQuevilly une manufacture " de cristaux blancs façon et qualité d'Angleterre ». Oppenheim était resté vingt-huit ans dans une fabrique de cristaux de Birmingham; l'administration française lui alloua une prime de r,20o livres pour qu'il fìt connaître ses procédés au gouvernement. On pense que sa verrerie dura peu et qu'il ne produisit 
que des marchandises médiocres; cependant, il avait chez lui un nommé Libourg, "graveur d'armes, chiffres et emblèmes sur verre et crystal ".

Quelle était la verrerie de Saint-Sever? A en juger par les lettres patentes de concession ou de confirmation, elle donnait « de plus excellents ouvrages qu'aucune de ce Royaume ». et « les ouvrages de Venise n'ont plus aucun avantage sur les leurs »' ${ }^{\prime}$. Ils sont “ si beaux et excellents qu'ils égalent ceux de Venise " ${ }^{2}$. D'après les mêmes documents, la fabrication comprenait les verres de cristal, les "canons" baguettes pour les patenostriers, les émaux et les glaces et miroirs soufflés. Il y a certainement de l'exagération dans les mentions

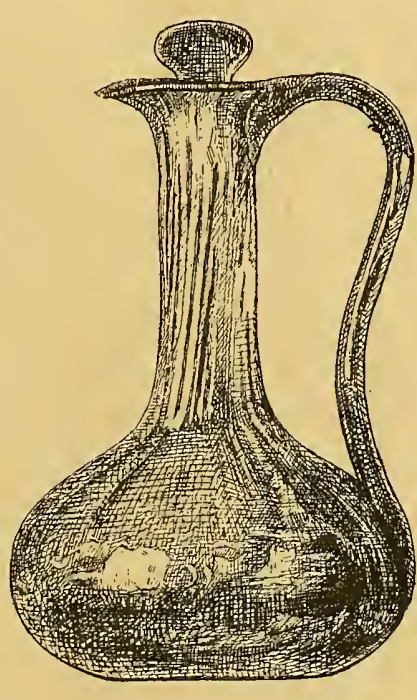

FIG. I I O. - FRANCE.

(NOR MANDIE.)

(Collection G. Le Breton.) des lettres patentes, cependant par l'examen de la très curieuse collection que M. Gaston Le Breton a formée des verres normands qu'il a pu recueillir et dont il publiera bientôt l'histoire ${ }^{3}$, nous pouvons nous faire

I. Lettres de concession, mars 1635.

2. Confirmation du privilège, juin 1642 .

3. L'ouvrage que prépare M. G. Le Breton portera le titre de: La Verrerie rouennaise. 
une idée exacte de la verrerie de table de Saint-Sever. Les bouteilles sont très simples; il y en a pour l'eau, le vin de table, les vins d'Espagne, le cidre; les verres

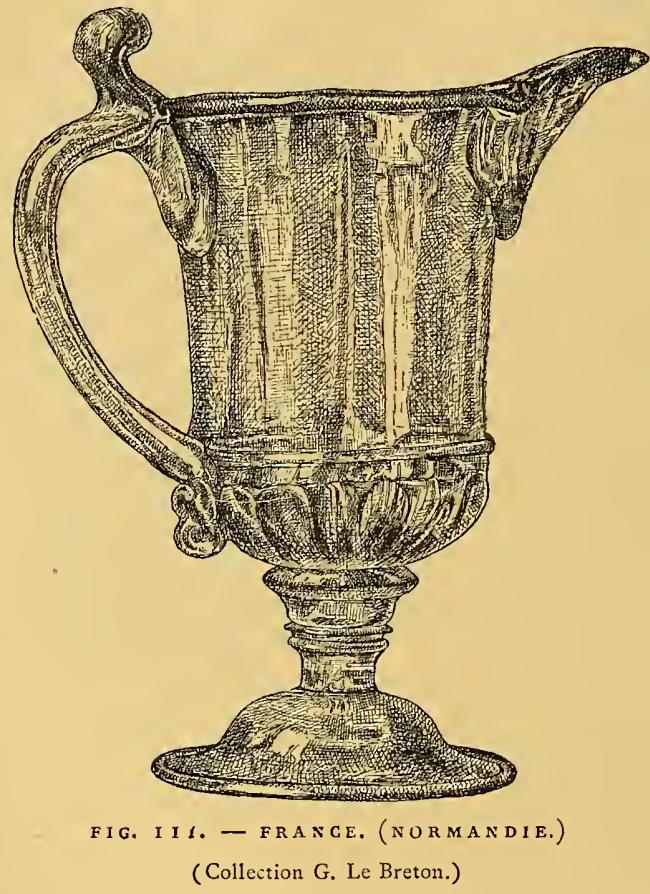

sont d'une forme élégante, élancée, très hauts sur tige et d'une capacité selon la convenance, assez forte pour le vin, mo ind re pour les liqueurs, petits et évasés pour les fruits confits; certains vases a ffectent des formes céra$\mathrm{miqu}$ e s, celle du vase en casque, par exemple. Les verres de Rouen, dont nous reproduisons quelques types, sont l'ouvrage du verrier proprement dit; ils ne sont généralement décorés ni par les émaux ni par la gravure; ces pièces sont d'un grand intérêt pour notre production nationale, et nous font regretter que les amateurs des 
autres contrées de la France n'aient pas, comme M. B. Fillon pour le Poitou et M. Le Breton pour Rouen, recueilli les verres dont nos aiëux se servaient dans les repas de famille et les fêtes d'apparat.

\section{I}

En Normandie comme en d'autres contrées, les rois de France ont encouragé " l'artifice de voirrerye » par des privilèges, dont le plus apprécié paraît avoir été celui de ne point, en travaillant le verre, déroger à une noblesse de race bien et dûment justifiée. C'est une erreur fort répandue que de croire que le métier de verrier conférait la noblesse; il n'en était rien et, selon un ancien proverbe, " pour faire un gentilhomme verrier, il fallait d'abord prendre un gentilhomme ". Les ouvriers comme les patrons pouvaient être gentilshommes et, dans cartaines verreries, il y avait l'atelier des nobles et l'atelier de ceux qui ne l'étaient pas. Le gentilhomme ouvrier de Normandie mangeait au souper seulement à la table du maître, car, pour les nécessités du service, il dînait devant son four; pendant le travail, il avait du cidre à discrétion. Il portait le chapeau brodé et l'épée; son cheval et son chien étaient nourris par le patron et soigné par les domestiques de celui-ci. Le gentilhomme ne soufflait pas la bouteille, le métier n'étant pas assez distingué. Il recevait par an, vers la fin du xvile siècle, I,300 livres comme ouvrier, 800 comme aide et 400 comme apprenti.

Les privilèges plus sérieux étaient ceux qui con- 
féraient le monopole de la fabrication et de la vente dans un pays et qui donnaient le droit de " coupper fougère à la faucille pour employer à l'artifice de voirrerye ", de ramasser le bois mori et de " coupper et abattre du vif boys tant seulement que la haye, la chas-

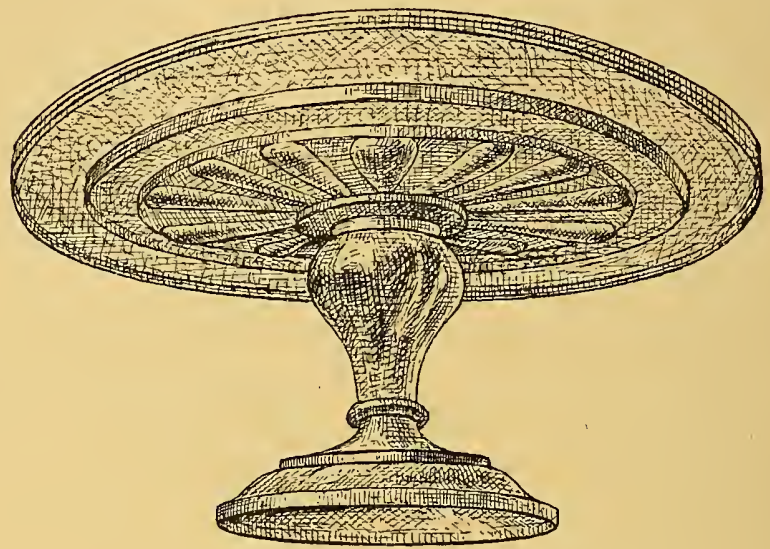

FIG. I I 2. - FRANCE. (NORMA NDIE.)

(Collection G. Le Breton.)

tellenye, la verderye en pouvoit porter, sans faire dégast aux bois et forest de Sa Majesté ». La redevance à servir était assez mince. En I4I6, Cacqueray payait au terme de Pâques " ung escu d'or » par an; d'autres servaient soixante boisseaux d'avoine ou un petit assortiment de verres de leur fabrication. La question du combustible donnait lieu à de fréquents débats; le grand-maître enquêteur et réformateur des Eaux et Forêts avait mission, dans l'intérêt de l'exploitation 
des forêts, de veiller à ce que les maîtres de verrerie ne fissent "qu'user de leurs droictures et franchises modérément sans aulcun excez ny abus "; aussi, sur les propositions de ce fonctionnaire, les privilèges étaient accordés, prorogés ou annulés.

Les gentilshommes verriers étaient exempts des tailles, aides et subsides, et le transport de leur marchandise n'était taxé d'aucun droit de " passaige, gabaile ni tributz quelconques ».

\section{I I}

La Normandie revendique avec raison pour l'un de ses enfants l'invention des glaces coulées. Il existait dans la forêt de Brix, à Tourlaville, près de Cherbourg, une verrerie gérée par un membre de la nombreuse famille de Cacqueray; après la mort du gérant, Louis XIV accorda le privilège à Richard Lucas, écuyer, sieur de Néhou, et à son neveu Louis, de fabriquer toutes espèces de cristaux, verres à vitres et à lunettes. La verrerie, dirigée avec intelligence, produisit des verres à vitres blancs, ce qui fut regardé comme une nouveauté et, en I656, les gentilshommes de Néhou furent invités par Anne d'Autriche à poser des vitres blanches dans l'église du Val-de-Grâce, alors en construction à Paris. A cette époque, il n'existait en France aucune fabrique de ces belles glaces dont l'usage était très répandu pour les carrosses et les appartements; c'était l'Allemagne et surtout Murano qui fabriquaient ces objets dont l'éclat répondait si bien aux goûts somptueux de 
Louis XIV. Cette situation ne pouvait convenir à Colbert, dont la formule économique était: "Il faut mettre le royaume en estat de se passer des etrangers ". De même que ce grand ministre avait fait venir des tapis. siers des Flandres pour fonder les manufactures des Gobelins et de Beauvais, de même il fit chercher à Florence des mosaïstes et à Venise des verriers. En i 664, il donna à François de Bonzi, évêque de Béziers, ambassadeur à Venise, des instructions pour l'embauchage de verriers et, l'année suivante, quinze d'entre eux arrivèrent à Paris. Un privilège royal fut accordé en octobre I 665 à une compagnie fondée par Nicolas Du Noyer, receveur général des tailles à Orléans. La manufacture fut établie à Paris à l'entrée de la rue de Reuilly, au faubourg Saint-Antoine. Le privilège consistait à fabriquer à Paris ou dans le royaume, en une ou plusieurs verreries, " des glaces, à miroirs des mesmes et divers grandeurs, netteté et proportion que celles que l'on fait et fabrique à Murano, près la ville de Venise, lozanges ou carreaux, transparens servant aux châssis et fenestre, vases de toutes façons, verroteries poùr les Indes, esmaux, pièces de cheminées, verres de cristail, services entiers de tables de toutes façons, figures de toutes manières et grandeur, tant pour servir à l'ornement de nos Maisons royalles que pour la commodité publique. "

Les ecclésiastiques ou nobles pouvaient être associés à l'entreprise sans déroger. Les matières premières pouvaient ètre réquisitionnées par la compagnie; le prix, en cas de contestation, devait en être fixé par le juge du plus prochain lieu; les verreries étaient exemptes des droits de passage, péage, traittes foraines; les ou- 
vriers étrangers, vénitiens ou autres, étaient, au bout de huit ans de séjour, censés et réputés Français et régnicoles, sans aucune lettre de naturalité ni droits à payer; tout le personnel de la manufacture fut exempt de toutes
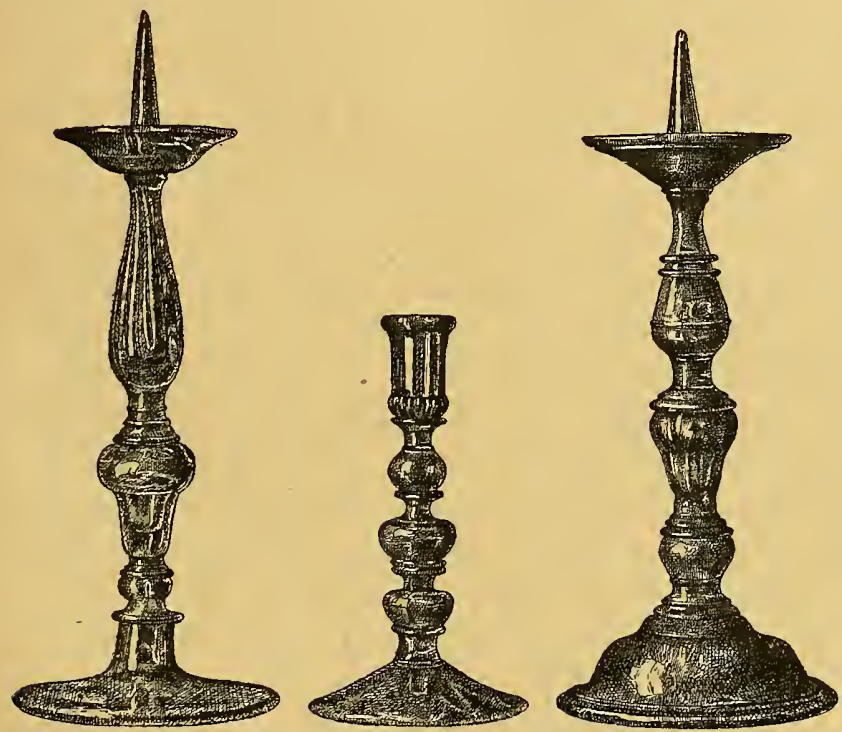

FIG. II 3. - FRANCE. (NORMANDIE.)

(Collection G. Le Breton.)

tailles et impositions, emprunts, garde de ville, logements de gens de guerre, tutelles, curatelles. Enfin Du Noyer reçut un prêt de douze mille livres pour frais de premier établissement et le droit de mettre au-dessus des portes un tableau aux armes de France avec l'inscription: Manufacture royale de glaces à miroirs. 
Malgré ces privilèges exorbitants, l'affaire ne marcha que médiocrement; les Vénitiens ne se plaisaient pas à Paris et ne voulaient rien enseigner aux Français; la désertion avait commencé et le recrutement à Venise était devenu plus difficile; les contrats étaient bien signés et l'argent accepté, mais les ouvriers ne s'exécutaient pas. Du Noyer se plaignit au roi et proposa comme remède à la situation de fonder un établissement loin de Paris, "dans un lieu où le bois coûte peu et la rivière soit à commandement "; il pensait aussi que, dans le fond d'une province, les ouvriers se fixeraient plus aisément et que le secret de la fabrication serait mieux gardé. L'idée était bonne, elle fút adoptée par Colbert. On chercha, on se souvint sans doute des vitres du Val-deGrâce: un arrangement fut fait avec Richard Lucas de Néhou, une succursale de la fabrique de Reuilly fut établie à Tourlaville, et, en I 666, l'établissement entier fut acheté par la compagnie de la Manufacture royale. De Néhou resta directeur pendant six ans et fut remplacé par son neveu Louis Lucas de Néhou. La fabrique prospéra si bien, qu'en 1670 Colbert écrivit à $M$. de Saint-André, ambassadeur à Venise : "La manufacture est assez bien établie dans le royaume pour n'avoir plus besoin d'un plus grand nombre d'ouvriers" En 1672, Colbert fut informé par le comte d'Avaux, successeur de M. de Saint-André, qu'un Vénitien offrait de fabriquer de plus grandes glaces qu'en France et de les polir; le ministre fit aussitôt prendre par le conseil un arrêt prohibant l'entrée des glaces en France et écrivit à l'ambassadeur, le 6 janvier 1673 : "Nos glaces sont maintenant plus parfaites que celles de Venise». 
Louis-Lucas de Néhou vint, en 1675 , diriger l'établissement de Paris, et c'est là qu'en r 688 il inventa le coulage des glaces, qui jusqu'alors étaient soufflées; il présenta à Louis XIV, en $\mathrm{I} 69 \mathrm{I}$, les quatre premières grandes glaces ainsi obtenues. Les inventions sont presque toujours contestées: un bourgeois de Paris, Abraham Thévart, prétendit, en I688, avoir inventé le coulage, mais la priorité en faveur de de Néhou a été reconnue ${ }^{1}$. Thévart avait obtenu, en $\mathrm{I} 688$, le privilège de couler et polir même, à l'exclusion du sieur de Bagneux, qui avait remplacé $\mathrm{Du}$ Noyer, des glaces de certaines dimensions", "des corniches, chambranles, moulures de profils composées de plusieurs membres d'architecture, figures ou autres ornemens en relief ". Néanmoins, les autres fabricants pouvaient, dans ce dernier genre, faire des bordures, moulures taillées à facettes ou à biseau, unies ou tortillées, des colonnes torses, frontons chantournés, figures sur fonds colorées ou autrement, armoiries, chiffres, couronnes, fleurs, fleurons, ornements, plans découpés et rapportés, à la condition que les objets aient moins de soixante pouces de long, ce qui était le minimum permis à Thérart. On peut juger, par les termes de ce privilège, du luxe de la glacerie; nous ne relevons cependant que peu de peintures sur glaces. Jean Le Moine, peintre des bâtiments du roi, en décora quelques-unes; il ne faut pas confondre cet artiste avec François Le Moine, beaucoup plus connu.

I. Cochin. La Manufacture des glaces de Saint-Gobain.

2. Voici les dimensions : en principe, 60 pouces sur 40 ; moins de 40 pour les glaces de plus de 70 , mais sans pouvoir descendre au.dessous de 25 sur 85 , de 3 o sur 70 . 
La manufacture royale des glaces, ne pouvant se développer à Paris, installa ses fours, en I 693 , au château de Saint-Gobain, près de La Fère, et, la même année, Thévart reçut le privilège de l'établissement. Il y eut de justes réclamations contre les différents privilèges accordés à Tourlaville et Saint-Gobain, et, attendu que les contestations élevées par les directeurs " les détourneraient de l'application qu'ils sont obligés d'avoir pour l'embellissement et la perfection de leurs ouvrages de glaces", une ordonnance annula les privilèges et les octroya, le I 8 avril I 695 , à François Plastrier. Les corporations des miroitiers et des lunetiers de Paris, les soldats de l'Hôtel des Invalides qui polissaient les verres de la fabrique de Ponthieu en $\mathrm{Pi}$ cardie, les propriétaires de cette verrerie, Lucas de Néhou réclamèrent aussitôt, mais ils furent déboutés en octobre r 695 , ce qui n'empêcha point la société Plastrier de tomber en liquidation en i 702. Un arrêt du Conseil d'État remit le privilège à Antoine Dagincourt, moyennant une somme de r,960,00o livres; la nouvelle compagnie fut mise en possession des établissements et dépendances, situés à Paris, rue de Reuilly, à SaintGobain, à Tourlaville, à Lézines et à Rouge-Fossé, près de Montmirail; Lucas de Néhou fut directeur de la compagnie de I 7 I o à I 728 , époque de sa mort.

La fabrication prit un nouvel essor; les glaces brutes étaient polies et doucies à Paris, où elles arrivaient, celles de Saint-Gobain par l'Oise et la Seine, celles de Tourlaville par Rouen et la Seine; elles étaient débarquées à la porte de la Conférence et au port Saint-Nicolas-duLouvre. La manufacture de Tourlaville perdit peu 
après de son importance; en 1777 , elle employait 542 personnes; en 1784 , elle n'en avait plus que 330 . Les guerres de la République et de l'Empire lui furent naturellement très défavorables; en I 806, la fabrication des glaces fut arrêtée et on ne produisit plus que du verre à vitre et des bouteilles jusqu'en I 824 , époque où tous les ouvriers furent envoyés à Saint-Gobain. Ce grand établissement éleva au plus haut point de perfection l'industrie des glaces, et il est depuis longtemps dans ce genre la première manufacture de glaces de l'Europe; grâce à lui, le prix du mètre carré de glace, qui était de 165 francs en I 702 , coûte aujourd'hui cinq fois moins.

Telle est l'histoire abrégée, assez confuse du reste, de l'origine et du développement de la fabrication des glaces coulées. La France n'a pas tenu, dans la verrerie de luxe et de service, un rang aussi élevé que l'Orient et que Venise; mais l'invention des glaces lui appartient en propre, et c'est pour cela que nous avons insisté sur cette partie de l'histoire du verre, quoiqu'elle soit du domaine de l'industrie. 


\section{L'ALLEMAGNE ET LA BOHÊME}

S'il est vrai que le moine Théophile soit de nationalité allemande, comme le veulent les érudits allemands, et même qu'il ait fait partie du couvent de Helmershausen en Westphalie, il faut reconnaître que ce n'est pas en Allemagne que l'auteur du Diversarum artium schedula a trouvé les éléments de ses leçons sur la verrerie. Dans l'énumération des ouvrages "qu'honore l'industrieuse Germanie », Théophile cite l'or, l'argent, le cuivre, le fer, le bois et la pierre, mais le verre n'est pas mentionné, et le moine n'eût pas manqué de le faire si réellement la fabrication du verre eût eu quelque importance. Les faits ne démentent pas cette hypothèse, et ni les historiens ni les découvertes n'ont apporté jusqu'à présent de preuves certaines d'une fabrication indigène d'un certain intérêt durant le moyen âge; néanmoins, il est bien évident qu'en Allemagne comme presque partout, il y a eu des fondeurs de verres communs.

On a découvert dans le sol allemand quelques verres 

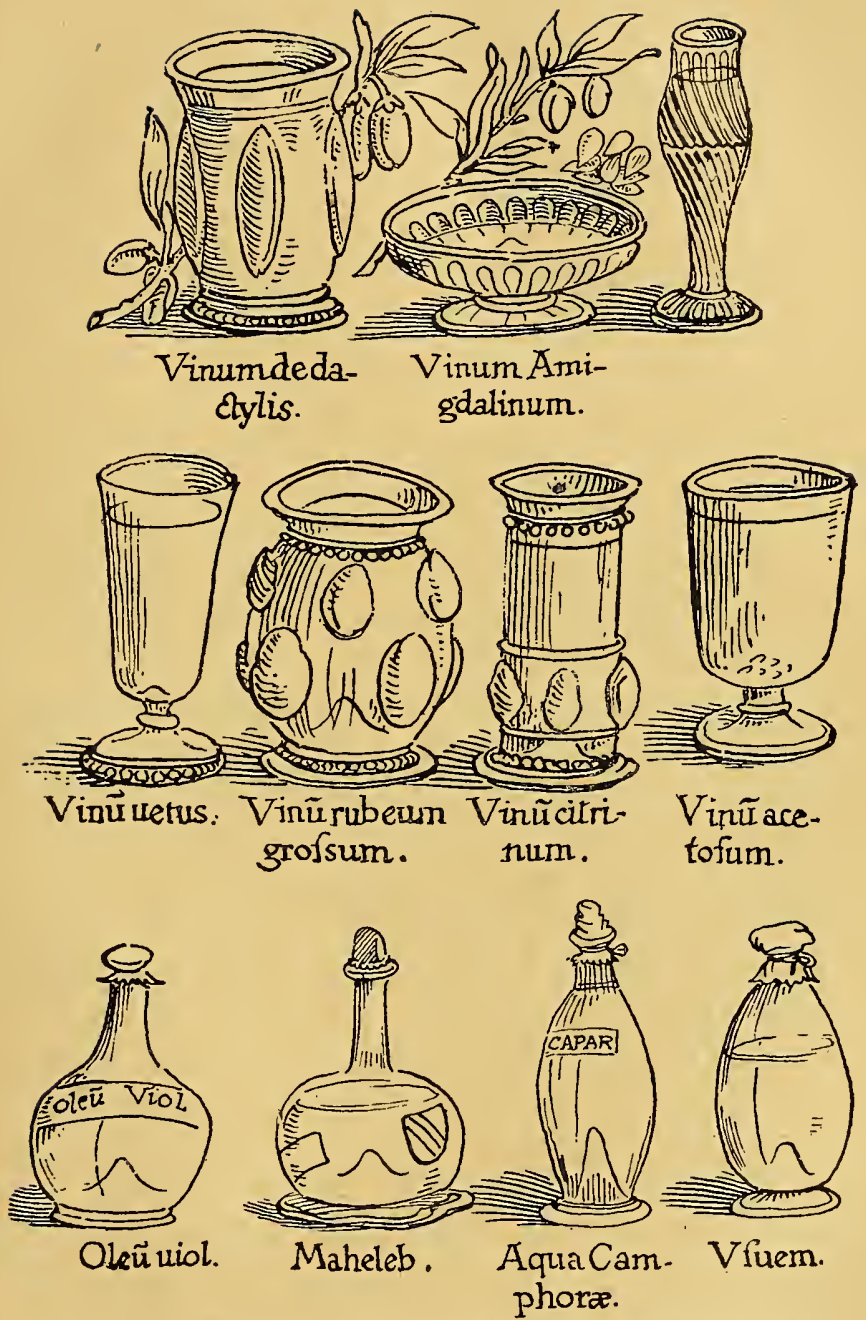

FIG. II 4. - ALLEMAGNE. VASES DE PHARMACIE ET VERRES A VINS. D'APRÈS UNE ESTAMPE DU XVIE SI ÈCLE. 
et des bijoux des premiers temps du moyen âge, mais ils ne prouvent pas l'existence de verreries allemandes;

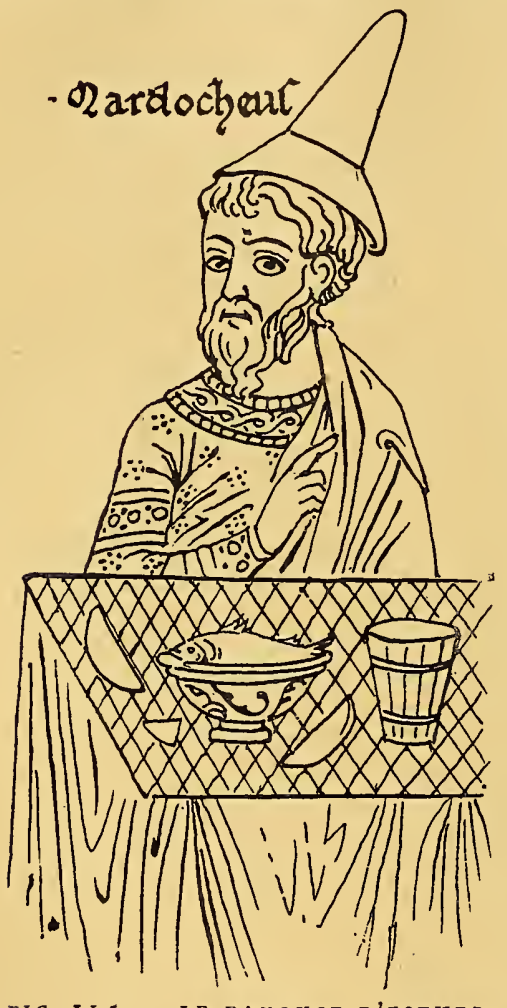

FIG. I I S. - LE BANQUET D'ESTHER.

(Dessin du Hortus deliciarum. xire siècle.) on croit que, vers 678, l'évêque de Mayence envoya des souffleurs de verre en Angleterre, au monastère de Wearmouth. On a relevé sur les registres de la ville de Cologne ${ }^{1}$, aux années de I I6o et I I 70, deux noms, Albertus et Otto, qui peuvent avoir appartenu à des verriers; on a trouvé dans le sarcophage du comte paladin Henri I ${ }^{\mathrm{er}}$, mort en I 80 , un vase cannelé avec des filets d'émail blanc autour du col; au xIl ${ }^{\mathrm{e}}$ siècle, le verre à boire en verre était peu répandu, ainsi que le prouve le dessin que nous reproduisons du "Hortus deliciarum ", où l'on voit

I. Meilo. Kunst und Künstler in Köln. 
Mardochée en présence du roi, au banquet d'Esther, boire dans un gobelet en bois (fig. I I 5). On a démontré qu'à Vienne, des décrets de $\mathrm{r} 354$ et de r 360 permettaient la vente des verres, soit de Venise, soit d'autres lieux, sur le grand marché seulement, tandis que les verres de forêt, c'est-à-dire sans doute les verres du pays, pouvaient être vendus partout ailleurs dans la ville; en $\mathrm{s} 363$, il y avait eu une corporation de verriers à Augsbourg. On assure qu'en 1420 Vincenz Roder se rendit d'Allemagne à Murano, pour enseigner aux Italiens la façon de doubler le verre avec des feuilles métalliques; on veut même qu'un siècle auparavant une pareille tentative ait déjà été faite par un Allemand; enfin

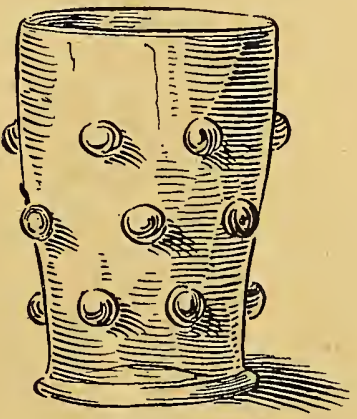

$\mathrm{HB} \cdot 1517$

FIG. I I G. - ALLEMAGNE.

XVI SI ÈCLE.

(Vie des saints et des saintes de la famille de l'empereur Maximilien.)

Dessin de Hans Burkmayer. on certifie qu'à la fin du xve siècle un Allemand apprit aux Vénitiens à faire le cristal, c'est-à-dire le verre à base de plomb; l'assertion nous paraît extrêmement hasardée, car dans les anciennes verreries de la Thuringe, situées dans le massif de montagnes des Fichtelgebirge, la fabrication du cristal était inconnue aussi bien que dans le reste de l'Allemagne. Ces verreries des Fichtelgebirge paraissent ètre les plus anciennement exploitées d'une façon suivie. A la vérité, il faut attendre jusqu'au $x^{\prime}{ }^{\mathrm{e}}$ siècle pour se 
trouver en présence de verres de fabrication allemande authentiques, présentant en même temps un caractère de décoration spéciale; l'Allemagne eut alors deux centres principaux de fabrication, Nuremberg et Prague.

Nuremberg avait déjà, au $x^{\mathbf{e}}$ siècle, une grande importance; c'était la première ville de l'Allemagne.

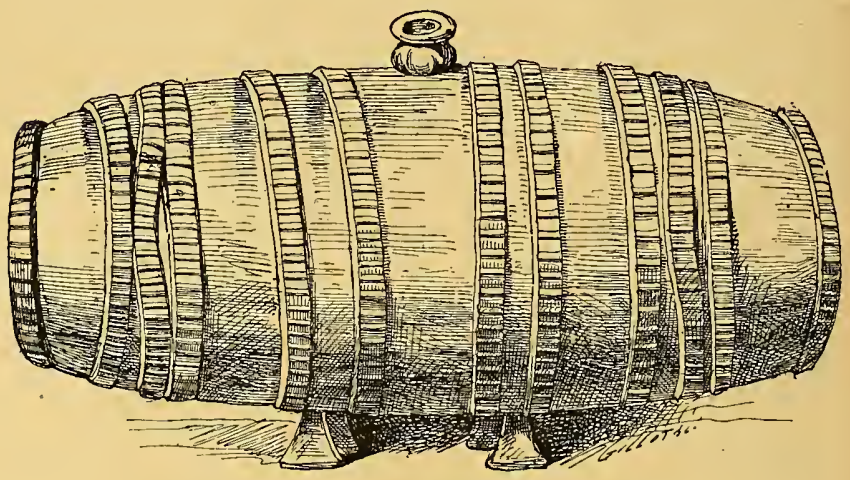

FIG. I 17. - ALIEMAGNF, XVI E SI ÈCIE.

Les marchands de Venise y passaient pour aller trafiquer, dans les pays du nord, dans les villes de la Hanse, en Pologne, en Hongrie, de leurs produits et des denrées que leurs navires allaient chercher dans les pays orientaux; Alvise Mocenigo, ambassadeur de la République auprès de Charles-Quint, écrit dans un rapport daté de r 548, en parlant de Nuremberg: "Cette ville a - la réputation de se mieux gouverner que toute autre cité allemande; aussi l'appelle-t-on la Venise de l'Allemagne. " A Venise, on disait : “Toutes les villes d'Alle- 


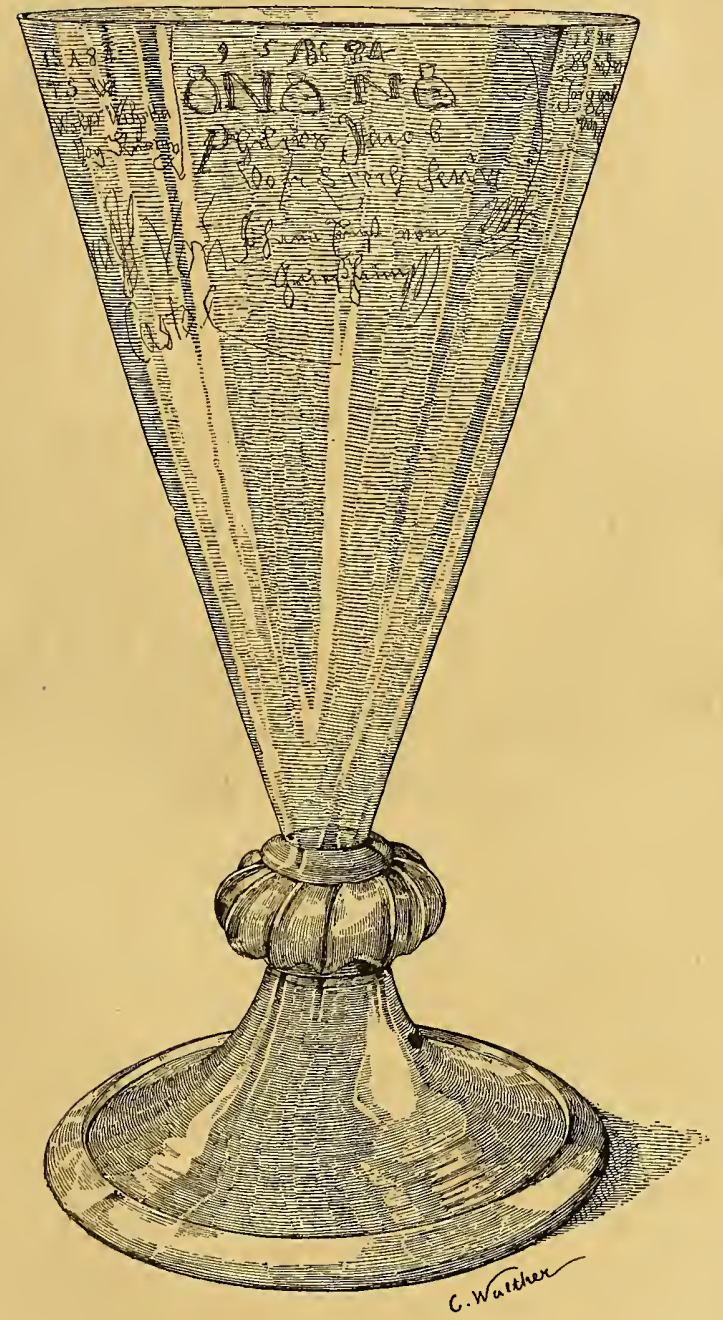

FIG. I I 8. - ALLEMAGNE, I s 8 t, - (Musée de Nuremberg.) 
magne sont aveugles, mais Nuremberg voit avec un œil ». Le gouvernement de la cité était exercé par des conseils choisis parmi les familles patriciennes; on remarque que les corps de métiers n'étaient que très faiblement représentés dans ces assemblées, et que dans le Petî Conseil, dont l'autorité, en dépit de son titre, était très grande, il n'y avait que huit représentants des métiers sur quarante-deux membres, c'est-à-dire une minorité sans action dans les décisions; - et dans ces métiers ne figurent pas les artisans, verriers, orfèvres, sculpteurs sur bois, ciseleurs; au temps d'Albert Dürer, il n'y avait pas encore de corporation dans la ville ${ }^{1}$, et ce n'est que vers 1530 que la corporation des menuisiers, la première en date, parvint à s'organiser. Cela tenait à un parti pris du gouvernement de la cité : il écartait systématiquement des conseils l'influence des corps de métiers, et s'il admettait leur présence ce n'était que poùr leur donner une satisfaction toute platonique; il s'opposait à tout groupement des hommes de métiers et des artistes. On peut supposer que ce système d'exclusion était provoqué par la crainte de voir les artisans et les artistes prendre dans la cohésion une force que l'on regardait comme nuisible aux intérêts de l'État, et peut-être les patriciens jugeaient-ils les artistes incapables de gérer les affaires publiques. La conséquence de cet état de choses fut l'absence de toute espèce de réglementation officielle dans l'exercice des métiers, et on s'accorde en Allemagne à trouver que cette liberté fut un, bienfait inappréciable pour le 
développement des arts. Il est curieux de comparer la situation des artistes de Nuremberg à celle de leurs confrères de Venise. D'une part, liberté complète; de l'autre, autorité et contrôle absolus s'exerçant sur les plus minces détails de la fabrication; ici, l'homme est tout, la corporation n'est rien; là, l'homme n'est rien, la corporation est tout; et, chose digne d'observation, les deux systèmes diamétralement opposés arrivent au même résultat : le développement de la production et la qualité du produit.

Ces antithèses peuvent rendre perplexes et hésitants ceux qui, attribuant aux maîtrises, aux corporations et aux jurandes le degré d'élévation auquel sont arrivés jadis les arts du mobilier et de la décoration, déplorent leur décadence actuelle et cherchent un remède à la situation. Il nous paraît cependant que plusieurs conséquences sont à tirer de

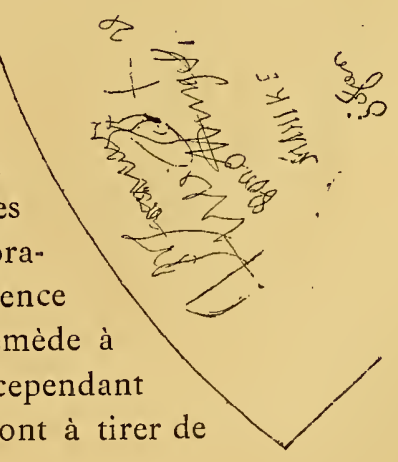


ces exemples. La première, c'est qu'en ces matières rien n'est absolu et que tel système, bon en Italie, est mauvais en Allemagne; la seconde est plus importante : la liberté complète dans l'exercice de la profession d'artiste, loin d'être un obstacle à l'éducation de l'élève et au développement des qualités du producteur, peut être un bienfait, sous la condi-

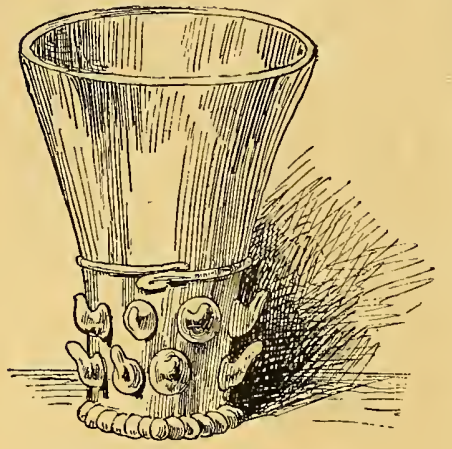

FIG. 120 . - AILEMAGNE.

XIVe SI ÈCLE. tion que l'élève et l'artiste aient l'amour du travail et le goût du métier. En effet, tandis que le système des corporations confine l'individu dans une profession, après l'avoir soumis à une éducation exclusive, le système de liberté lui permet de passer d'un atelier dans l'autre, de s'exercer par exemple à la ciselure sur métaux, pour apprendre ensuite l'émaillage, la sculpture sur bois, la gravure sur verre, et finalement adopter la profession qui lui paraît entrer le plus dans ses aptitudes naturelles.

Il nous a paru intéressant de présenter sous une forme biographique l'existence de quelques-uns des maîtres de Nuremberg, Autour d'Albert Dürer le jeune, qui était peintre, sculpteur, ciseleur en métaux, émailleur et orfèvre, gravitait une pléiade d'artistes, les uns originaires de la ville, les autres venus de divers points de l'Allemagne et même des Flandres; c'est dans ces 
ateliers que se sont formés les décorateurs sur verre dont voici les principaux :

La famille des Hirschvogel est restée célèbre en A]lemagne; de la fin du $x v^{e}$ à la fin du $x v I^{e}$ siècle, elle fournit à Nuremberg plusieurs générations de peintres sur verre; quoique nous n'ayons pas à traiter ici l'art des vitraux, nous devons signaler cette famille d'artistes, car les peintressur verre ne s'adonnent pas toujours exclusivement aux vitraux et l'un des Hirschvogel a tenu un

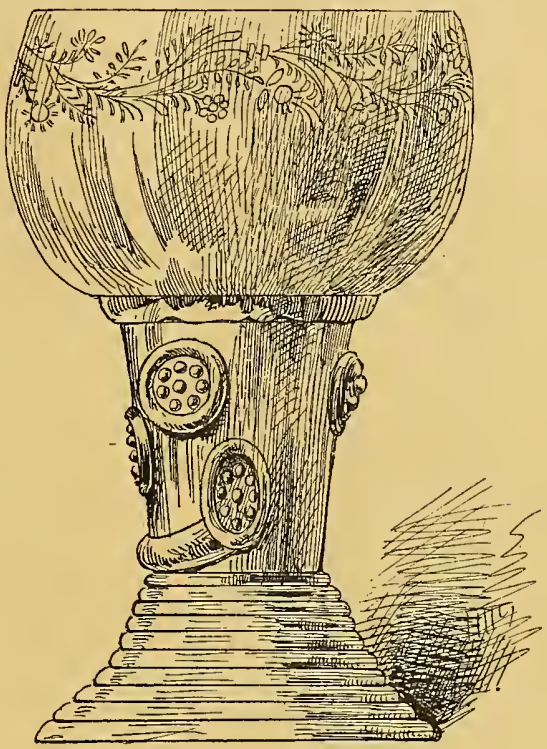

FIG. I21. - ALLEMAGNE,

RÖMER DU XVII SIÈCLE. rang très important dans la verrerie allemande. Veit ${ }^{1}$ Hirschvogel le Vieux (146I-I525) peignit les beaux vitraux qui décorent les quatre grandes fenêtres de l'abside de l'église Saint-Sebald, à Nuremberg; son fils Veit Hirschvogel le Jeune $(\dagger 1553)$ fut très habile peintre sur verre, gra-

I. Le prénom Veit correspond au nom français Guy.

LA VERRERIE. 
veur sur cuivre et émailleur. Il eut deux fils, Sebald

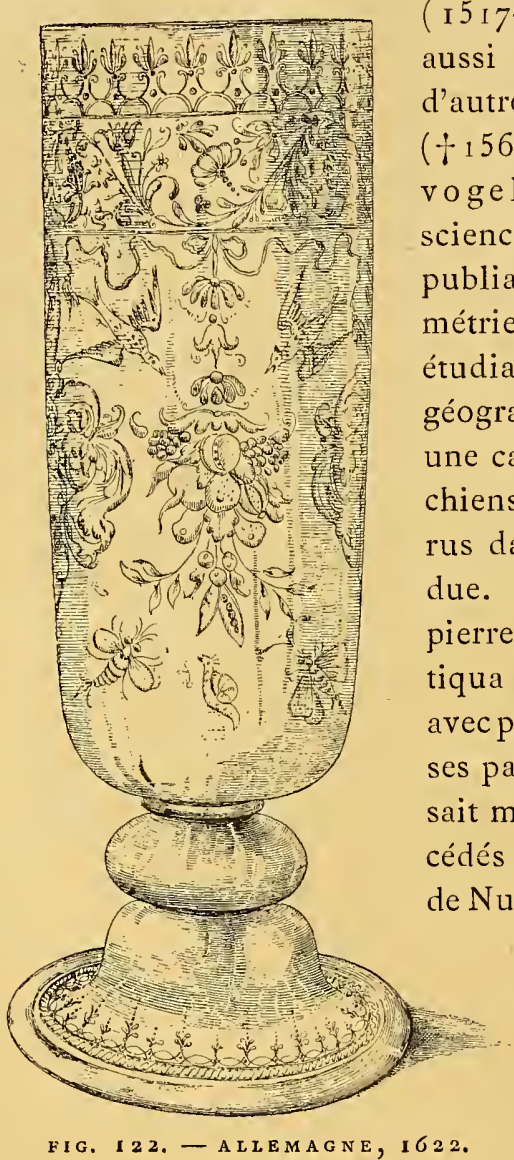

(Musée de Nuremberg.)

( $1517-1589)$ qui peignit aussi sur verre et exerça d'autres arts, et Augustin $(† 1560)$. Augustin Hirschvogel s'adonna aux sciences mathématiques; il publia un traité sur la géométrie et la perspective, étudia l'astronomie et la géographie, et fit paraître une carte des pays autrichiens qu'il avait párcourus dans toute leur étendue. Il fut graveur sur pierre et céramiste; il pratiqua la peinture sur verre avec plus de perfection que ses parents, car il connaissait mieux qu'eux les procédés de cuisson. La ville e Nuremberg suivait d'un œil inquiet le développement qu'avait pris à Venise la fabrication du verre; à l'effet d'arrêter l'importation toujours croissante des verres de Venise en Allemagne, elle résolut de pénétrer les fameux secrets des Vénitiens, et, en 153I, 
elle subventionna les potiers Hans Nickel, Oswald Rinhardt et Hieronymus Reich, qui sans doute à leur.
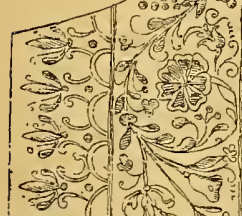

15

क्षे:
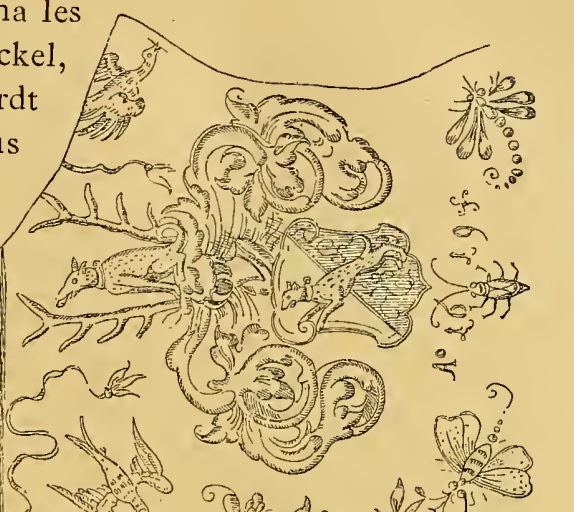

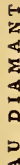

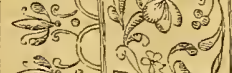

ar
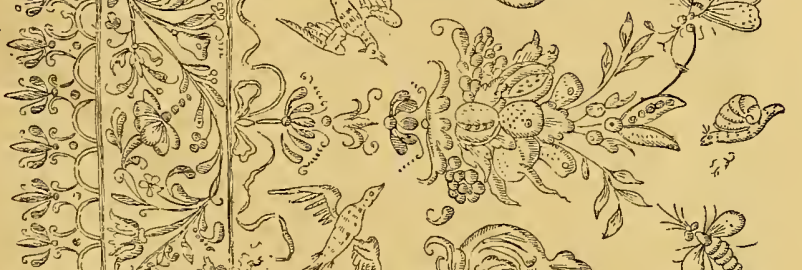

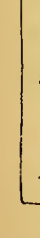
gnaient celui de verriers, pour leur faciliter l'établissement d'une fabrique de verres de Venise. A la subvention fut attachée la condition que les secrets (2) 
raient communiqués qu'à leurs enfants, et à Augustin Hirschvogel qui lui-même fut aussi envoyé en Italie. En 1532, Hirschvogel conclut une association avec Hans Nickel et la fabrication des verres à la façon de Venise commença alors industriellement.

Jean Wessler, en I6oo, portait le titre de tailleur de verre; c'est le premier Allemand qui prit cette qualification.

Georges Schwanhard l'aîné, né à Nuremberg en I60I, apprit d'abord le dessin et la sculpture chez les maîtres renommés de la ville; il prit goùt à la gravure sur verre, et, pour se perfectionner dans cet art, se rendit dans l'atelier de Gaspard Lehmann, à Prague ${ }^{1}$, où il fit de tels progrès qu'à la mort de son maître, en 1622 , il recueillit sa succession; plus tard il retourna à Nuremberg, établit un atelier qui devint célèbre; sa spécialité consistait dans les fleurs, les paysages, les emblèmes et les grotesques gravés à la roue et au diamant. Il eut pour clients les grands seigneurs et notamment le prince évêque de Mayence et les évêques de Wurtzbourg et de Bamberg; l'empereur Ferdinand III le fit venir à Prague en 1652 , afin de fournir aux graveurs sur verre les dessins dont ils avaient besoin. Ferdinand semble avoir pris goût au métier, car il se fit enseigner la gravure au diamant par Schwanhard, qui mourut en 1667, laissant une nombreuse famille composée de trois filles et de deux fils. Sophie, Marie et Suzanne furent de bonnes élèves de leur père et s'adonnèrent plus spécialement à la gravure des ornements,

I. Voir page 276 . 
des fleurs et des formules de souhaits; Georges était maladif et ne fit qu'une courte carrière dans la gravure sur verre; Henri sut acquérir une célébrité qui dépassa celle de son père. Henri Schwanhard s'adonna d'abord aux lettres et en particulier à la poésie; il quitta ces études pour embrasser avec passion la profession de son père et bientôt il devint d'une extrême habileté dans le dessin et la perspective; ses inscriptions sur verre en lettres latines avec paraphes étaient
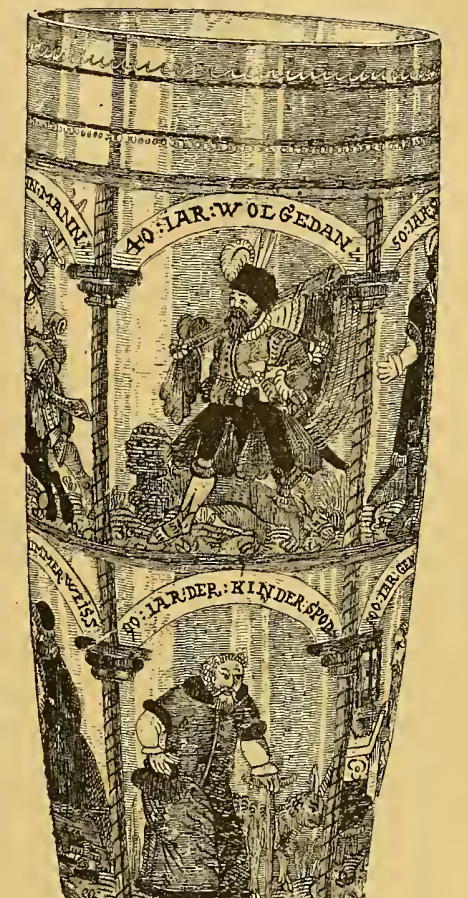
comparées aux chefs-d'œuvre des plus forts calligraphes du temps; il poussa très loin aussi l'art plus difficile de tailler des figures en relief, mais ce qui doit le rendre particulièrement intéressant pour l'histoire de la verrerie, c'est l'invention qu'il a faite de la gravure à l'acide. C'est à tort que cette invention est regardée comme de notre temps : après l'année 1670 , Henri Schwanhard laissa un jour tomber une goutte d'acide sur le verre de ses lunettes; il remarqua que le verre était devenu mat et aussitôt il tira parti de cette observation pour son métier de graveur ${ }^{1}$; il produisit ainsi des verres à fond mat avec dessins en clair ${ }^{2}$. L'invention ne semble avoir été largement appliquée ni au xviI ${ }^{\mathrm{e}}$ $\mathrm{ni}$ au $\mathrm{xvIII}^{\mathrm{e}}$ siècle, les échantillons sont rares, et ce n'est que depuis quelques années qu'elle a pris un réel développement. H. Schwanhard mourut en 1693 . Nous reproduisons (fig, I 28) un verre gravé à l'acide par Schwanhard; il se trouve à l'École de commerce de Nuremberg.

La famille Schwanhard n'était pas seule à pratiquer la gravure sur verre, à Nuremberg, pendant la seconde moitié du xvil ${ }^{\mathrm{e}}$ siècle. On trouve encore:

Schwinger (Hermann), (1640-I683); il apprit d'abord la gravure sur cuivre et la sculpture sur bois, puis il fit cinq ans d'apprentissage dans l'atelier de Schminten (Stephan) et acquit une juste célébrité pour les arbres, les feuilles et le paysage.

I. J.-G. Doppelmayr. Historische nachricht yon der Nürnbergischen mathematicer und Künstlern. Nürnberg, 1730.

2. L'acide fluorhydrique étendu d'eau produit une altération de la surface du verre; les parties à préserver sont garanties par une couche de vernis de graveur. 


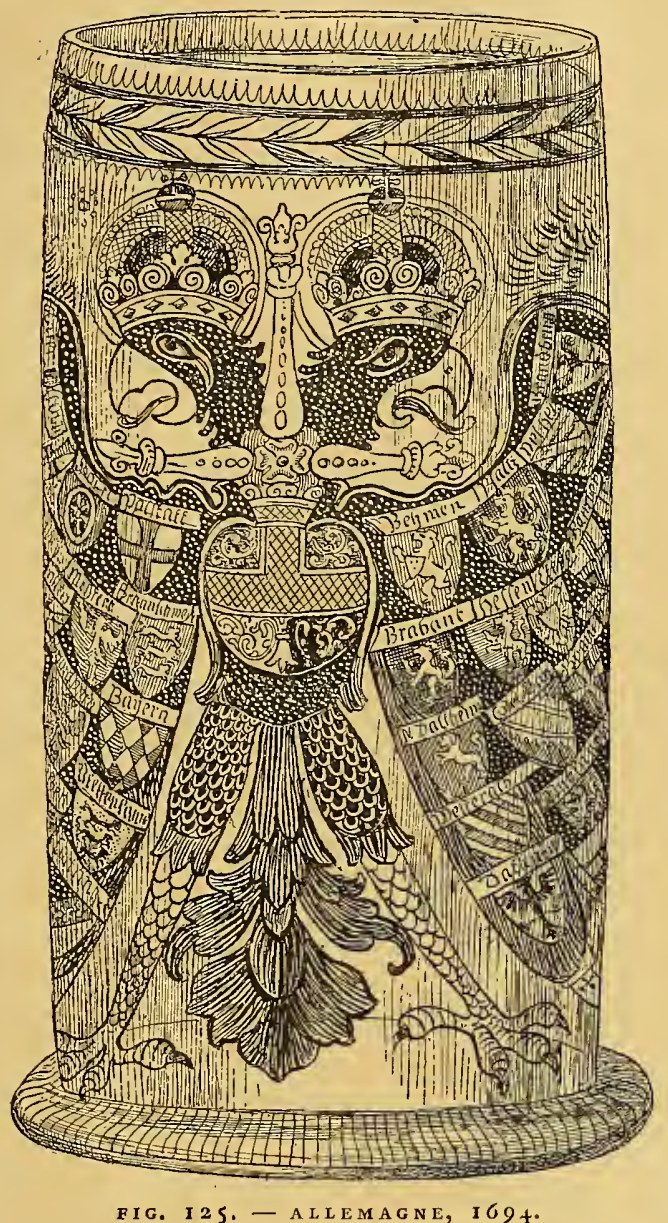

VIDERCOME DU SAINT EMPIRE ROMAIN.

(Musée de Nuremberg.)

Fino (Abraham) $(+1657)$, originaire d'Amsterdam, 
se livra à plusieurs arts, notamment au soufflage du verre à la lampe d'émailleur; il enseigna ce métier agréable à nombre d'amateurs.

Jean Schapper $(t \mathrm{r} 670)$ était peintre sur verre, mais il exerçait aussi son art sur les, verres à boire et les

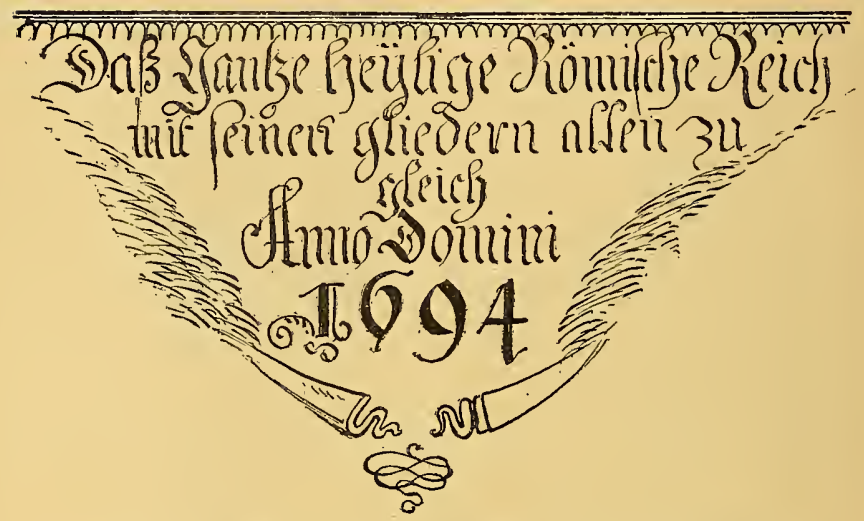

FIG. I26. - INSCRIPTION DU VERRE DU SAINTEMPIRE ROMAIN $\mathrm{N}^{0} 125$.

brocs de faïence; le musée de Berlin conserve de lui plusieurs verres émaillés datés de I66I, I 665 et 1666 ; il était originaire des environs de Hàmbourg.

Jean Hell était né à Augsbourg en 1637, il mourut en r709. Pendant neuf années, il apprit à dessiner, à graver et à repousser; arrivé à Nuremberg en 1668, il s'associa avec un orfèvre nommé Gotzens et prit la spécialité des anneaux de "trinité » en or repoussé et émaillé. Il taillait aussi des verres d'optique et des figures de toutes couleurs; un verre émaillé signé de 
lui à la date de 1675 se trouve au musée de Berlin.

Michel Sigismond Hack (I643-I 72 I) apprit l'orfèvrerie chez Georges Kötenbecken à Nuremberg, puis se rendit à Augsbourg et à Vienne. Laguerre contre les Turcs le laissa sans travail; il se fit soldat et parcourut la Hongrie, les Pays-Bas et la France, où il fut interné comme prisonnier de guerre. Il passa ensuite en Angleterre où il souffla le verre, il revint dans son pays où il fit la guerre aussi bien qu'il avait exercé précédemment son métier de verrier. Il avait pour spécialité les instruments de physique, baromètres et thermomètres, et les verres de complexion pour mesurer les degrés de la fièvre; il fabriqua aussi des balles explosibles en verre appelées larmes bataviques

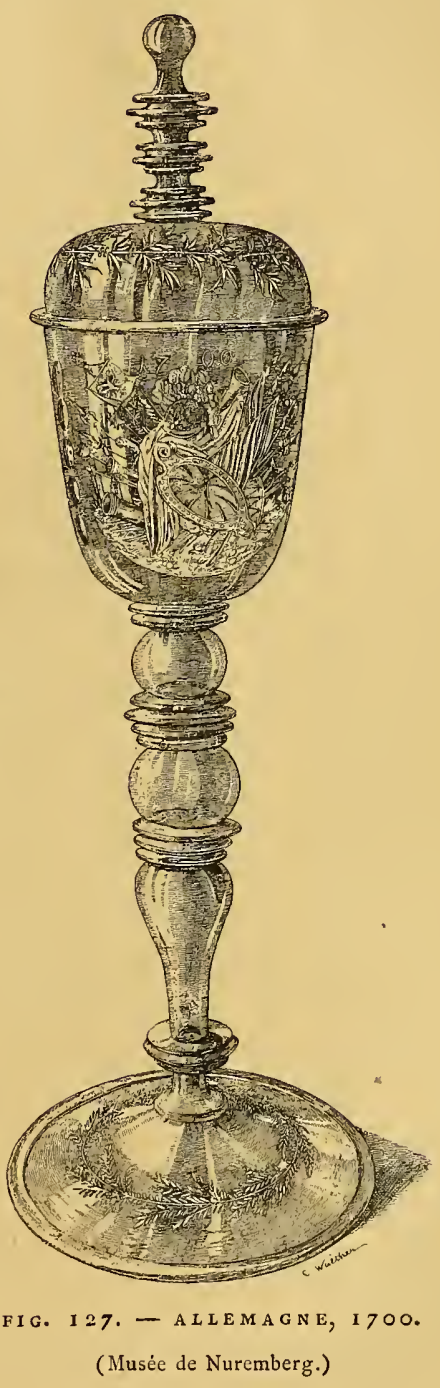


et de petites figures de plongeurs à l'usage des charlatans.

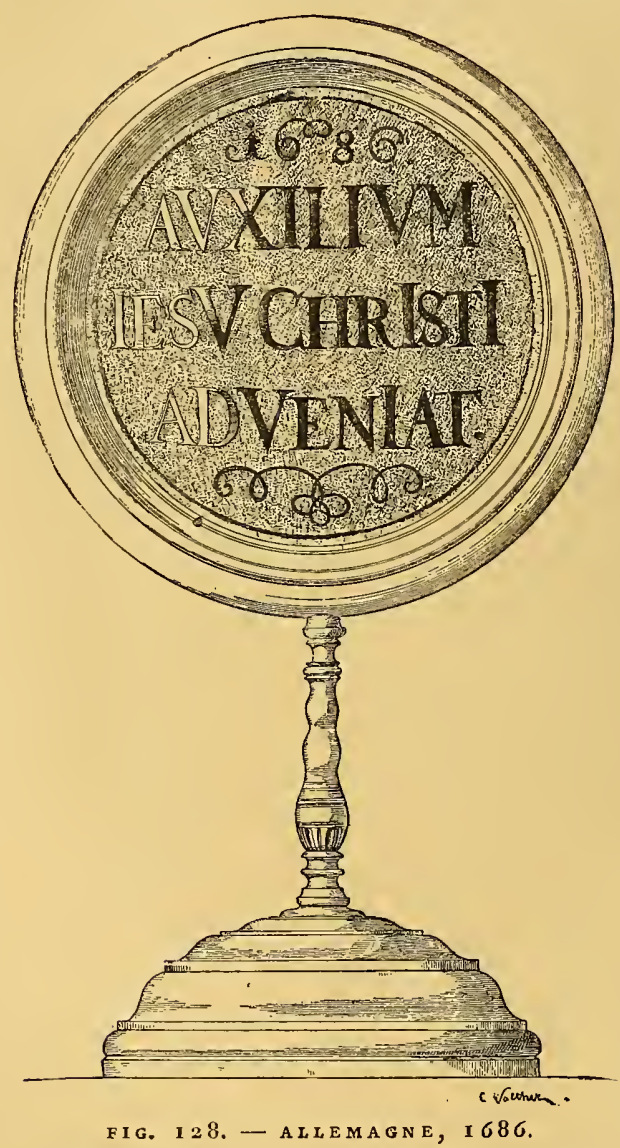

GRAVURE A L'ACIDE, PAR SCHWANHARD.

(École du commerce à Nuremberg.)

D'autres maîtres, C. Schweizer, H. Wesslar à la fin 
du xvie, A. W. Maürl, le graveur Huck, dans les premières années du $x$ vIII $^{\circ}$ siècle, jouissaient d'une certaine célébrité.

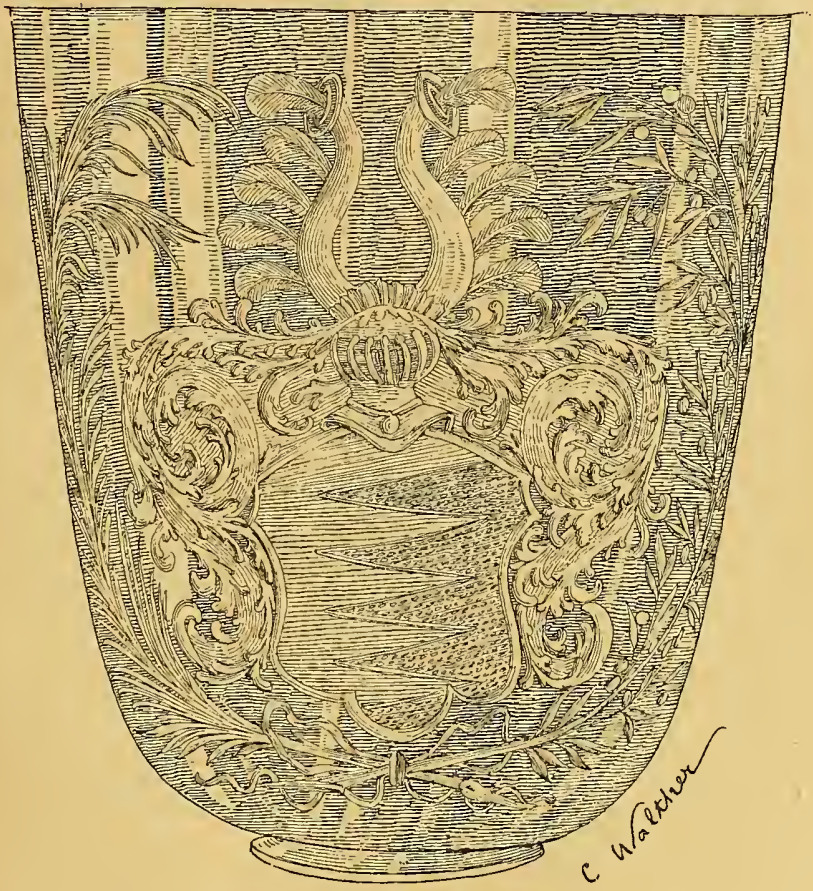

F1G. 129. - ALLEMAGNE. DÉTAIL DE LA GRAVURE

DU VERRE N $N^{0} 127$.

Ces notices biographiques donnent une idée exacte de l'art de la verrerie en Allemagne depuis la Renaissance; avant cette époque, les verres se présentent sous des aspects généraux et simples, car ils résultent 
du travail du verrier proprement dit; ce sont des verres soufflés ou moulés avec des appendices, boutons, cercles, torsades appliqués à chaud. La matière est commune, verdâtre, la forme résulte de la préoccupation essentielle de rendre l'objet solide et commode à l'usage; on ne trouve nul souci de charmer l'œil par une décoration inutile. Dès le $\mathrm{xIV}^{\mathrm{C}}$ siècle, on rencontre un verre à boire qui peut être présenté comme type (fig. I 20); c'est un gobelet évasé, garni vers la base d'une suite de boutons en relief. En le rapprochant des verres trouvés en Angleterre, en Allemagne et en France, et qui sont des temps mérovingiens (fig. 55), on constate entre ces pièces certaines analogies qui prouvent que le gobelet du $\mathrm{XIV}^{\mathrm{e}}$ siècle est le résultat d'une lente et successive transformation des verres primitifs; malgré les perfectionnements, le type restera longtemps encore le verre préféré en Allemagne et dans les Pays-Bas ${ }^{1}$. Nous le retrouvons, en effet, avec quelques variantes entre les mains des corporations et des compagnies d'arquebusiers dont les banquets ont fourni tant de sujets de tableaux aux peintres hollandais. Sous l'influence d'Albert Dürer (1471-1528), les arts décoratifs prennent un remarquable essor et, grâce au système d'éducation professionnelle adopté par les artistes, tous les arts de la décoration participent au mouvement et en profitent. La verrerie se transforme à vue d'œil, non que l'ancienne et simple fabrication ne se poursuive toujours, mais la verrerie de luxe vient en honneur, grâce aux peintres verriers qui ne dédaignent pas de décorer les verres à boire d'é-

1. Rapprocher et comparer les verres $\mathrm{n}^{\mathrm{0s}}$ 55-120-132-12:. 


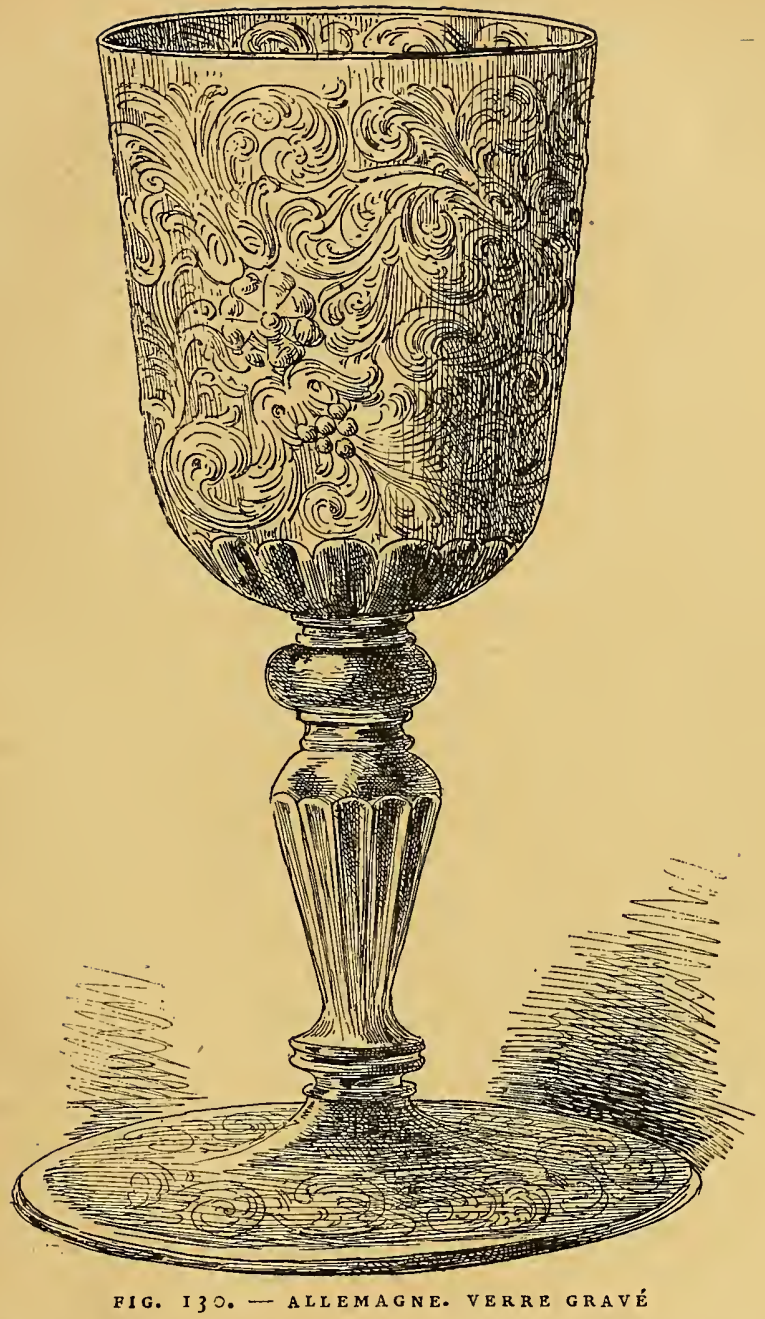

DROVENANT DU TRÉSOR DE LA CATHÉdRALE DE MAYENCE.

(Musée de Cluny.) 


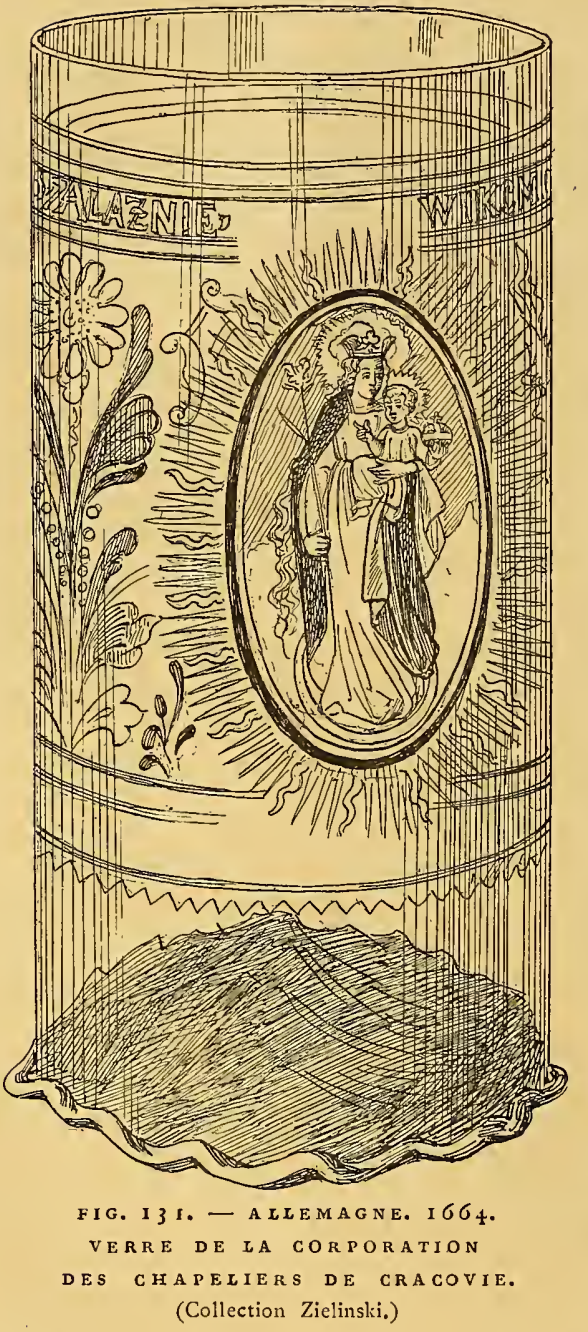

maux de couleur; $\mathrm{ma}$ is bientôt ces artistes comprennentquela matière est insuffisante et Hirschvogel part pour l'Italie, à l'effet de pénétrer les procédés vénitiens. De retour à Nuremberg, il imite d'abord 1 a forme et le décor des verres de Venise à ce point qu'il est impossible de distinguer les uns des autres, d'autant plus que les verriers nurembergeois se mirent aussi à décorer les verres blancs provenant de Venise. Nous reproduisons une gourde faite par Hirsch- 
vogel (fig. I34); elle est, pour la forme et le décor en émail bleu et blanc, absolument pareille aux objets similaires fabriqués à Murano ${ }^{1}$. La nouvelle fabrication prit une telle extension que le commerce de Venise avec l'Allemagne s'en ressentit bientôt; elle ne se borna pas, on peut le comprendre, à l'imitation servile de Venise, elle donna des verres allemands pour la forme et italiens pour le décor, et réciproquement, puis des verres tout à faitallemands. Dès s 553 , on constate de grands hanaps et des vidercomes très allemands de caractère. Celui qui figure au musée de Berlin porte cette date; il est décoré en émail de

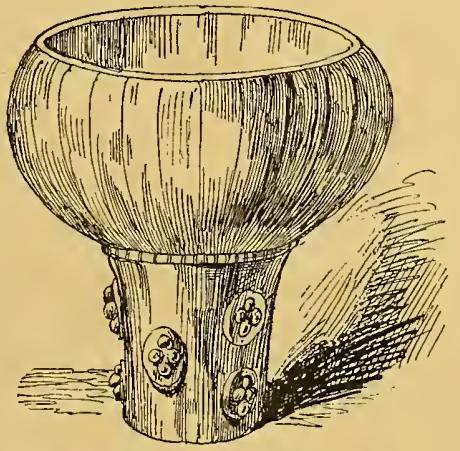

FIG. I 32 . - ALIEMAGNE.

$X V I^{e}$ SIÈcLE.

l'aigle héraldique aux ailes armoriées et d'une série d'écussons; le type n'a jamais été abandonné depuis.

$\mathrm{La}$ gravure sur verre ne prit d'extension en Allemagne qu'après la décoration en émail; au xvir ${ }^{\circ}$ siècle, elle est pratiquée par de nombreux artistes et se manifeste par des paysages, des fleurs, des grotesques, des arabesques, des ornements géométriques et calligraphiques, des épisodes de la vie domestique, des êtres animés, des armoiries, des paysages, des oiseaux, par tous les éléments, en un mot, de la décoration de la Renaissance.

I. Les armes sont celles de la famille Kretz, de Nuremberg. 
Les graveurs se servent de la molette et du diamant et même de l'acide; la gravure est plus profonde, plus ferme, car le verre, qui maintenant a un caractère allemand, est plus épais qu'à Venise. Sa forme se modifie, tout en restant toujours un peu lourde, mais elle prend,

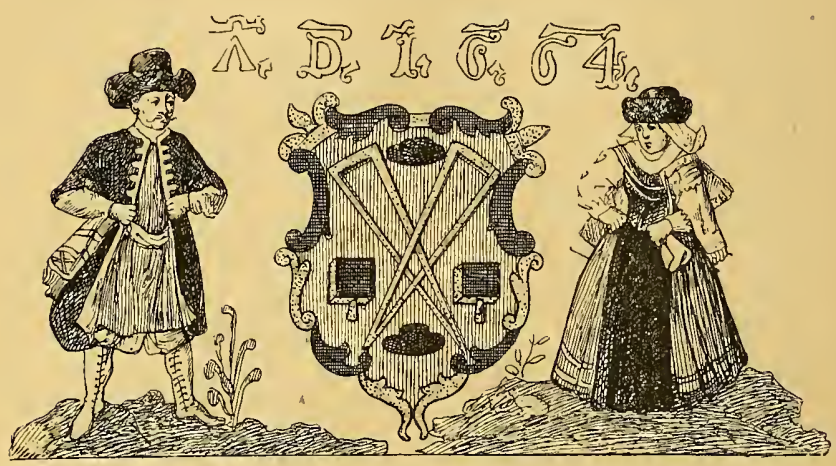

FIG. 133. - ÉCUSSON DU VERRE DE LA CORPORATION DES CHAPELIERS DE CRACOVIE. I664. (FIG: 131.) INSCRIPTION :

Wilkom Bracia wypszacie raznie

Ktospelni stance mu za lazme.

(Soyez les bienvenus, frères, buvez gaiement, ce verre tiendra lieu d'étude à qui le videra.)

dans les verres de luxe et de fantaisie, une allure plus dégagée; le verre à boire du $\mathrm{XIv}^{\mathrm{e}}$ siècle devient le "romer», le verre à vin du Rhin, classique en Allemagne comme la flûte à champagne l'est en France aux $\mathrm{XVII}^{\mathrm{e}}$ et $\mathrm{XVIII}{ }^{\mathrm{e}}$ siècles.

Les principales dénominations des verres de l'Alle- . magne sont :

Becher : gobelet, cornet. 


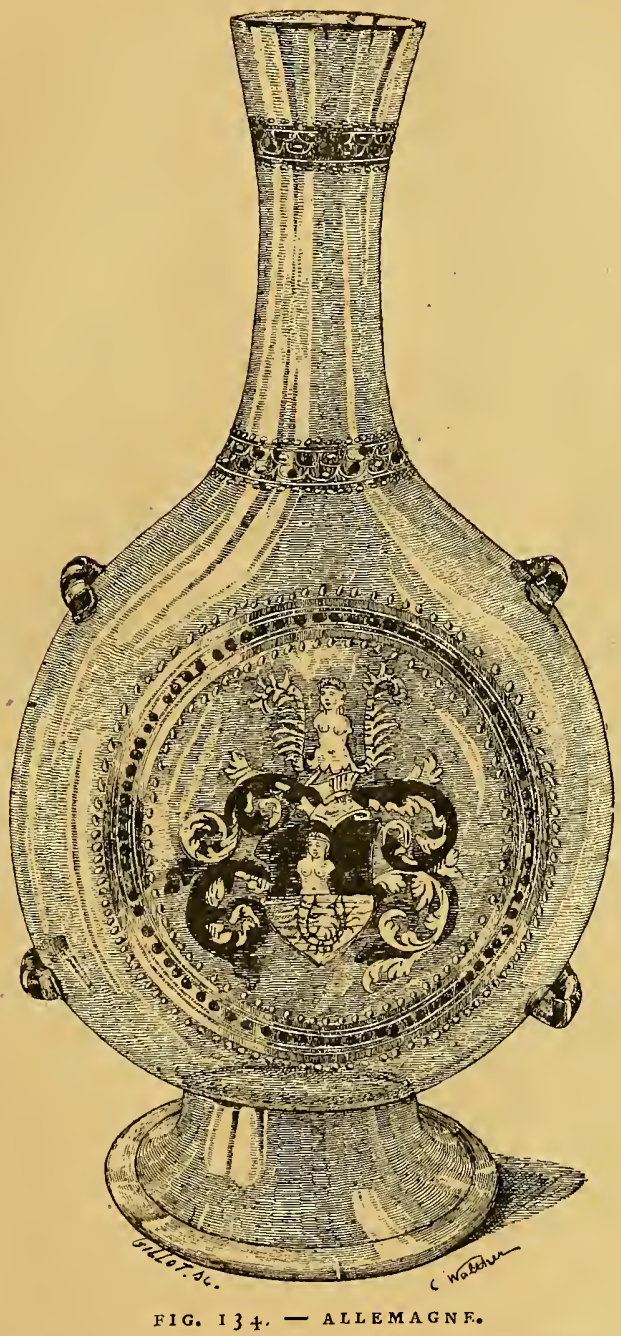

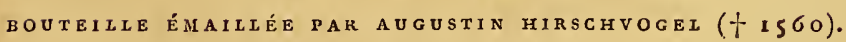
(Musée de Nuremberg.)

LA VERRERIE. 
Römer : verre de la forme classique des verres à vin du Rhin.

Willkomm : verre de bienvenue en traduction littérale; en France et en Angleterre, on a changé ce mot en celui de vidercome, qui donne une idée de retour, de revenir de nouveau.

Pokal : bocal; l'expression s'applique plus particulièrement à des verres ayant un couvercle.

Humpen : hanap.

Flasche : bouteille, fiolle.

Passglass : verre cylindrique dont le pied est formé d'un simple cordon ou d'un renflement.

Kanne : aiguière, canette.

Henkelkanne : aiguière, canette à anse.

Gutruf ou Gutrolf : flacon à col étroit pour verser doucement .

Flugelglass : verre à boire à anses en façon d'ailes.

Kelchglass : verre à boire en forme de calice.

Waldglass, se dit des verres qui se fabriquaient au $\mathbf{X}_{1} \mathbf{v}^{\mathbf{e}}$ siècle dans les forêts de l'Autriche.

Les noms: verres des Apôtres, verres des Sept Électeurs, verres du Saint-Empire, se donnent aux vidercomes décorés des figures des apôtres, des armoiries des sept Électeurs, des armoiries du Saint-Empire romain et de ses dépendances.

Les verreries de la Bohême ne prennent une réelle importance que vers la fin du $\mathrm{xvI}^{\mathrm{e}}$ siècle; il en existait 
certainement déjà auparavant : on en cite à Daubitz, en I 442, et à Falkenau en I 443; une autre, dirigée par Peter Berka, près de Georgenthal, paraît même être antérieure. En r 504, il yavait à Kreibitz une verrerie tenue par Amon Friedrich; en 1536, un Suédois, Wander, fonde un établissement à

Gr ü n w a $1 \mathrm{~d}$, dans le nord de la Bohême, et il reçut l'aigle en r 599 , c'est-à-dire le privilège impéria l; un nommé Schurer invente, paraît - il, le verre bleu au cobalt en i 540 . Mais ces établissements n'eurent au-

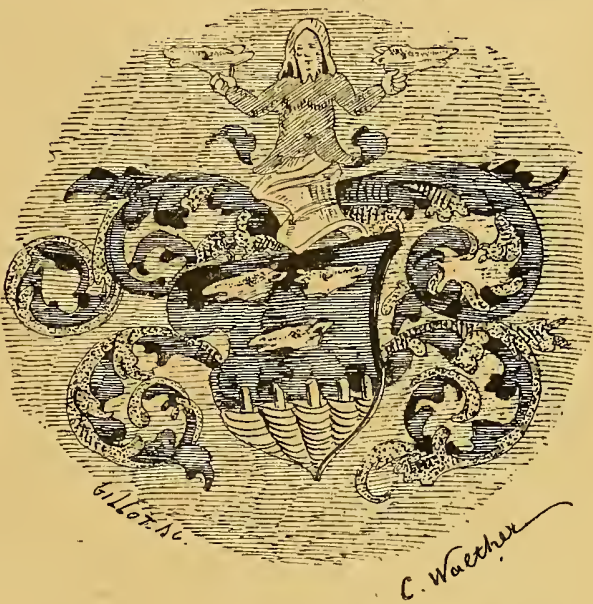

FIG. I 35 . - ALLEMAGNE. XVI SIÈCLE.

Décoration émaillée du verre fig. 134 . cune influence sur l'art de la verrerie en Bohệme; c'est à Prague que cet art prit naissance. La capitale de la Bohême avait déjà, au Xrv ${ }^{e}$ siècle, une école de peinture renommée; l'empereur Charles IV, qui réunit sur sa tête les couronnes d'Allemagne et de Bohème et dont le règne eut lieu de i 347 à 1378 , favorisait lés arts; il construisit des palais à Prague sur le Hradschin, et fit venir d'Italie des mosaïstes qui représentèrent sur un mur de la cathédrale de Saint-Veit le ju- 
gement dernier où figurent l'empereur, sa femme et les six patrons de la Bohême.

Les successeurs de Charles IV eurent moins de soucis des arts que ce prince et laissèrent Nuremberg prendre la suprématie. Cependant l'empereur Rodolphe II (1576-I6I2) fut passionné pour les sciences et les arts; d'un caractère sombre, il restait enfermé dans son palais, s'occupant d'astronomie et de beaux-arts et négligeant les affaires du gouvernement au point de se laisser enlever par son frère Mathias une partie de son empire. Il avait appelé à Prague des Italiens célèbres dans la gravure sur cristal de roche; cet art était pratiqué alors par Bernardi à Castelbolognese, par les Misuroni à Milan, par Bontalenti à Florence; lorsque l'empereur établit sa résidence à Vienne, les graveurs sur cristal de roche furent privés de travaux; ils pratiquèrent alors leur art sur le verre du pays. Mais les Italiens n'eurent pas longtemps le monopole de la gravure et, dès 1590 , l'empereur avait donné à un Allemand, Gaspard Lehmann, le titre officiel de graveur sur pierres fines et sur verre. Lehmann était de sa profession ciseleur sur métaux; il s'adonna à la gravure sur pierres fines et chercha ensuite à appliquer ses procédés sur le verre; il réussit et conquit la faveur du souverain, qui l'attacha à sa personne à Prague et à Vienne; l'artiste devint célèbre et fit école; Schwanhard l'aîné, de Nuremberg, vint à Prague, à l'atelier de Lehmann, et profita si bien de son enseignement qu'il remplaça le -maître dans ses fonctions à sa mort, en r622. Avec Lehmann, la verrerie de Bohême changea d'aspect; avant lui, les verriers faisaient venir des modèles et 
des verres de Venise et se contentaient de les décorer dans le goût allemand, au moyen d'émaux colorés; mais, dès qu'ils se mirent à tailler le verre, ils durent changer les formes. Le verre de Venise, dont l'essence est la légèreté, comporte une gravure fine et délicate, mais non point la taille ou la gravure profonde; il fallut donc aux artistes de la Bohême une matière plus résistante, c'est-à-dire plus épaisse; les formes subirent dès lors un changement radical : elles devinrent plus lourdes, plus solides, plus confortables, et en ceci, du reste, elles se rapprochèrent du style allemand.

En même temps que la gravure et la taille, la fabrication fit des progrès; le verre de Bohême était primitivement assez grossier, mal raffiné, verdâtre; il devint plus fin. et blanc, les verriers ayant pris pour but l'imitation du cristal de roche. Ainsi créé, le

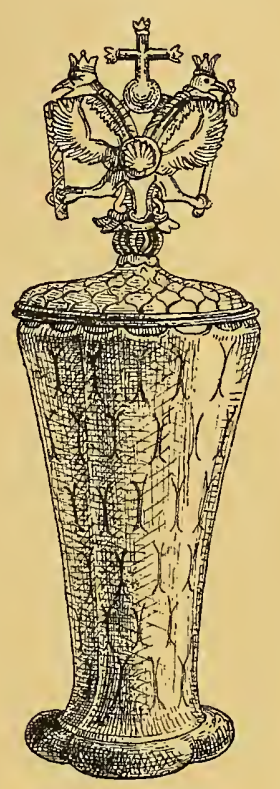

FIG. I3 6 . - ВОНЁ $\mathrm{ME}$. XVII SIÈCLE.

(Musée du South-Kensington.) genre de Bohême fit en Europe de très rapides progrès et fut adopté en Allemagne et dans les Pays-Bas, soit par les verriers du pays, soit par les marchands d'articles d'importation.

La fabrication de Bohême prit un développement considérable, qu'il ne nous est pas possible de suivre 


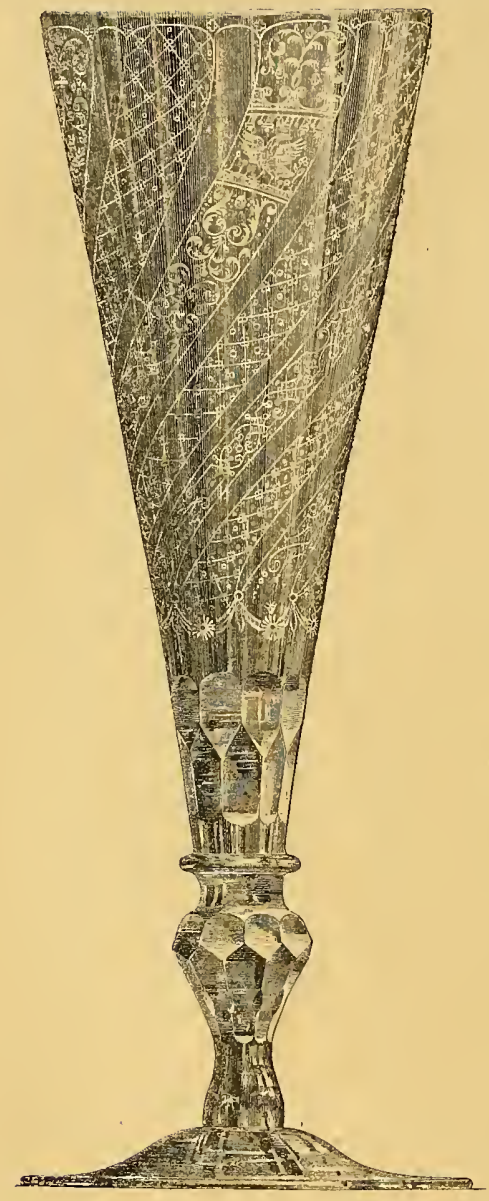

FIG. I 37. - BOHÊME. XVII SIÈCLE.

avec détail; de nombreuses verreries s'élevèrent, notamment à Winterberg, Helmback, Harrachdorff, Reichenberg, Prichowitz, Antoniwald, Turnau, Haïda et, en général, dans les contrées favorables à ce genre d'industrie, à cause de l'abondance du bois et de la fréquence des cours d'eau qui servaient de force motrice aux tours des graveurs. Un verrier nommé Kreybich eut une part importante dans le succès des verres de Bohême; nous le citons pour montrer ce que peut la volonté d'un homme poussé par l'amour du gain et par l'orgueil national. Kreybich apprit son métier pendant seize ans, mais il poussa d'abord la brouette pour vendre des marchandises 
dont il s'approvisionnait à Winterberg, centre important de fabrication; il parcourut la Styrie, la Carinthie, la Carniole, le pays de Salzbourg, la basse Autriche, la Prusse, la Pologne, la Russie. II fut à Londres où il trouva sept verreries en activité; il fit peu d'affaires en Angleterre, quoique ses verres décorés de couleurs et taillés y fussent estimés; de retour surle continent, il visita l'Italie, la Hongrie, la Valachie et Constantinople; après quarante ans de voyages, il mouruten 736 . Un autre artiste, Franz Weidlich, renommé pour la taille en creux et en relief, venditses produits en Espagne et en Portugal. Le verre de Bohême fut mis ainsi, sur toutes les places de commerce, en concurrence avec le verre de Venise; la Bohême triom-

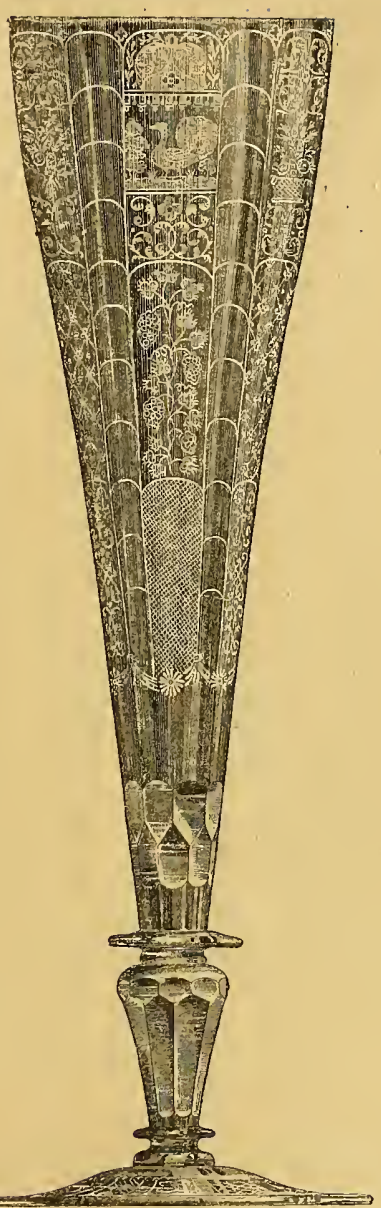

FIG. X 38 . BOHÊME. XVII SIÈCLE. pha, Venise passa de mode à ce point que vers i 730 , 
un Vénitien, Giuseppe Briati, vint en Bohême pour y apprendre le mode de travail, et qu'en i $736 \mathrm{Ja}$ cobus Busenello obtint le privilège de fabriquer à $\mathrm{Mu}$ rano des verres façon Bohême. A la fin du xvirre siècle, la Bohême comptait soixante-dix verreries et cinq mille verriers.

Le verre de Bohême est un verre allemand; les Tchèques, peuple slave établi en Bohême depuis le $v^{e}$ siècle, n'ont absolument rien donné du caractère et des goûts de leur race aux verres qu'ils ont fabriqués; ils ont travaillé comme les Allemands; et presque toujours sous la direction des Allemands. Lehmann, le véritable créateur du verre de Bohême, n'était pas Tchèque, et Schwanhard, son successeur dans l'atelier royal de Prague, était de Nuremberg; à l'époque de ces deux artistes, le verre de Bohême n'était pas du type général qu'on lui a donné depuis et qu'il a conservé. C'était un verre blanc gravé, puis on le tailla à facette, et à la taille s'ajouta la gravure; mais le cristal anglais, qui prit rang dans le commerce de la verrerie sur le continent vers le milieu du xvine siècle, porta au verre blanc de Bohême un coup funeste : la matière anglaise, beaucoup plus belle, se prêtait infiniment mieux à la taille à facette et le verre de Bohème fut battu à son tour comme il avait battu le verre de Venise. Les fabricants alors reprirent le verre colorié qui avait précédé la verrerie de luxe créée par Lehmann et son atelier et s'adonnèrent avec ardeur à la fabrication du verre colorié et gravé, qui est devenu le type moderne de la verrerie de Bohême.

Mais il est encore, en Bohême, une autre fabrication 
d'une importance très grande : celle de la verroterie, dont l'origine remonte à la seconde moitié du xvile siècle. Les fabricants du cercle de Turnau voulurent, à cette

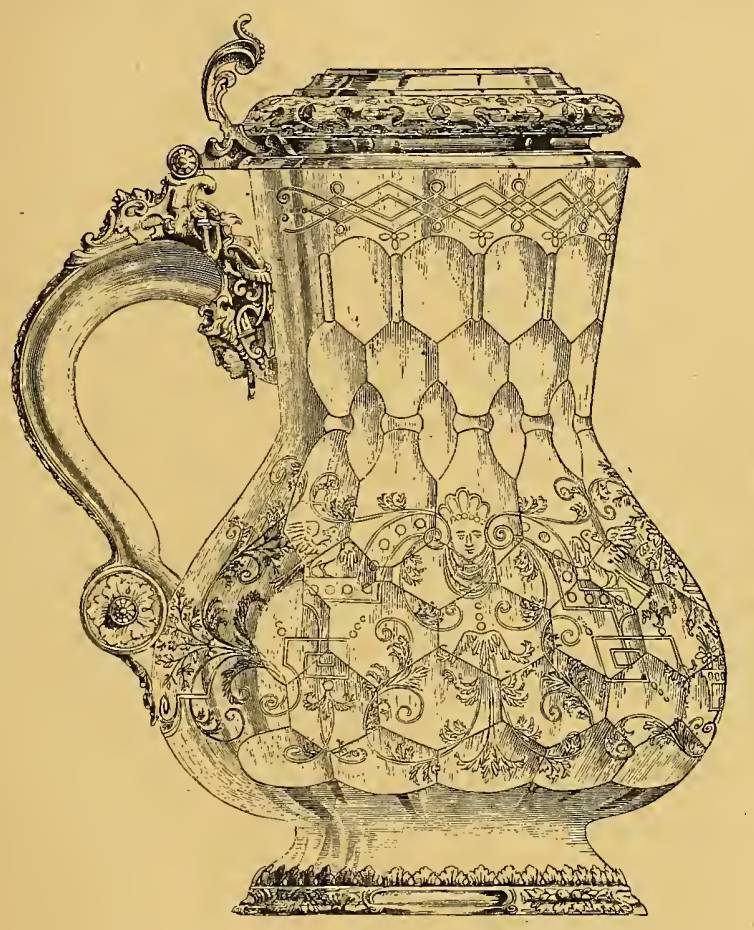

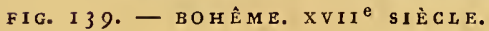

époque, lutter avec les Vénitiens, qui tenaient le marché dans le monde entier. Ils ne purent soutenir la concurrence et furent obligés de suspendre la fabrication jusque vers I II , où un nommé Fischer la reprit avec 
succès, si bien que dans le cercle de Turnau il y avait, en 1786 , quatre cent quarante-trois patrons dans ce genre d'industrie; il est juste d'ajouter que le personnel de ces ateliers est très restreint, et que le plus souvent le patron n'a autour de lui que sa famille et quelques apprentis et ouvriers.

La Bohême du xvir siècle produisit aussi des verres à vitres par le soufflage, mais la question de la priorité du procédé reste douteuse; enfin c'est la Bohème qui pendant longtemps, et maintenant encore, fournit à la lustrerie les prismes taillés dans des conditions de bon marché que nul pays ne peut égaler. Nous n'avons pas besoin d'ajouter qu'à côté de ces industries se développa parallèlement la fabrication de la gobeletterie et de la verrerie communes.

En résumé, la Bohême doit son renom mérité dans l'art de la verrerie au talent de ses artistes et à son industrieuse population. La fabrication a su, en tous les temps, se plier aux caprices de la mode et du goût, et toujours donner a ses produits un caractère décoratif très marqué; ce qui nous séduit, nous l'avouons, ce sont moins les grandes pièces de luxe, de formes très étudiées, d'une gravure savante, fine et délicate, que les simples gobelets à l'usage des gens du peuple; malgré ses imperfections et en raison de sa naïveté, nous aimons ce décor, qui laisse voir en blanc sur un champ de rubis ou de topaze le cerf classique bondissant dans la forêt de sapins. La gravure est simple, sommaire, à grands traits; le procédé n'a rien du fini, de la recherche que la Renaissance a entraînée après elle; il semble qu'il appartienne à ce moyen âge qui a im- 
primé un caractère si élevé à ses œuvres décoratives; et, en fait, ce gobelet est une ouvre d'art en son genre, et le rôle qu'il remplit est d'un intérêt supérieur, car il constitue une pénétration de l'art dans les plus modestes intérieurs en un temps où, à l'inverse de la coutume antique, les ustensiles sont de pius en plus réduits aux formes et aux dispositions strictement nécessaires à leurs fonctions utiles.

\section{I I}

En dehors des deux grands groupes, Nuremberg et la Bohême, l'Allemagne cultivait l'art de la verrerie en d'autres lieux. En 1428, on trouve à Vienne un verrier de Murano, Onofrius de Blondio; une verrerie est tenue par Nicolas Walch, en 1486 , sur le terrain du Prater, entre la ville et le Danube. Dès r 5o3, la fabrication des miroirs faisait la fortune d'une verrerie allemande dont nous ignorons l'emplacement; la production de cette fabrique inquiéta le Grand Conseil de Venise, qui donna aux frères Anzolo del Gallo le privilège de " specchiai ", miroitiers, pour leur permettre de faire concurrence aux Allemands.

Vers I 584, le duc Guillaume V employait en Souabe un verrier italien nommé Scarpoggialo. L'empereur Ferdinand III (1608-r657) protégea un graveur sur verre nommé Struden. Léopold $I^{\text {er }}$ fit venir à Vienne, 


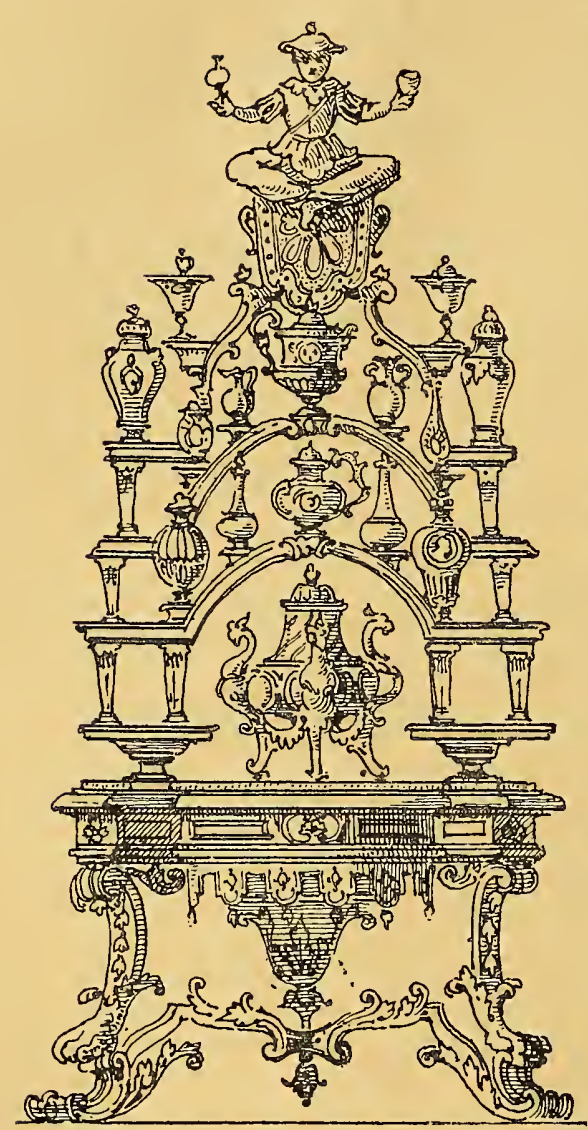

FIG. I 40 , 一 ALLEMAG NE. XVIII SIÈCLE. CRÉDENCE EN BOIS DORÉ

SERVANT A EXPOSER L'ORFĚVRERIE, LA CÉRAMIQUE ET LA VERRERIE, PAR P. DECKER. en 1679 , un verrier vénitien, Berardo Marinetti. La Saxe, qui confine à la B o hême, e u t d'importantes verreries a u $\mathrm{xvI}^{\mathrm{e}}$ siècle; on cite de ce temps un artiste saxon J. Swaerzer; au siècle suivant, la Saxe entra en Jutte active avec la Bohême et fabriqua desverres gravés et des verres décorés d'émaux.

Francfort s u r-le-Mein compte des graveurs sur verre assez renommés : Hess (Johan) vers i6 6 o, Hans(Johan-Benedick) en r 669 , Hess (Peter), qui vécut de 1709 à 1782 , Cologne et d'autres pays alle- 
mands exportent dès I 600 des verres dans les Flandres. Vers 1659 , nous trouvons dans une verrerie, à Lhorsur-le-Mein, trois Français : Pierre Bernard, Guillaume Brument et Louis Truffet; au commencement du siècle suivant, à la verrerie de Clarenthal, près de Wiesbade, se trouvent des verriers d'origine normande.

En I 669, le prince d'Anhalt, Jean-Georges II, fonda au château d'Oranenburg une verrerie qui, l'année suivante, fut transférée dans la ville de Dessau; elle éteignit ses feux en 1685. On y fabriquait des verres de luxe, des fleurs de couleur, des guéridons et des verres filigranés de Venise, sous la direction de deux Italiens, Marinetti de Murano et Ludovico Savonelli, qui précédemment avaient été à Vienne; un autre Italien, Joselli, $\mathrm{y}$ faisait des miroirs avec des cadres en verre qui furent vendus avec succès aux foires de Leipzig.

Au xviItésiècle, parmi d'autres graveurs on peut citer Rechnagel en I 7 10 à Berlin, Martin Teuber en I720 à Ratisbonne, Gottfried Spiller vers r 730 à Berlin, Schurich dans la même ville, vers la même époque, et Michel Vais à Dessau.

On comprend que dans une histoire générale de la verrerie nous ne puissions suivre dans leur développement les verreries importantes de tous les pays, et, 'pour l'Allemagne comme pour l'Autriche, nous avons dû nous borner aux établissements, aux artistes et aux savants qui ont eu une influence déterminante sur la production générale. Parmi les savants allemands, Kunckel tient un rang très distingué. Né en i 630 dans le Holstein, il fut chimiste, d'abord au service du duc de Lauenbourg, puis à la cour de Saxe et enfin à la 
verrerie de Potsdam; il publia en 1679 un important ouvrage : Ars vitriaris experimentalis; c'est un traité technique de la verrerie. Kunckel ne s'occupa ni du décor ni de la forme, mais il perfectionna les procédés de fabrication et produisit des verres émeraude et d'un très beau rouge rubis; il mourut en 1702 , laissant à la science des enseignements pratiques dont elle a su profiter.

I. Beckmann. Histoire d'A nhalt. 


\section{LA HOLLANDE - LES FLANDRES L'ESPAGNE}

Nous savons peu de choses sur l'origine des verreries dans les Provinces-Unies. On y fabriquait des verres à vitres au $\mathrm{xv}^{\mathrm{e}}$ siècle. Un document de 1485 indique qu'en Angleterre les vitres hollandaises étaient mises en concurrence avec les vitres de Normandie et de Venise. Au $\mathrm{xvI}^{\mathrm{e}}$ siècle, deux Hollandais, Cornelius Drebbel en I 572 et Zacharie Jansen en I 59o, se disputent l'invention du microscope composé. Au cours du xvir siècle, les États-Généraux des Provinces-Unies délivrèrent des autorisations de verreries. En r6 15, Sybert Meynertsz, von Duyn et Hugo Spierings furent privilégiés pour quinze années; ils eurent le droit exclusif de fabriquer et de faire fabriquer, par des procédés de leur invention et nouveaux dans le pays, des verres à vin du Rhin de la forme du röemer et des verres à bière. Dirk van Cattenburg est, en $\mathrm{i} 665$, investi du privilège de fabriquer de petits et de grands miroirs, en verre fin et ordi- 
naire, analogues à ceux de Venise. Un verrier de Hambourg, établi à là Haye, est autorisé, en r668, pour quinze années, à produire la verrerie blanche et de couleur. Josias Olivius, déjà fabricant de verreries fines à Rotterdam, fut, en $\mathrm{I} 687$, autorisé à faire des glaces françaises pour miroirs, grandes, rondes, unies ou gravées, " dont l'art, créé en France, a été introduit dans les Provinces-Unies par des familles françaises ${ }^{1}$ ». Dès I 670 , la manufacture royale de glaces, fondée par Colbert en r665, était assez forte pour se passer de l'importation étrangère, et ses produits battaient en brèche ceux de Venise; il est logique de supposer que les familles françaises mentionnées par le livre des octrois et pensions des États-Généraux avaient quitté notre pays vers 1685 , après la révocation de l'édit de Nantes, qui porta un coup si funeste à nos industries. La Hollande importait aussi des verres de Venise et d'Allemagne; les formes indigènes se ressentent de ces provenances. Les verres de luxe fabriqués dans le pays se rapprochent avec quelque lourdeur des verres de Murano, et les verres à bière ordinaires sont semblables à ceux de l'Allemagne; nous en avons le témoignage dans les collections et dans les tableaux des maîtres hollandais; il est à présumer que les graveurs se sont fréquemment servis de verres étrangers.

Nous pouvons entrer dans quelques détails sur l'art du graveur sur verre, pratiqué avec succès dans les

I. M. Henri Havard, dont la compétence est si grande pour ce qui tient aux arts et à l'industrie de la Hollande, a bien voulu nous communiquer les notes précédentes, qu'il a relevées sur les registres des États-Généraux. 
LA HOLLANDE, LES FLANDRES, L'ESPAGNE. 289

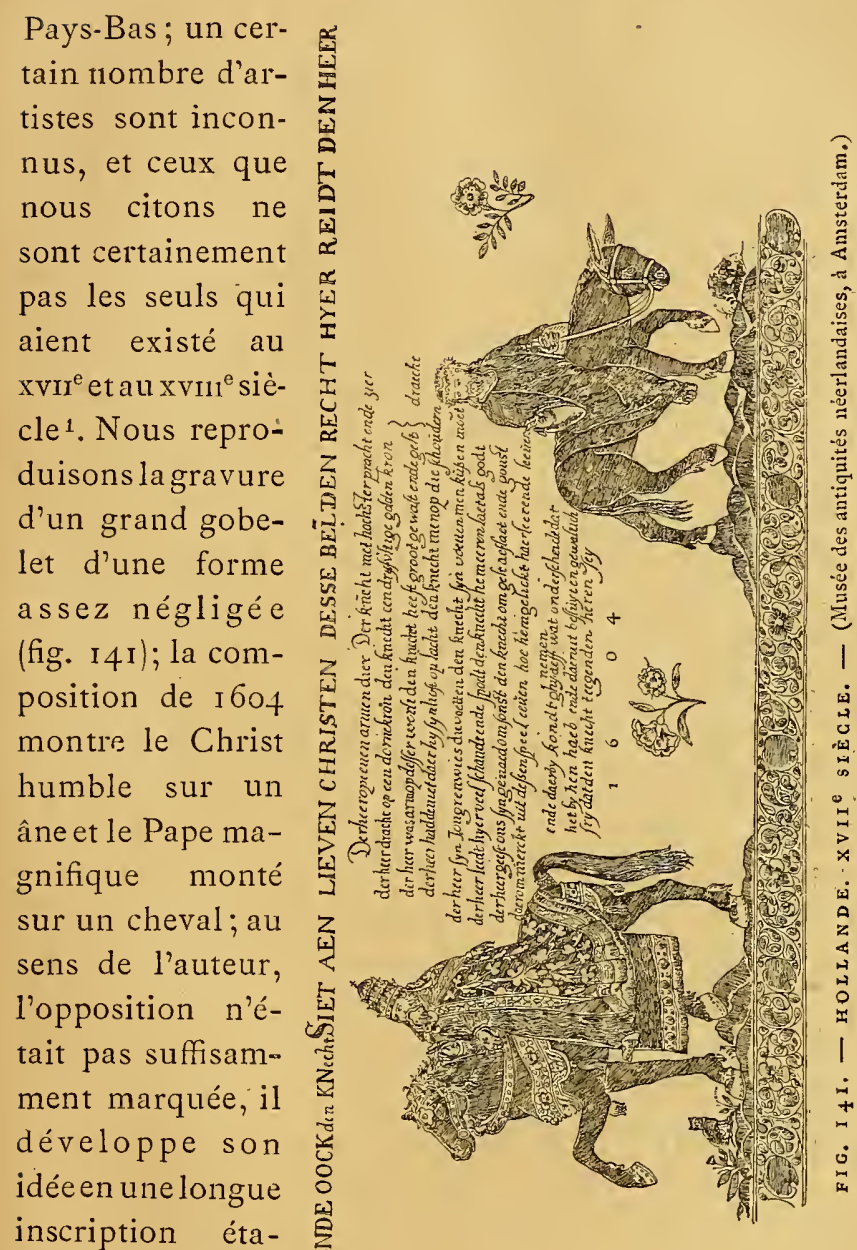

blissant entre le

Seigneur et le serviteur un parallèle dont la con-

I. Nous devons la plupart de ces renseignements à.un amateur LA VERRERIE, 
clusion prouve que le serviteur est l'ennemi du Seigneur; il est inutile d'ajouter que le graveur inconnu appartenait à la religion réformée. La gravure dénote une main exercée; ce n'est certes pas l'œuvre d'un novice, et quoique cette date de $6_{0} 0_{4}$ soit, à notre connaissance, la plus ancienne de la gravure hollandaise, il est hors de doute qu'au commencement du xvil siècle la gravure sur verre était un art très avancé. Anna Rœmers Visscher signe deux verres à boire, en I62 I et r646, les décore de fleurs et d'insectes', inscrit sur l'un des vers italiens et surl'autre une devise en hollandais: Vincens tui (abstenez-vous). Maria Tesselschade, vers la même époque, grave un verre avec les mots en français : A demain les affaires!

Un graveur dont le nom est inconnu, mais dont voici le monogramme, a laissé des ouvrages plus importants : - un

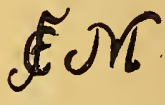
verre de la forme classique des verres à vin du Rhin, daté de i652, montrant les scènes de la Nativité et la Fuite en Égypte, séparées par une inscription hollandaise: « Louange soit à Dieu au ciel, et paix sur la terre à l'homme bonne volonté ! " - Un verre à boire co-

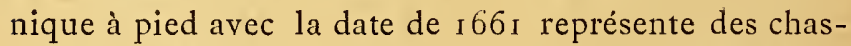
seurs avec des faucons et des chiens. - Un grand bocal gravé, en I 644, d'après la composition de J. Bouchorst de l'ouvrage : Descriptions et louanges tirées de la ville de Haarlem : la Victoire couronnée par un Génie tient une palme d'une main et de l'autre s'appuie sur l'écus-

hollandais, M. D. Henriques de Castro, dont le père, mort en I 863 , était un graveur sur verre qui a dignement continué les traditions de ses prédécesseurs. 
son de Haarlem; à ses pieds le lion néerlandais couché, sur la face opposée trois navires s'apprêtent à l'attaque d'une place forte; au-dessus on voit une clochette dans un ornement : c'est la cloche de Damiette rapportée de l'expédition de i 2 i 8 à laquelle la gravure fait allusion. - Un verre de r652, à sujet de galanteries, fait voir un chevalier offrant une tulipe à une bergère et un satyre lutinant une nymphe; les motifs sont accompagnés des inscriptions en hollandais : " Moi pour l'argent ", "Moi pour l'amour ».

Un autre graveur dont le nom est également inconnu a inscrit son monogramme, en 1685 , sur un verre montrant des paysans qui dansent et sur un grand verre en tulipe (fig. I42). La composition est du genre nommé " jardin hollandais ". Elle montre la Navigation dans un trophée d'armes; d'une main elle tient une balance, de l'autre elle distribue des fleurs et des fruits; près d'elle, une femme avec trois enfants; en avant, le Lion néerlandais et la Patrie tenant au bout d'une lance le chapeau des gueux, emblème de la liberté. L'inscription principale, Pax atque libertas, donne la signification du verre; sur le pied une inscription hollandaise : "A l'année prochaine avec amour nouveau ", marque un départ et un désir de retour. Le monogramme W C est accompagné d'un millésime, I 69 I ou. 697 , et de la date du 23 novembre. Si le millésime, ce qui est possible, est I 697 , on pourrait trouver dans la gravure une glorification du traité de Ryswick; conclu deux ans auparavant, qui termina la guerre du Palatinat.

D'autres verres, gravés au xvir siècle, portent des 
écussons, le Lion néerlandais, des musiciens, le portrait des stathouders Guillaume I I et Guillaume II, des fleurs et des fruits, l'orange surtout, des inscriptions françaises : Vive le prince d'Orange! des allégories, la Foi, l'Espérance, la Charité, et des ornements de tout genre. Plusieurs de ces compositions sont de Pierre Nolpe, graveur du temps très estimé.

Le $\mathrm{xvIII}^{8}$ siècle hollandais fournit Greenwood, Schouman, Wolff, très connus, et J.-H. Hoolaert, Pierre Luyten, Wilhelm Fortuyn, J. van den Blijk, et d'autres sans doute; nous ne retiendrons que les plus distingués de ces graveurs sur verre. Franz Greenwood est né à Rotterdam en I680; on le trouve à Dordrecht, employé à la municipalité, et c'est là qu'il exerce la gravure sur verre au diamant avec un rendu qui lui est particulier : il grave les parties en lumière et laisse le verre uni dans les ombres. La célèbre collection Six conserve de lui un grand verre à boire gravé en 1722 : c'est une femme, la palette à la main, devant le cheva-. let; à côté, une figure de satyre en buste, et au bas un singe, la patte dans la couleur; un second verre, de 1724 , représente un personnage en costume du $\mathrm{xVIII}^{\mathrm{e}}$ siècle, le verre à la main; l'inscription AANZIEN DO ET GEDENKE veut dire : " Regarder fait ressouvenir "; la composition est d'après Jean de Miéris; un troisième verre de 1743 montre un personnage du $\mathrm{xv}_{11^{\mathrm{e}}}$ siècle regardant avec satisfaction un verre à vin qu'il tient à la main.

Aart Schouman (1 7 10-I 792) était un artiste distingué et très estimé de ses concitoyens; il fut régent de l'Académie de dessin et président de la confrérie Pictura, 
LA HOLLANDE, LES FLANDRES, L'ESPAGNE. 293 à la Haye; il était graveur, peintre d'histoire et com-

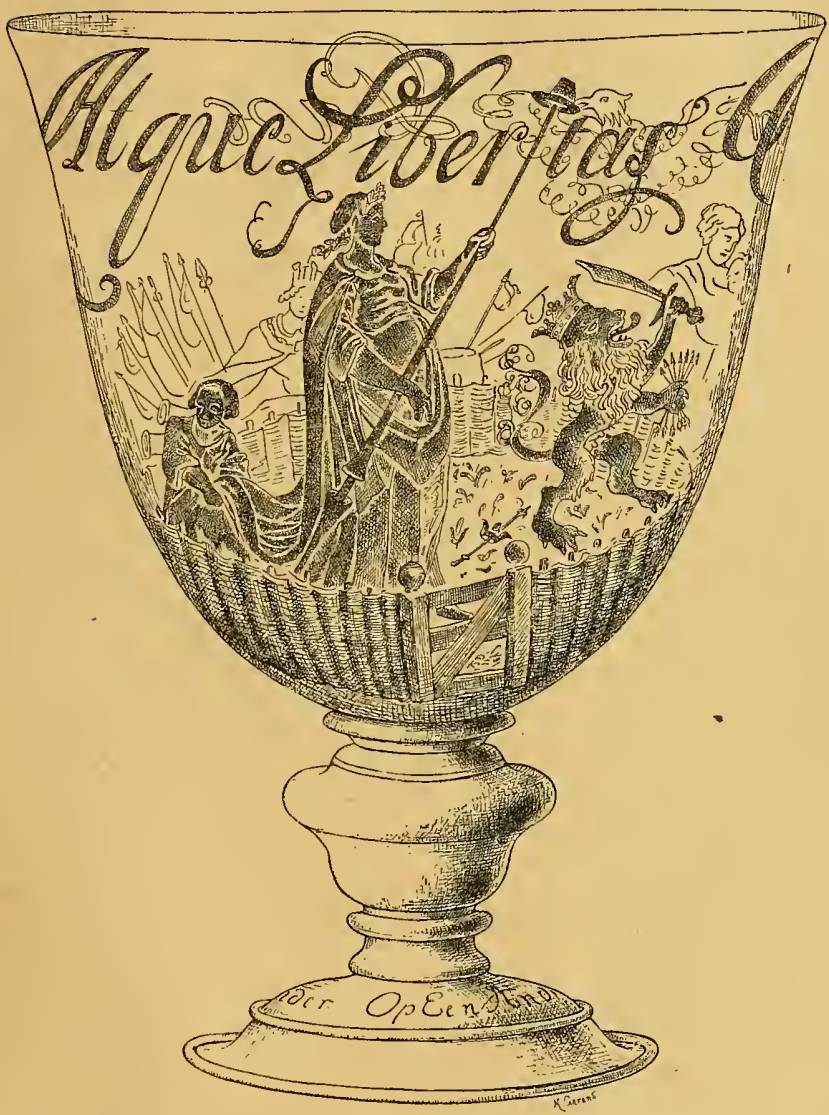

FIG. I +2 . - FOLLANDE. XVII SIÈCLE,

(Musée des antiquités néerlandaises, à Amsterdam.)

posa des modèles de tapisserie. Il est regrettable que 
les verres gravés de Schouman soient si rares, car on n'en compte que deux : sur l'un est un homme, un verre de bière à la main, et sur l'autre l'effigie de Guillaume IV; il nous semble qu'on pourrait attribuer à cet artiste le portrait de la femíme de Guillaume $\mathrm{V}$, dont nous donnons un dessin qui ne peut faire comprendre l'extrême délicatesse de la gravure, sem-

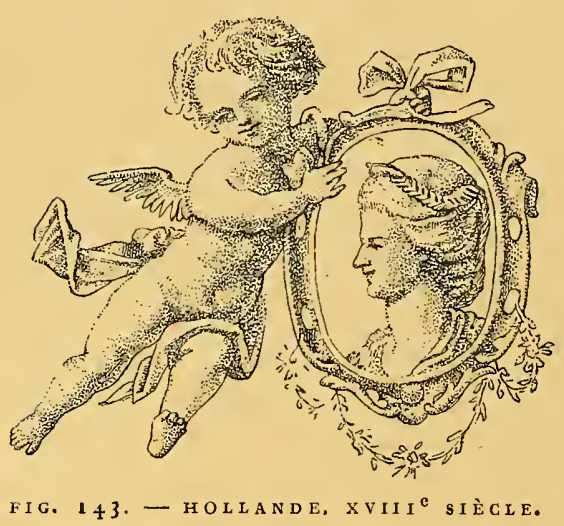

(Musée des antiquités néerlandaises, à Amsterdam.)

blable à un nuage blanc légèrement opaque sur un ciel clair et vibrant.

Wolff est le plus réputé des graveurs sur verre de la Hollande et aussi celui dont le plus grand nombre d'ouvrages a été conservé; on ignore son prénom; il se maria en ${ }^{7} 87$ et mourut jeune, avant la fin de l'année r 808 . C'était un artiste d'un caractère singulier; dénué de ressources, il mit devant sa porte ses meubles de mariage et les vendit; il entra chez un peintre en voitures et se perfectionna dans la décoration des panneaux de luxe. Un certain nombre de ses verres font partie des collections Six et de Castro; il a gravé à la molette et en pointillé au diamant. Ses compositions n'ont rien d'exclusif; elles embrassent le genre des Watteau et des Boucher, et aussi des sujets plus sé- 
rieux. Nous en citerons quelques-uns : Enfants dans les nuages; - Allégories à l'amitié, avec le mot Wriendschap, représentées par des génies dans les nues se versant à boire, de jeunes garçons sous des arbres, des soldats invalides se passant le cruchon de bière; Séances de musique entre garçons et filles; - Écussons particuliers avec ornements; - Écussons du stathouder Guillaume $\mathrm{V}$ avec génies dans les nuages et les mots français : Je maintiendray; - Écussons des ProvincesUnies; - Fleurs, corne d'abondance, faisceaux de licteurs, Lion néerlandais la patte sur une pique surmontée du chapeau de la liberté; - Lion au repos sur des nuages, caressé par un génie; Minerve casquée armée de la lance et du bouclier; génie avec un serpent et un miroir et l'inscription : Sic oportet; - Écussons de Guillaume $\mathrm{V}$ et de la princesse FrédériqueSophie de Prusse, sa femme, avec la Liberté rompant ses chaînes et tenant à la main la pique surmontée du chapeau des gueux. Wolff rendait à Guillaume $\mathrm{V}$ un hommage fort exagéré ; ce prince, qui clôt la suite des stathouders, vit déchoir la puissance de la Hollande, et ne fut rétabli dans son pouvoir que par les armées étrangères. On attribue à Wolff les effigies du professeur en théologie Jacob van Nuys Klinkenberg, du pensionnaire Cornelius de Gijzelaar, du bourgmestre Hendrik Hooft avec deux vers dont voici le sens : “ Ceci est le Caton Hollandais Hooft, fuyant la tyrannie; s'il revient en triomphe, les Pays-Bas seront libres. »

Nous avons insisté sur la Hollande, non seulement à cause de la qualité du travail, mais parce que, dans ce pays plus particulièrement, nous pourrions même dire. 
exclusivement, la patrie, la liberté, l'affranchissement du territoire ont été glorifiés par les graveurs sur verre. Ces artistes se sont élevés ainsi dans une sphère supérieure; ils ont contribué à maintenir le sentiment patriotique, en faisant pénétrer leurs compositions dans l'intérieur de la demeure et en les traduisant sur des objets usuels.

\section{II}

“ Ung gobelet et une aiguière de voirre blant de Flandres, garny d'argent ». Cet article, inscrit dans l'inventaire du roi de France Charles V, dressé en I 38o, est la plus ancienne mention que nous ayons trouvée de la verrerie flamande. En I42 I, un nommé Annieul était verrier à Namur. Les registres des comptes, de janvier 1453 à décembre 1454 , de la ville de Lille contiennent un règlement fait à Gosselin de Vieuglise, "maître voirrier » en cette ville, pour fournitures faites à l'occasion du banquet « du Faisan », donné dans le palais de Lille par Philippe le Bon; la fourniture comprenait des vitraux peints, “une fontaine de voirre » et " quatre plateaux de voirre ${ }^{1}$. "Nous avons déjà vu les plats de verre en usage dans les festins du vi ${ }^{\mathrm{e}}$ siècle.

Avañt i 5o3, il existait dans les Flandres une fabrique de miroirs, le Grand Conseil de Venise ayant donné, en cette année, à Andrea et à Domenico de Angelo del Gallo le droit de fabriquer des miroirs, afin de

1. Houdoy. Verreries à la façon de Venise. La fabrication flamande. 
faire concurrence à une maison allemande associée à une maison flamande. L'inventaire de Marguerite d'Autriche, fait en 1523 , indique " un grant voire vert donné par M.S. de Liège, le couvercle et le pied d'argent doré ». Jean Quarré, d'Anvers, et plusieurs ouvriers verriers sont appelés en Angleterre par la reine Élisabeth, en i 567. CharlesQuint et Philippe II accordent des privilèges à un ouvrier de Venise, Ambrosio de Mongarda, établi à Anvers. En 1599, Gridolphi, qui avait épousé la veuve de son compatriote Mongarda, obtient de l'infante Clara-Eugénia, à laquelle Philippe II avait cédé les Pays-Bas, le privilège de " faire voire de cristal à la faschon de Venise », à la condition de ne point porter atteinte aux privilèges dú comte de Lallaing pour " plats voires à faire miroires ${ }^{ \pm} \leadsto$. Les privilèges accordés aux Ita-

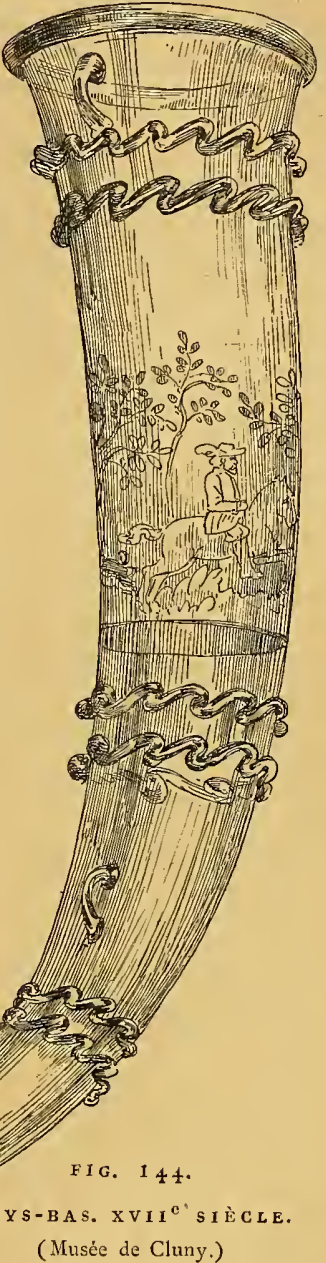

(Musée de Cluny.) liens des Flandres ne s'appliquaient qu'aux verres imiI. M. J. Houdoy, dont les travaux ont mis en lumière les ver - 
tés de Venise, mais l'importation des verres de Venise véritables était permise, ainsi que celle des verres communs fabriqués en France et en Allemagne; il paraît que

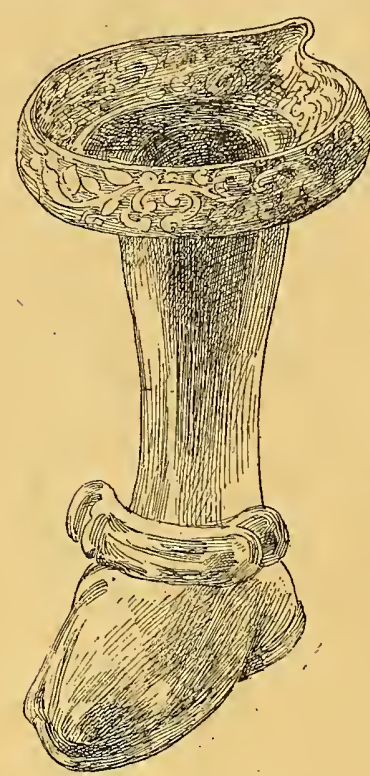

FIG. $1+5 \cdot-P A Y S-B A S$. (Musée de Cluny.) dans ces pays les fabricants imitaient à s'y méprendre les verres de Venise et qu'ils les introduisaient comme tels dans les Flandres. Les privilégiés réclamèrent. Gridolphi et son associé Jean Bruyninck, "livreurs de voires de l'hôtel de leurs Altesses sérénissimes Albert et Isabelle, enfants de Philippe II ", obtinrent, en 1608 , le droit exclusif de vente et de fabrication des verres soit de provenance directe de Venise, soit de façon de Venise; de sorte que les fabriques établies sur les frontières, à Mézières notamment, " sont allées en fumée. " L'établissement de Gridolphi passa successivement dans les mains de Ferrante Morron, de Van Lemens et de Colinet. Van Lemens était propriétaire d'une verrerie fondée à Bruxelles, en $6_{2} 6$, par Anthoine Miotti, pour fabriquer “ des verres, des

riers vénitiens établis dans les Flandres, suppose avec vraisemblance que la fabrique du comte de Lallaing est cette maison flamande dont il est question dans la requête présentée au conseil des Dix par del Gallo. 
LA HOLLANDE, LES FLANDRES, L'ESPAGNE. 299

vases, des couppes et des tasses de fin cristal de toutes couleurs ". Dans les Flandres comme ailleurs, les privilèges donnaient lieu à d'incessantes contestations; les droits n'étaient pas nettement délimités et les princes ne tenaient qu'un médiocre compte de leurs octrois antérieurs. Deux Italiens, Ludovico Caponago et Jean Savonetti, attaquèrent Collinet et obtinrent le droit exclusif pour la vente et la fabrication de toute espèce de verres, sauf « le vittre en table servant à faire des fenêtres ». En I653, Jean Savonetti fut rem. placé par Francesco Savonetti; cet Italien disparut en $\mathrm{i} 658$, et alors commence la série des verriers flamands, Henry et Léonard Bonhomme, Théry Lambotte, Barbe de Thiers, Ambroise Du-

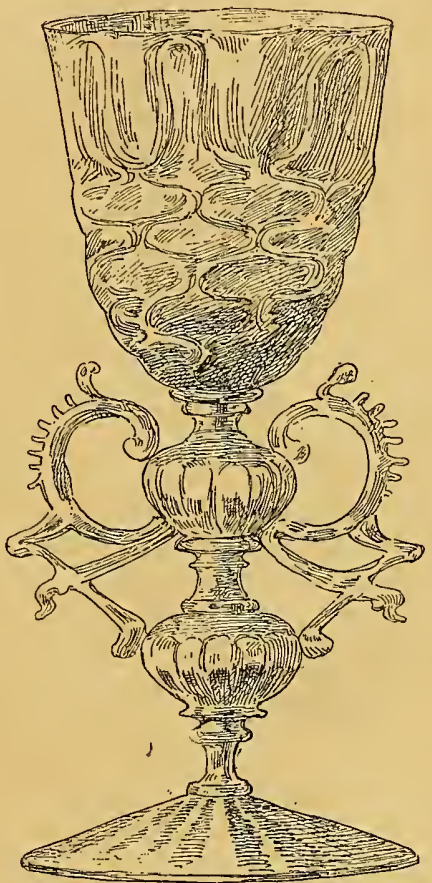

FI G. $I \pm 6 .-$ PA Y S-B A .

(Musée de Cluny.) quesne.

Ce rapide exposé indique suffisamment le genre des verreries fabriquées dans les Flandres; le service de luxe était imité des verres de Venise, mais il était plus lourd de forme, et les verres à boire ordinaires res- 
semblaient aux verres allemands; la fabrication des verres à vitres avait pris une grande extension, quoique

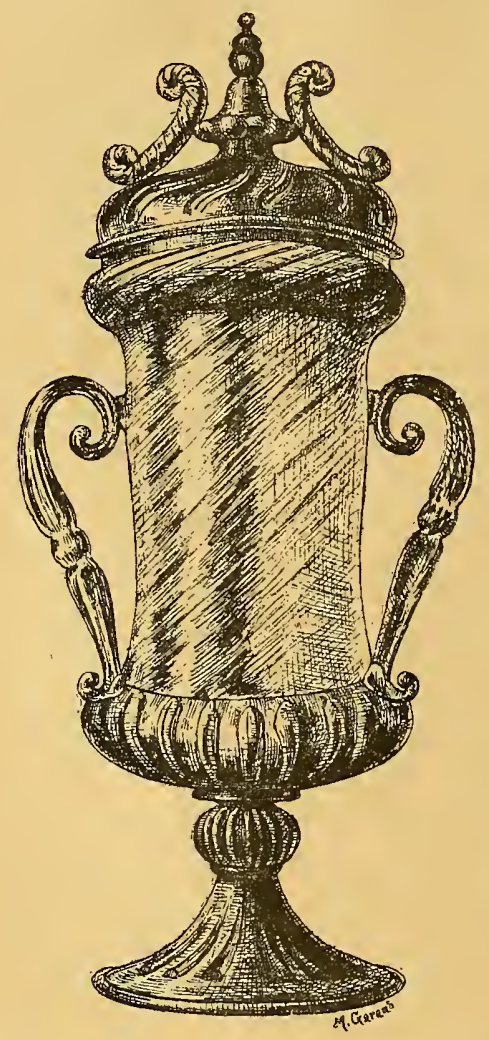

FIG. 147 . ESPAgNE. XVI ${ }^{\mathrm{e}}$ SIİCLE.

(Collection Davillier.) cet article fût exempt de droits à l'importation. Nous retrouvons à Fourmies et à Bruxelles nos gentilshommes verriers de la Lorraine, Paul et Josué d'Hennezel, qui fabriquent des miroirs à la façon de Venise, des grands verres à vitre ronds à la façon de Normandie et des vitres carrées à la façon de Lorraine; l'industrie des verres à vitres est restée prospère, et de nos jours encore elle constitue, dans les anciennes provinces flamandes, une fabrication très importante.

\section{I I}

Ainsi que la Gaule, l'Espagne avait eu des verreries dans l'antiquité. Pline l'affirme et Isidore de Séville, évêque de 6 o ì 636 , semble assurer que, de 
LA HOLLANDE, LES FLANDRES, L'ESPAGNE. 301 son temps, le verre foncẹ était le mẹilleur pour les mi-

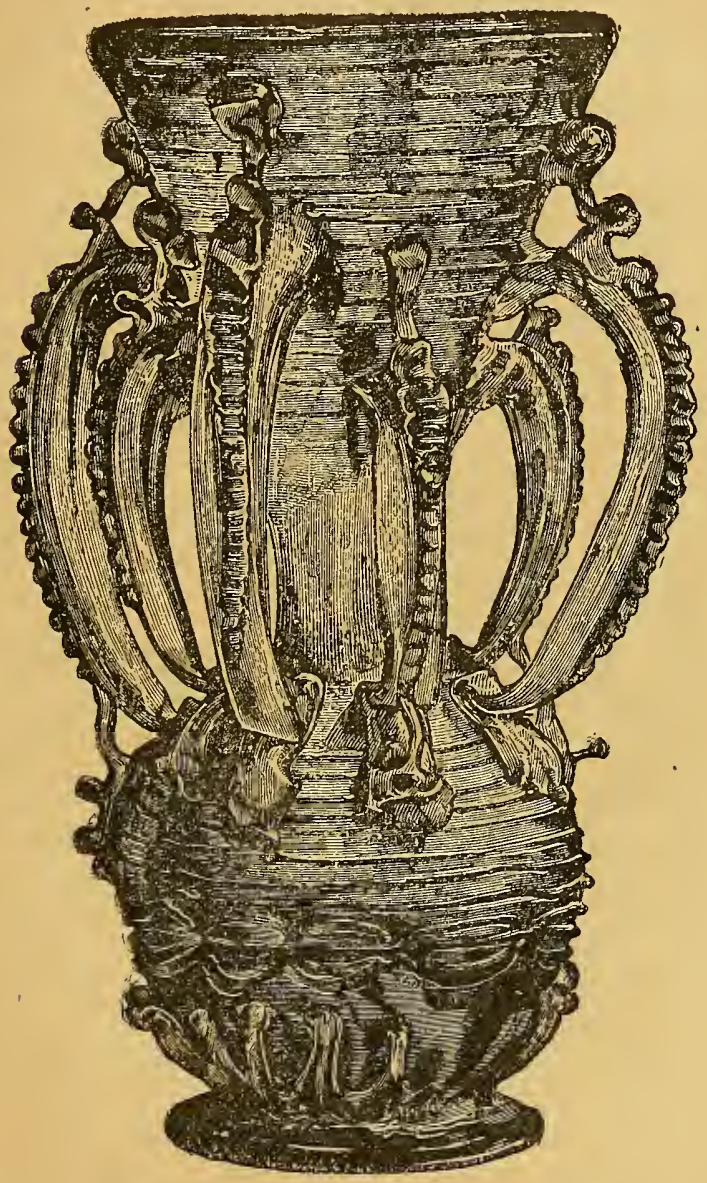

FIG. I 4 8. - ESPAGNE. XVI SIÈCLE.

roirs, Sous la domination arabe, des verreries renom- 
mées pour la qualité de leurs produits existaient à Murcie et à Almeria ${ }^{1}$. La reine Isabelle la Catholique concéda, le 8 juin 1475 , un privilège avec exemption des droits d'alcavala, impôt sur la vente, aux moines du couvent de San-Geronimo de Guisando, pour établir un four de verrerie à la Venta de los toros de Guisando. $\mathrm{Au} \mathrm{xv}^{\mathrm{e}}$ siècle, on trouve des verreries à Caspe, en Aragon.

Les archives municipales de Barcelone font mention de verreries existant dans cette ville dès le xive siècle; elles continuèrent à fabriquer durant le siècle suivant, car, en 5 o 3 , Ferdinand le Catholique envoya à la reine Isabelle deux cent soixante-quatorze pièces de verre de Barcelone qui étaient dignes de leur haute destination; ces verres attirèrent l'attention de l'ambassadeur vénitien Navagaro, qui visitait l'Espagne en I 523; il en vit plusieurs offerts par la princesse à la Capella Reale de la cathédrale de Grenade. Un inventaire dressé sous le règne de Philippe II ( ( 555-I 582) mentionne, sous la rubrique Bidrios de Barcelona, cent dix-neuf pièces de verreries de diverses formes dont un certain nombre de lampes émaillées. Il y avait en Catalogne d'autres verreries à Cervello, à Almatret et à Mataro; cette dernière ville est restée célèbre, au Xvir et au Xvir ${ }^{\mathrm{e}}$ siècle, pour sa belle fabrication; lorsque les princes étrangers parcouraient l'Espagne, le roi les faisait conduire sur une galère à Mataro, pour visiter les verreries.

I. La plupart des renseignements sur l'Espagne nous ont été donnés par M. Ie baron Charles Davillier; la mort a empêché cet érudit si regretté de mettre la dernière main à deux ouvragés sur la verrerie et la peinture sur verre en Espagne. 
LA HOLLANDE, LES FLANDRES, L'ESPAGNE. 303

Il existait des verreries, au $x{ }^{\mathrm{e}}$ siècle, à Séville. à

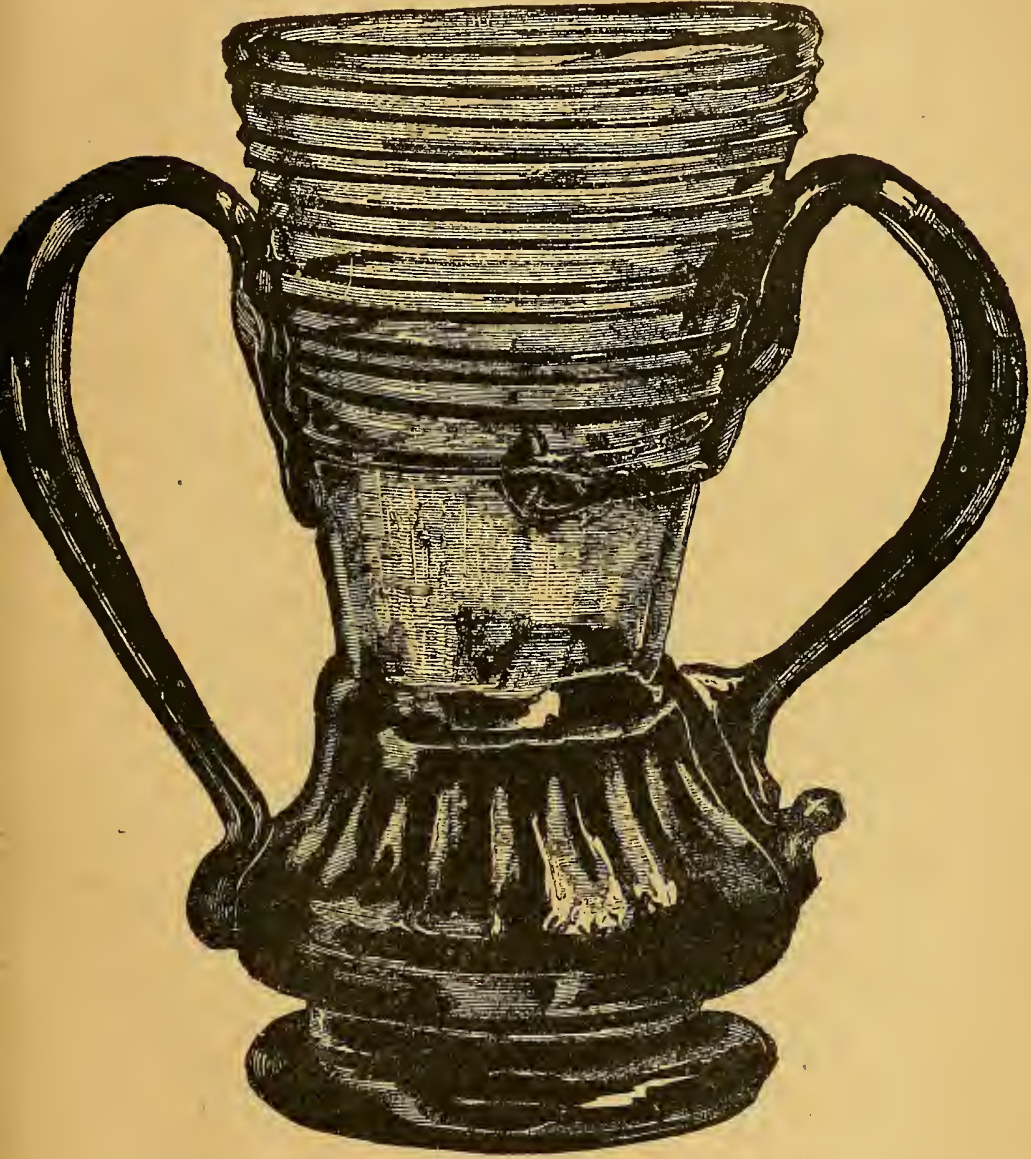

FIG. I +9. 一 ESAGNE. XVI SIĖCL.

Olleria dans le royaume de Valence, à Cebreros dans 
la province de Ségovie, à Recuenco dans celle de Cuença, à Tolède et près de cette ville, à Cadalso de los Vidrios, où l'on se livrait aussi à l'imitation des pierres précieuses. Vers I 560, Philippe II, qui se plaisait à tous les détails de la construction de l'Escurial, s'occupa de faire garnir de verres les fenêtres du palais; il ordonna une enquête sur la fabrication en Europe ${ }^{1}$; les verreries d'Espagne, de Normandie, de Bourgogne et de Lorraine envoyèrent leurs échantillons; on jugea que les verres de Normandie étaient pius clairs que ceux des autres pays. L'histoire ne dit pas quelle verrerie eut la fourniture, mais ce ne fut pas celle de Barcelone, parce que ses produits étaient d'un prix trop élevé.

Vers le milieu du xvır' siècle, deux Français, Antoine Berger puis Claude Seigne, travaillaient à la fabrique royale de cristaux de Saint-Ildephonse, où l'on produisait des vases et de grandes glaces. Berger avait embauché des ouvriers français; il revint en France pour en chercher d'autres, mais il fut mis à la Bastille; Seigne était un ancien ouvrier de Nevers; il était aussi employé à la fabrique de faïence de Saint-Ildephonse, dont l'existence est peu connue.

Les verres espagnols sont très rares dans les musées français; le musée de Kensington en possède quelquesuns; il est dès lors difficile de se faire une idée exacte de leurs genres, qui doivent être assez variés. Quelques verres sont décorés d'émaux verts et jaunes, qui semblent être l'une des caractéristiques de la fabrication espagnole; nous savons par les textes que l'on fabri-

I. Le baron Davillier possédait le texte de cette enquête annoté de la main de Philippe II. 
LA HOLLANDE, LES FLANDRES, L'ESPAGNE. 30S

quait des lampes également émaillées, en imitation sans doute des lampes arabes. La manufacture royale de Saint-Ildephonse produisait des verres de toutes formes, gravés et taillés. La forme de quelques-uns des verres connus du $\mathrm{xvI}^{\mathrm{e}}$ siècle espagnol est exubérante, bizarre; les anses ont des développements exagérés; c'est une sorte de verrerie de Venise sans délicatesse, façonnée par de rudes mains. Mais, nous le répétons, nous manquons d'éléments complets pour asseoir notre jugement, et la verrerie espagnole, comme celle de bien d'autres pays, attend son histoire particulière. 


\section{L'ANGLETERRE - LA CHINE}

Comme dans tous les pays qui furent soumis à la domination romaine, on trouve en Angleterre des verres antiques, mais il n'est pas démontré que ces verres ne proviennent pas exclusivement de l'importation. Les tombeaux des Saxons contemporains de la conversion du pays au christianisme fournissent quelques pièces de verres semblables à ceux de nos tombes mérovingiennes. $\mathrm{Au} \mathrm{vII}^{\mathrm{e}}$ siècle, l'Angleterre était fort peu avancée dans l'industrie du verre, puisque l'abbé Benedict, Biscopus, dut faire chercher en France des verriers pour fabriquer les vitres du couvent de Wearmouth et que quelques années après, vers 678 , on pria l'évêque de Mayence d'envoyer en Angleterre un verrier capable de souffler des vases. Les vitres de la cathédrale d'York avaient déjà, quelques années auparavant, été fournies par des verriers français. Le xIII siècle révèle, sur les registres des taxes de Colchester, trois verriers, Robert, Mathieu et Henri. Les inventaires et les découvertes ressortissant au xive siècle prouvent l'existence de pièces de verre, mais non une fabrication locale. $\mathrm{Au} \mathrm{xv} v^{\mathrm{e}}$, on faisait certainement du verre à vitre en Angleterre, car John Prudde de Westminster recom* 
mande de ne pas s'en servir pour la chapelle de Beauchamp, à Warwick, et ẹn 1485 on préfère aux verres anglais les verres hollandais, vénitiens et normands. La présence des Italiens à Londres est constatée en I 550; huit verriers de Murano étaient enfermés dans les cachots de la Tour, parce qu'ayant reçu de l'argent, ils n'avaient pas travaillé en conséquence; ils allaient être pendus lorsqu'ils s'adressèrent au Conseil des Dix, s'excusant d'avoir quitté Murano malgré la loi, parce qu'ils manquaient de travaux dans leur pays; le Conseil les autorisa à rester en Angleterre jusqu'à la fin de leur engagement; en ceci le Conseil fit sans doute un acte politique agréable à la couronne d'Angleterre, car le décret de 1547 chargeait des émissaires de tuer les verriers fugitifs et nous avons vu que le décret ne resta pas toujours lettre morte. Dans la seconde moitié du xvi siècle, on constate à Londres, à Crutched Frias en 1557 , une verrerie qui fabriquait le flint-glass, c'est-à-dire le verre blanc fait avec le sable du flint, silex. En I 568, entre Jean Quarré, verrier d'Anvers appelé en Angleterre par la reine Élisabeth, et Antoine Bechu, d'une part, et Thomas et Balthasar de Hennezel, verriers de la Lorraine, d'autre part, est signé un contrat obligeant les Lorrains à venir en Angleterre pour fabriquer du verre et enseigner leur industrie. En I 574, des verriers français établis près de Petworth virent leurs verreries brûlées et pillées; en I 589, quinze verreries fonctionnaient en Angleterre.

Le $\mathrm{xvIl}^{\ominus}$ siècle est de beaucoup le plus important, dans l'histoire de la verrerie en Angleterre; il vit le premier emploi industriel du charbon de terre comme chauffage de verrerie et la découverte du verre à base de 
plomb, c'est-à-dire du cristal. Il semble qu'antérieurement à 16 I 1 une patente royale fut accordée à un verrier, William Slingsby, pour l'usage de la houille; en i 6 i 5 ; une proclamation de Jacques Ier défendit absolument le bois comme combustible et prohiba l'importation de la verrerie étrangère ; cette disposition fut modifiée, en I 620 , à l'égard des pièces de verre rares et curieuses. Un fabricant, Sir Robert Mansell, dont le nom est inséparable des progrès de la verrerie en Angleterre, obtint en 16 I 6 le privilège exclusif de la fabrication du verre dans le royaume; des établissements nombreux furent exploités par ses soins. Ils produisaient des verres pour les fenêtres, des vases de tous genres, des verres d'optique, des verres à la façon de Venise, car le personnel n'était pas exclusivement anglais, et Mansell, à défaut d'Anglais, dut faire venir de Mantoue une équipe tout entière. Les concessionnaires ne sont pas plus en Angleterre que dans les autres pays à l'abri de la concurrence, et de la concession ne résulte pas nécessairement la fortune. Mansell prouva en 1634 qu'il avait perdu trente mille livres sterling, parce que ses ouvriers l'abandonnaient pour aller travailler en Écosse et en Irlande, et que, malgré la prohibition, la verrerie italienne et française pénétrait en Angleterre; et cependant, contrairement à l'usage qui voulait que les monopoles fussent confirmés chaque année par le Parlement; la patente de Mansell avait été affranchie de cette approbation dis 1624 , et une nouvelle ordonnance défendit l'importation des verreries étrangères, en 1635.

On n'a pu, même en Angleterre, se prononcer d'une manière formelle sur l'invention du cristal, ou du moins 
sur la date précise de l'exploitation industrielle de l'invention. Nous avons déjà eu l'occasion de le dire : le verre à base de plomb était connu de l'antiquité, et, d'autre part, l'expression " cristal » étant depuis fort longtemps employée pour désigner le verre blanc de belle qualité, occasionne, en Angleterre comme ailleurs, certaines confusions dans les textes. L'écrivain anglais, le docteur Merret, disait vers 1665 : « Le verre de plomb n'est point en usage dans nos verreries anglaises, à cause de sa trop grande fragilité... Si cette espèce de verre avait la même solidité que le verre cristallin, il serait supérieur à tous les autres, à cause de la beauté de sa couleur. " Donc. le cristal était connu dans les fabriques anglaises, mais depuis quelle année? Un praticien distingué, M. Bontemps ${ }^{1}$, pense que l'invention du cristal anglais est la conséquence du chauffage à la houille; avec le feu de bois, le verre est fondu dans des creusets ouverts; avec le feu de houille, dont la flamme impure ternit la blancheur du verre, on ferma les creusets par le haut et la cueille se fit par une bouche située en dehors du four : le creuset fermé devant renfermer des éléments plus fusibles que le creuset ouvert, le chimiste augmenta la fusibilité de la masse par l'adjonction de l'oxyde de plomb. Il est possible que le cristal ait été ainsi inventé, mais ce n'est là qu'une hypothèse, car.on peut fondre le verre ordinaire aussi bien que le cristal dans des pots fermés. Quoi qu'il en soit, on pense que, dès I623, Mansell, dans la verrerie de Newcastle-sur-Tyne, fit usage du plomb, et qu'en $\mathrm{I}^{6} 3$ cette matière était

I. G. Bontemps. Guide'dus?verrier. 
d'un emploi courant à la verrerie de Lambeth. A la fin du siècle, la fabrication du cristal était très répandue; elle continua au xvir ${ }^{\mathrm{e}}$ siècle, mais les produits ne paraissent pas avoir été très satisfaisants. Le mémoire de Bosc d'Antic, dont nous avons déjà eu l'occasion de parler, constate en 1760 que le cristal anglais n'est pas d'une bonne couleur, qu'il est plutôt jaune ou brun, mal fondu et plein de taches. Il n'en reste pas moins acquis que le cristal est d'invention anglaise, et qu'en France la verrerie de Saint-Louis, la première en date pour le cristal, ne put le fabriquer qu'en $\mathrm{r} 782$. L'industrie anglaise a donc apporté à la verrerie un contingent très important; elle eut aussi une influence très marquée sur les formes. Le flint-glass taillé en prisme décompose la lumière; le verrier anglais chercha à tirer parti de cette propriété pour donner plus de prix à la fabrication; il arriva naturellement à tailler à facettes la surface extérieure des cristaux, mais la taille dénature la forme et elle exige une épaisseur de verre qui alourdit; dès lors, l'objet est devenu massif et la grâce que Venise avait mise à la mode fut abandonnée pour l'article anglais, solide et confortable, mais sans élégance. Les cristaux anglais ${ }^{1}$ furent adoptés sur tous les marchés, et la Bohême s'en ressentit à ce point, qu'impuissante à lutter, en tant que qualité de verre, avec le cristol anglais, elle négligea les verres blancs gravés pour s'adonner de nouveau aux verres colorés.

I. Compositions du cristal : silice, 52 ; potasse, 12,8 ; oxyde de plomb, 35,2. - Flint-glass pour l'optique : silice, 44,44; potasse, II,II; oxyde de plomb, 44,44. - Le Crown-glass est un verre ordinaire servant à l'optique. 
Depuis plusieurs années, quelques objets de verrerie de la Chine et du Japon sont entrés dans les collections; ce sont, en général, de petites bouteilles plates, à col étroit, destinées à contenir du tabac. Elles sont en verre transparent et en verre opaque, décorées, soit à l'extérieur

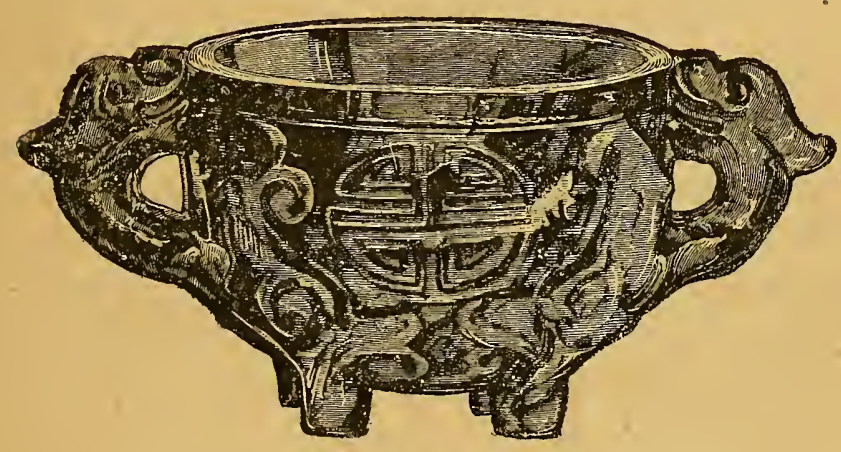

FIG. ISO. - CHINE. VASE AVEC IE SIGNE DE LONGÉVITÉ.

soit à l'intérieur, en relief ou en peinture; l'objet est d'une bonne exécution, tant pour le profil que pour le décor. Nous reproduisons trois de ces tabatières à la grandeur réelle; elles donneront une idée juste de la fabrication: la tabatière cylindrique porte son décor colorié à l'intérieur; nous ne pouvons expliquer comment l'habileté de main a pu arriver à ce résultat surprenant. De quelle époque sont ces tabatières, et quelle est l'histoire de la verrerie en Chine? A la première 
question on peut répondre que les verreries chinoises réunies dans les collections d'Europe paraissent être modernes, c'est-à-dire ne pas remonter au delà du $\mathrm{xvIu}^{\mathrm{e}}$ siècle. Nous n'essayerons pas de résoudre le se-

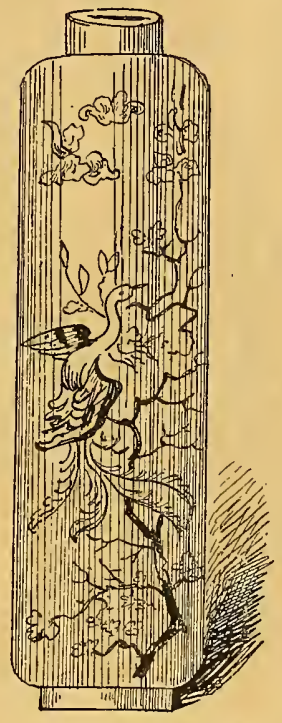

FIG. ISI. - CHINE.

(Collection Vapereau.) cond problème, et nous nous contenterons de donner quelques renseignements sommaires : les difficultés de l'écriture, l'absence de monuments, rendent le travail inabordable pour tous autres que les habitants de la Chine, nationaux ou étrangers; c'est d'eux que nous attendons l'histoire de la verrerie chinoise. A en croire la tradition, l'empereur Ou-Ti, de la dynastie des Han, eut, vers l'an 140 avant notre ère, une fabrique de lieou-li. Après le $\mathrm{II}^{\mathrm{e}}$ siècle, il y aurait eu des verreries à ShanTung dans l'empire du Nord. Edrisi, géographe arabe, parle en I 54 de la ville de Djan-Kou comme produisant du verre. Dans le récit d'un historien de l'année I 350 , on constate une expression qu'on traduit par le mot «verre». Le missionnaire Ricci assure que les Chinois fabriquaient du verre de son temps, vers la fin $\mathrm{du} \mathrm{xvI}^{\mathrm{e}}$ siècle. Le Père Duhalde en dit autant au siècle suivant, mais il entre dans quelques détails qui font douter de la véracité de son récit, car il parle d'une certaine élasticité qui serait le propre du verre chinois. Un rapport de $\mathrm{i} 774$, rédigé 
dans le but de faciliter l'importation en Chine des produits français, engage les fabricants à faire de petites bouteilles à tabac semblables à celles que fabriquent les Chinois, et enfin le révérend $\mathrm{A}$ : Williamson rapporte que les roches du voisinage de Po-Shan-Hien, pulvé-
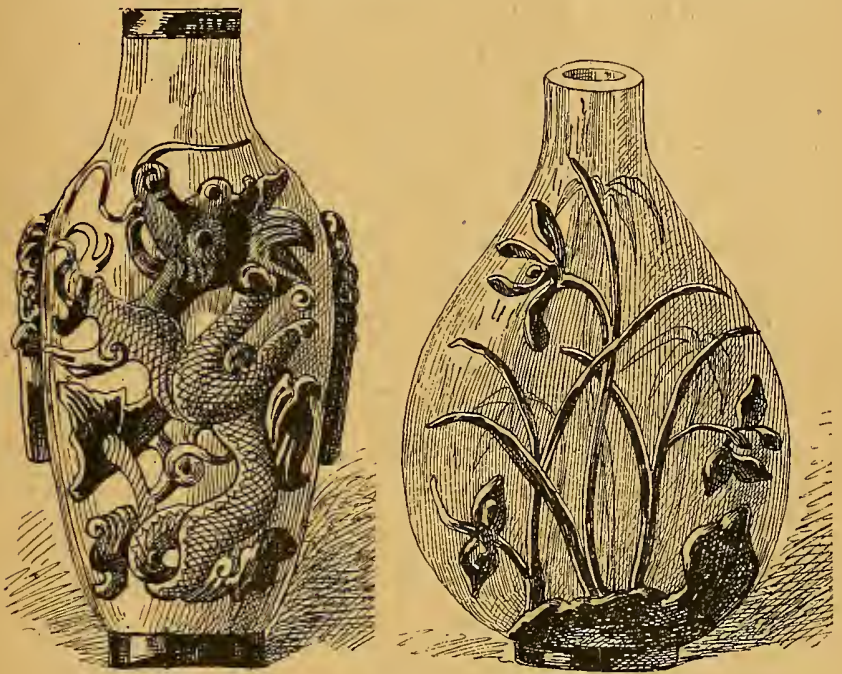

FIG. I S 2. - CHINE. - (Collection Vapereau.)

risées et fondues avec du nitrate de potasse, donnent un verre que les industriels appliquent aux vitres, aux vases de tous genres et à la verroterie.

De quelle valeur sont ces assertions? L'expression lieou $l i$, qui n'a pas d'équivalent dans la langue française, se marque par les signes et se rapporte à un émail transparent bleu foncé dans lequel il
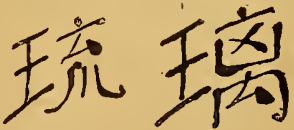
entre du lapis-lazuli; il y a donc quelque témérité à 
faire remonter l'origine du verre à l'empereur Ou-Ti. Nous savons aussi qu'à la suite du voyage du Vénitien Marco Polo, les fabricants de Murano exportèrent en Chine, à la fin du xur siècle, de grandes quantités de verroteries, qui servirent notamment aux boutons des mandarins; au siècle suivant, Andolo de Savignone, ambassadeur de Gênes en Chine, sollicita et obtint du Grand Conseil l'autorisation de faire l'exportation des verroteries; la fabrication locale ne se serait certainement pas adressée aux Vénitiens, si elle avait pu suffire aux besoins du pays. Et de fait, le pays du kaolin ne pouvait pas être propice à la verrerie, tous les vases de service étant en porcelaine. On pourrait prouver que dans les contrées où la céramique a été en grand honneur, comme en Grèce, la verrerie a été négligée; de même que dans les pays, comme à Rome, où la céramique était médiocre, le verre a été mis en honneur. Reste cependant le verre pour l'éclairage artificiel et le verre à vitre; quelque minces et transparents que soient la porcelaine, la corne et le papier, ces matières absorberont toujours plus de lumière que le verre, et rien ne vaut le verre pour la clôture des fenêtres. Nous avons peine à comprendre comment les pays de l'extrême Orient ont pu se passer du verre à vitre dès qu'ils l'ont connu, et pourquoi ils font si peu de cas, maintenant, de ce produit fabriqué sur lieux par des industriels européens. 


\section{L'A R T}

En principe, la verrerie est soumise aux règles générales de la décoration: la forme doit être déduite de la destination, le décor doit être inspiré par la forme, la matière doit être employée selon ses qualités expressives; en fait, ces règles ont été peu suivies. Nous allons essayer de chercher pourquoi.

\section{I}

Quelle que soit la date de l'origine du verre, elle est certainement postérieure à celle de la céramique : c'est en cuisant certaines terres qu'on a vu des larmes vitrifiées, et c'est ensuite dans des creusets de terre qu'on a fondu le verre; et comme les vases en terre et les vases en verre servaient à des usages presque identiques, on a naturellement donné aux seconds les formes des premiers. Pendant de longues périodes, le verre n'a pas figuré sur la table des princes, l'or, l'argent et le cristal de roche seuls étaient en honneur, et c'est en ces matières qu'étaient façonnées les coupes et les aiguières; lorsque le verre a été ensuite substitué au métal, le verrier a pris naturellement encore les formes déjà créées. C'est ainsi qu'on peut expliquer comment la verrerie de service n'affecte presque jamais de forme absolument particulière.

La taille est le décor normal du verre; par ses facet- 
tes et ses angles elle fait briller la matière; elle en enlève une partie, il est vrai, mais sans altérer sensiblement la forme générale de l'objet. L'émaillage est d'un emploi plus difficile, car il atteint directement la qualité essentielle du verre qui est la transparence. Les pièces de verrerie sont presque toujours de forme ronde; à travers la première paroi le regard se porte sur la face opposée; de là, dans les lignes du décor gravé ou émaillé, un trouble ou une confusion nuisible au motif représenté; afin de parer à cette difficulté, les verriers romains ont choisi le verre de couleur pour leurs objets d'art, et les Arabes ont posé leurs émaux sur un champ teinté ou doré. La rareté relative des verres historiés tient sans doute à ce fait et aussi à l'extrême fragilité de la matière; on comprend l'hésitation d'un artiste à entreprendre un travail long et difficile sur un objet que le moindre choc peut anéantir.

\section{I}

Il a manqué à la verrerie une tradition suivie et d'efficaces protections.

Les Égyptiens ont été plus préoccupés de la fonte et des mélanges que du décor et de la forme de leurs verres. Les Grecs n'ont pas éprouvé le besoin de faire des objets d'art en verre : aucune fouille n'en a révélé, aucun poète ne les a chantés, aucun historien ne les mentionne; on a voulu démontrer, au moyen d'un texte, que Glaucus avait ciselé le verre; ce n'est qu'une pure supposition. Glaucus était un ciseleur remarquable; il fit, selon Athénée, la coupe de métal ornée 
d'animaux et de plantes que Halyatte, roi de Libye, offrit au temple de Delphes, mais il n'y a pas de preuves que cet artiste ait travaillé le verre. Les Romains n'ont donc rien pu emprunter aux Grecs et ils ont dû inventer un art nouveau; après eux viennent les Grecs du Bas-Empire, et les plus anciens verres de cette origine s'éloignént de très loin du style des verres romains. Les Arabes, il est vrai, se rattachent aux Grecs, mais après eux la chaîne est rompue et les premiers verres de Venise sont très inférieurs aussi bien aux verres antiques qu'à ceux de l'Orient.

La tradition des couvents a fait également défaut à la verrerie. On signale bien quelques fabriques dans les monastères, mais on peut croire que c'étaient surtout des fabriques de vitraux. Pendant tout le moyen âge, l'art s'était réfugié dans les cloîtres, mais pour les moines les objets servant à la célébration du culte et à l'ornement du temple étaient seuls du domaine de l'art, et la verrerie était presque prohibée par l'Église.

\section{I I}

Est-ce à dire que le verre restera condamné à une sorte d'infériorité à l'égard de la céramique et des métaux? Certes, non. La matière est incomparable et le champ reste ouvert aux artistes qui tenteront de l'explorer. Qu'ils cherchent d'abord des formes rationnelles, conformes à l'usage, ce qui fait défaut à la généralité de la verrerie moderne de service; dans cette recherche, qu'ils ne perdent pas de vue le principe formulé par Phocylide. "En quelque chose que ce soit, la beauté 
résulte de la justesse des proportions. „La forme étant déterminée, on aura pour la décorer beaucoup moins de peine, à la condition de respecter les divisions de l'espace. Le corps, les anses, la jambe, le pied d'une coupe, par exemple, pourront recevoir un décor particulier, si, par le style et les dispositions, ce décor concourt à l'unité et à l'harmonie de l'ensemble. Si le décor est circulaire il pourra être gravé en mat sur un fond clair, et réciproquement; s'il doit montrer un sujet historié il gagnera à ne couvrir que l'une des parois.

Le verre blanc est le seul propre au service de table, puisque seul il fait valoir le contenu dont la limpidité est la première qualité apparente. Le verre de couleur trou. vera son emploi dans les pièces de dressoir et de fantaisie.

En résumé, si le verre, en tant que produit industriel, a doté l'humanité d'un bienfait inappréciable, il n'a peut-être pas tenu, dans les arts de la décoration usuelle, le rang élevé auquel il aurait pu être appelé. Les exemples de l'antiquité, de l'Orient et de Venise sont là cependant pour prouver le parti que l'on peut en tirer; il convient aussi de ne pas oublier que dans l'histoire des grands arts décoratifs le verre a joué un rôle important : il a donné lieu à la mosaïque et la mosaïque a conduit aux vitraux peints. A ces titres, le verre mérite d'être classé dans les matières nobles dignes de l'attention et de l'estime des artistes. 


\section{T A B L E}

Préface. . . . . . . . . . . . . . 5

L'ANTIQUI TÉ.

I. Les écrivains... . . . . . . . . . . . . 7

II. L'Égypte, la Grèce, la Phénicie, l'Italie, les Gaules . . . I4

1II. La fabrication ............. . . 20 20

IV. L'usage . . . . . . . . . . . . . . . . . . 26

V. La décoration ............. . . . . . . . . 45

VI. Les vases murrhins. . . . . . . . . . . . 59

LES CHRÉTIENS ET LES JUIFS.

I. L'usage. . . . . . . . . . . . . . . 63

II. Les verres orbiculaires . . . . . . . . . . 67

III. Les verres gravés . . . . . . . . . . . . 72

IV. Les Juifs. . . . . . . . . . . . . . . . . 77

L'ORIENT.

I. Constantinople, les Perses, les Grecs, les Arabes . . 80

II. Le Coran . . . . . . . . . . . . . . 87

III. Les califes . . . . . . . . . . . . . . . . 89

IV. Les jetons arabes. . . . . . . . . . . . . . . . 97

V. Le $\mathrm{xIII}^{\mathrm{e}}$ siècle ................ . . . I I I

VI. Le xive siècle................ . . 108

L'OCCIDENT.

I. Les Mérovingiens, les Alemani, les Saxons, la Normandie, Ie Poitou........... I I . . . . . . . .

II. Les verres à vitre, les trésors . . . . . . . . . I 24

III. Le moine Théophile. . . . . . . . . . . . I29

VENISE.

I. L'histoire, les décrets . . . . . . . . . I . I38

II. L'organisation du travail, les Italiens à l'étranger. . . . I48

III. La fabrication. . . . . . . . . . . . I56

IV. Les diverses espèces de verreries......... I67 
LA FRANCE.

I. L'usage et le glossaire.. . . . . . . . . . . . I78

II. Les écrivains, les inventaires .......... I83

LA FRANCE.

I. Les verreries de l'Ouest et du Centre, les verreries éparses sur le territoire............. 194

II. Les produits. . . . . . . . . . . . 203

\section{LA F R A C E.}

I. Les provinces de l'Est, les chartes, Ies gentilshommes verriers.............. . . 2 215

II. L'Académie des sciences. . . . . . . . . . 227

LA FRANCE.

I. La Normandie, Ies produits . . . . . . . . . 229

II. Les gentilshommes verriers . . . . . . . . . . 239

III. La fabrication des glaces ............. 24 I

L'A L LEMAGNE ET LA BOHÊME.

I. Nuremberg, Ies produits. .......... 248

II. La Bohême, les produits . . . . . . . . 274

III. Les autres pays allemands. . . . . . . . . . . 283

LA HOLLANDE, LES FLANDRES, L'ESPAGNE.

I. La Hollande. . . . . . . . . . . . . 287

II. Les Flandres. . . . . . . . . . . . . 296

III. L'Espagne . . . . . . . . . . . . . . 300

\section{L'ANGLETERRE ET LA CHINE.}

I. L'Angleterre............... . . . 306

II. La Chine ............... . . 3 II

$$
\text { L'A RT. }
$$

I. L'Art .................. . . 3 I 5 








$$
d^{0}
$$




\section{SMITHSONIAN INSTITUTION LIBRARIES}

